\title{
Microeconometric evidence of financing frictions and innovative activity
}

Citation for published version (APA):

Tiwari, A. K. (2010). Microeconometric evidence of financing frictions and innovative activity. [Doctoral Thesis, Maastricht University]. Universitaire Pers Maastricht. https://doi.org/10.26481/dis.20101104at

Document status and date:

Published: 01/01/2010

DOI:

10.26481/dis.20101104at

Document Version:

Publisher's PDF, also known as Version of record

\section{Please check the document version of this publication:}

- A submitted manuscript is the version of the article upon submission and before peer-review. There can be important differences between the submitted version and the official published version of record.

People interested in the research are advised to contact the author for the final version of the publication, or visit the DOI to the publisher's website.

- The final author version and the galley proof are versions of the publication after peer review.

- The final published version features the final layout of the paper including the volume, issue and page numbers.

Link to publication

\footnotetext{
General rights rights.

- You may freely distribute the URL identifying the publication in the public portal. please follow below link for the End User Agreement:

www.umlib.nl/taverne-license

Take down policy

If you believe that this document breaches copyright please contact us at:

repository@maastrichtuniversity.nl

providing details and we will investigate your claim.
}

Copyright and moral rights for the publications made accessible in the public portal are retained by the authors and/or other copyright owners and it is a condition of accessing publications that users recognise and abide by the legal requirements associated with these

- Users may download and print one copy of any publication from the public portal for the purpose of private study or research.

- You may not further distribute the material or use it for any profit-making activity or commercial gain

If the publication is distributed under the terms of Article $25 \mathrm{fa}$ of the Dutch Copyright Act, indicated by the "Taverne" license above, 


\title{
Microeconometric Evidence of
}

\author{
Financing Frictions \\ and \\ Innovative Activity
}

Amaresh K Tiwari 
(c) Amaresh K Tiwari, 2010

All rights reserved. No part of this publication may be reproduced, stored in a retrieval system, or transmitted in any form, or by any means, electronic, mechanical, photocopying, recording or otherwise, without the prior permission in writing from the author.

This book was typeset by the author using $\mathrm{LT}_{\mathrm{E}} \mathrm{X}$.

Published by Universitaire Pers Maastricht

ISBN: 978-90-5278-999-6

Printed in The Netherlands by Datawyse Maastricht 


\title{
Microeconometric Evidence of
}

\author{
Financing Frictions
}

\author{
and \\ Innovative Activity
}

PROEFSCHRIFT

ter verkrijging van de graad van doctor

aan de Universiteit Maastricht,

op gezag van de Rector Magnificus,

Prof. mr. G.P.M.F. Mols,

volgens het besluit van het College van Decanen,

in het openbaar te verdedigen op

donderdag 4 November 2010 om 16.00 uur

door

Amaresh K Tiwari 


\section{Promotores:}

Prof. dr. F.C. Palm

Prof. dr. Pierre Mohnen

\section{Copromotor:}

Dr. Sybrand Schim van der Loeff

\section{Beoordelingscommissie:}

Prof. dr. Bronwyn Hall (voorzitter)

Prof. dr. Jacques Mairesse

Prof. dr. Patrick Sevestre (Eurepue Université Paris, France)

This research was supported by the The Netherlands Organization for Scientific Research (NWO). A grant, Grant No. 400-03-109, to carry out the research is gratefully acknowledged. 


\section{Acknowledgements}

Working on my Ph.D. over the past years has been as much an exciting experience as it was daunting. There was joy when interesting results were obtained after some hard work. But there has also been frustration when results turned out uninteresting or no results could been obtained at all. The arduous but nonetheless exiting a journey over; I finally have a thesis of my toils. However, this thesis would not have been possible without the continued support of a number of people who helped me over the recent years. I would like to take the opportunity here to thank them.

First and foremost I would like to thank my supervisors, Franz Palm, Pierre Mohnen and Sybrand Schim van der Loeff for their relentless support and encouragement. I need hardly mention that the standard of excellence expected was seldom, if ever, met; but their patience and understanding continues to overwhelm me. During the course of Ph.D., I had been beset with many a personal problems. The generosity of my supervisors during such times shall never be forgotten. I would also like to add that I have enjoyed our collaboration tremendously over the years, not only during our stimulating, but at times, even merry meetings. I am also grateful for the fact that your doors have always remained open to discuss questions, problems or ideas. I would also like express remorse over the unfortunate accident that resulted in Dr. Sybrand Loeff ill health, and for which he had to discontinue office. During the initial stage of my Ph.D. I remember running to his office every now and then. Suggestions and discussions apart, his wit and humor would put me out of gloom and difficult situations.

I would like to thank the members of the reading committee, Bronwyn Hall, Jacques Mairesse and Patrick Sevestre, for their time and careful reading of the manuscript. I thank all my colleagues at the Department of Quantitative Economics for providing an extremely pleasant working atmosphere. In particular, I would like to thank Karin van den Boorn and Haydeé Hallmanns for their administrative support and Bram Driesen, who personally contributed to this thesis in form of the Dutch summary. 
I am also grateful to all colleagues I met at conferences and workshops and who provided stimulating discussion and comments.

Last but not least I would like to thank my family and friends. My parents Uday Narayan Tiwari and Girija Tiwari, my brother Samaresh Tiwari and my sister in law Uma Tiwari have always supported me in all possible ways. I would like to, but will not be able to name all friends who deserve credit here. However, I would like to thank Rudrani Bhattacharya, Mridu Prabal Goswami, Anirban Kar and Roald Versteeg for their long-lasting and close friendship.

Amaresh K Tiwari

Maastricht, 2010 


\section{Contents}

Acknowledgements $\quad$ v

1 Introduction $\quad 1$

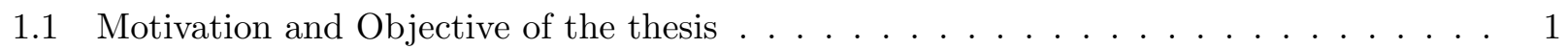

1.2 Contributions and Thesis Structure . . . . . . . . . . . . . . . . 3

2 Financial Constraints and Investment: Evidence for Large Companies in The $\begin{array}{ll}\text { Netherlands } & 7\end{array}$

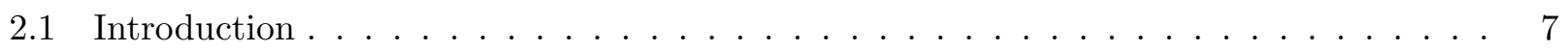

2.2 The Basic Model . . . . . . . . . . . . . . . . . . . . . . . . . 11

2.3 Investment and Financial Constraints _ . . . . . . . . . . . . . . . . . . . 14

$2.3 .1 \quad$ Financial Regimes . . . . . . . . . . . . . . . . . . 16

2.3.2 Financial Constraint Revisited . . . . . . . . . . . . . . . . . . . 16

2.3.3 The Structural Model . . . . . . . . . . . . . . . . . . . . . . . . 20

2.4 Data and Estimation . . . . . . . . . . . . . . . . . . . . . 22

2.5 Results . . . . . . . . . . . . . . . . . . . . . . . 24

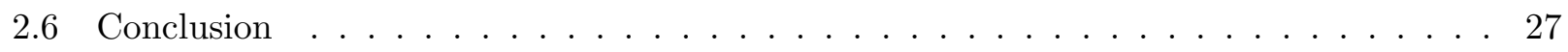

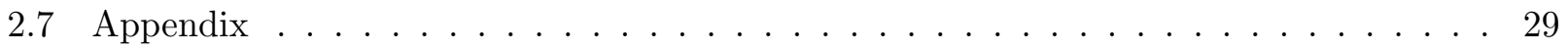

3 Financial Constraints and R\&D Investment: Evidence from CIS 41

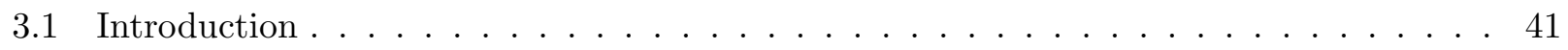








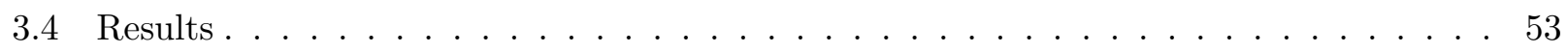

$3.4 .1 \quad$ R\&D Intensity $\ldots \ldots \ldots \ldots \ldots \ldots \ldots \ldots \ldots$

3.4.2 Financial Constraint . . . . . . . . . . . . . . . . . 56

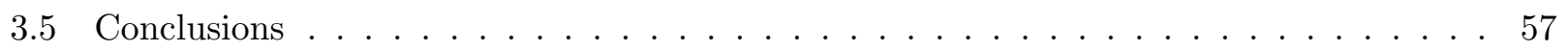

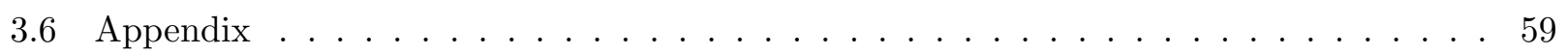

3.A A Model of Financial Constraint . . . . . . . . . . . . . . . . . . 59

3.B Note on Estimation . . . . . . . . . . . . . . . . . . . . . 63

3.C Descriptive Statistics and Results . . . . . . . . . . . . . . . . . . . 64

4 Financial Constraints and Other Obstacles: Are They a Threat to Innovation $\begin{array}{ll}\text { Activity } & 69\end{array}$

4.1 Introduction . . . . . . . . . . . . . . . . . . . . . . . . . 69

4.2 Obstacles to Innovation and their Impact: Some Facts . . . . . . . . . . . . . . . 70

4.3 Review of Empirical Evidence on Financial and other Obstacles to Innovation . . . . . 75

4.4 Discussion of the Empirical Findings and of their Policy Implication . . . . . . . . 77

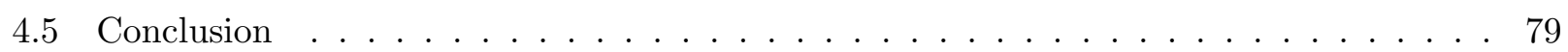

5 Capital Structure, Innovation, and Agency: A Contingent Claim Analysis 81

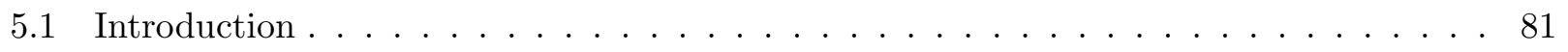

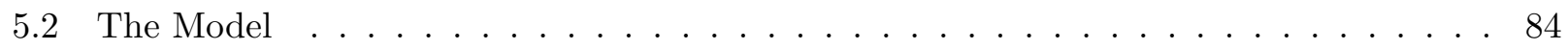

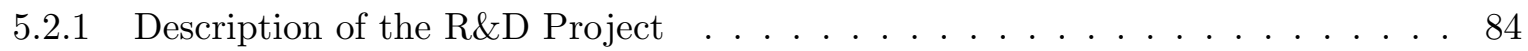

5.2 .2 Income/Cash Flows of the Firm and Firm Valuation . . . . . . . . . . . 86

5.2 .3 Debt Characteristic . . . . . . . . . . . . . . . . . . 87

5.2 .4 Liquidation . . . . . . . . . . . . . . . . . 88

5.3 Valuation of the Levered Firm: Valuation when Debt is Safe . . . . . . . . . . . . 89

5.3.1 Mothballing and Resuming of the R\&D Project: The Switching Problem . . . 89

5.3.2 Starting the R\&D Project: The Irreversible Investment Problem . . . . . . . 99

5.4 Valuation when Debt is Risky . . . . . . . . . . . . . . . . . . . . 109

5.4.1 Mothballing and Resuming of the R\&D Project: The Switching Problem . . . 109

5.4.2 Starting the R\&D Project: The Irreversible Investment Problem . . . . . . . 117

5.5 Comparison with Scale Expansion _ . . . . . . . . . . . . . . . . . . 124

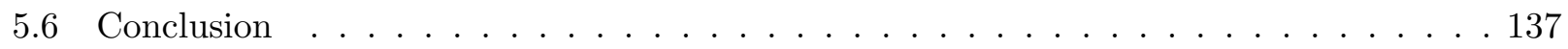




5.A Derivation of the Hamilton-Bellman-Jacobi Equation: The Switching Problem . . . . 138

6 Financial Constraints, Capital Structure and Innovation: An Empirical Investigation

6.1 Introduction . . . . . . . . . . . . . . . . . . . . . 141

6.2 Innovation, Capital Structure, and Firm Dynamics _ . . . . . . . . . . . . . 145

6.3 R\&D Investment and Financial Constraints . . . . . . . . . . . . . . . . . . 148

6.4 Data and Construction of Variables . . . . . . . . . . . . . . . . 151

6.5 Empirical Strategy . . . . . . . . . . . . . . . . . . . 156

6.5.1 R\&D Investment, Endogenous Financial Constraint and Endogenous Selection with Endogenous Long-Term Debt: A Three step Procedure . . . . . . . . . . 156

6.5.2 Identification and Estimation of Average Partial Effects . . . . . . . . . . 176

6.6 Results . . . . . . . . . . . . . . . . . . . . . . . . 180

$6.6 .1 \quad$ Second Stage . . . . . . . . . . . . . . . . . . . . 181

6.6.2 Third Stage: R\&D Switching Regression . . . . . . . . . . . . . . . . 188

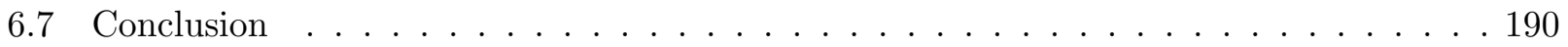

6.8 Appendix . . . . . . . . . . . . . . . . . . . . . . 192

6.A Identification of Structural Parameters with

Expected a Posteriori Values of Individual Effects . . . . . . . . . . . . . . . . . . 192

6.B Derivation of the Correction Terms . . . . . . . . . . . . . . . . . . 199

6.C Asymptotic Covariance Matrix of the Second and Third Stage Estimates . . . . . . . 202

6.D Second and Third Stage Estimation Results . . . . . . . . . . . . . . . 207

6.E Descriptive Statistics . . . . . . . . . . . . . . . . . . 210

7 Conclusions $\quad 215$

7.1 Summary, limitations and further research . . . . . . . . . . . . . . . . 215

$\begin{array}{ll}\text { Bibliography } & 219\end{array}$

$\begin{array}{ll}\text { Nederlandse samenvatting } & 231\end{array}$ 



\section{List of Tables}

2.1 Financial Regimes $\ldots \ldots \ldots \ldots \ldots \ldots \ldots \ldots \ldots$

2.2 Distribution of firms among different Sectors _ . . . . . . . . . . . 29

2.3 Descriptive Statistics of the Euler Equation Variables for the Sample of

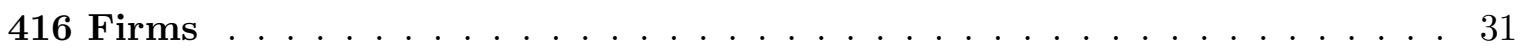

2.4 Descriptive Statistics for the 2 Group of Firms $\ldots \ldots \ldots$

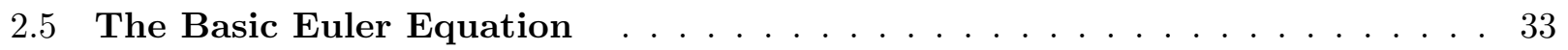

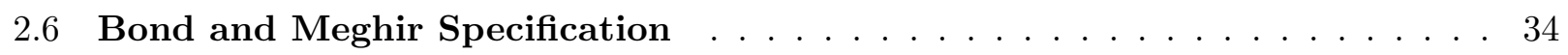

2.7 Euler Equation Augmented with additional Financial variables . . . . . . . 35

2.8 Euler Equation Augmented with additional Financial variables: For firms Investing intermittently and Investing Continuously $\ldots \ldots \ldots$

2.9 Structural Estimates $\ldots \ldots \ldots \ldots \ldots \ldots$

2.10 Behavior of Variables among Three Categories of firms sorted according to Index of Financial Constraint constructed using Structural Estimates . . . 38

2.11 Correlation between $L H S_{t}$ and $\hat{\Theta}_{t+1}^{t} \ldots \ldots \ldots \ldots \ldots$

2.12 The Euler Equation augmented with the Estimated Index of Financing Premium on External Finance . . . . . . . . . . . . . . . . . . 39

3.1 Mean Distribution of R\&D Intensity along Alliance in the Introduction in New Products and Process . . . . . . . . . . . . . . . . . . . 64

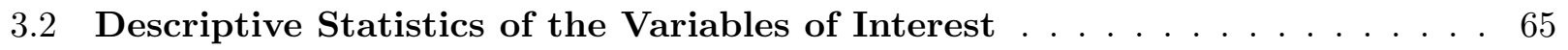

3.3 Specification for $\mathbf{R} \& \mathbf{D}$ Intensity $\ldots \ldots \ldots \ldots$

3.4 Specification for Financial Constraint $\ldots \ldots \ldots \ldots$ 


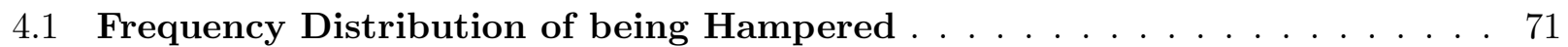

4.2 Contribution of various Factors towards Abandoning, Prematurely Stopping, Seriously Slowing Down and Not Starting of at least oneR\&D Project 71

4.3 Determinants OF Abandoning $(A B)$, Prematurely Stopping $(P S)$, Seriously Slowing Down $(S S D)$, and Not Starting $(N S)$ R\&D Projects . . . . . . . . 74

4.4 Marginal Effects of the Explanatory Variables evaluated at their Means

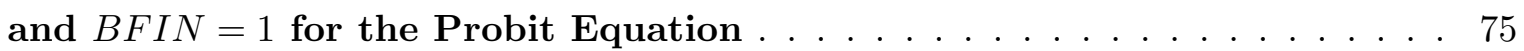

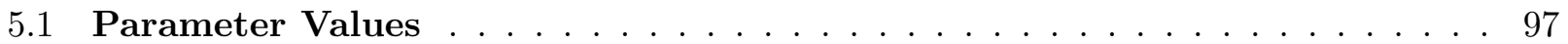

6.1 Number of Enterprises and Number of Strata . . . . . . . . . . . . 153

6.2 Total number Innovating Firms, Non-Innovating Firms, and Financially

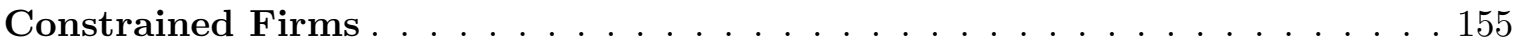

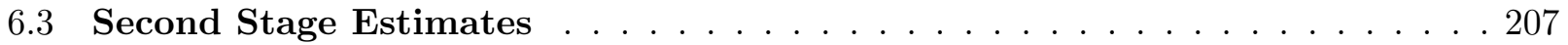

6.4 Average Partial Effects for Second Stage _ . . . . . . . . . . . . . . 208

6.5 Third Stage: R\&D Switching Equation _ . . . . . . . . . . . . . . . 209

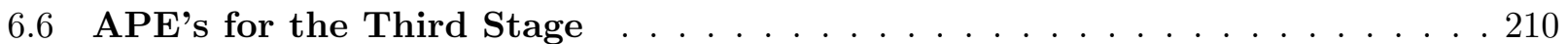

6.7 Descriptive Statistics of Variables for Censored and Non-Censored Variables . . . . . . . . . . . . . . . . . . . . . . . . . 210

6.8 Total number of enterprise, $N_{f}$, and number of enterprise within a firm






\section{List of Figures}

5.1 Mothballing/Resuming threshold, $x^{*}$, and Liquidation threshold, $x_{l} \ldots \ldots \ldots$

5.2 Starting the R\&D project threshold, $x^{I}$, and liquidation threshold, $x_{L I}$, before starting the project. . . . . . . . . . . . . . . . . . . . . 103

5.3 Starting the R\&D Project Threshold, $x^{I}$, and Liquidation Threshold, $x_{L I} \ldots \ldots 5$

5.4 Maximum level of safe debt after starting the $\mathrm{R} \& \mathrm{D}$ project, $D^{*}$, and before starting the project, $D^{I}$, as a function of the fraction, $f$, of the initial investment, $I$, that can be retained in the event of liquidation. . . . . . . . . . . . . . . 105

$5.5 D^{*}$ and $D^{I}$ for (a) $\lambda=0.8$, (b) $\lambda=0.5$, (c) $\lambda=0.2 \ldots \ldots \ldots \ldots$

$5.6 D^{*}$ and $D^{I}$ for $(\mathrm{a}) \phi_{1}=0.5,(\mathrm{~b}) \phi_{1}=0.65 \ldots \ldots \ldots \ldots$

5.7 Mothballing/Resuming threshold and Default threshold for Risky Debt as compared to Mothballing/Resuming threshold and Liquidation threshold for Safe Debt at a fixed

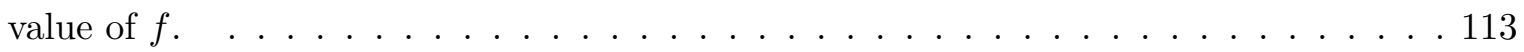

5.8 (a) Investment Threshold when Debt levels are Default Risk-Free for Switching and Risky for Starting as compared to when Debt levels are Default Risk-Free for both Switching and Starting, (b) Liquidation Threshold when Debt levels are Default RiskFree for Switching and Risky for Starting as compared to when Debt levels are Default Risk-Free for both Switching and Starting . . . . . . . . . . . . . . . . . . . . . 119

5.9 (a) Investment Threshold when Debt levels are Risky for both Switching and Starting as compared to when Debt levels are Default Risk-Free for both Switching and Starting, (b) Liquidation Threshold when Debt levels are Risky for both Switching and Starting as compared to when Debt levels are Default Risk-Free for both Switching and Starting 121 
5.10 (a) Investment Threshold when Debt levels are Risky for Switching and Default RiskFree for Starting as compared to when Debt levels are Default Risk-Free for both Switching and Starting, (b) Liquidation Threshold when Debt levels are Risky for Switching and Default Risk-Free for Starting as compared to when Debt levels are Default Risk-Free for both Switching and Starting . . . . . . . . . . . . . . . . . . 123

5.11 Scale expansion threshold, $x_{e}$, liquidation threshold before investing in scale expansion, $x_{l b}$, and liquidation threshold after investing in scale expansion, $x_{l b} \ldots \ldots \ldots$. . . . 129

5.12 Scale Expansion threshold, $x_{e}$, and Starting of R\&D Project threshold, $x^{I}$. . . . . 130

5.13 (a) Liquidation threshold before scale expansion, $x_{l b}\left(\bar{g}, \phi_{1}^{\prime}\right)$, and before starting the R\&D project, $x^{L I}$. (b) Liquidation threshold after scale expansion, $x_{l a}\left(\bar{g}, \phi_{1}^{\prime}\right)$, and

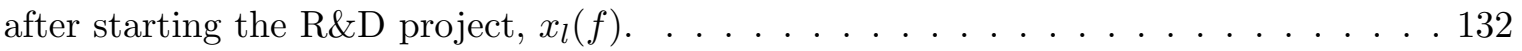

5.14 (a) Maximum amount of risk-free debt before scale expansion, $D_{b}$, and before investing in $\mathrm{R} \& \mathrm{D}, D^{I}$. (b) Maximum amount of risk-free debt after scale expansion, $D_{a}$, and $D^{*}$, the maximum amount of safe debt after having invested $I$ to start the R\&D project.134

5.15 (a) Scale Expansion threshold, $x_{e}$, and starting of R\&D Project threshold, $x^{I}$. (b) Liquidation threshold after scale expansion, $x_{l a}\left(\bar{g}, \phi_{1}^{\prime}\right)$, and after starting the R\&D project, $x_{l}(f)$. (c) Maximum amount of risk-free debt after scale expansion, $D_{a}$, and $D^{*}$, the maximum amount of safe debt after having invested $I$ to start the R\&D project.136

6.1 APE of long-term Debt to Asset Ratio on Unconditional Probability of Innovation. . . 212

6.2 APE of long-term Debt to Asset Ratio on Probability of Innovation conditional on being Financially Constrained, $\frac{\partial \operatorname{Pr}\left(s_{i t}=1 \mid f_{i t}=1\right)}{\partial d_{i t}}$, and APE of long-term Debt to Asset Ratio on Probability of Innovation conditional on not being Financially Constrained,

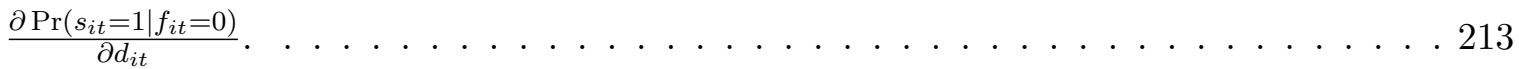




\section{Introduction}

\subsection{Motivation and Objective of the thesis}

The importance of innovative activity by firms for securing economic growth and welfare is by now well recognized and has been widely documented in the scientific literature. Important as it might be, we also know that market failure for $R \& D$ investment can be quite severe. Firms lacking internal means of finance seek out external sources to finance their innovative activity. However, capital market frictions generated by information asymmetry often lead to a large gap between the cost of external financing and internal financing. This notion of costly external financing stands in contrast to the more complete-markets approach underlying conventional models of investment emphasizing expected future profitability and the user cost of capital as key determinants of investment.

Information theoretic models in finance and economics show how asymmetry in information can lead to a large premium being charged on external funds or, at the extreme, to a rationing of external funds. Given the nature of $\mathrm{R} \& \mathrm{D}$, the risks involved in carrying out $\mathrm{R} \& \mathrm{D}$ activity are even greater than physical investment. Consequently, R\&D investment could be subject to even greater market failure than physical investment.

However, these information theoretic models provide only qualitative guidance for empirical work, since few have both endogenous investment and finance decisions, and since few are, by nature, couched in terms of observable variables. Therefore, with the exception of few recent studies, empirical literature has turned to two loose arguments to motivate tests of the connection between finance and investment. One strand of the literature, that ad hoc classifies firms as constrained and unconstrained firms and use reduced form accelerator type models, hypothesizes that financing constraints cause an excess sensitivity of investment to internal funds for constrained firms as compared to unconstrained ones. The second strand, which uses the framework of structural Euler equations, hypothesizes that financing constraints affect the firm's incremental intertemporal substitution of investment today for investment tomorrow, via the shadow value of scarce external funds. These 
models that were initially developed to study company level investment have also been used to study to $R \& D$ investment pattern of firms.

The two methodologies, however, have been questioned in their ability to identify the effect of financing friction on firm level $R \& D$ investment. For the reduced form accelerator type models, the criticism stems from the fact that proxies to control underlying investment opportunities are imperfectly measured and the cash flows as a measure of internal wealth could be correlated with demand signals. Also, as mentioned earlier, in order to see the effect of financing frictions on firm level investment, firms are ad hoc classified as constrained or unconstrained. Hence, the endogeneity of financing constraints are not taken into account, implying that the conclusion drawn about the sensitivity of investment to realized cash flows as proxy for shifts in the internal wealth for the constrained and unconstrained firm may not be correct. As far as estimation of Euler equations is concerned, since the equations are derived on the assumption of smooth adjustment cost and ignores the fixed component, the estimation suffers from misspecification. In Chapter 2, which deals with company level investment, we point out this source of misspecification.

Given the above, part of the objective of the thesis is to use alternative strategies to study the effects of financing frictions on R\&D investment. More specifically, in three of the chapters, we use firms' reportage on financial constraint faced by them to assess the extent of market failure related to $R \& D$ investment. To motivate the use of reported financial constraint, we derive an empirical specification from a theoretical model in a contractual framework. Also, using the reported financial constraint as a regressor allows us to address the issue of simultaneity of investment decision and the constraint faced.

Apart from the main issue of the effect of financing frictions on innovation and investment, the study also looks into how other factors may influence the firm's investment and innovation decision making. These factors could well be incentives that are distributed across firm characteristics, the study of which are topics of industrial organization. Among others, the objective of this study has also been to empirically explore how such incentives interact with financing frictions. In Chapter 6 we study how financing and innovation decision are related across the distribution of firm characteristics such as firm size, age, leverage, and financing constraints faced by them.

Though the literature in corporate finance, which uses the real option framework, is replete with studies on agency issues between different classes of claimants over investment decision of firms, we have not found any that studies agency issues between bond holders and stock holders over R\&D investment. Of the five chapters in this study, one is a theoretical study of the agency problem between 
bond holders and stock holders over R\&D investment, which is risky due to technical uncertainties involved in R\&D activity and due to intangibility of assets employed and produced. Apart from the study of agency problem, this study also compares R\&D investment with scale expansion program of a firm.

\subsection{Contributions and Thesis Structure}

The collection of studies is presented in five chapters, which can be read in any order. Some overlap, especially in the discussion of the existing literature, has been inevitable. The thesis contributes to the literature on financing frictions and investment in several respects. In Chapter 2 we study the effect of financing frictions on company level investment in physical capital. The study presents evidence that the problems of asymmetric information affect the firms' allocation of real investment expenditure over time. We do this by estimating the structural form of Euler equation (both linearized and nonlinear) of investment. Here we find that including the effect of a shadow price of external finance greatly improves the Euler equation's performance in comparison to the standard neoclassical specification. We also construct an index of financial constraint from the estimates of the structural model. We find that firm's investment decreases with the degree of financial constraint. However, we also find that for a group of firms that disinvest and/or invest intermittently, the Euler equation based on smooth adjustment cost seems inappropriate, reflecting the misspecification due to ignoring the fixed or the non-convex component of adjustment cost.

In Chapter 3 we empirically investigate the effects of financing constraints on R\&D investment. In this study, however, the analysis is conducted using CIS Netherlands data which is collected at enterprise level rather than the company level. Here, using direct information on financial constraints from questionnaires as reported by the firms, rather than the commonly used balance sheet information, this study presents evidence that; after having controlled for traditional factors as size, market share, cooperative arrangement, and expected profitability; financial constraints affect a firm's decision on how much to invest in $\mathrm{R} \& \mathrm{D}$ activities. Apart from financing constraints, the study also looks at other hampering factors as market uncertainty and institutional bottlenecks, regulations and organizational rigidities that affect R\&D investment. To estimate our model, a semiparametric estimator of sample selection is employed to control for potential endogeneity of the regressors. Besides, studying the effect of financial constraint on R\&D the study also investigates what firm characteristics are associated with the firm being financially constrained. We find that old firms and firms that belong to a group are less financially constrained when it comes to undertaking R\&D 
activities. The empirical specification in this study had been derived from a theoretical model of investment in a contractual framework, written by Gale and Hellwig (1985). To our knowledge, we have not seen any other paper that empirically shows the negative effect of financing constraints, as reported by enterprises, on $\mathrm{R} \& \mathrm{D}$ investment.

In Chapter 4 we examine the importance of financial and other obstacles to innovation in the Netherlands using statistical information from the CIS 3.5 innovation survey. We report results on the effect of these obstacles on the firms' decision to abandon, prematurely stop, seriously slow down, or not to start an innovative project. In this study we find that financing constraints act as a major hampering factor in the firms' pursuit of innovation. We also find that certain fundamentals such as market uncertainty and economic uncertainty based on which firms make their investment decision become more relevant when financial constraints do not bind. These results are compared with those from other studies in the Netherlands and other countries. This chapter ends with a discussion of policy measures that have been taken to overcome, or at least attenuate these obstacles, such as $\mathrm{R} \& \mathrm{D}$ tax incentives, venture capital financing and policy mix packages.

In Chapter 5 we study financing and $R \& D$ investment decision in a real-option framework. The chapter concentrates on the study of implication of risk associated with R\&D investment for agency conflict between bond holders and equity holders of the firm. The riskiness for R\&D investment is primarily derived from the intangibility of assets employed in conducting $R \& D$, which is lost in the event of liquidation, and the technical uncertainty associated with successful completion of the project. We find that when intangibility of assets involved is high and the intensity with which R\&D can be completed is low the equity holders of the firm in maximizing their claim overinvest, thus shifting the burden of risk on to the bondholders. Apart from the study of the agency problem, this study also compares R\&D investment with scale expansion program of the firm. By comparing the two, we are able to shed some light over many empirical findings that document R\&D intensive firms being less leveraged as compared to non R\&D performing firms.

In chapter 6 we use a panel data of three waves, to investigate the effect of financial constraint on $R \& D$ investment and study the determinants of financial constraints. We also investigate the factors that influence or provide incentives for a firm to take up R\&D activity. Unlike the study in Chapter 3, we wanted to use financial information as reported in the balance sheet of the companies. However, the information on R\&D in the CIS data is at the level of enterprise, and not all enterprises constituting the company were surveyed. Hence we had to get an estimate of R\&D related variables for the company using information at the enterprise level and the sampling design of the CIS surveys. 
The findings of Chapter 6 can be summarized as follows. First, financial constraints adversely affect a firm's $R \& D$ intensity as measured by the ratio of $R \& D$ expenditure to capital asset, reducing the R\&D intensity by more than half for an average firm. Second, firms that are highly leveraged are more likely to be financially constrained, and that highly leveraged firms are less likely to be innovators. Third, it is more likely that a firm to will not innovate when it increases its leverage when it is not financially constrained as compared to a firm that is financially constrained. Fourth, the change in probability to innovate for a unit change in leverage, conditional on no financial constraint is almost constant, while the same, conditional on being financially constrained, varies over the distribution of firm characteristic such as age, size, and existing leverage. Fifth, the decision to innovate, the financial constraints faced, and the choice of capital structure are endogenously determined. Sixth, the $R \& D$ intensity of firms with different characteristics, conditional on being financially constrained and conditional on not being unconstrained, are different. Seventh, the sensitivity of R\&D investment to cash flows is higher for financially constrained firms. The econometric exercise entails using a three step procedure, where expected a posterior (EAP) values of time invariant individual effects obtained from the first stage reduced form are used as substitutes for the time invariant individual effects that are to be controlled for in the structural equations of the second and third stage. The chapter provides the theoretical underpinnings for such a procedure. To our knowledge, the estimator proposed to estimate a system of equations with endogenous regressors in a panel data set up is new to the literature.

Finally Chapter 7 summarizes the main findings of the thesis, discusses the limits of the current work and presents some outlines for further research. 



\section{2}

\section{Financial Constraints and Investment: Evidence for}

\section{Large Companies in The Netherlands}

\section{$2.1 \quad$ Introduction}

One of the implications of the well-known Modigliani-Miller theorem $(1958,1961)$ is that a firm choosing the optimal levels of investment should be indifferent to its capital structure and the neoclassical theory of the firm assumed further that its financial position was irrelevant. Yet both informal observations and systematic empirical evidence have suggested that capital structure and financial position are of considerable importance to firm behavior. In contrast with the predictions of the Modigliani and Miller (1958) theorem, most firms seem to prefer internal sources to finance investment. According to Stephen A. Ross et al. (2006), about 80 percent of all financing is done with internally generated funds. Explanations for this behavior usually highlight the role of information asymmetries (Myers, 1984) and agency issues (Jensen and Meckling, 1976) in raising the costs of external funds. Many studies using different specifications of the neoclassical investment model and different data sets have convincingly rejected simple models based on the null hypothesis of perfect capital market.

Beginning with Fazzari, Hubbard, and Petersen (1988) there has been a spurt of empirical research, exploring the determinants of firm level investment. The empirical strategy has been to assess whether the neoclassical investment criterion holds for firms facing low information costs, while failing for firms with high information costs and to measure the effects of net worth on investment for firms with high information cost, holding constant, investment opportunities. Theoretical models of imperfections in capital markets imply that external financing is more costly than internal financing for many firms. Hence, for given levels of investment opportunities, information costs, and market interest rates, firms with higher net worth should invest more. Test of the effects of net worth on investment pose significant challenges, including the need to control for investment opportunities 
and information costs. Also, models of informational imperfections stress that net worth effects on investment should be concentrated among borrowers for which information costs are very high and accordingly empirical research should examine industry case studies or panel data to discriminate between the decisions at any point in time of "constrained" and "unconstrained" firms that proxy for the extent of informational asymmetry. An intuitive beginning is often given by selecting a priori groupings of "constrained" and "unconstrained" firms. However, as discussed in Section 2.3.2, there might be a number of problems with such splitting. The methodology we employ controls for information cost that classify firms into "constrained" and "unconstrained" firms without running into problems of endogeneity of sample splitting.

Most empirical research in this area has followed the approach in Fazzari, Hubbard, and Petersen (1988), who argued and found that if groups of firms face finance constraints, their investment will respond strongly to movements in cash flow, holding investment opportunities constant. These authors argue that a regression of investment on $q$ - as a proxy for investment opportunity - and cash flow should yield a greater cash flow sensitivity for constrained firms. These authors do find cash flow sensitivity increasing in the degree of financial constraint. This finding they claim to be an evidence of financial constraints. More recently, however, a number of papers have questioned this approach from both empirical and theoretical angles. On the empirical side Kaplan and Zingales (1997) and Cleary (1999) have provided evidence that cash-flow sensitivity need not identify liquidity constrained firms; that is, sensitivity is not monotonic in the degree of constraints. Further, Erickson and Whited (2000), Bond and Cummins (2001), Cooper and Ejarque (2001) have demonstrated that observed cash-flow sensitivity is likely an artifact of measurement error in the usual proxy for investment opportunities: Tobin's $q$. In particular, Erickson and Whited (2000) explain that measurement error can explain differential investment-cash flow sensitivities across groups of firms, if combined with at least one of the following, purely mechanical, effects: differences in the variance of cash flow, differences in the covariance between investment and $q$, and, as also noted by Poterba (1988), differences in the amount of measurement error in $q$. On the theoretical side, Gomes (2001) and Alti (2003) simulate dynamic investment models, demonstrating that significant cash flow coefficients are not necessarily generated by financing frictions. Conversely, Gomes shows that financing frictions are not sufficient to generate significant coefficients on cash flow.

The aim of the chapter is twin fold. First, the chapter addresses the question of the interdependence of finance and investment by estimating the Euler equation to isolate the role of finance constraints in the "marginal" intertemporal decision to invest. We do this by augmenting the Euler 
equation with financial state variables that enter through the shadow value of external finance. We estimate both reduced form and structural versions of the model. The Euler equation methodology complements previous studies in that it exploits the cross sectional heterogeneity among different firms to test for the role of financial factors. In addition, it points out the specific impact of financial factors on the intertemporal allocation of investment through their effects on the shadow price of external finance. The results generally support the view that a firm's financial position affects its investment.

The methodology is in close connection to many papers in the literature: Whited (1992), Hubbard and Kashyap (1992), Hubbard, Kashyap, and Whited (1995), Love (2003), Whited and Wu (2005), to name a few. The essential idea in these papers is that the standard neoclassical assumptions of absence of financial frictions, perfect foresight and symmetric information are violated for firms that face a constraint on dividend payout or a constraint on borrowing and that, among other factors, the financial position of the firm determines whether the above mentioned constraints are binding or not. Consequently, financial variables should enter directly into the Euler equation through their effect on the Lagrange multiplier on the constraint. A number of criticism could be levelled against such an approach. One can claim that the shadow value pertaining to binding of constraint on outside finance, being the change in the value of firm upon the relaxation of the constraint, would require explicit solution to the value function and the Lagrange multiplier. However, Gomes, Yaron, and Zhang (2006) have provided theoretical justification for such an approach, by showing that the typical assumptions about the nature of the financing frictions are captured by a "financing cost" function, which in turn characterizes the Lagrange multiplier .

An important contribution to the literature has been the one by Bond and Meghir (1994). By assuming that the firm faces an exogenous time-varying probability of bankruptcy that depends on the ratio of outstanding debt to capital they explicitly allow for debt finance and financial assets to enter the Euler equation. In this chapter we also estimate the specification provided by them. We found that the model is marginally rejected through the rejection of tests of overidentification upon instrumenting with additional financial variables. This could suggest that there is room for these additional financial variables to enter the Euler equation. Besides, since our objective is to characterize, or explore the factors affecting the financing premium on external finance, we would like to have a rich specification of the Lagrange multipliers that could also be thought of as a premium on external finance.

The second purpose of the chapter is to point out one of the many potential instances where the 
Euler equation methodology that examines only marginal decisions, since it is based on models with convex capital-stock adjustment costs, could fail even after controlling for the effect of financial factors on the intertemporal substitution of investment. The chapter begins by deriving the investment Euler equation under the assumptions of the neoclassical framework. This we term as the basic model. Our first set of estimates show that the model based on the assumptions of the standard neoclassical theory is soundly rejected. Also, following Whited (1988), we divide our sample into firms that invest continuously and firms that invest intermittently or disinvest. The rationale for such a split is to be found in the discussion in Dixit and Pindyck (1994) on the behavior of investment in the presence of fixed costs of adjustment, different purchase and resale prices of capital goods, and irreversibility. These models usually predict that investment will be "lumpy" in the sense that firms will remain inactive for periods of time, only investing when the profitability of capital goods rises enough to overcome fixed costs of adjustment or, in the case of models of irreversibility, the option value of waiting to invest. Studies of investment at the plant level, such as Doms and Dunne (1998), have provided evidence of such behavior. Certainly, if firm investment can be characterized by this sort of a model, tests of neoclassical Euler equations based on smooth, convex adjustment costs are destined to fail, since the Euler equation implies that a firm will continuously adjust its capital stock incrementally to small changes in profitability. For the group of firms that invest continuously the Euler equation of the standard model ought to hold even in the presence of fixed costs, while for those that invest intermittently it should not. Our results are in tandem with Whited (1998) that although the model is rejected for both groups, it is rejected only marginally for the first group and quite strongly for the second.

The rest of the chapter is organized as follows. Section 2.2 derives the Euler equation for estimation under the assumptions of the neoclassical framework. In Section 2.3 presents some models of finance and investment. Section 2.4 discusses the data and the estimation technique. Section 2.5 discusses the results. Concluding remarks and directions for further research are provided in the last section. 


\subsection{The Basic Model}

The firm maximizes the expected present discounted value of future dividends, $d_{i, t}$, which are given by

$$
V_{i 0}=E_{i 0}\left\{\sum_{t=0}^{\infty}\left[\prod_{j=0}^{t} \beta_{j}\right] d_{i, t}\right\}
$$

where $\beta_{j}$ is the one-period discount factor common to all firms and assuming that the costlessly adjustable variable factor has been maximized out of the problem, $d_{i, t}$ is given by

$$
d_{i, t}=\Pi\left(K_{i, t}, I_{i, t}\right)=F\left(K_{i, t}\right)-\psi\left(K_{i, t}, I_{i, t}\right)-p_{i, t} I_{i, t}
$$

In (2), $\Pi$ is the net revenue function. Gross investment, $I$, occurs at the start of the period and is immediately productive, but the firm faces strictly convex adjustment costs of $\psi\left(K_{i, t}, I_{i, t}\right)$ in changing its capital stock, with $\psi_{I}()>0, \psi_{K}()<0$ and $\psi_{I I}()>0 . F\left(K_{i, t}\right)$ is the firm's real production function and $p_{i, t}$ is the relative price of capital.

Given the above infinite horizon problem the optimality equation is given by

$$
V_{i, t}\left(K_{i, t-1}\right)=\max _{I_{i, t}} \Pi\left(K_{i, t}, I_{i, t}\right)+\beta_{t+1}^{t} E_{i, t}\left[V_{i, t+1}\left(K_{i, t}\right)\right]
$$

The expectations operator $E_{i, t}[$.$] is conditional on information available at the start of period t$ and expectations are taken over future interest rates, input and output prices, and technologies. The capital stock $K$, evolves according to the equation of motion

$$
K_{i, t}=\left(1-\delta_{i}\right) K_{i, t-1}+I_{i, t}
$$

where $\delta_{i}$ is the firm specific depreciation rate. The model assumes symmetric information and that the firm's objective is to maximize the wealth of the marginal shareholder. $r_{t}$ is defined to be the firm's nominal required rate of return between periods $t$ and $t+1, \beta_{t+1}^{t}=1 /\left(1+r_{t}\right)$ is the firm's discount factor. The model also assumes that the marginal shareholder is risk neutral, so that $r_{t}$, equals the interest rate on default free bonds and is given exogenously to the firm.

With a single control variable $I_{i, t}$ and a single state variable $K_{i, t-1}$, the first order condition with 
respect to $K_{i, t-1}$ yields the following Euler equation

$$
\gamma_{i, t}=\left(1-\delta_{i}\right)(\partial \Pi / \partial K)_{i, t}+\left(1-\delta_{i}\right) E_{i, t}\left[\beta_{t+1}^{t} \gamma_{i, t+1}\right]
$$

where $\gamma_{i, t}=\partial V_{i, t} / \partial K_{i, t-1}$ is the shadow value of capital. Moreover, from the first-order condition for investment, $I_{i, t}$, we can obtain

$$
0=(\partial \Pi / \partial K)_{i, t}+(\partial \Pi / \partial I)_{i, t}+E_{i, t}\left[\beta_{t+1}^{t}\left(\partial V_{i, t+1} / \partial K_{i, t}\right)\right]
$$

Combining (5) and (6), we can write the first order condition for optimal investment as

$$
\left(1-\delta_{i}\right)\left[(\partial \Pi / \partial I)_{i, t}\right]+\gamma_{i, t}=0
$$

since (7) holds for period $t+1$ as well, we obtain

$$
\left(1-\delta_{i}\right)\left[(\partial \Pi / \partial I)_{i, t+1}\right]+\gamma_{i, t+1}=0
$$

substituting for $\gamma_{i, t}$, from (7) and $\gamma_{i, t+1}$, from (8) the Euler equation, (5), can be written as

$$
\left(1-\delta_{i}\right) \beta_{t+1}^{t} E_{i, t}\left[(\partial \Pi / \partial I)_{i, t+1}\right]=(\partial \Pi / \partial I)_{i, t}+(\partial \Pi / \partial K)_{i, t}
$$

To estimate the model the expectations operator in (9) is replaced with an expectational error, $e_{i, t+1}$, where $E_{i, t}\left(e_{i, t+1}\right)=0$ and $E_{i, t}\left(e_{i, t+1}^{2}\right)=\sigma_{i, t}^{2}$. This gives the following equation:

$$
\left(1-\delta_{i}\right) \beta_{t+1}^{t}\left[(\partial \Pi / \partial I)_{i, t+1}\right]=(\partial \Pi / \partial I)_{i, t}+(\partial \Pi / \partial K)_{i, t}+e_{i, t+1}
$$

$E_{i, t}\left(e_{i, t+1}\right)=0$ implies that $e_{i, t+1}$ is uncorrelated with any time $t$ information, and $E_{i, t}\left(e_{i, t+1}^{2}\right)=\sigma_{i, t}^{2}$ implies that errors can be heteroscedastic. The rational expectations assumption also provides model identification, since it implies that any variable known to the firm at time $t-1$ can be used as instruments to estimate (10). Given (2), (10) can be written as

$$
\left(1-\delta_{i}\right) \beta_{t+1}^{t}\left[\psi_{I}\left(I_{i, t+1}, K_{i, t+1}\right)+p_{i t}\right]=\left[\psi_{I}\left(I_{i, t}, K_{i, t}\right)+p_{i, t+1}\right]-\left[F_{K}\left(K_{i, t}\right)-\psi_{K}\left(I_{i, t}, K_{i, t}\right)\right]+e_{i, t+1}
$$


The right-hand side represents the marginal costs of investing today which consists first of the marginal adjustment cost minus the gains from increase in the capital stock which is marginal product of capital and the marginal reduction in adjustment costs from an increment in the capital stock. The left hand side is the marginal cost of investing tomorrow. Optimal investment implies that on the margin the firm must be indifferent between investing today and transferring those resources to tomorrow.

In order to implement the Euler equation tests, it is necessary to parameterize the model in (11). First, consider a proxy for the marginal product of capital. If the firm's production function is homogeneous of degree $\eta>1$, and if an assumption of constant returns to capital is made then the proposed measure will understate the actual value by the amount $(\eta-1)\left(Y_{i t} / K_{i, t}\right)$, where $\mathrm{Y}$, is output. Also, if the firm has market power, then, strategic considerations notwithstanding, profit maximization implies that the above measure of the marginal product of capital must be modified by scaling the variable factor costs upward by the term $\mu=\left(1-1 / \varepsilon_{d}\right)^{-1}$, where $\varepsilon_{d}$ is the absolute value of the elasticity of the firm's demand curve. Since firms with monopoly power operate on the elastic portion of their demand curves, the above expression should be greater than one. Given these considerations, the following measure of the marginal product of capital is used.

$$
F_{K}\left(K_{i, t}\right)=\left(\eta Y_{i, t}-\mu C_{i, t}\right) / K_{i, t}
$$

where $C_{i, t}$ is the variable cost of production.

Second, following a number of authors, eg. Bond and Meghir (1994) and Whited (1992), the adjustment cost of capital is assumed to be of the following functional form.

$$
\psi\left(K_{i, t}, I_{i, t}\right)=\alpha / 2\left((I / K)_{i, t}-v\right)^{2} K_{i, t}
$$

With these two assumptions (11) can be written as

$$
\begin{array}{r}
\left(1-\delta_{i}\right) \beta_{t+1}^{t}\left(\alpha\left((I / K)_{i, t+1}-v\right)\right)= \\
\left(\alpha\left((I / K)_{i, t}-v\right)\right)+\left(-\eta Y_{i, t}+\mu C_{i, t}\right) / K_{i, t}-\left(\alpha / 2\left((I / K)_{i, t}^{2}-v^{2}\right)\right)+e_{i, t+1}
\end{array}
$$

Rearranging we get the estimation equation as

$$
(I / K)_{i, t}=\beta_{1}(I / K)_{i, t-1}+\beta_{2}(I / K)_{i, t-1}^{2}+\beta_{3}(Y / K)_{i, t-1}+\beta_{4}(C / K)_{i, t-1}+\beta_{5} I D_{i}+f_{t}+a_{i}+e_{i, t}
$$


where ID is industry dummy, $f_{t}$ is a fixed time effect, and $a_{i}$ is a fixed firm effect. The above theory predicts that $\beta_{1}$ and $\beta_{4}$ should have a positive sign while $\beta_{2}$ and $\beta_{3}$ should be negative.

\subsection{Investment and Financial Constraints}

The standard model of investment presented above has no role for financial policy. For a firm financed only by equity, net revenue equals the net distribution to shareholders, i.e. dividend payments net of any new share issues. The choice between retained earnings and new share issues as sources of investment finance is irrelevant to the maximization of (3) since each unit of new equity issued allows the firm to pay out dividends valued at one unit, and has no effect on net present value. If the firm can raise finance by issuing risk-free debt at an interest rate $i_{t}$, the only internal solution for debt policy requires $i_{t}=r$, and renders debt policy similarly irrelevant. Debt policy remains irrelevant even in the presence of bankruptcy risk, so long as there are no deadweight costs of bankruptcy.

But we know that the firm's financial policy may play a substantive role in the investment decision. A firm may find to its advantage to use one source of investment finance in preference to another. For example, a preference for retained earnings over new share issues will arise if the tax system favors capital gains over dividend income or if significant transactions charges must be paid when placing new shares. The presence of bankruptcy costs makes debt finance increasingly expensive as the probability of bankruptcy rises, although tax advantages may make debt finance attractive at low levels of borrowing. In this situation the firm faces a financial "pecking order" or hierarchy of costs associated with different sources of investment finance. The availability of low-cost internal finance may then be a significant factor in its investment decision.

Consider a firm that issues bonds and that $B_{i, t}$ is the stock of outstanding debt at the beginning of period $t$. The sources and uses of funds relation for a firm that issues debt can be written thus:

$$
d_{i, t}=\left(F\left(K_{i, t}, \epsilon_{i, t}\right)-\psi\left(K_{i, t}, I_{i, t}\right)-p_{i, t} I_{i, t}\right)+B_{i, t}-\left(1+r_{t}\right) B_{i, t-1} .
$$

where $d_{i, t}$ can be thought of as dividends, $\epsilon_{i, t}$ is a shock to the profit function that follows a Markov process and that is observed by the firm at time $t$ and $r_{t}$ is the interest rate that the firm has to pay on the past levels of debt and $p_{i, t}$ is the relative price of capital . The assumption on the revenue function $F($.$) and the adjustment cost function \psi(.,$.$) is the same as above.$

The firm maximizes equation (1) subject to the capital stock accumulation identity (4). The firm 
also faces a constraint on outside finance:

$$
d_{i, t} \geq d_{i, t}^{*}
$$

Unlike Bond and Meghir (1994) we do not model new share issue. We restore to the arguments in Whited and $\mathrm{Wu}(2006)$ that (17) "limits the amount of outside equity financing, and a negative value for $d_{i, t}^{*}$ implies that the firm is able to raise outside equity finance. Although negative dividends are not a feature of most equity markets, in the absence of taxes negative dividends can be considered equivalent to new share issues, since on the margin both have the same effect on old shareholders". The presence of debt implies that the firm can go bankrupt. Both the probability of bankruptcy and the interest rate charged by lenders will depend on the amount borrowed. In the event of bankruptcy, like Bond and Meghir (1994), we assume that ownership of the firm is transferred from the shareholders to the creditors, although the bankruptcy process in period $t$ may involve deadweight costs. Bond and Meghir (1994) assume that the interest rate $r_{t}$ and the probability of bankruptcy both depend on the amount borrowed $B$, and the size of the firm $K$, only through the ratio $(B / K)$. Moreover they assume that bankruptcy costs depend on $B$, but not on $K$, and that they are homogeneous of degree one in $B$. In such a case they arrive at the Euler equation characterizing the optimal path for investment as

$$
\begin{array}{r}
-(1-\delta) \beta_{t+1}^{t} E_{i, t}\left[\left(1+\lambda_{i, t+1}\right)(\partial \Pi / \partial I)_{i, t+1}\right]= \\
-\left(1+\lambda_{i, t}\right)(\partial \Pi / \partial I)_{i, t}-\left(1+\lambda_{i, t}\right)(\partial \Pi / \partial K)_{i, t}-\nu_{i, t}(B / K)_{i, t}^{2}
\end{array}
$$

where $\lambda_{i t}$ the Lagrange multiplier associated with $(17)^{1}$. It can be interpreted as the shadow cost associated with raising new equity, which implies that external (equity) financing is costly relative to internal finance. In the absence of financial constraint, that is, when $\lambda_{i t}=0$, assuming constant returns to scale and $\left(Y_{i, t}-C_{i, t}\right) / K_{i, t}$ as cash flows they arrive at the following equation:

$$
\begin{gathered}
(I / K)_{i, t}=\beta_{1}(I / K)_{i, t-1}+\beta_{2}(I / K)_{i, t-1}^{2}+\beta_{3}(Y / K)_{i, t-1}+ \\
\beta_{4}(C F / K)_{i, t-1}+\beta_{5}(B / K)_{i, t-1}^{2}+\beta_{6} I D_{i}+f_{t}+a_{i}+v_{i t}
\end{gathered}
$$

where ID is industry dummy, $f_{t}$ is a fixed time effect, and $a_{i}$ is a fixed firm effect.This they term it as the basic equation. In absence of bankruptcy cost this should be same as (14), but differs due to

\footnotetext{
${ }^{1}$ See Bond and Meghir (1994) for the derivation of the Euler equation and the optimal level of debt.
} 
the assumption of constant returns to scale.

\subsubsection{Financial Regimes}

Though we do not model issue of new equities, it might be worth while, if only to get a feel of the data, to delve into what Bond and Meghir (1994) term as financial regimes based on new equity issue and dividend payout. Let $D_{i, t}$ be a dummy that takes value 0 when the firms do not pay any dividends and 1 if it does and let $N_{i, t}$ be the dummy for that takes value 1 if a firm issues new equity and 0 if does not or withdraws some of it's outstanding equity.

Regime 1. $D_{i, t}>0, N_{i, t}=0$

The firm generates sufficient net revenue to finance its investment from retained earnings and pay positive dividends. The Kuhn-Tucker multiplier $\lambda_{i t}$, which measures the shadow value of internal finance, is zero.

Regime 2. $D_{i, t}=0, N_{i, t}=0$

The firm generates insufficient net revenue to finance all the investment it would like to make at the cost of retentions, but finds it optimal not to issue new shares given their higher cost. Investment expenditure is constrained by the availability of internal finance.

Regime 3. $D_{i, t}=0, N_{i, t}>0$

The firm again exhausts its net revenue to finance investment, but here has sufficiently attractive investment opportunities remaining that it issues shares to finance a higher level of investment. For firms in Regime 1 in both period $t$ and period $t+1$, the Euler equation in (16), in absence of bankruptcy cost, reduces to the basic form of (6). The same applies for firms in Regime 3 in both periods, provided unit transactions costs of issuing new shares is small. In all other cases investment depends on the unobservable $\lambda_{i t}$ and the basic Euler equation should be rejected. Table 2.1 shows that for the sample of 416 Dutch firms, 95.86 percentage of the firm-years do not pay dividends and 13.13 percent of them issue new equity. By this token 84 percentage of the firm year observations could be regarded as constrained.

\subsubsection{Financial Constraint Revisited}

Many papers, based on essentially ad hoc criteria, have classified firms into "constrained" and "unconstrained" to capture the extent of financing frictions. Different studies have used different criteria to a priory classify firms into constrained and unconstrained firms. This emphasis raises two issues: whether different sample splits lead to consistent results, and whether any fixed grouping is 
Table 2.1: Financial Regimes

\begin{tabular}{ccccc}
\hline \hline & & \multicolumn{2}{c}{ Dividends } \\
& & Zero & Positive & Total \\
\hline \multirow{3}{*}{ New } & Zeros & 2,787 & 104 & 2,891 \\
Equity & & $(83.74)$ & $(3.13)$ & $(86.87)$ \\
& Positive & 403 & 34 & 437 \\
& & $(12.11)$ & $(1.02)$ & $(13.13)$ \\
& \multirow{2}{*}{ Total } & 3,190 & 138 & 3,328 \\
& & $(95.85)$ & $(4.15)$ & 100.00 \\
\hline
\end{tabular}

Time Period: 1996-2003

reasonable. The assumption that only a particular group of firms faces costly external financing is analytically and empirically convenient. However, it is more plausible that firms switch between "constrained" and "unconstrained" regimes depending upon shifts in investment opportunities and the availability of internal or external financing. Moreover, to take an example, to test the hypothesis of no financial regimes Bond and Meghir (1994) define a dummy variable $S_{i, t}$, which is zero when dividends are positive and share issues zero in both periods $t$ and $t-1$ (i.e. when the firm is in Regime 1 in both these periods), and is one in all other cases. In their sample each of the two sub-samples given by this classification contains about half the observations in the full sample. They then interact this dummy with all right-hand side variables and estimate the model as before. However, for our sample pursuing such a classification does not lead to any observation in Regime 1. Also, it is important to consider investment and financial policy jointly; firms may, for example, accumulate liquidity as a buffer against future constraints. In other words, since the variables based upon which a sample is split and investment are joint decisions, there is issue of endogenous splitting that would have to be dealt with. Gomes, Yaron and Zhang (2006) have avoided specifying the underlying source of these frictions and shown that the typical assumptions about the nature of the financing frictions are captured by a "financing cost" function, which provides a tractable framework to examine the role of financing frictions on intertemporal allocation of investment.

Recently Gomes, Yaron, and Zhang (2006) show that one can rewrite a constrained problem as an unconstrained one with embedded multipliers, which gives a characterization of the multiplier, $\lambda_{i t}$, as a measure of the premium on external finance. By linking this "shadow-price" to essentially observable variables, one is able to recast the problem in a way that is amenable to empirical analysis, that is to say that in the presence of financial market imperfections, $\lambda_{i t}$ are state-dependent and time varying. A number of papers in the literature estimate this Euler equation directly by assuming a parametric form for the shadow cost term: Whited (1992), Hubbard and Kashyap (1992), Hubbard, 
Kashyap, and Whited (1995), and Jaramillo, Schianterelli, and Weiss (1996), Love(2003), Whited and $\mathrm{Wu}(2006)$.

In the absence of bankruptcy cost equation and assuming rational expectations (18) can be written as

$$
\left(1-\delta_{i}\right) \beta_{t+1}^{t} E_{i, t}\left\{\Theta_{t, t+1}(\partial \Pi / \partial I)_{i, t+1}\right\}=(\partial \Pi / \partial I)_{i, t}+(\partial \Pi / \partial K)_{i, t}
$$

which can, upon expansion be written as

$$
\begin{gathered}
\left(1-\delta_{i}\right) \beta_{t+1}^{t} E_{i, t}\left\{\Theta_{t, t+1}\left[\psi_{I}\left(I_{i, t+1}, K_{i, t+1}\right)+p_{i, t+1}\right]\right\}= \\
\psi_{I}\left(I_{i, t}, K_{i, t}\right)+p_{i, t}-\left[F_{K}\left(K_{i, t}\right)-\psi_{K}\left(I_{i, t}, K_{i, t}\right)\right]+e_{i, t+1}
\end{gathered}
$$

where $\Theta_{t, t+1}=\frac{\left(1+\lambda_{i, t+1}\right)}{\left(1+\lambda_{i, t}\right)}$ and $p_{i, t}$ is the relative price of capital good. Following Love (2003), we linearize $^{2}$ the product of $(1-\delta) \beta_{t+1}^{t}, \Theta_{t, t+1}$ and the marginal cost of investment (expression in curly brackets in (20), here denoted as $\left.\{.\}_{t}\right)$ as $(1-\delta) \beta_{t+1}^{t} \Theta_{t, t+1}\{.\}_{t}=\bar{\beta} \gamma \Theta_{t, t+1}+\bar{\beta}\{\cdot\}_{t}+\gamma \beta_{t+1}^{t}$. Hence,

\footnotetext{
${ }^{2}$ To see this let
}

$$
f\left(\beta_{t+1}^{t}, \Theta_{t, t+1},\{.\}_{t}\right)=E\left(\beta_{t+1}^{t} \Theta_{t, t+1}\{.\}_{t}\right)
$$

where $(1-\delta) \beta_{t+1}^{t}=\beta_{t+1}^{t}$. Using a first-order Taylor approximation around the means we get,

$$
\begin{array}{r}
f\left(\beta_{t+1}^{t}, \Theta_{t, t+1},\{.\}_{t}\right)=f\left(E\left(\beta_{t+1}^{t}\right), E\left(\Theta_{t, t+1}\right), E\left(\{.\}_{t}\right)\right)+ \\
f^{\prime}\left(\beta_{t+1}^{t \prime}, \Theta_{t, t+1}^{\prime},\{.\}_{t}^{\prime}\right)\left\{\left[\beta_{t+1}^{t}-E\left(\beta_{t+1}^{t}\right)\right],\left[\Theta_{t, t+1}-E\left(\Theta_{t, t+1}\right)\right],\left[\{\cdot\}_{t}-E\left(\{.\}_{t}\right)\right]\right\}^{\prime}
\end{array}
$$

where $\beta_{t+1}^{t \prime} \in\left(\beta_{t+1}^{t}, E\left(\beta_{t+1}^{t}\right)\right), \Theta_{t, t+1}^{\prime} \in\left(\Theta_{t, t+1}, E\left(\Theta_{t, t+1}\right)\right)$ and $\{.\}_{t}^{\prime} \in\left(\{.\}_{t}, E\left(\{.\}_{t}\right)\right)$. Also, suppressing the time scripts, $f^{\prime}\left(\beta^{\prime}, \Theta^{\prime},\{.\}^{\prime}\right)=\{\partial f / \partial \beta, \partial f / \partial \Theta, \partial f / \partial\{\}$.$\} . Replacing f$ with the expectation operator, $E$, this is equal to $\left\{E\left(\Theta^{\prime}\{.\}^{\prime}\right), E\left(\beta^{\prime}\{.\}^{\prime}\right), E\left(\beta^{\prime} \Theta^{\prime}\right)\right\}$. Since $\Theta_{t, t+1}$ could be above or below one, its mean should be a value around one. Denoting the unconditional mean of $\{$.$\} as \gamma$, and the average of $\beta_{t+1}^{t}=(1-\delta) \beta_{t+1}^{t}$ as $\bar{\beta}$, ignoring the constant terms and assuming that covariance between the financing constraints factor and the marginal cost of investment (the term in $\{\}$.$) is constant, gives us$

$$
(1-\delta) \beta_{t+1}^{t} \Theta_{t, t+1}\{.\}_{t}=\bar{\beta} \gamma \Theta_{t, t+1}+\bar{\beta}\{.\}_{t}+\gamma \beta_{t+1}^{t}
$$


assuming that the relative price of capital is $1^{3},(20)$ can be written as

$$
\begin{array}{r}
{\left[\psi_{I}\left(I_{i, t+1}, K_{i, t+1}\right)+1\right]=-\gamma \Theta_{t, t+1}-\frac{\gamma \beta_{t+1}^{t}}{\bar{\beta}}+} \\
\frac{1}{\bar{\beta}}\left[\psi_{I}\left(I_{i, t}, K_{i, t}\right)+1\right]-\frac{1}{\bar{\beta}}\left[F_{K}\left(K_{i, t}\right)-\psi_{K}\left(I_{i, t}, K_{i, t}\right)\right]+e_{i, t+1}
\end{array}
$$

Here we assume a linear approximation representing the dependence of $\Theta_{t, t+1}$ term on a financial state variable represented by

$$
\Theta_{t, t+1}=\theta_{1}(C F / K)_{t}+\theta_{2}(B / K)_{t}+\theta_{3}(L Q / K)_{t}+\theta_{4}(I N E X P / K)_{t}+\theta_{5}(N E / K)_{t}
$$

where $(C F / K)_{t}$ is Cash Flow, $(B / K)_{t}$ long term level of Debt, $(L Q / K)_{t}$ is Liquidity, $(I N E X P / K)_{t}$ is the Interest Expense of the firm and $(N E / K)_{t}$ is the amount of New Equity issued by the firm, all normalized by the total assets of the firms. With the assumptions made in (12) and (13) one arrives at the following estimation equation.

$$
\begin{gathered}
(I / K)_{i, t}=\alpha_{1}(I / K)_{i, t-1}+\alpha_{2}(I / K)_{i, t-1}^{2}+\alpha_{3}(Y / K)_{i, t-1}+\alpha_{4}(C / K)_{i, t-1}+\alpha_{5}(C F / K)_{i, t-1}+ \\
\alpha_{6}(B / K)_{i, t-1}+\alpha_{7}(L Q / K)_{i, t-1}+\alpha_{8}(I N E X P / K)_{i, t-1}+\alpha_{9}(N E / K)_{i, t-1}+\alpha_{10} I D_{i}+f_{t}+a_{i}+e_{i, t}(26)
\end{gathered}
$$

The main hypothesis in this exercise can be stated as

$$
H_{0}: \alpha_{5}>0 ; \alpha_{6}<0 ; \alpha_{7}>0 ; \alpha_{8}<0 ; \alpha_{9}<0
$$

Like in most empirical studies we use the firm's cash flow as a proxy for independent changes in the net worth of a firm. An increase in the cash flow should ease off, or have a negative impact on the shadow value of external funds. The maintained assumption in such an approach is that the component of shifts in net worth as a result of changes in expected future profitability has been taken care of, in the sense that given the Markovian nature of the model, the Euler equation governs the firms decision of how much to invest today relative to investment tomorrow. Financing constraints expected to bind or not bind in the far future have already been incorporated in the optimal time $t$ level of investment and have no direct impact on the time $t-1$ decision to invest now versus postpone tomorrow. Secondly in order to make sure that variation in investment today versus investment tomorrow are explained by effects of financing constraints in general and cash

\footnotetext{
${ }^{3}$ This would be equivalent to assuming a constant rate of inflation for the investment goods. In notational terms we are assuming that $p_{i, t+1}-\frac{1}{\beta} p_{i, t}$ is constant.
} 
flows as a measure of changes in net worth in particular, on the supply side, we need to control for productivity, which as in Whited and Wu (2006) is done via (11). The argument being that the Markovian structure of the model implies that one only needs to control for capital productivity at time $t$.

The positive coefficient on the debt to assets ratio indicates that a more highly leveraged firm will have a higher shadow value of external funds; that is, it will be more financially constrained.

The ratio of the firm's interest expense to the firm's asset indicates the likelihood of firm financial distress, relative to its fundamental health or need to borrow. Since interest expenses are deducted from cash flows, it captures the idea that if a firm can generate sufficient internal funds, it will not have a great need to borrow and will not be likely to run up against its debt limit or given a specified probability of bankruptcy, the firm will not exceed its optimal debt limits.

The rationale for the inclusion of liquidity or cash stock among the set of financial state variable parameterizing the shadow value of, or the premium on, external finance is that the firms practice precautionary savings; that is, they need to build up liquid assets in order to invest. This variable again is likely to ease off the constraint on external finance.

Since in the absence of taxes new issues of equity can be considered equivalent to negative dividends this has a direct bearing on the shadow value of external finance. As far as data on equity is concerned, the company accounts do not make a distinction between internal and external equity and also we do not have any information as whether our firms are listed or not. Nevertheless, changes in the equity holdings of the firms, be it internal or external, do have a bearing on the ownership structure of the firm.

\subsubsection{The Structural Model}

In an alternative formulation, assuming that investment becomes productive capital with a oneperiod lag and that the firm discount rate, the effective price of capital goods, and profits are all appropriately tax adjusted, one can write, taking rational expectations, the Euler Equation as follows.

$$
\begin{aligned}
\beta_{t+1}^{t} \frac{\left(1+\lambda_{i t+1}\right)}{\left(1+\lambda_{i t}\right)}\left\{F_{K}\left(K_{i, t+1}\right)-\psi_{K}\left(I_{i, t+1}, K_{i, t+1}\right)+(1-\delta)\right. & \left.\left(\psi_{I}\left(I_{i, t+1}, K_{i, t+1}\right)+p_{i, t+1}\right)\right\} \\
& =\psi_{I}\left(I_{i t, K i t}\right)+p_{i, t}+e_{i, t+1}
\end{aligned}
$$


Assuming (12) and a cubic adjustment cost approximated as ${ }^{4}$,

$$
\psi\left(K_{i, t}, I_{i, t}\right)=\left(\alpha_{0}+\frac{\alpha_{2}}{2}\left(\frac{I}{K}\right)_{i, t}^{2}+\frac{\alpha_{3}}{3}\left(\frac{I}{K}\right)_{i, t}^{3}\right) K_{i, t}
$$

yields the following equation.

$$
\begin{array}{r}
\beta_{t+1}^{t} \frac{\left(1+\lambda_{i t+1}\right)}{\left(1+\lambda_{i t}\right)}\left[\left(\eta Y_{i, t+1}-\mu C_{i, t+1}\right) / K_{i, t+1}-\left(\alpha_{0}+\frac{\alpha_{2}}{2}\left(\frac{I}{K}\right)_{i, t+1}^{2}+\frac{2 \alpha_{3}}{3}\left(\frac{I}{K}\right)_{i, t+1}^{3}\right)+\right. \\
\left.\left(1-\delta_{i}\right)\left\{\left(\alpha_{2}\left(\frac{I}{K}\right)_{i, t+1}^{2}+\alpha_{3}\left(\frac{I}{K}\right)_{i, t+1}^{3}\right)+p_{i, t+1}\right\}\right]=\left(\alpha_{2}\left(\frac{I}{K}\right)_{i, t}^{2}+\alpha_{3}\left(\frac{I}{K}\right)_{i, t}^{3}\right)+p_{i, t}+e_{i, t+1}
\end{array}
$$

If the outside equity constraint is binding, the effects of external finance constraints show up in the term $\Theta_{t, t+1}=\frac{\left(1+\lambda_{i, t+1}\right)}{\left(1+\lambda_{i, t}\right)}$ which is the relative shadow cost of external finance. In the absence of finance constraints, $\Theta_{t, t+1}=1$. On the other hand, if the equity constraint binds, then generally $\Theta_{t, t+1} \neq 1$, unless $\lambda_{t}=\lambda_{t+1}$. As also noted in Gomes, Yaron, and Zhang (2006), this last observation implies that finance constraints can only affect investment if they are time-varying. It is the shadow value of the constraint today, relative to tomorrow, that is important. An important consideration is that without the assumption of risk neutrality, this would imply that high-risk firms would have higher discount rates than low-risk firms. However, the risk of any individual firm should be primarily related to the variability of its earnings. To the extent that this variance is constant over time in a short panel like ours, it should be picked up by the fixed effect. However, we assume that the expected value of the discount factor is equal to $\left(1+r_{f}\right)^{-1}$ where $r_{f}$ is the risk free rate of return equal to long term interest rate on government bonds.

We estimate this equation using GMM technique as outlined by Hansen(1982). In this specification, however we, as in Whited and $\mathrm{Wu}$ (2006), parameterize $\lambda_{i, t}$ as function of contemporaneous financial state variables rather than $\Theta_{t, t+1}$ as in (25).

$$
\lambda_{t}=\lambda_{1}(C F / K)_{t}+\lambda_{2}(B / K)_{t}+\lambda_{3}(L Q / K)_{t}+\lambda_{4}(I N E X P / K)_{t}+\lambda_{5}(N E / K)_{t}
$$

The main hypothesis here can be stated as

$$
H_{0}: \lambda_{1}<0 ; \lambda_{2}>0 ; \lambda_{3}<0 ; \lambda_{4}>0 ; \lambda_{5}>0
$$

After estimating (30), we construct $\Theta_{t, t+1}=\frac{\left(1+\lambda_{i, t+1}\right)}{\left(1+\lambda_{i, t}\right)}$ and the quantity in [.] on the left hand side of

\footnotetext{
${ }^{4}$ Notice that the linear term has not been included as $\psi_{I}\left(K_{i, t}, I_{i, t}\right)$ of the linear term would be a constant and would be subsumed in the relative price term.
} 
(30), $L H S_{t+1}=\left[\left(Y_{t+1}-\mu C_{t+1}\right) / K_{t+1}-\left(\alpha_{0}+\frac{\alpha_{2}}{2}\left(\frac{I}{K}\right)_{t+1}^{2}+\frac{2 \alpha_{3}}{3}\left(\frac{I}{K}\right)_{t+1}^{3}\right)+(1-\delta)\left\{\left(\alpha_{2}\left(\frac{I}{K}\right)_{t+1}^{2}+\right.\right.\right.$

$\left.\left.\left.\alpha_{3}\left(\frac{I}{K}\right)_{t+1}^{3}\right)+p_{t+1}\right\}\right]$. Here we expect to see a negative correlation between $\Theta_{t, t+1}$ and $L H S_{t+1}$. The expected negative correlation has the following economic interpretation. In the absence of financing constraints, a positive expected productivity shock increases the left side of (30). All else equal, the optimizing firm will then invest more today relative to tomorrow in anticipation of that shock, thereby equalizing the two sides of (30). Once financing constraints enter the picture, the negative correlation between $\Theta_{t, t+1}$ and $L H S_{t+1}$ implies a dampening of this intertemporal substitution effect. To test whether there is a significant negative correlation between $\Theta_{t, t+1}$ and $L H S_{t+1}$, we run the following regression.

$$
\widehat{L H S_{t}}=\beta_{1}(I / K)_{t-1}+\beta_{2}(I / K)_{t-1}^{2}+\beta_{3} \hat{\Theta}_{t}^{t-1}+\beta_{4} p_{t-1}+\beta_{5} I D+f_{t}+a_{i}+v_{i t}
$$

which is derived from (30) and could be thought of as a linearzation of (30), akin to the arguments in footnote 2 used to derive (24). Here we expect, $\beta_{1}>0, \beta_{2}<0, \beta_{3}<0$ and $\beta_{4}>0$.

\subsection{Data and Estimation}

We use yearly firm-level data of Dutch manufacturing and services. These are Financial data from balance sheets of the SFGO firms. The panel spans 8 years form 1996 to 2003 . We select our sample by first deleting any firm-year observations with missing data or for which total assets, the gross capital stock, or sales are either zero or negative. Also since the estimation of the Euler equation involves lagged dependent variable, with other regressors potentially endogenous, instrumenting with period $t-2$ variables would require that at least three periods of data be available. We dropped those firms for which data was not available for at least three periods. Whited (1992), Whited (1998); Whited and Wu (2005); Aghion et al (2004) have deleted the firms for which (de)consolidation accounts for more than 15 percent of the book value of the capital assets, the argument being that these investment models are not suited for large investment such as mergers and acquisition. To arrive at the data set we finally use for estimation we also use the same criterion of 15 percent.

In this chapter we estimate (15), (19), (26) and (30). To control for the technological difference across sectors we also include industry dummies. The lagged values of the dependent variable on the right-hand side of the two equations are necessarily correlated with the firm-specific effects, and we allow the output, cost and the financial variables to be potentially correlated with $a_{i}$ also. To 
estimate (15), (19), and (26), the dynamic models consistently from a short panel we use a Generalized Method of Moments estimator of the kind developed by Arellano and Bond (1991). The unobservable $a_{i}$ can be eliminated from the two equations by transforming all variables by the forward Helmert's or orthogonal deviations transformation proposed by Arellano and Bover (1995). The important property of this transformation is that if $x_{i}$ is serially uncorrelated then $x_{i, t-s}$ will be uncorrelated with the transformed variable for $s>2$. This implies that if the error term $e_{i, t}$, is serially uncorrelated in (14), (19) and (26) lagged values of the (untransformed) dependent variable and other right-hand side variables dated $t-s$ will be uncorrelated with the transformed error term for $s \geq 2$. These lagged values will therefore be valid instruments in the transformed model and a GMM estimator can be formed which optimally exploits all the (linear) moment restrictions specified by the model ${ }^{5}$. The implicit reduced form for the endogenous variables is allowed to be different in each cross-section and each reduced form uses potentially all available moment restrictions. In practice very remote lags are unlikely to be informative instruments and hence we do not use all available moment restrictions. In our estimation we use instruments lagged $t-2$ onwards. This is only possible if the test statistic for second-order serial correlation based on residuals from the first-difference equation does not reject the for lack of second-order serial correlation in the first-difference residuals.

To estimate (30) we use GMM technique as outlined by Hansen (1982). We estimate (30) in first differences to eliminate possible fixed firm effects a procedure that allows us to use instruments dated at $t-2$. In other words, we use GMM to estimate conditional moment conditions of the form $E_{t-2}\left(z_{i, t-2} \cdot\left(e_{i, t}-e_{i, t-1}\right)\right)$. To determine if the specification we use is correct we use the test developed by Newey and West (1987), which can be described as a GMM analog to a standard likelihood-ratio test. The product of the minimized value of the objective function and the number of observations, the "J-statistic", has a $\chi^{2}$ distribution with $q-p$ degrees of freedom where $q$ is the number of moment conditions or the number of instruments and $p$ is the number of parameters to be estimated. Let $J_{U}$ be the J-statistic for an unrestricted model, and let $J_{R}$ be the J-statistic for a restricted model where a subset of the parameters are excluded. The Newey and West (1987) test for the significance of the parameters excluded follows from noting that $J_{R}-J_{U}$ will be distributed as a $\chi_{2}$ with degrees of freedom equal to the number of parameters excluded. Intuitively, if excluding this parameter produces a significant increase in the J-statistic, then this exclusion restriction is rejected.

\footnotetext{
${ }^{5}$ The instrument set for each regression is stated along with the estimates in the appendix.
} 


\subsection{Results}

The estimates of the basic equation, equation (15), are reported in Table 2.5. The Table has three sets of estimates. Column (a) is for the whole data set, (b) for the firms investing continuously and (c) for the firms that invest intermittently. The set of instruments includes $t-2$ lag of investment, its square, output, cost, cash flow, and debt. The results indicate that the basic Euler equation without financial constraint is rejected. As discussed earlier the dynamics imply that the coefficient of output should have been negative and that of cost positive. As it turns out both coefficients have the opposite sign. Moreover they are significant at 10 percent level significance for the whole data set and at 1 percent level of for the firms that invest intermittently, indicating that the incidental profits and losses imbedded in these variables have an effect on investment. In other words, cash flow, which is derived from these variables and which we deem here to be an independent change in the net worth of a firm, might have a role to play in the determination of investment. To be noted is the fact that the instrument set consists of two financial variables, namely cash flow and debt. As it turns out the Sargan Test for overidentification is rejected at 6 percent for the whole data set and at 1 percent for the firms that invest intermittently. This could be an indication that these variables could belong to the Euler equation. However, to be noted is the fact that, the Sargan Test does not reject the overidentification restrictions for the data set where firms invest continuously and the coefficient on output and cost, though they have the wrong signs, are not significant. This could lend credence to Whited (1998), that the Euler equation of the standard model ought to hold for firms that invest continuously, even in the presence of fixed costs, while it should not for the firms that invest intermittently.

Table 2.6 report the estimates for the Bond and Meghir (1994) specification - equation (19). The coefficients obtained in these two estimates are as expected and qualitatively the same as in their paper. In Table 2.6 the coefficients for the Cash Flow and the Debt are jointly significant at 10 percent level of significance for column (a) and are highly significant in column (b), suggesting that investment decisions are related to the financial conditions of the firms. However, the instrument set for the estimates in column (b) in Table 2.6 include additional financial variables namely Liquidity, Interest Expense, New Equity and Current Liabilities. The Sargan test for overidentification restrictions are rejected at 13 percent level of significance for column (b). This could be an indication that augmenting the Euler equation with additional financial variables through the parameterizations of Lagrange Multipliers that pertain to the non negativity of dividends, could improve the performance of the model. 
Table 2.7 reports the estimates of the Euler equation, equation (16) augmented with financial variables. The financial variables that appear in the equation through the shadow value of external finance, are Cash Flow, outstanding Debt, Interest Expense, New Equity issued, and Liquidity. The coefficient on these variables, baring Liquidity, have the expected signs. The difference between the estimates in column (a) and (b) is that the estimates in column (b) include additional variables namely Log of Market Share, Grants, Provision, Current Assets and Liabilities, Depreciation and Taxes in its instrument set. While the coefficients are jointly significant for both sets of estimates, Interest Expense is also significant at 5 percent for column (b). Also, to be noted is the fact that with inclusion of additional instruments, the coefficients on output and cost though appearing with the wrong sign are no longer significant.

Table 2.8 presents separate estimates of the Euler equation augmented with financial variables for firms that invest continuously and for firms that invest intermittently ${ }^{6}$. Among the set of Financial variables for the group of firms that invest intermittently we do not include Cash Flow as it turned out to be insignificant, with the wrong sign. In Table 2.8 for the firms that invest intermittently we have three columns. The estimates in column (a) are obtained using orthogonal deviations while those in (b) and (c) are obtained using first differences. In these estimates we do not obtain the correct sign for the adjustment cost parameters. However, we obtain significant results with correct signs on the Financial variables. Also the magnitude of the coefficients on these financial variable are larger than that obtained for the full sample. To be noted is the fact that liquidity, as precautionary savings has a significant effect on the lowering the shadow price of external finance for these firms and its effect for these firms appear to be 10 times as important compared to the full sample of firms. Interest expense seem to have twice as much effect on the shadow price of external finance than it is for the full sample of the data. But the failure of the model for firms investing intermittently, in terms of incorrect signs on investment terms still suggest some sort of misspecification, which may arise due non-convexities in adjustment cost. The estimates for the firms that invest continuously, suggests that financial variables do not significantly affect the shadow value external finance, but that adjustment costs are significant determinants in the intertemporal substitution of investment.

\footnotetext{
${ }^{6}$ For the firm that invest intermittently we also have a specification, column (c) in Table 2.8, where the adjustment cost assumed is an approximation of cubic adjustment cost, to see if such an specification might provide with a better proxy for adjustment cost to these set of firms. With such an adjustment cost we obtain

$$
\begin{gathered}
(I / K)_{i, t}=\alpha_{1}(I / K)_{i, t-1}+\alpha_{2}(I / K)_{i, t}^{2}+\alpha_{3}(I / K)_{i, t-1}^{2}+\alpha_{4}(I / K)_{i, t-1}^{3}+\alpha_{5}(Y / K)_{i, t-1}+\alpha_{6}(C / K)_{i, t-1} \\
\alpha_{7}(B / K)_{i, t-1}+\alpha_{8}(L Q / K)_{i, t-1}+\alpha_{9}(I N E X P / K)_{i, t-1}+\alpha_{10}(N E / K)_{i, t-1}+\alpha_{11} I D_{i}+f_{t}+a_{i}+e_{i, t}
\end{gathered}
$$

In this specification we would expect $\alpha_{1}>0, \alpha_{2}<0$, and $\alpha_{4}<0$, while the sign on $\alpha_{3}$ is indeterminate and depends on the relative magnitude of the parameters of the adjustment cost.
} 
Table 2.9 presents the results of our structural estimates. Here we assume constant returns to scale, that is $\eta=1^{7}$. The set of instruments here is fairly large. The instrument set comprises of $t-2$ lag of $(I / K),(I / K)^{2},(I / K)^{3},(I / K)^{4}$, Output, Cost, Cash Flow, Debt, Dividends, Liquidity, Log of Total assets, Interest Expense, Log of Market Share, Grants, Provision, Other liabilities, Inventories, Depreciation, Current Assets, Currents Liabilities, Dummy if Equity was repurchased, Sales Growth, Dummy if Profitability was positive in the last period, Long Term Interest Rates on Government Bonds and 4 Industry Dummies. Dividends and Dummy if Profitability was positive in the last period have been found by Fama and French (2000) to be good predictors of profitability. In our application, Profitability is represented by the ratio of cash flow to assets as in Whited and $\mathrm{Wu}$ (2006). Unlike Whited and Wu (2006) we do not include average profitability over any number of previous periods, as we only have 8 periods of data and this would restrict the number of periods with which we can work.

One potential weakness in our estimation seemed to be that we do not control for the stochastic discount factor $\beta_{t+1}^{t}$ by parameterizing it as do Whited and $\mathrm{Wu}$ (2006), since company accounts data do not provide the needed information to do so. Now we know that a high risk firm will behave as if it had a higher discount rate than a low risk firm. To the extent that the risk of any individual firm which is primarily related to the variability of its earnings and the variability in earnings being related to profitability, see Fama and French (2000), we have included the predictors of profitability in our instrument set and see what the test of overidentifying restrictions suggest. However, our overidentification results are sound. Other instruments such as Dummy for Equity repurchase, Log of Market Share and Sales Growth, would seem to play a role in affecting the financing premium on external finance. But often these turned out be insignificant factors with wrong sign. The definition of other instruments are included in the appendix.

As we can see from Table 2.9 the variables that enter $\lambda_{t}$ have the expected sign. For example, the positive coefficient on the debt to assets ratio indicates that a more highly leveraged firm will have a higher shadow value of external funds; that is, it will be more financially constrained. The sign on interest expense is again positive as expected, though insignificant here. Liquidity in this estimate seems to have a significant negative impact on the shadow cost of external finance. Most studies in the literature do not consider financing through new equity, claiming that most of the external financing takes place through debt financing. In our data, however 98 percent of firms have outstanding equity and 52 percent of firms report issuing new equity at least once during the period

\footnotetext{
${ }^{7}$ The estimates of $\eta$ did not turn out to be significant and were not robust to changes in the starting values.
} 
of our sample. Note this does not include retained earnings. As our results suggest issuance of new equity does increase the chances of a binding constraint on external finance.

The other parameter estimates also seem sensible. For example, the mark-up and adjustment cost parameters are all positive and significantly different from zero. Our adjustment cost parameters suggest that on the margin for a unit Euro of investment the firm has to pay an adjustment cost of about 20 cents. The mark-up, as expected, is greater than one, and is significantly so.

In our next step, we construct $\hat{\Theta}_{t, t+1}=\frac{\left(1+\hat{\lambda}_{i, t+1}\right)}{\left(1+\hat{\lambda}_{i, t}\right)}$ and $\widehat{L H S_{t+1}}$ defined earlier using the estimates of the structural equation. Having constructed these we estimated Equation (33). We expect a negative sign on the coefficient of $\hat{\Theta}_{t, t+1}$ as $\hat{\Theta}_{t, t+1}$ has a dampening effect on the intertemporal substitution of capital. Table 11 reports a simple correlation between $\hat{\Theta}_{t, t+1}$ and $\widehat{L H S_{t+1}}$ and this correlation is negative. Illustrated in Table (12) are the the estimates of Equation (33). The sign of the estimated coefficients are as expected and $\hat{\Theta}_{t, t+1}$ comes out to be strongly significant, albeit small in magnitude, upon being instrumented with additional variables, lending credence to the estimates of our structural model.

\subsection{Conclusion}

In part this chapter has tried to identify some of the sources of misspecification in the neoclassical model of investment. The poor performance of the neoclassical model of investment can be attributed to the presence of frictions in the financial market. We find that the neoclassical model of investment is better behaved for firms that invest continuously than for those that invest intermittently or disinvest. This could be attributed to the presence of fixed costs of adjustment that may be significant factor in explaining the investment patterns for firms that do not invest continuously.

We also find that ad hoc augmentation of the financial variables, though with some justification, leads to a better fit. In particular, we find that the impact of some of the financial variables on the shadow value of external finance is more pronounced for the firms that invest intermittently or disinvest. However, we also find that the model in a reduced form setting, based on the dynamics implied by differentiable adjustment cost, has not produced the desired result. Output and cost terms continue to have the wrong signs for the full sample of the data as well as the for firms investing intermittently though not significantly for this set of firms. And the adjustment cost parameters, for the firms investing intermittently are certainly not as expected. Such results as obtained from our sample for firms investing intermittently puts into question the nature of intertemporal substitution of investment in presence of financial constraint. The failure of the model could be due to the restrictions 
imposed through the linearization and/or ignoring the non convexities in the adjustment cost. The index of financial constraint constructed through the estimated parameters of the structural model does, seem to have a bearing in explaining intertemporal substitution of investment in presence of financial frictions.

Much room remains for further investigation of investment process in presence of financial constraint. In particular we would like to ask how financial position of the firm and the cost of adjustment (fixed and smooth) interact and to what extent it affects investment. We intend to take up such an exercise in the future. 


\subsection{Appendix}

Table 2.2: Distribution of firms among different Sectors

\begin{tabular}{lcc}
\hline \hline Sector & No. of Firms & Percentage \\
\hline Agriculture and Hunting & 2 & 0.48 \\
Extraction of Minerals & 7 & 1.68 \\
Industry & 163 & 39.18 \\
Production and Distribution of Electricity, Gas and Water & 17 & 4.09 \\
Building & 24 & 5.77 \\
Wholesale and Retail Activities & 123 & 29.57 \\
Hotels and Restaurants & 4 & 0.96 \\
Transport, Storage and Communications & 40 & 9.62 \\
Exploitation and Trade in Real Estate and Leasing & 25 & 6.01 \\
Other Socio-Cultural Activities & 11 & 2.64 \\
\hline All & 416 & 100 \\
\hline
\end{tabular}

\section{Definition of Variables}

Output is the Net turnover and other company revenues of the firm.

Cost constitutes of wages, salaries and all social security charges plus cost of raw and ancillary materials and all other costs.

Capital assets constitutes of tangible and intangible assets.

Cash flow if defined as provision for depreciation of assets plus operating profit after tax, interest and preference dividend.

Debt constitutes of the book value of Long-term liabilities to group companies, capital members co-operative society and other participating interests, subordinated loans and debentures.

Current Liabilities are the book value of Long-term liabilities that are due within one year.

Grants are the value of the sums relating to investment premiums, subsidies and such like.

Provisions are liabilities that include latent tax liabilities, pension liabilities, and liabilities pertaining to guarantees, reorganization, important up keeping, own risk and environment.

Liquidity is defined as short-term receivables such as trade receivables, commercial papers, balances in the current account and the periodic payments of long-term receivables from group companies and participating interest. It also consists of short-term securities, easily transferable in cash and cash, bills of exchange, cheques, deposit accounts current accounts and other short term receivables from financial institutions.

Ln(Market Share) is the log of the ratio of firms output with respect to the industry output.

New Equity is defined as the difference between the year beginning and the year end of the book 
value of Capital Paid and Called and Share Premium Reserve.

Note: As far as data on equity is concerned, the company accounts do not make a distinction between internal and external equity. Internal equity is reported as "share premium reserve". But "share premium reserve" has another component, which is the one that arises from the truest sense of its definition, that is, what is over and above the par value of "capital called and paid".

$\delta_{i}$, the rate of Depreciation is calculated as follows, suppressing the firms subscript, $\delta=2 / L$, where $L$ is the estimated average life of capital goods. The estimated average life of capital good in any year is calculated as

$$
L_{t}=\frac{G K_{t-1}+I_{t}}{D P R C_{t}}
$$

where, $G K_{t}$ is the reported value of gross property, plant, and equipment at time $t, D P R C_{t}$ is the reported depreciation at time $t . L$ is calculated by taking the average over $L_{t}$. 


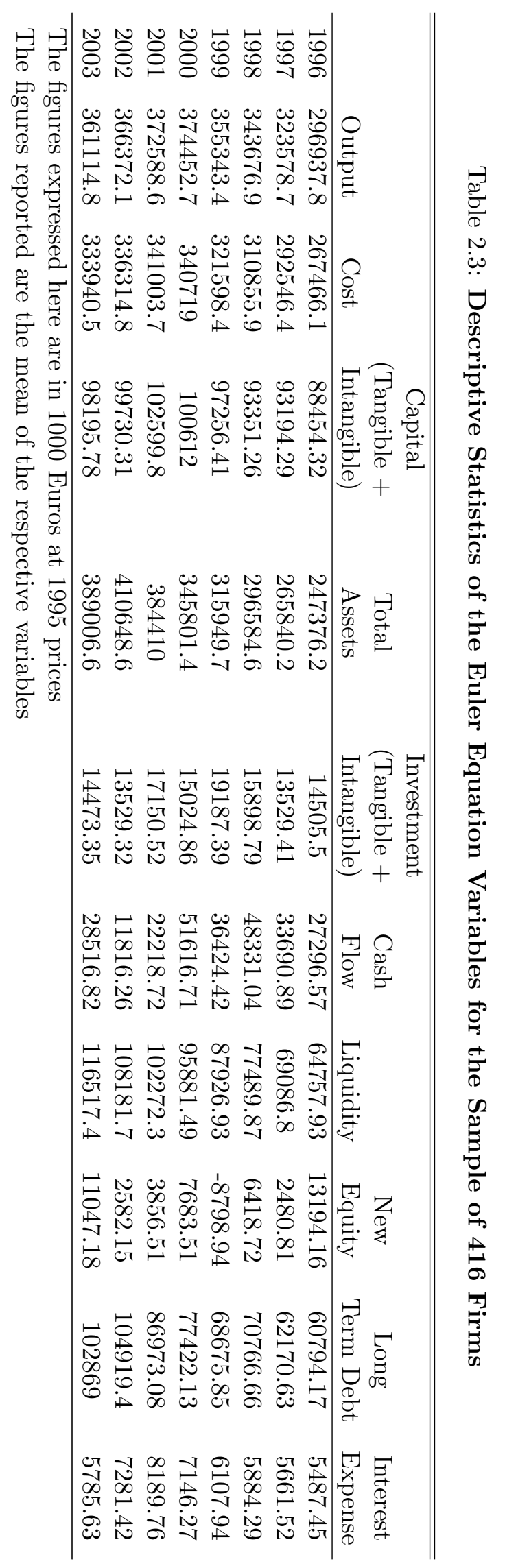




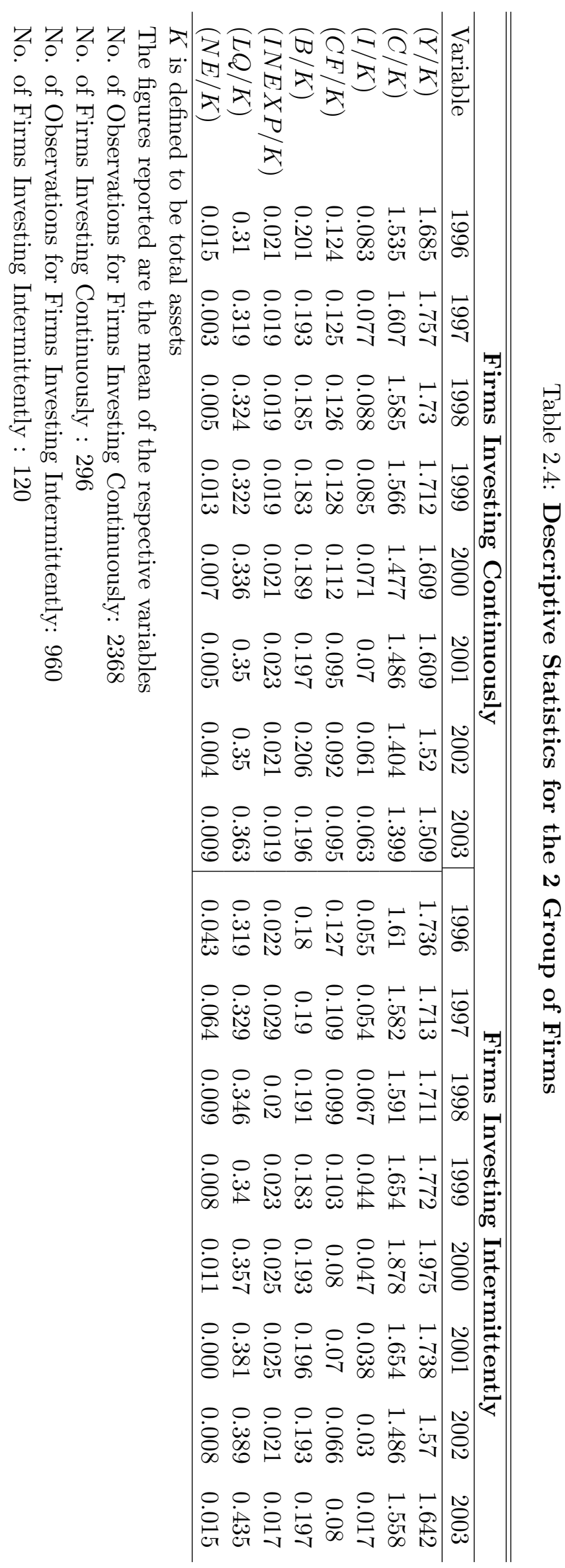


Table 2.5: The Basic Euler Equation

The Euler Equation takes the following form $(I / K)_{t}=\beta_{1}(I / K)_{t-1}+\beta_{2}(I / K)_{t-1}^{2}+\beta_{3}(Y / K)_{t-1}+$ $\beta_{4}(C / K)_{t-1}+\beta_{5} I D+f_{t}+a_{i}+v_{i t}$. I/K is the ratio of investment to the capital stock, Y is Output, $\mathrm{C}$ is Cost, ID is industry dummy, $f_{t}$ is a fixed time effect, and $a_{i}$ is a fixed firm effect. The estimates in column $(a)$ are for the whole data set, those in $(b)$ are for the firms that invest continuously and the estimates in $(c)$ are for the firms that invest intermittently. The instrument set used in estimation is $t-2$ lags of $(I / K),(I / K)^{2}$, Output, Cost, Cash Flow, and Debt.

\begin{tabular}{lrrr}
\hline \multicolumn{4}{l}{ Transformation Used: Orthogonal Deviations } \\
Normalizing Variable: Deflated Tangible and Intangible Assets \\
\hline Dependent Variable $(I / K)_{t}$ & \multicolumn{1}{c}{$(\mathbf{a})$} & \multicolumn{1}{c}{$(\mathbf{b})$} & \multicolumn{1}{c}{$(\mathbf{c})$} \\
\hline$(I / K)_{t-1}$ & 0.0981 & 0.0703 & 0.1447 \\
& $(0.061)$ & $(0.102)$ & $(0.120)$ \\
$(I / K)_{t-1}^{2}$ & $-0.0161^{*}$ & -0.0165 & $-0.0357^{* * *}$ \\
& $(0.009)$ & $(0.016)$ & $(0.012)$ \\
$(Y / K)_{t-1}$ & $0.0063^{*}$ & 0.0301 & $0.0143^{* * *}$ \\
& $(0.003)$ & $(0.020)$ & $(0.003)$ \\
$(C / K)_{t-1}$ & $-0.0062^{*}$ & -0.0302 & $-0.0139^{* * *}$ \\
& $(0.003)$ & $(0.020)$ & $(0.003)$ \\
\hline Wald(Joint) & 31,83 & 12,95 & 43.77 \\
Degress of Freedom & 10 & 10 & 10 \\
Probability & {$[0.000]$} & {$[0.226]$} & {$[0.000]$} \\
Wald (Time) & 8.095 & 6.669 & 4.132 \\
Degress of Freedom & 6 & 6 & 6 \\
Probability & {$[0.231]$} & {$[0.353]$} & {$[0.659]$} \\
Sargan Test & 5.767 & 4.015 & 10.26 \\
Degress of Freedom & 2 & 2 & 2 \\
Probability & {$[0.056]$} & {$[0.134]$} & {$[0.006]$} \\
AR $(1)$, N $(0,1)$ & -3.997 & -1.938 & -3.045 \\
Probability & {$[0.000]$} & {$[0.053]$} & {$[0.002]$} \\
AR $(2)$, N $(0,1)$ & 1.438 & 1.179 & 0.6998 \\
Probability & {$[0.150]$} & {$[0.238]$} & {$[0.484]$} \\
\hline
\end{tabular}

Total No. of Observations :3328

Total No. of Firms : 416

No. of Observations for Firms Investing Continuously:2368

No. of Firms Investing Continuously : 296

No. of Observations for Firms Investing Intermittently: 960

No. of Firms Investing Intermittently : 120

Time Period: 1996-2003

Significance levels : $\quad *: 10 \% \quad * *: 5 \% \quad * * *: 1 \%$ 
Table 2.6: Bond and Meghir Specification

The Euler Equation takes the following form $(I / K)_{t}=\beta_{1}(I / K)_{t-1}+\beta_{2}(I / K)_{t-1}^{2}+\beta_{3}(Y / K)_{t-1}+$ $\beta_{4}(C F / K)_{t-1}+\beta_{5}(B / K)_{t-1}^{2}+\beta_{6} I D+f_{t}+a_{i}+v_{i t} \mathrm{I} / \mathrm{K}$ is the ratio of investment to the capital stock, $\mathrm{CF}$ is firm's Cash Flow, $\mathrm{Y}$ is Output, $\mathrm{B}$ is the stock of long-term debt, ID is industry dummy, $f_{t}$ is a fixed time effect, and $a_{i}$ is a fixed firm effect. The instrument set used in estimating column $(a)$ is all lags of $(I / K), t-2$ and $t-3$ of $(I / K)^{2}$ and $t-2$ of Output, Cost, Cash Flow, square of Debt . The instrument set for the estimates in column $(b)$ include the additional financial variables namely; Liquidity, Current Liability, New Equity, Interest Expense. All variables are expressed in real terms.

\begin{tabular}{|c|c|c|}
\hline \multicolumn{3}{|c|}{$\begin{array}{l}\text { Transformation Used: Orthogonal Dev } \\
\text { Normalizing Variable: Total Assets }\end{array}$} \\
\hline Dependent Variable $(I / K)_{t}$ & (a) & (b) \\
\hline$(I / K)_{t-1}$ & $\begin{array}{r}0.05223 \\
(0.041)\end{array}$ & $\begin{array}{l}0.0675^{*} \\
(0.035)\end{array}$ \\
\hline$(I / K)_{t-1}^{2}$ & $\begin{array}{l}-0.0367^{*} \\
(0.018)\end{array}$ & $\begin{array}{l}-0.0395^{* *} \\
(0.016)\end{array}$ \\
\hline$(Y / K)_{t-1}$ & $\begin{array}{l}0.0218^{*} \\
(0.012)\end{array}$ & $\begin{array}{c}0.0118^{*} \\
(0.006)\end{array}$ \\
\hline$(C F / K)_{t-1}$ & $\begin{array}{r}0.0666 \\
(0.041)\end{array}$ & $\begin{array}{l}0.0663^{* *} \\
(0.028)\end{array}$ \\
\hline$(B / K)_{t-1}^{2}$ & $\begin{array}{l}-0.1049^{*} \\
(0.062)\end{array}$ & $\begin{array}{l}-0.0903^{* *} \\
(0.040)\end{array}$ \\
\hline Wald (Joint) & 25.94 & 30.81 \\
\hline Degress Of Freedom & 11 & 11 \\
\hline Probability & {$[0.007]$} & {$[0.001]$} \\
\hline Wald (Time) & 25.27 & 43.65 \\
\hline Degress Of Freedom & 6 & 6 \\
\hline Probability & {$[0.000]$} & {$[0.000]$} \\
\hline Sargan & 36.91 & 44.69 \\
\hline Degress Of Freedom & 31 & 35 \\
\hline Probability & {$[0.214]$} & {$[0.126]$} \\
\hline $\operatorname{AR}(1)$ & -3.673 & -3.533 \\
\hline Probability & {$[0.000]$} & {$[0.000]$} \\
\hline $\operatorname{AR}(2)$ & 1.655 & 1.504 \\
\hline Probability & {$[0.098]$} & {$[0.133]$} \\
\hline Wald (Finance) & 4.735 & 8.227 \\
\hline Degress Of Freedom & 2 & 2 \\
\hline Probability & {$[0.094]$} & {$[0.016]$} \\
\hline $\begin{array}{l}\text { No. of Observations: } 3328 \\
\text { No. of Firm: } 416 \\
\text { Time Period: } 1996-2003\end{array}$ & & \\
\hline Significance levels & $5 \%$ & \\
\hline
\end{tabular}




\section{Table 2.7: Euler Equation Augmented with additional Financial variables}

The specification here is $(I / K)_{t}=\alpha_{1}(I / K)_{t-1}+\alpha_{2}(I / K)_{t-1}^{2}+\alpha_{3}(Y / K)_{t-1}+\alpha_{4}(C / K)_{t-1}+\alpha_{5}(C F / K)_{t}+$ $\alpha_{6}(B / K)_{t}+\alpha_{7}(L Q / K)_{t}+\alpha_{8}(I N E X P / K)_{t}+\alpha_{9}(N E / K)_{t}+\alpha_{10} I D+f_{t}+a_{i}+e_{i, t}$. The debt term in column (a) is Total Debt, Long Term debt and Current Liability, while in column (b) is Long Term Debt. The instrument set for the estimates of column (a) consists of all lags of $(I / K), t-2$ and $t-3$ of $(I / K)^{2}$ and $t-2$ of Output, Cost, Cash Flow, Total Debt, Liquidity, Interest Expense. Where as the instrument set for (b) also includes Depreciation, Log of Market Share, Grants, Provision, Current Assets and Liabilities and Taxes.

\begin{tabular}{|c|c|c|}
\hline \multicolumn{3}{|c|}{$\begin{array}{l}\text { Transformation Used: Orthogonal Deviations } \\
\text { Normalizing Variable: Total Assets }\end{array}$} \\
\hline Dependent Variable $(I / K)_{t}$ & (a) & (b) \\
\hline \multirow[t]{2}{*}{$(I / K)_{t-1}$} & $0.096^{*}$ & 0.048 \\
\hline & $(0.047)$ & $(0.039)$ \\
\hline \multirow{2}{*}{$(I / K)_{t-1}^{2}$} & $-0.055^{* *}$ & $-0.032^{*}$ \\
\hline & $(0.023)$ & $(0.019)$ \\
\hline \multirow[t]{2}{*}{$(Y / K)_{t-1}$} & $0.127^{* *}$ & 0.092 \\
\hline & $(0.063)$ & $(0.058)$ \\
\hline \multirow[t]{2}{*}{$(C / K)_{t-1}$} & $-0.112^{*}$ & -0.090 \\
\hline & $(0.067)$ & $(0.061)$ \\
\hline \multirow[t]{2}{*}{$(C F / K)_{t-1}$} & 0.051 & $0.056^{* *}$ \\
\hline & $(0.042)$ & $(0.029)$ \\
\hline \multirow[t]{2}{*}{$(B / K)_{t-1}$} & $-0.147^{* * *}$ & $-0.133^{* * *}$ \\
\hline & $(0.046)$ & $(0.042)$ \\
\hline \multirow[t]{2}{*}{$(L Q / K)_{t-1}$} & -0.139 & 0.028 \\
\hline & $(0.098)$ & $(0.064)$ \\
\hline \multirow[t]{2}{*}{$(I N E X P / K)_{t-1}$} & -0.092 & $-0.110^{*}$ \\
\hline & $(0.078)$ & $(0.062)$ \\
\hline \multirow[t]{2}{*}{$(N E / K)_{t-1}$} & 0.003 & -0.008 \\
\hline & $(0.015)$ & $(0.011)$ \\
\hline Wald (Joint) & 41.040 & 43.280 \\
\hline Degrees of Freedom & 14 & 14 \\
\hline Probability & {$[0.000]$} & {$[0.000]$} \\
\hline Wald (Time & 17.400 & 18.770 \\
\hline Degrees of Freedom & 6 & 6 \\
\hline Probability & [0.008] & {$[0.005]$} \\
\hline Sargan & 33.750 & 38.400 \\
\hline Degrees of Freedom & 30 & 37 \\
\hline Probability & {$[0.291]$} & {$[0.406]$} \\
\hline $\operatorname{AR}(1)$ & -3.654 & -3.551 \\
\hline Probability & {$[0.000]$} & {$[0.000]$} \\
\hline $\operatorname{AR}(2)$ & 1.560 & 1.673 \\
\hline Probability & {$[0.119]$} & {$[0.094]$} \\
\hline Wald (Finance) & 12.740 & 12.470 \\
\hline Degrees of Freedom & 5 & 5 \\
\hline Probability & {$[0.026]$} & {$[0.029]$} \\
\hline \multicolumn{3}{|l|}{ No. of Observations: 3328} \\
\hline \multicolumn{3}{|l|}{ No. of Firm: 416} \\
\hline \multicolumn{3}{|l|}{ Time Period: 1996-2003 } \\
\hline
\end{tabular}


Table 2.8: Euler Equation Augmented with additional Financial variables: For firms Investing intermittently and Investing Continuously

The specification for column (c) is $(I / K)_{t}=\alpha_{1}(I / K)_{t-1}+\alpha_{2}(I / K)_{t}^{2}+\alpha_{3}(I / K)_{t-1}^{2}+\alpha_{4}(I / K)_{t-1}^{3}+$ $+\alpha_{5}(Y / K)_{t-1}+\alpha_{6}(C / K)_{t-1}+\alpha_{7}(C F / K)_{t}+\alpha_{8}(B / K)_{t}+\alpha_{9}(L Q / K)_{t}+\alpha_{10}(I N E X P / K)_{t}+\alpha_{11}(N E / K)_{t}+$ $\alpha_{12} I D+f_{t}+a_{i}+e_{i, t}$, while for (a) and (b) is the same as Table 7. The instrument set for the estimates of column (a) consists of all lags of $(I / K), t-2$ and $t-3$ of $(I / K)^{2}$ and $t-2$ of Output, Cost, Cash Flow, Debt, Liquidity, Interest Expense, New Equity, Taxes, Grants, Provision, Deprecation and Current Assets and Liabilities . Transformation used for column (a) and (d) is Orthogonal Deviation and for (b) and (c) is First Difference. Column (d) has the estimates of the augmented Euler equation for the firms that invest continuously.

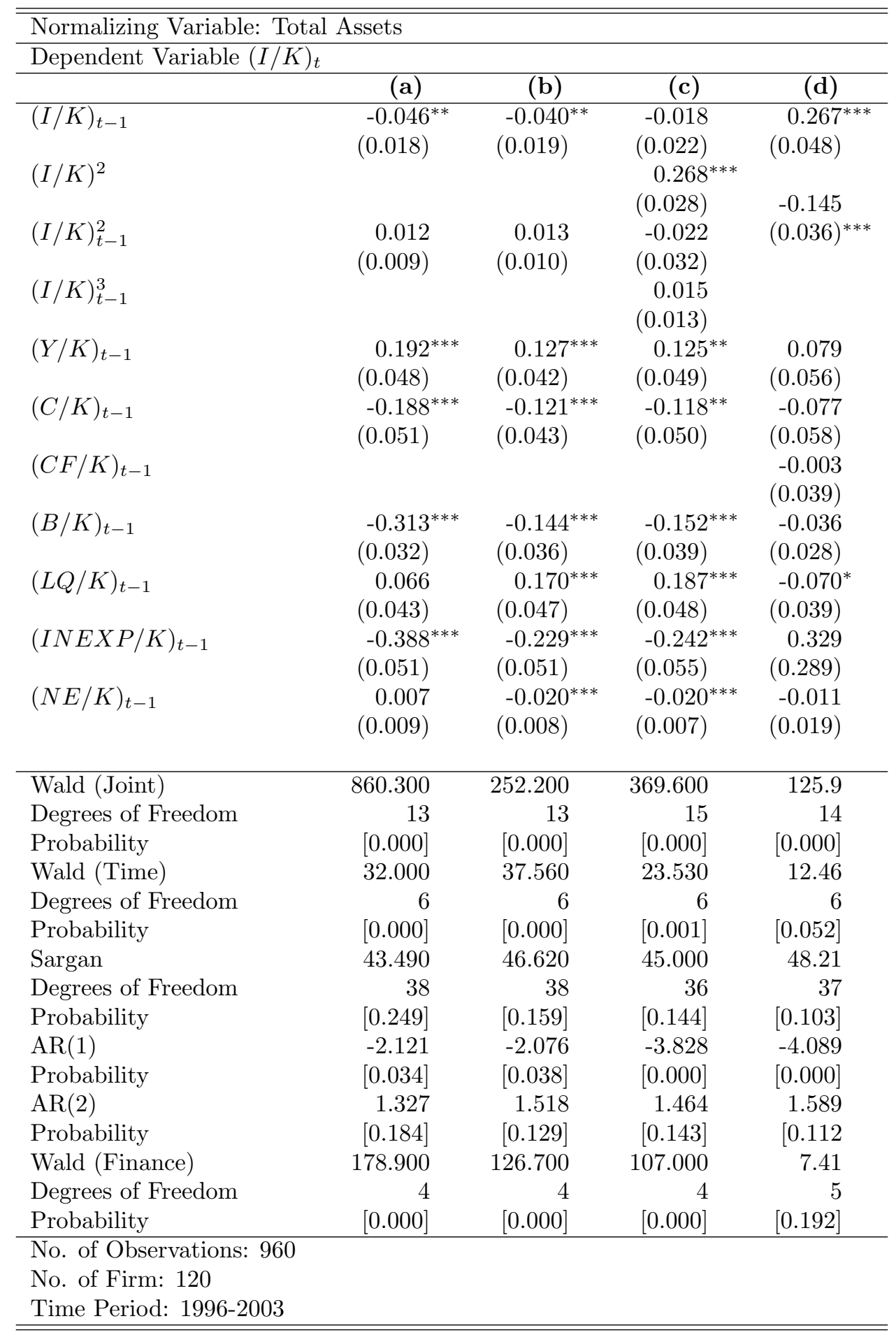


Table 2.9: Structural Estimates

The Euler equation estimated is the following: $\beta_{t+1}^{t} \frac{\left(1+\lambda_{i t+1}\right)}{\left(1+\lambda_{i t}\right)}\left[\left(Y_{i, t+1}-\mu C_{i, t+1}\right) / K_{i, t+1}-\left(\frac{\alpha_{2}}{2}\left(\frac{I}{K}\right)_{i, t+1}^{2}+\right.\right.$ $\left.\left.\frac{2 \alpha_{3}}{3}\left(\frac{I}{K}\right)_{i, t+1}^{3}\right)+\left(1-\delta_{i}\right)\left\{\left(\alpha_{2}\left(\frac{I}{K}\right)_{i, t+1}^{2}+\alpha_{3}\left(\frac{I}{K}\right)_{i, t+1}^{3}\right)+p_{i, t+1}\right\}\right]=\left(\alpha_{2}\left(\frac{I}{K}\right)_{i, t}^{2}+\alpha_{3}\left(\frac{I}{K}\right)_{i, t}^{3}\right)+p_{i, t}+e_{i, t+1}$ The instrument set used in estimation is $t-2$ lag of $(I / K),(I / K)^{2},(I / K)^{3},(I / K)^{4}$, Output, Cost, Cash Flow, Debt, Dividends, Liquidity, Log of Total assets, Interest Expense, Log of Market Share, Grants, Provision, Other liabilities, Inventories, Depreciation, Current Assets, Currents Liabilities, Dummy if Equity was repurchased, sales growth, Dummy if Profitability was positive in the last period, Long Term Interest Rates on Government Bonds and 4 Industry Dummies.

\begin{tabular}{lc}
\hline \hline & (a) \\
\hline$\alpha_{2}$ & $0.5056^{* *}$ \\
$\alpha_{3}$ & $(0.2181)$ \\
& $-0.2876^{* *}$ \\
$\mu$ & $(0.1216)$ \\
& $1.0145^{* * *}$ \\
$(C F / K)_{t-1}$ & $(0.0198)$ \\
& $-0.6303^{* * *}$ \\
$(B / K)_{t-1}$ & $(0.0708)$ \\
& $1.4738^{*}$ \\
$(L Q / K)_{t-1}$ & $(0.8240)$ \\
& $-0.8698^{* * *}$ \\
$(I N E X P / K)_{t-1}$ & $(0.0675)$ \\
& 1.2905 \\
$(N E / K)_{t-1}$ & $(1.1014)$ \\
& $0.7822^{* * *}$ \\
\hline Test of Overidentification & $(0.2864)$ \\
Degrees of Freedom & 4.368 \\
Probability & 18 \\
\hline No. of Observations: 3328 & 0.9996 \\
No. of Firm: 416 & \\
Time Period: 1996-2003 & \\
\hline \hline
\end{tabular}


Table 2.10: Behavior of Variables among Three Categories of firms sorted according to Index of Financial Constraint constructed using Structural Estimates

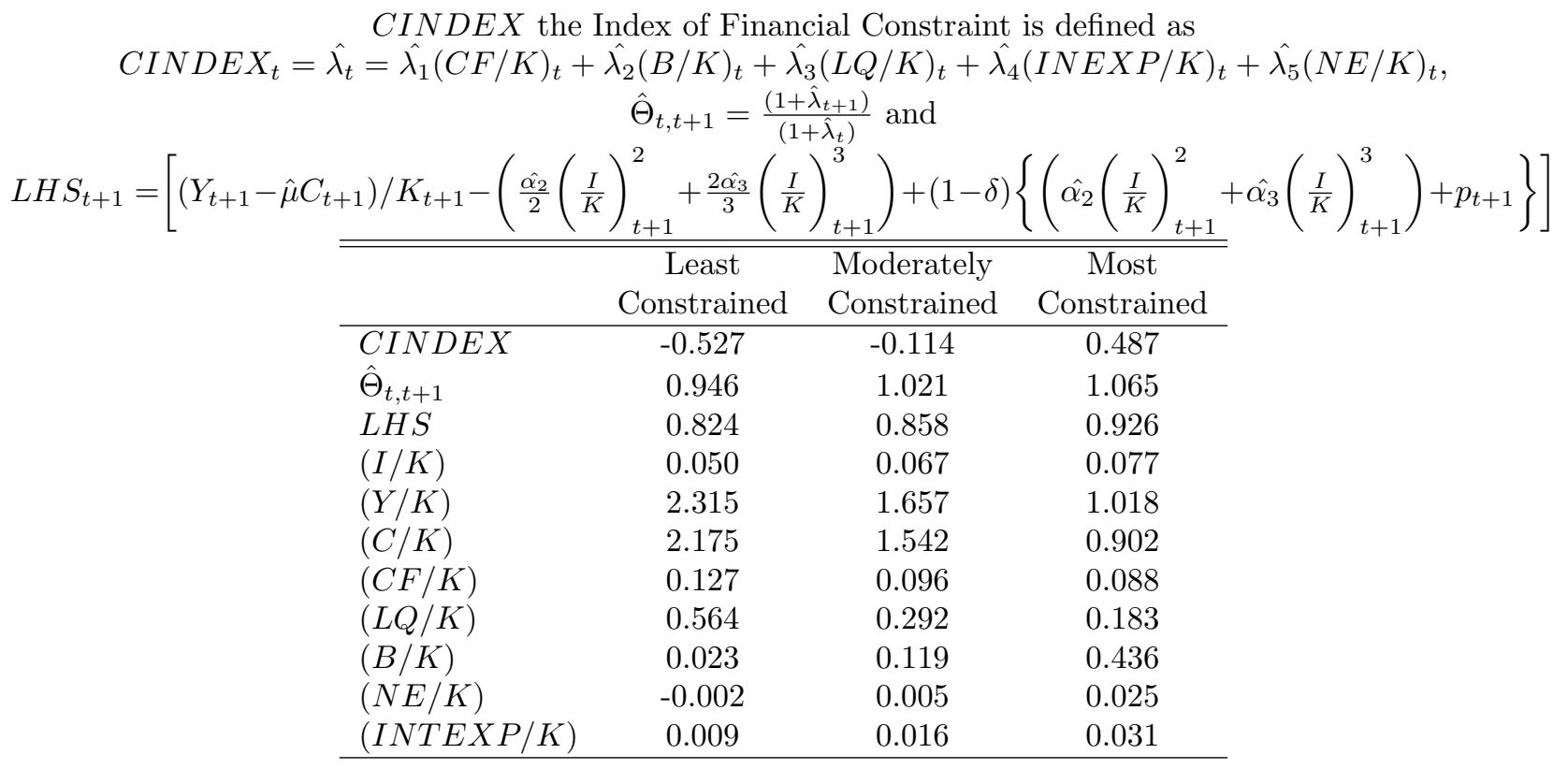

Table 2.11: Correlation between $L H S_{t}$ and $\hat{\Theta}_{t+1}^{t}$

\begin{tabular}{lcc}
\hline \hline & $L H S$ & $\hat{\Theta}$ \\
\hline$L H S$ & 1.0000 & \\
$\hat{\Theta}$ & -0.0030 & 1.0000 \\
\hline
\end{tabular}


Table 2.12: The Euler Equation augmented with the Estimated Index of Financing Premium on External Finance

The Euler equation estimated is the following: $L H S_{t}=\beta_{1}(I / K)_{t-1}+\beta_{2}(I / K)_{t-1}^{2}+\beta_{3} \hat{\Theta}_{t}^{t-1}+\beta_{4} p_{t-1}+\beta_{5} I D+$ $f_{t}+a_{i}+v_{i t}$. The estimates in column (a) and column (b) are exactly identified while the estimates in (c) use additional instruments as GMM type instruments of all lags of $(I / K)^{1}$ and $(I / K)^{2}$ and $t-2$ level instruments constituting of $\hat{\Theta}_{t+1}^{t}$, Grants, Provision, Taxes Inventories, Depreciation, Current Assets, Current Liabilities, Other Liabilities, Log of Market share and Industry dummies. The estimates in (a) and (c) use orthogonal deviations and that (b) uses first difference.

\begin{tabular}{|c|c|c|c|}
\hline \multicolumn{4}{|c|}{ Normalizing Variable: Total Assets } \\
\hline Dependent Variable $L H S_{t}$ & (a) & (b) & (c) \\
\hline \multirow{2}{*}{$(I / K)_{t-1}$} & 0.146 & 0.113 & 0.012 \\
\hline & $(0.354)$ & $(0.107)$ & $(0.028)$ \\
\hline \multirow{2}{*}{$(I / K)_{t-1}^{2}$} & -0.077 & -0.076 & -0.012 \\
\hline & $(0.154)$ & $(0.056)$ & $(0.015)$ \\
\hline \multirow[t]{2}{*}{$\hat{\Theta}_{t-1, t}$} & -0.027 & -0.117 & $-0.042^{* * *}$ \\
\hline & $(0.193)$ & $(0.104)$ & $(0.014)$ \\
\hline \multirow{2}{*}{$p_{t-1}$} & 0.366 & 0.704 & 0.097 \\
\hline & $(0.387)$ & $(1.051)$ & $(0.109)$ \\
\hline Wald Joint & 3.676 & 11.060 & 27.660 \\
\hline Degrees of Freedom & 10 & 10 & 10 \\
\hline Probability & {$[0.961]$} & {$[0.272]$} & {$[0.002]$} \\
\hline Wald Time & 6.770 & 18.950 & 53.270 \\
\hline Degrees of Freedom & 5 & 5 & 5 \\
\hline Probability & {$[0.238]$} & {$[0.002]$} & {$[0.000]$} \\
\hline \multicolumn{3}{|l|}{ Sargan Overidentification } & 42.760 \\
\hline \multicolumn{3}{|l|}{ Degrees of Freedom } & 36 \\
\hline \multicolumn{3}{|l|}{ Probability } & {$[0.203]$} \\
\hline $\operatorname{AR}(1), \mathrm{N}(0,1)$ & -1.044 & -2.559 & -2.759 \\
\hline Probability & {$[0.297]$} & {$[0.011]$} & {$[0.006]$} \\
\hline $\mathrm{AR}(2), \mathrm{N}(0,1)$ & 0.152 & 0.672 & 0.583 \\
\hline Probability & {$[0.879]$} & {$[0.502]$} & {$[0.560]$} \\
\hline Wald Variables of Interest & 1.396 & 3.349 & 21.840 \\
\hline Degrees of Freedom & 4 & 4 & 4 \\
\hline Probability & {$[0.845]$} & {$[0.501]$} & {$[0.000]$} \\
\hline \multicolumn{4}{|l|}{ No. of Observations: 2912} \\
\hline \multicolumn{4}{|l|}{ No. of Firm: 416} \\
\hline \multicolumn{4}{|l|}{ Time Period: $1997-2003$} \\
\hline
\end{tabular}





\section{Financial Constraints and R\&D Investment: Evidence}

\section{from CIS}

\subsection{Introduction}

The connection between finance and investment starts with any violation of the Modigliani- Miller theorem, Modigliani and Miller (1958), usually modeled formally via imperfect information. According to Ross, Westerfield and Jordan (2006) about 80 percent of all financing is done with internally generated funds. Explanations for this behavior usually highlight the role of information asymmetries (Myers and Majluf, 1984) and agency issues (Jensen and Meckling, 1976) in raising the costs of external funds.

The notion of financial constraint that is employed in this paper is that of credit rationing which arises due to informational asymmetry between the borrower/firm and the lender about the quality of project that a firm wishes to undertake and also due to the risk of bankruptcy in the event of the failure of the project. Gale and Hellwig (1985) compare optimal contracts with the first best situation. First best situations are those that arise when borrowers and lenders share the same information about the nature and the outcome of the project, that is, they are situations where there is no informational asymmetry. An optimal contract is incentive compatible, which allows borrowers to truthfully reveal (since the firm has more information about the project than the lender) the outcome of the project and also takes into consideration that borrowers in their optimization program account for the possibility of bankruptcy and the costs associated with it. Gale and Hellwig (1985) also show that standard debt contracts that require a fixed repayment when the firm is solvent and that require the firm to be declared bankrupt if this fixed payment cannot be met and the creditor is allowed to recoup as much of the debt as possible from the firm's assets, are also optimal. In equilibrium, a standard debt contract, which is also optimal, will usually involve credit-rationing in the sense that the optimal loan is smaller and interest rate is higher than it would have been under the first best outcome. 
Empirically, the existence of financial constraints for innovative firms is most frequently investigated by examining the sensitivity of $R \& D$ investment to financial factors, see Himmelberg and Petersen (1994), Harhoff (1998), and Mulkay, Hall and Mairesse (2001). It is estimated by using the same models as for physical investment, see Mulkay et al. (1999), that is to say, by using the reduced form of accelerator models of investment, see Fazzari, Hubbard and Peterson (1988) and Bond, Elston, Mairesse and Mulkay (1997), or by using the structural framework of Euler equations as in Bond and Meghir (1994). Himmelberg and Petersen (1994) find a large and significant relationship between R\&D and internal finance for US small firms in high-tech industries. Similar results are obtained by Mulkay et al. (2001) with French and United States firms. In addition, they find that cash flow has a much larger impact on R\&D investment for US firms than for the French ones. Harhoff's results about German firms are less conclusive. He finds a weak but significant cash flow effect on R\&D by using an investment accelerator model, while Euler-equation estimates appear to be non-informative. However, Kaplan and Zingales (1997, 2000) and Cleary (1999) have provided evidence that cash flow sensitivity need not identify liquidity constrained firms, that is, sensitivity is not monotonic in the degree of constraints. Cash flow provides information about future investment opportunities, hence, investment cash flow sensitivity may equally occur because firms are sensitive to demand signals. On the theoretical side, Gomes (2001) and Aydogan (2003) simulate dynamic investment models, demonstrating that significant cash flow coefficients are not necessarily generated by financing frictions. Conversely, Gomes (2001) shows that financing frictions are not sufficient to generate significant coefficients on cash flow.

Among the many ways to study the effect of financing frictions on physical/R\&D investment, one is to construct an index of financial constraints based on a standard intertemporal investment model augmented to account for financial frictions. External finance constraints affect the intertemporal substitution of investment today for investment tomorrow, via the shadow value of scarce external funds. Recently Gomes, Yaron, and Zhang (2006) showed that one can rewrite a constrained problem as an unconstrained one with embedded multipliers that give a characterization of the shadow value, as a measure of the premium on external finance. This shadow value, in turn, depends on observable financial variables and proxies that signal the worthiness of firms, as debt, equity, liquidity, cash flow, and bond ratings to name a few. Generalized method of moments estimation of the model provides an estimate of the shadow value that is then used as an index of financial constraint. Many papers in the literature on financing frictions use this approach to study the effect of financing premium on the behavior of investment, see Whited (1992) and Bond and Meghir (1994) and Whited and Wu 
(2006).

However, in our data set, which we obtain from the Community Innovation Survey (CIS), we do not have information on balance sheets of the firms/enterprises ${ }^{1}$, which would allow us to assess the effect of internal/external finance on the behavior of R\&D investment. But, from a question asked to the firms we know whether a firm, and to what degree, was hampered in its pursuit of R\&D activities by the presence of financial constraints. This avoids the task of constructing an index of financial constraint to study the behavior of $R \& D$ investment in the presence of capital market frictions. That is, we have an index of financial constraint that is a function of the financial position of the firm and its willingness to undertake $\mathrm{R} \& \mathrm{D}$ activities. The above statement needs some explanation. A constructed index of financial constraint is only a function of the financial state variable and this index is purged of the effects of future expected profitability. However, this is not the case for firms reporting whether they are financially constrained or not in our data set. In other words, the firms reporting that they are financially constrained are also the ones that express a willingness to invest in R\&D activities, but their financial position is not sound enough for them to take up R\&D activities. That is, if two firms are equal in every respect but one firm is in a better financial position than the other, then the firm that is in a better financial position is less likely to hit its debt limit than the firm whose financial position is not sound. Ceteris paribus, the worse the financial position of the firm, the greater is the loan demanded, which implies that higher is the repayment obligation to the lending agency and hence greater the risk of bankruptcy. This risk is the prime factor for underinvestment. That is, firms might get some external finance to finance their projects, but not to the extent that they desire.

There are many situations when the firm may report that financial factors are constraining innovation. The prerequisite is that the firm is attempting to undertake innovative activity. The firm must then consider that its attempt to pursue that activity has been hampered by the lack of finance and or the cost of that finance. It need not be that all firms that are financially constrained would report that they are financially constrained, for example, they may not be innovation active in the period, or they may face other kinds of constraints that inhibit their R\&D activities, which imply that financial constraint is not binding.

The aim of the paper is twin fold. The first is to study the effect of financial constraint, as reported by the firms among other variables, on innovation activity here measured by $R \& D$ investment, and secondly, to establish determinants of financial constraint.

\footnotetext{
${ }^{1}$ The data collected through CIS are at the enterprise level and not at the company level. Here we use the term firm and enterprise exchangeably.
} 
There are many problems one faces when estimating the impact of financial and other variables on innovation, selection and endogeneity of the explanatory variables being the chief among them. Problems of sample selection arise since only those firms report R\&D expenditure that chose to indulge in R\&D activities. Savignac (2005) examines the impact of financial constraints on innovation for established firms in France. An indicator based on the firm's assessment of financial constraints is found to significantly reduce the probability that a firm undertakes innovation activities. However, in her paper she only account for the endogeneity of the indicator, indicating whether a firm is financially constrained or not. But, endogeneity of other control variables could also lead to inconsistent estimates. To overcome the potential endogeneity of the regressors we use Lewbel's approach to handling such problems. For studying the determinants of R\&D investment we use Lewbel's (2006) semiparametric estimator that handles both the problem of selection and endogeneity. For the binary response model, in which we study the determinants of financial constraint we employ Lewbel's (2000, 2004) semiparametric binary choice model that accounts for endogeneity of the regressors.

Our results generally support the view that financial constraints affect R\&D investment and that the financial constraints are less binding in the presence of other constraints on innovation, such as market or economic uncertainty or regulation and organizational rigidities. Other significant determinants of $R \& D$ investment that we find are the age of the firms, market share, cooperation in R\&D activities and firms' share of innovative sales.

Ideally, we would have liked to assess the impact of the financial position of the firms after controlling for investment opportunities or future expected profitability. However, the Community Innovation Surveys do not provide us with the balance sheet information of the firms. Instead of this financial information we include age and a dummy for group membership of the firm. Our results suggest that age and belonging to a group are significant determinants of financial constraint. We believe that these variables pick up the effect of financial health of the firm. Our results also suggest that the presence of other constraints on innovation, such as market uncertainty, regulation and organizational rigidities, also reduces the probability of a firm being financially constrained though not significantly so. Expected future profitability, as proxied by the share of innovative sales in the total sales of the firm, increases the probability of financial constraint after controlling for information costs that are implied by the financial position of the firm, which is proxied by age, market share and a dummy for belonging to a group.

The rest of the paper is organized as follows. Section 3.2 describes the data. Section 3.3 presents the models of financial constraint and a model to assess the effect of financial constraint on R\&D 
investment. Section 3.4 discusses the results and finally section 3.5 concludes.

\subsection{Data}

The data used for our analysis are collected by Statistics Netherlands. The Dutch Innovation Surveys are conducted every two years. To implement our model we use the fourth Dutch Innovation Survey, CIS 3.5, which pertains to the years 2000-02. The Innovation Survey data are collected at the enterprise level. A combination of a census and a stratified random sampling is used. A census is used for the population of large (250 or more employees) enterprises, and stratified random sampling is used for small and medium sized enterprises. The size of an enterprise is measured by the number of employees, and the stratum variables are the economic activity and the size of an enterprise, where the economic activity is given by the Dutch standard industrial classification.

Since in our model we want to control for the endogeneity of the regressors, we use as instruments lagged values of some of our potential endogenous regressors. Hence we merged CIS 3.5 with the CIS 3, containing information for the years 1998-2000. This leaves us, after cleaning the data, with a total of 3958 enterprises for our analysis out of which 1531 report to be innovating.

The last page in the appendix shows a table that is directly borrowed from the CIS 3.5 questionnaire. Section 8a of the table asks an innovating firm if it is hampered in its pursuit of innovating activities. Section $8 \mathrm{~b}$ of the questionnaire asks the non-innovating firms if it is important for them to take up innovating activity and whether they are hampered in some way or another. The number of non-innovating firms that answer in the affirmative to question $8 \mathrm{~b}$ is 95 . These 95 firms could be thought of as potentially innovating firms. Thus the total number of innovating and potentially innovating firms is 1626. If either type of firm, innovating as well as potentially innovating, replies in the affirmative to the general hampering question then it is asked to fill out Section 9, in which it is asked to specify the hampering factor(s) and to what extent it affects its innovation projects. We construct a binary variable $D F I N$ that takes value 1 if the firm answers that, because of financial problems, some of its projects are (a) seriously delayed, (b) prematurely stopped or(c) did not start. Out of 1626 innovating as well as potentially innovating firms, 583 firms report that they are hampered in some way or another in their innovation activities. Of these, 178 firms report that they are hampered due to financial reasons. 


\subsection{The Model}

In this section we present a model of financial constraint and then study the decision of the firm to innovate and how much to invest in $R \& D$ in the presence of financial constraint ${ }^{2}$. We refer to appendix A for a discussion of the model.

Firms wish to undertake risky ventures but lack the necessary resources, so they turn to the investors (banks or other deposit-taking, financial institutions) for external finance. Venture capital and other types of non-deposit private equity are not considered in our analysis. The firm is assumed to be risk-neutral; it maximizes the expected value of its wealth. The returns to the risky venture are described by a revenue function $f$ : an investment of $R$ units produces a revenue of $f(s, R)$ units in state $s, s$ being the state of nature. The revenue function is also assumed to exhibit decreasing returns to scale. Assume that $f(s, R)=s \phi(R ;$.$) , "." represents other parameters characterizing the$ firm. A crucial assumption is that agents have asymmetric information. The firm observes the state free of charge, but the lender can only observe the state by paying some observational cost. Gale and Hellwig (1985) have shown that the optimal contract between the firm and the lender is a standard debt contract that involves a fixed repayment obligation and a declaration of bankruptcy if and only if the repayment obligation cannot be met, and a confiscation of whatever wealth remains in the event of bankruptcy.

Under an optimal contract the firm maximizes its wealth taking into account the possible risk of bankruptcy and subject to the constraint that the zero profit condition of the lender is satisfied. The zero profit condition states that the expected return from lending to the firm should at least be equal to the amount that the lender can earn from lending this amount at the risk free rate of interest $i r$. Let $R_{o p}$ be the amount of R\&D capital demanded by the firm under an optimal contract.

To invoke the notion of financial constraint, let us now see what happens under the assumption that both the lender and the firm can directly observe the state of nature. In such a situation, which is termed first best, since the firm and the lender share the same information about the nature of the project and the lender can costlessly observe the states of nature, the problem is the same for the firm and for the lender.

Let, $R_{f b}$ be the solution to the firm's problem under the first best situation. Gale and Hellwig (1985) have shown that $R_{f b} \geq R_{o p}$ that is to say that the amount of $\mathrm{R} \& \mathrm{D}$ capital demanded in the first best situation is at least as great as the amount lent under an optimal contract. $R_{f b}$ is strictly greater than $R_{o p}$ if there is a positive probability of bankruptcy and if the cost borne by the lender

\footnotetext{
${ }^{2}$ See Gale and Hellwig (1985) for a detailed discussion.
} 
for investigation in the event of bankruptcy is positive.

However, it should be noted that $R_{o p}$ is a function of the distribution of the states of nature over which it bases its expectations and which we seek to capture through the expected future profitability $E(\pi)$, firm characteristics $F C$, the organizational and the institutional constraints that the firm faces and which deter a firm from taking up R\&D activities $C O N$, the liquid wealth $W_{0}$ that the firm has at its disposal, and the risk free rate of interest $i r$.

$$
R_{o p}=R_{o p}\left(E(\pi), F C, C O N, W_{0}, i r\right)
$$

Gale and Hellwig $(1985,1986)$ and Gomes et al. (2006) show that $R_{o p_{i r}}^{\prime}<0, R_{o p_{W}}^{\prime}>0, R_{o p_{E}}^{\prime}>0$ and $R_{o p_{C O N}}^{\prime}<0$. In words this means that as the risk free rate of interest rises the demand for $\mathrm{R} \& \mathrm{D}$ capital decreases, as the liquid wealth of the firm increases the demand for R\&D capital increases and as the future expected profitability, $E(\pi)$, increases the demand for R\&D capital increases. Also since the fixed payment to the lender when the firm is solvent increases with the amount lent, the effects of $i r, W_{0}, E(\pi), C O N$ on the fixed payment to the lender are qualitatively the same as those on $R_{o p}$.

Let $r$ be the equilibrium rate of interest that the firm pays so that the lender's zero-profit constraint is satisfied. This rate of interest is the interest rate actually paid by the firm when it is not bankrupt. This implies that

$$
r=r\left(R_{o p}\right)
$$

Since the fixed repayment obligation by the firm to the lender increases with the amount of loan it can be shown that rate of interest is non decreasing in the amount of $R \& D$ demanded under an optimal contract. Equation (1) implies that

$$
r=r\left(E(\pi), F C, C O N, W_{0}, i r\right)
$$

Since the demand for $R \& D$ capital increases in expectation of future profitability it can be shown that $r_{E}^{\prime}>0$ and since the demand decreases due to presence of institutional factors that hamper $\mathrm{R} \& \mathrm{D}$ activities, $r_{C O N}^{\prime}<0$. Also since the demand for external sources of funding decreases with the increase in the internal wealth of the firm, this implies that $r_{W_{0}}^{\prime}<0$. 
Define the function $\mathrm{fin}^{3}$ as

$$
\text { fin }=\operatorname{fin}\left\{r\left(E(\pi), F C, C O N, W_{0}\right), \epsilon\right\}
$$

where $\epsilon$ is an idiosyncratic disturbance term. The inequalities discussed above imply that $\operatorname{fin}_{E}^{\prime} \geq 0$, $f i n_{C O N}^{\prime} \leq 0$ and fin $_{W_{0}}^{\prime} \leq 0$. We say that a firm is financially constrained if,

$$
\text { fin } \geq F,
$$

where $F$ corresponds to the threshold value on the loan that the firm can get. This constraint becomes binding if the rate of interest demanded by the lender on extra units of loan exceeds a certain threshold that the firm is unable to meet. Consequently, the firm would not be able to meet its required $R \& D$ investment level. The rate of interest corresponding to the threshold could be thought of as the interest rate on the maximum amount of debt a firm can incur. This threshold can differ from firm to firm depending on the financial position of the firm. Take the example of two firms that are equal in every respect but one firm has a better financial position than the other. The firm that is in a better financial position is less likely to hit its debt limit than the firm whose financial position is not sound. It should be noted that what is driving these results is the positive probability of bankruptcy. Ceteris paribus, the worse the financial position of the firm, the greater is the loan demanded, which implies that the fixed repayment obligation and the risk of bankruptcy are also greater.

Before we set up our econometric model we would like to note that the observed R\&D expenditure corresponds to $R_{o p}$, the optimal R\&D capital demanded under the optimal/standard debt contract, but the observed outcome is closer to the first best level if the firm does not report that it is financially constrained. Our objective here is to assess how the observed outcome/R\&D expenditure behaves under the presence of financial constraint.

We hypothesize that

$$
D F I N=I[\text { fin }-F>0]
$$

where DFIN is the binary variable that takes value 1 if the firm reports that it is financially

\footnotetext{
${ }^{3}$ We now ignore the risk free rate of interest $i r$, since it should stay constant for a single period of survey.
} 
constrained and 0 otherwise and $I$ is the indicator function that equals one if its argument is true and zero otherwise.

For our empirical analysis of the effects of financial constraints on R\&D investment we now seek to set up a model, whose estimation will help us judge the effects of financial constraint on R\&D investment. Any such empirical model would have to take into account the sample selection that arises in our data set. Also, in a model of sample selection, common unobservables may affect both the outcome ( $R \& D$ investment) and the probability of selection (the decision to innovate) in unknown ways. To handle endogeneity in a model of sample selection we use Lewbel's (2006) estimator, which takes the form of simple weighted averages, GMM or two stage least squares. Lewbel shows that the distribution function of potential outcomes, conditional on covariates, can be identified given an observed variable $V$, called very exogenous variable, that affects the selection probability in certain ways and is conditionally independent of the error terms in a model of potential outcomes. The nice thing about this estimator is that it is semiparametric and there are no stringent assumption on the error terms ${ }^{4}$.

We specify the model below. Equation (6) is our main regression equation in which we seek to establish our determinants of R\&D intensity, (7) is our innovator selection equation, and (8) is the indicator function given in (5).

Let $L R_{i}$ be $\log$ of $\mathrm{R} \& \mathrm{D}$ intensity of a plant $i$, where $\mathrm{R} \& \mathrm{D}$ intensity is defined as level of $\mathrm{R} \& \mathrm{D}$ investment in a year divided by the year value of the plant $i^{\prime} s$ sales ,

$$
\begin{array}{r}
L R_{i}=\left(S I N V_{i} \beta_{1}+D F I N_{i} \beta_{2}+X_{i} \beta_{3}+V_{i} \beta_{4}+\epsilon_{i}\right) D_{i} \\
D_{i}=I\left[0 \leq V_{i}+M\left(S I N V_{i}, D F I N_{i}, X_{i}, e_{i}\right)\right] \\
D F I N_{i}=I\left[\operatorname{fin}_{i}-F_{i}>0\right],
\end{array}
$$

where $D_{i}$ equals one if the firm $i$ is an innovator and zero otherwise. If $D_{i}=1$ we observe some R\&D expenditure which may also be zero. In our estimation we use $\log$ of $R \& D$ intensity instead of $R \& D$ expenditure. For those firms that are innovators and for whom R\&D intensity is zero ${ }^{5}, \log$ of $R \& D$ intensity is taken to be a little lower than the lowest $R \& D$ intensity for a firm with positive $R \& D$ expenditure. We do this because logarithmic transformation of zero is not defined and therefore such

\footnotetext{
${ }^{4}$ Appendix B carries a note on estimation.

${ }^{5}$ Out of 1531 innovating firms 107 or about 7 percent of them do not have R\&D expenditure for the period of the survey.
} 
an exercise prevents us from losing any data during estimation.

Our variable $V^{6}$, the very exogenous regressor, is the size of firms measured in terms of employment. The assumption on $V$ is that it is an observed, continuously distributed covariate (or known function of covariates) with large support. The coefficient on $V$ has been normalized to 1 . In the Schumpeterian tradition, it makes sense to include size as an explanatory variable in the main as well as the selection equation. It can also be argued that if there are fixed costs of investing, then as Cohen and Klepper (1996) argue, large firms are more incited to engage in innovative activities because they can amortize these costs by selling more units of output ${ }^{7}$.

$M$ is an unobserved latent variable which is a function of explanatory variables other than size. We also assume $M$ to be linear function of its arguments. $I$ is the indicator function that equals one if its argument is true and zero otherwise.

$S I N V_{i}$ is the share of innovation in the total sales of the firm. Analogous to the literature on physical investment $S I N V_{i}$ could be thought of as a proxy for $q$ which is the expectation of the marginal contribution of new capital goods to future profit. We also experimented with alternative proxies for $q$, like lagged values of share of Innovation ${ }^{8}$. Mulkay et al. (2001) assess the impact of cash flow or profits on R\&D and physical investment. The share of innovative sales could be a more accurate measure of the value accruing out of $R \& D$ investment than cash flow or profits.

Below are listed the other explanatory variables included in $\mathrm{X}$ of equations (6) and (7):

DOTH: This variable caries the effect of other hampering factors. This is a dummy variable that takes value one if a firm is constrained because of one of the following factors: (a) internal organization, (b) market uncertainties, or (c) regulation. The primary aim of constructing this variable is to see the effect of other hampering factors as uncertainty or institutional factors such as regulation and organizational rigidities on $R \& D$ intensity and to see the effect of financial constraint in the presence of such factors.

DCOOPERATION: The literature on cooperation and R\&D activities is not sparse. The crux of the issue lies in knowledge spillover and its effect on investment. Spillovers increase the relative profitability of $R \& D$ cooperation once spillovers are sufficiently high. But higher spillovers also increase the incentives to cheat by partner firms and the profits from free riding. Firms can increase the effectiveness of incoming spillovers by investing in "absorptive capacity". Cohen and

\footnotetext{
${ }^{6}$ To make sure that $V$ or the log of size has a large support we demean it. With this exercise, we make sure that $V$ takes negative as well as positive values.

${ }^{7}$ Nilsen and Schiantarelli (2003) find strong statistical evidence of this relationship, including much greater incidences of zero investments in small versus large plants. They attribute this relevance of plant size both to the presence of absolute as well as relative fixed costs and to potential indivisibilities in investment.

${ }^{8}$ See Nilsen and Schiantarelli (2003)
} 
Levinthal (1989) show that external knowledge is more effective for the innovation process when the firm engages in own R\&D. Increased absorptive capacity through investments in internal $R \& D$ efforts thus increases the effectiveness of incoming information. Also when firms are not direct competitors but market independent or produce complementary goods, cooperation is associated with higher R\&D investment levels independently of the amount of spillovers.

$A G E^{9}$ : In our specification we also include the age of the firms. CIS data do not provide this information. The birth date of the firm was obtained from the Business Register.

LOG(MKTSHARE): This variable is a logarithmic transformation of the market share, defined as the ratio of sales of the firm to the total sales of the industry. It is a proxy for concentration or the degree of monopoly. Schumpeter (1942) argues that a firm is incited to innovate if it enjoys a monopoly position to prevent entry of potential rivals.

Firms in the questionnaire were asked if the innovation activities of the firm were driven by non-technological (market oriented) reasons or by technological aspect, for example new technology.

NONTECHR: This variable takes value 1 if non-technological (market oriented) factors dominated the innovation activities of the firm. In the literature on innovation activities it has been argued that demand pull plays an important role in driving innovation activities. The basic underlying premise in demand pull playing a role is (a) that the ability to make inventions is widespread, flexible, and responsive to profit-making opportunities; and (b) that the larger an the market is, the more inventive activity will be directed toward it, partly because the profitability of invention rises with market size, all else equal, and partly because chance encounters between inventive talent and a problem needing solution are more frequent, the more productive activity there is devoted to meeting some demand. We assume that the variable, NONTECHR, proxies the demand pull that that the firm faces with regard to the output it produces.

TECHR: This variable takes value 1 if technological factors dominated the innovation activities of the firm. Also, the literature on innovation activities it has been argued that changes in the state-of-the-art in technological knowledge gives rise to technological opportunity, which the firms want to reap. We assume that $T E C H R$ proxies the technological opportunity or technological push that arise out of development in science and technology.

Innovating firms are asked if they have introduced new products or processes into the market, and if so, if the new products or processes are (a) developed by the enterprise, (b) developed in alliance with third parties, or (c) developed mainly by third parties.

\footnotetext{
${ }^{9}$ The age of the firms are available from 1967 onwards.
} 
PDOTH is a dummy equal to one if the new products were developed mainly by third parties.

PDALOTH ia a dummy equal to one if the introduced new products were developed in alliance with third parties.

PCOTH is a dummy equal to one if the introduced new processes were developed mainly by third parties.

$P C A L O T H$, is a dummy with value one if the new process were developed in alliance with third parties.

The rationale for including these dummies in the specification can be found in Table 3.1. It is evident from that Table that the R\&D intensity monotonically decreases with the degree of alliance. However, it should be mentioned that this is not the same as cooperation in R\&D activities with other institutions. Summary statistics reveal, see Table 3.2, that the mean R\&D intensity is higher for those firms that have entered into cooperative arrangements with other institution than for those that have not, but also that the R\&D intensity monotonically decreases with the degree of alliance in the introduction of new products or processes.

In some of the specifications we also include a dummy variable $D S I N P L$ that takes value one if the enterprise is also a company. That is, it takes value one if it does not belong to a group headed by a company that has many enterprises working for it.

Earlier we have explained the construction of our binary variables DFIN. In our bid to explain what causes financial constraint we use Lewbel's $(2000,2004)$ semiparametric estimator to estimate a binary choice model. For our estimation we choose a simple functional form for the function, fin $-F$, that is given by

$$
f_{i n}-F_{i}=V_{i}+R\left(X_{i}, \epsilon_{i}\right),
$$

where $V$ and $X$ include variables that parameterize the arguments in the function fin. $R$ is a latent variable, which we assume to be a linear function of variables other than $V$, the very exogenous regressor, and the error term $\epsilon$. Thus, the estimation equation is given by the following equation:

$$
D_{F I N}=I\left[0 \leq V_{i}+R\left(X_{i}, \epsilon_{i}\right)\right] .
$$

$V$ in our model is the size of firms measured in terms of employment. The coefficient on $V$ has been normalized to 1 . The assumption on $V$ is that it is an observed, continuously distributed covariate 
(or known function of covariates) with large support ${ }^{10}$. It is known that small firms may be more tightly constrained because they have less access to internally generated funds for the financing of an innovation project and therefore have to approach outside financiers. These considerations imply that the size of the firm has a bearing on the financial wealth of the firm, especially with respect to financing of R\&D investment from internal funds. Problems of information asymmetries may also be more severe for small firms in terms of raising outside finance. Moreover for smaller, newer firms there may be no track record upon which to base a case for funding and/or there may be fewer realizable assets to use as collateral. Thus size may have an implication in raising the required rate of return independently of the financial position of the firms.

For the same reason as stated in the model on R\&D intensity we use $S I N V_{i}$, the share of innovation in the total sales of the firm as a proxy for future expected profitability.

As mentioned earlier, a proper explanation of a firm being financially constrained necessitates information on the balance sheet of the firms. But since we do not have such information we use the age of the firm, the log of market share, and a dummy if a firm belongs to a group, as proxies for wealth.

We include the age of the firm since it might be the case that long established firms that have survived exit are financially more sound than new entrants. Age carries a reputation effect which can have a bearing on accessability to outside funds.

In our specification we also include a dummy, DSINPL, which takes value 1 if the firm does not belong to a group. It could be quite possible that the firm in question, if faced with financial distress, could be bailed out by the company to which it belongs. It is also possible that the company to which this enterprise belongs engages in diverse activities and produces diverse products which reduces its risk of being bankrupt, thus enhancing its ability to borrow more. Descriptive statistics of the variables used can be found in Table 3.2 of Appendix C.

\subsection{Results}

The section discussing the results has two subsections. The first section discusses the results of the sample selection model in which we establish the determinants of R\&D intensity and the next section discusses the result of the binary choice model, where we sought to explain the probability of a firm being financially constrained.

\footnotetext{
${ }^{10} \mathrm{An}$ implication of the large support assumption for $V$ is that, for any value $X$ and $\epsilon$ may take on, it is possible for $V$ to be small enough to make $D=0$, with probability one, or large enough to make $D=1$ with probability one.
} 


\subsubsection{R\&D Intensity}

In this subsection, we discuss the results of the effect of the financial variable, DFIN, after controlling for the effect of other variables that influence the choice of $R \& D$ investment.

Table 3.3 presents the result for R\&D intensity. The estimates in the columns differ by specification and the choice of instruments.

The common set of instruments for all the seven columns includes the age of the firm, $A G E$; the logarithm of market share, LOG(MKTSHARE), the lagged dummy variable for financial constraint, $D F I N_{-1}$; the lag of the share of innovative sales in total output of the firm, $S I N V_{-1}$; the lag of the dummy if the firm cooperated with others in its R\&D endeavors, DCOOPERATION $N_{-1}$; the

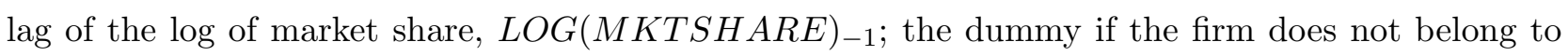
a group $(D S I N P L)$; the dummy if a firm also did nontechnological innovation (DNONTECH) and its lag, $\left(\right.$ DNONTECH $\left._{-1}\right)$; the dummy that is equal to one if new products were developed in alliance with third parties $(P D A L O T H)$; the dummy that takes value one if new processes were developed in alliance with third parties $(P C A L O T H)$; dummy variable that takes value 1 if nontechnological reasons or market oriented reasons were important in driving innovation activities, NONTECHR; dummy variable that takes value 1 if technological reasons were important in driving innovation activities, TECHR; total investment of the firm during the last period, $I N V T_{-1}$ and sectoral dummies.

The instrument set in Column (a) also includes PDALOTH, PCALOTH, DFIN * DOTH -1 $_{1}$ and $D_{-1}$. In Column (b) the additional instruments are PCALOTH and DOTH $H_{-1}$. The specification in column (c) and (d) do not include NONTECHR and TECHR. The instrument set for column (c) is the same as those of column (b), while in column (d) the only additional instrument is PCALOTH. The specification in column (e) and (f) does not have SIZE. The additional instrument in column (e) is PCALOTH, while that in (f) the additional is PDALOTH. From the Sargan test of overidentifying restrictions it seems that the decision to introduce new services in alliance with the third parties could be potentially endogenous to the decision on how much to invest in $\mathrm{R} \& \mathrm{D}$ activities.

The results from the estimates suggest that, controlling for other factors, a firm is adversely affected in its pursuit of $R \& D$ activities, as measured by $R \& D$ intensity, by the presence of financial constraint. The large negative sign on DFIN is testament to this fact. From our discussion of the model we know that given the uncertainty, the risk of bankruptcy is large for firms that are not financially healthy. This risk plays an important part in reducing the amount of R\&D investment. 
We include DOTH to assess the effect of other constraints and also to assess the impact of financial constraint in presence of other hampering factors. The results of our analysis suggest that such factors as captured by DOTH also have a negative effect on the amount of R\&D capital a firm wishes to use. We also find that the effects of these constraints are much weaker with respect to financial constraint suggesting that, if there are any major hampering factors, then these are financial constraints. To capture the effect of financial constraint in the presence of other hampering factors, we include the interaction of DFIN and DOTH, DFIN *DOTH. The effect of financial constraint in the presence of other constraints that are not functions of financial constraints is captured by the sum of the coefficients of DFIN,DFIN *DOTH and DOTH. Our results imply that financial constraints are less binding if other market uncertainties or institutional hampering factors are also present. It should also be noted that, in spite of the fact that these variables are very correlated, the coefficient estimates are individually significant. The sum of the coefficients on DFIN and DOTH, $D F I N * D O T H$ is negative in columns (a) and (b), but turns out to be positive positive for the rest of the variables. This, however, does not weaken our conclusion that, if a firm is only constrained because of financial reasons in its pursuit of $R \& D$ activities, the effect of financial constraint is quite prominent.

Our results suggest that $\mathrm{R} \& \mathrm{D}$ intensity reacts strongly to $S I N V$, which is the share of innovative sales in the total sales of the firm that we assumed to be a proxy for future expected profitability. The strong positive sign on $S I N V$ suggest that, higher the future expected profitability higher would be the $R \& D$ investment. In addition we find that older firms are more R\&D intensive after controlling for other factors. However, we find that firms that have a higher market share also have a lower R\&D intensity. Not surprisingly, the sign of this coefficient is positive when we use the logarithm of $R \& D$ expenditure instead of the logarithm of $R \& D$ intensity as dependent variable. These findings are not new; they only suggest that a monopoly firm does indeed invest more than a firm in a more competitive industry but proportionately less as it increases in size measured by sales ${ }^{11}$. Our results suggest that, controlling for other factors, older firms tend to have a higher R\&D intensity than younger firms and that the spillover effects of cooperation lead to higher R\&D intensity. It could also suggest that the cooperative arrangements are made with non-rivals or with firms that are engaged in producing complementary goods ${ }^{12}$.

The specification also includes $D S I N P L$, which is a dummy for being a single plant in a company, that is it takes value 1 if it does not belong to a group. What we find here is that, after controlling

\footnotetext{
${ }^{11}$ See Cohen, Levin and Mowery (1987) and Geroski (1990).

${ }^{12}$ See De Bondt et al., (1992) and Röller et al. (1997).
} 
for other factors, the firms that do not belong to a group have lower investment than those who do belong to a group, reflecting the fact that, enterprizes belong to a group could be special units, set up with the purpose of carrying our R\&D activities for the whole group. We find that larger and younger firms are more R\&D intensive. The variables NONTECHR and TECHR, however do not turn out to be significant.

\subsubsection{Financial Constraint}

This section discusses the results of the binary choice models in which we seek to explain the determinants of the financial constraint itself. Our dependent variable is DFIN which is the binary variable that takes the value one if the firms finds itself being financially constrained in the pursuit of $R \& D$ activities and zero otherwise. As stated earlier to handle potential endogeneity of the regressors we use Lewbel's (2000, 2004) semiparametric estimator.

To estimate the binary choice model we construct another dependent variable DFIN* which is $D F I N-I(V \geq 0)$ weighted by the inverse of the conditional density function of the negative of the logarithm of the size of the firm measured in terms of employment, the very exogenous variable $V$, using the same notation as in Lewbel's $(2000,2004)$ papers. $I$ is an indicator variable that takes the value 1 if the argument in parentheses is true. $Y$, the set of conditioning variables is the union of all the explanatory variables and the instruments (see Appendix 3B). We take the negative of the logarithm of size because one of the assumptions of the model is that, as $V$ decreases, the probability of DFIN being zero increases (refer to footnote 9).

The results of the binary choice model in which we seek to explain the determinants of financial constraint are presented in Table 3.4. The set of instruments is mentioned in the Table. The more striking results of this part of our analysis are the coefficient estimates that we obtain on age and DSINPL. The results suggest that the older a firm is, the less likely it is to be financially constrained and significantly so. This is understandable, since older firms, having survived preemption, are more likely to be financially stable than new firms. Also, older firms have a better reputation than younger firms and therefore they have greater access to external funds. Secondly, the estimation results indicate that a firm is more likely to be financially constrained if it does not belong to a group. This could suggest that if it belongs to a group, then the firm has at its disposal some alternative avenues of financing its projects, that are closed to firms that do not belong to a group. The fact that it belongs to a group may be an indication that the group is engaged in diverse activities and thus less prone to risk than a single enterprise engaged in a single activity. As explained earlier, 
$D F I N$ is a function of the financial state variables. In the absence of information on the balance sheets, the effect of financial state variables is included in the error term. Hence, the instruments that are supposed to be correlated with the regressors are also correlated with the error term. But since the results of the test of overidentifying restrictions do not lead to rejection, we conclude that age and the dummy indicating that the firm belongs to group are picking up the effects of financial variables.

As explained earlier the binary variable $D F I N$ is an indicator of the firm's willingness to undertake R\&D activity as well as of its financial position. As a proxy for future expected profitability we experiment both with the current value of the share of innovative sales $S I N V$ and with its lag. Our results suggest that controlling for other variables, the probability of a firm being financially constrained is higher, the higher is its future expected profitability, as proxied by SINV or its lag, but not significantly so.

The results in Table 3.4 also suggest that a firm facing a priori hampering factors other than financial constraints are less willing to undertake R\&D activities and are thus less likely to be hit by financial constraints. The results on overidentification restrictions do not suggest that there is simultaneity in the determination of DOTH and DFIN, since DOTH is included in the instrumental variables.

\subsection{Conclusions}

In this paper we empirically investigate the determinants of $R \& D$ and investment. In particular, our aim is to see how financial constraints affect a firm's R\&D intensity. We find that a firm that reports that it is financially constrained but not otherwise constrained is adversely affected in its pursuit of R\&D activity. Financial constraints have a large and a significant impact in affecting R\&D investment.

However, financial constraints are less binding if the firm runs up into other hampering factors or other constraints that are not a function of financial constraint itself. We obtain this result both by looking at the effect of financial constraint on $R \& D$ intensity in the presence of other constraints, such as market uncertainty, institutional constraints and organizational rigidities, and looking at the probability for a firm to be financially constrained in the presence of other than financial constraints. We also find that the effect of these other constraints is much weaker than that of financial constraint, which confirms the findings of many papers that financial factors are the major stumbling block in pursuit of any activity. However, this does not diminish the fact that institutional and organizational 
rigidities also reduce the amount or R\&D investment. Policy makers while taking into account the hampering factors that inhibit R\&D activities should also consider such factors. Also, since financial constraint seems to be the most important factor that inhibits R\&D activities, policy makers should consider setting up institutions that would allow economically sound projects get the required finance to be carried out. In particular, care should be taken of young firms and firms that do not belong to a group, since these firms are the ones that are more susceptible to the exigencies of nature, as is well reflected in our analysis. Finally, as a comment on financial constraint, we note that, age and group membership, as proxies for the financial wealth of a firm, appear to be significant predictors of a firm being financially constrained.

One of the shortcomings of our paper is that, we have not used financial information from the balance sheet of the firms, but instead used proxies for financial state variables. As a part of our future research agenda we would like to enrich our model by using data from the balance sheet of the firms in the explanation of financial constraint. Also, for our future research we plan to carry out our investigation of financial constraint on $\mathrm{R} \& \mathrm{D}$ investment in a dynamic setting by using more waves of CIS data. This would also necessitate a dynamic model of financial constraint and investment. 


\subsection{Appendix}

\section{A A Model of Financial Constraint}

In this appendix we present a model of financial constraint and study the decision of a firm to innovate and how much to invest in R\&D in the presence of financial constraints ${ }^{13}$. Firms wish to undertake risky ventures but lack the necessary resources, so they turn to the investors, banks or other deposittaking, financial institutions, for external finance. Venture capital and other types of non-deposit private equity are not considered in our analysis. The firm's initial net wealth is $W_{0}=A_{0}-R_{0}$, where $A_{0}$ is the firms's initial liquid assets and $R_{0}$ the firm's initial indebtedness. Assume that the firms need of R\&D expenditure $R$ is greater than $W_{0}$. The firm is assumed to be risk-neutral; it maximizes the expected present value of its wealth. The returns to the risky venture are described by a revenue function $f$ : an investment of $R$ units produces a revenue of $f(s, R)$ units in state $s$, $s$ being the state of nature. The revenue function is also assumed to exhibit decreasing returns to scale. Assume that $f(s, R)=s \phi(R ;$.$) , "." represents other parameters characterizing the firm. A$ crucial assumption is that agents have asymmetric information. The firm observes the states free of charge, but the lender can only observe the states by paying some observational cost. Gale and Hellwig (1985) have shown that the optimal contract between the firm and the lender is a standard debt contract, which involves a fixed repayment obligation $\bar{R}_{l}$, and a declaration of bankruptcy if and only if the repayment obligation cannot be met, and a confiscation of whatever wealth remains in the event of bankruptcy.

Under an optimal contract the firm takes into account the possible chances of bankruptcy. If the firm declares bankruptcy its revenue is reduced to $\alpha s \phi(R ;$.$) , where 0 \leq \alpha \leq 1$, and it suffers a fixed nonpecuniary penalty whose monetary equivalent is $K \geq 0$. Under an optimal contract the firm solves the following problem:

$$
\max _{R, \bar{R}} E\left[s \phi(R ; F C, C O N)-\bar{R}_{l}\right]^{+}-\operatorname{Pr}\left[s \phi(R ; .)<\bar{R}_{l}\right] K
$$

\footnotetext{
${ }^{13}$ See Gale and Hellwig (1985) for a detailed discussion.
} 
subject to

$$
\begin{array}{r}
E \tilde{R}_{l} \geq(1+i r)\left(R-W_{0}\right) \\
R \geq 0,
\end{array}
$$

where $[X]^{+} \equiv \max \{X, 0\}, \operatorname{Pr}[$.$] denotes a probability, the expectation is taken over the states of$ nature, $i r$ is the risk free rate of return, $F C$ is firm characteristics, $C O N$ is other constraints such as institutional factors that deter firms from taking up R\&D activities and $\tilde{R}_{l}$ is given by

$$
\tilde{R}_{l}= \begin{cases}\bar{R}_{l} & \text { if } s \phi(R ; .) \geq \bar{R}_{l} \\ \alpha s \phi(R ; .) & \text { if } s \phi(R ; .)<\bar{R}_{l}\end{cases}
$$

$\tilde{R}_{l}$ is a random variable, which is the lender's gross return under a standard debt contract. $\bar{R}_{l}$, under the standard debt contract is the fixed payment to the lender when the firm is solvent. In the event of bankruptcy, that is if $s \phi(R ;)<.\bar{R}_{l}$, the revenue is reduced to $\alpha s \phi(R ;$.$) , and since the$ lender is allowed to recoup whatever he/she can, the lender's revenue in the state of bankruptcy is $\alpha s \phi(R ;$.$) . One can interpret (1-\alpha) s \phi(R ;$.$) as the cost borne by the lender for investigation in the$ event bankruptcy. Equation (11) is the zero profit condition of the lender, which states that the expected return from lending to the firm should be at least equal the amount he/she can earn from lending the same amount at the risk free rate of interest $i r$. Let $R_{o p}$ be the solution to (10) and (11).

To invoke the notion of financial constraint let us now see what happens under the assumption that both the lender and the firm can directly observe the state of nature. In such a situation, which is termed first best, since the firm and the lender share the same information about the nature of the project and the lender can costlessly observe the states of nature, the problem of firm as well as the lender is the same. This can be written as

$$
\max _{R} E\left\{s \phi(R ; .)-(1+i r)\left(R-W_{0}\right)\right\}
$$

Let, $R_{f b}$ be the solution to the above problem. Gale and Hellwig (1985) have shown that $R_{f b} \geq$ $R_{o p}$ and that $R_{f b}>R_{o p}$ if $\operatorname{Pr}\left[s \phi(R ;)<.\bar{R}_{l}\right]>0$ and $\alpha<1$, that is to say that the amount R\&D capital demanded in the first best situation is at least as great as the amount lent under an optimal contract and is strictly greater if there is a positive probability of bankruptcy and if the cost borne by the lender $(1-\alpha) s \phi(R ;$.$) is positive.$

Let $r$ be the equilibrium rate of interest that the firm pays so that the lender's zero-profit con- 
straint is satisfied. This rate of interest $r$ in (13) is the interest rate actually paid by the firm when it is not bankrupt and is given by:

$$
(1+r)\left(R_{o p}-W_{0}\right)=\bar{R}_{l}
$$

This implies that

$$
r=r\left(R_{o p}, \bar{R}_{l}\right)
$$

However it should be noted that both $R_{o p}$ and $\bar{R}_{l}$ are determined simultaneously and are functions of the distribution of the states of nature, which we denote here by $h(s)$; firm characteristics, $F C$; the organizational and the institutional constraints that the firm faces and which deters a firm from taking up R\&D activities, $C O N$; the liquid wealth $W_{0}$ that the firm has at its disposal and the risk free rate of interest $i r$.

$$
\begin{gathered}
R_{o p}=R_{o p}\left(E(\pi), F C, C O N, W_{0}, i r\right) \\
\bar{R}_{l}=\bar{R}_{l}\left(E(\pi), F C, C O N, W_{0}, i r\right) .
\end{gathered}
$$

Here we seek to capture the distribution of the states of nature on which a firm bases its expectation with a single variable, $E(\pi)$, the expected future profitability and is given by $E(\pi) \equiv E\left[s \phi^{\prime}(R)\right]=$ $\int s \phi^{\prime}(R) h(s) d s$.

Gale and Hellwig $(1985,1986)$ and Gomes, Yaron, and Zhang $(2006)$ show that $R_{o p_{i}}^{\prime}<0, R_{o p_{W}}^{\prime}>$ $0, R_{o p_{E}}^{\prime}>0$ and $R_{o p_{C O N}}^{\prime}<0$, where " " denotes the derivative of the variable with respect to the subscript variable. In words this means that as the risk free rate of interest rises the demand for R\&D capital decreases, as the liquid wealth of the firm increases the demand for $\mathrm{R} \& \mathrm{D}$ capital decreases and as the future expected profitability, $E(\pi)$ increases the demand for R\&D capital increases. Also since the fixed payment to the lender when the firm is solvent, $\bar{R}_{l}$, increases with the amount lent, the effect of $i r, W_{0}, E(\pi), C O N$ on $\bar{R}_{l}$ are qualitatively the same as those on $R_{o p}$.

Equation (14) and (15) imply that ${ }^{14}$

\footnotetext{
${ }^{14}$ In fact the rate of interest $r$ does not have an independent meaning in the context of the model. It is just another characterization of the fixed repayment obligation of the firm, $\bar{R}_{l}$. We only introduce it here so that we can write the estimation model.
} 


$$
r=r\left(E(\pi), F C, C O N, W_{0}, i r\right) .
$$

Since the demand for $R \& D$ capital increases in expectation of future profitability it can be shown that $r_{E}^{\prime}>0$ and since the demand decreases due to presence of institutional factors that hamper $\mathrm{R} \& \mathrm{D}$ activities, $r_{C O N}^{\prime}<0$. Also since the demand for external sources of funding decreases with the increase in the internal wealth of the firm, this implies that $r_{W_{0}}^{\prime}<0$.

Define the function $\mathrm{fin}^{15}$ as

$$
\text { fin }=\operatorname{fin}\left\{r\left(E(\pi), F C, C O N, W_{0}\right), \epsilon\right\}
$$

where $\epsilon$ is an idiosyncratic disturbance term. The inequalities discussed above imply that $\operatorname{fin}_{E}^{\prime} \geq 0$, $\mathrm{fin}_{C O N}^{\prime} \leq 0$ and $\mathrm{fin}_{W_{0}}^{\prime} \leq 0$. We say that a firm is financially constrained if,

$$
\text { fin } \geq F \text {, }
$$

that is, if the rate of interest demanded by the lender on extra unit of loan exceeds a certain threshold, which the firm is unable to meet. Consequently the firm would not be able to meet its required R\&D investment level. The rate of interest corresponding to the threshold could be thought of as the interest rate on the maximum amount of debt a firm can incur. This threshold can differ from firm to firm depending on the financial position of the firm. For example, consider two firms that are equal in every respect but one firm has a better financial position than the other. The firm that is in a better financial position is less likely to hit its debt limit than the firm whose financial position is not sound. It should be noted that what is driving these results is the positive probability of bankruptcy. Ceteris paribus, worse the financial position of the firm, greater is the loan demanded which implies higher the fixed repayment obligation and thus greater the chances of bankruptcy.

\footnotetext{
${ }^{15}$ We now ignore the risk free rate of interest $i r$, since it should stay constant for a single period of survey.
} 


\section{B Note on Estimation}

Given our estimation model equation (6) and (7)

$$
\begin{array}{r}
L R=\left(S I N V \beta_{1}+D F I N \beta_{2}+X \beta_{3}+V \beta_{4}+\epsilon\right) D \\
D=I[0 \leq V+M(S I N V, D F I N, X, e)]
\end{array}
$$

where $L R$, the $\log$ of $\mathrm{R} \& \mathrm{D}$ intensity is the outcome and $D$ is the decision variable to innovate. $D$ takes value $=1$ if the firm chooses to innovate and zero otherwise. Define

$$
U^{*}=Z\left(L R^{*}-\left(S I N V \beta_{1}+D F I N \beta_{2}+X \beta_{3}+V \beta_{4}\right)\right)
$$

where $Z$ is the vector of instruments and $L R^{*}$ is the unobserved $R \& D$ intensity for firms which report to be non-innovators and therefore do not report their R\&D intensity. In such a situation the coefficients of the model could be estimated by two stage least squares or a GMM technique using the the moment condition $E\left(U^{*}\right)=0$. But what we observe in fact is $U$, which is given by

$$
U=Z\left(L R-\left(S I N V \beta_{1}+D F I N \beta_{2}+X \beta_{3}+V \beta_{4}\right)\right) D
$$

In the presence of selection, GMM or two stage least squares is infeasible because we only observe $L R$ instead of $L R^{*}$, and unobservables that determine the selection such as $M$, the unobserved latent variable, are correlated with $L R^{*}$ and $U^{*}$. But the estimation of our required coefficients could become feasible given a consistent estimator of $E\left(U^{*}\right)$. Define the weighting scalar $W$ by $W=D / f(V \mid Y)$ where $f$ is the conditional probability density function of $V$, introduced earlier, given $Y$, which is the union of the set of instruments and the other covariates, that is, DFIN, SINV and $X$, that appear in equation (6). Lewbel (2005) shows that

$$
E\left(U^{*}\right)=\operatorname{plim}_{n \rightarrow \infty} \sum_{i=1}^{n}(U i W i) / \sum_{i=1}^{n} W_{i} .
$$

The main assumptions required for equation (19) to hold are that the support of $V \mid Y$ contains the support of $-M \mid Y$ (these could all equal the real line, for example), and that

$$
V\left|Y, U^{*}, M \sim V\right| Y
$$


that is, $V$ is conditionally independent of the unobserved latent variables of the model, conditioning on the set of covariates $X$. Given the above our estimates are based on the moment conditions.

$$
E\left[Z W\left(L R-\left(S I N V \beta_{1}+D F I N \beta_{2}+X \beta_{3}+V \beta_{4}\right)\right)\right]=0 .
$$

We estimate the above by using the method of two stage least squares. To estimate the conditional density of $V$ given $Y, f(V \mid Y)$ we employ nonparametric density estimation, the estimator being described in Lewbel and Schennach (2007).

\section{C Descriptive Statistics and Results}

Table 3.1: Mean Distribution of R\&D Intensity along Alliance in the Introduction in New Products and Process

\begin{tabular}{cccc}
\hline \hline & $\begin{array}{c}\text { Mainly by } \\
\text { your } \\
\text { enterprise }\end{array}$ & $\begin{array}{c}\text { Cooperation } \\
\text { with } \\
\text { third parties }\end{array}$ & $\begin{array}{c}\text { Mainly by } \\
\text { third parties }\end{array}$ \\
\hline Product & 1.45 & .68 & .35 \\
Process & $(1363)$ & $(679)$ & $(296)$ \\
& 1.70 & .77 & .24 \\
& $(643)$ & $(601)$ & $(441)$ \\
\hline
\end{tabular}

The figure in parentheses is the number of observations.

These number are from the full sample of CIS 3.5,

which has 10628 observations. 
Table 3.2: Descriptive Statistics of the Variables of Interest

\begin{tabular}{|c|c|c|c|c|}
\hline \multicolumn{5}{|c|}{ Variables that are observed only for the Innovators } \\
\hline & Mean & St. Dev. & Min & Max \\
\hline$L R$ & -5.09 & 3.80 & -19.70 & 4.84 \\
\hline$S I N V$ & 17.15 & 22.61 & 0 & 100 \\
\hline DCOOPERATION & .41 & .49 & 0 & 1 \\
\hline$P D A L O T H$ & .21 & .41 & 0 & 1 \\
\hline PDOTH & .08 & .28 & 0 & 1 \\
\hline PCALOTH & .16 & .36 & 0 & 1 \\
\hline PCOTH & .08 & .28 & 0 & 1 \\
\hline \multicolumn{5}{|c|}{ Variables that are observed for all firms } \\
\hline & Mean & St. Dev. & Min & Max \\
\hline$D F I N$ & 0.04 & 0.21 & 0 & 1 \\
\hline DOTH & 0.11 & 0.32 & 0 & 1 \\
\hline$D F I N * D O T H$ & 0.04 & 0.18 & 0 & 1 \\
\hline$L O G(M K T S H A R E)$ & -8.88 & 2.27 & -18.26 & -0.48 \\
\hline$S I Z E$ & 218.34 & 1014.91 & 2.67 & 39591.50 \\
\hline$D S I N P L$ & 0.44 & 0.50 & 0 & 1 \\
\hline$A G E$ & 22.37 & 11.59 & 2.00 & 35.00 \\
\hline
\end{tabular}




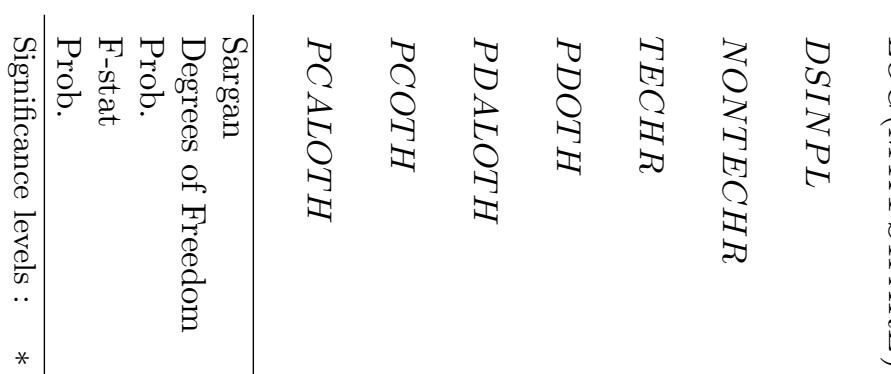

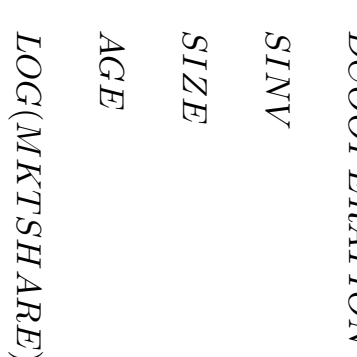

官

i o * वg



-

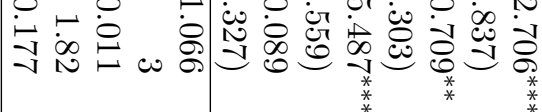

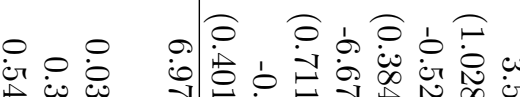

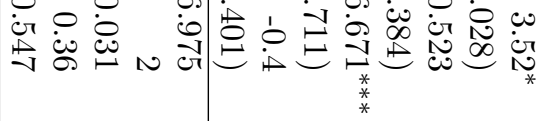

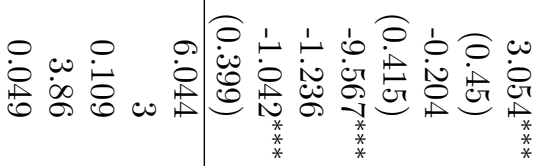

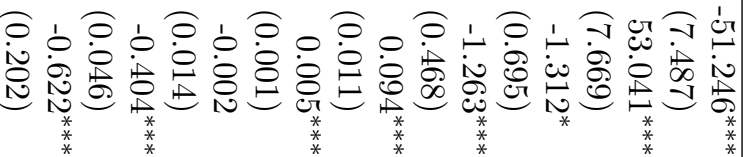

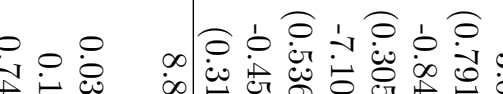

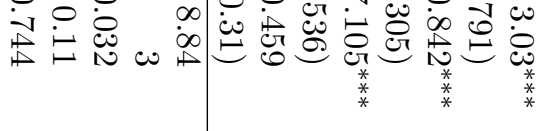

Oे

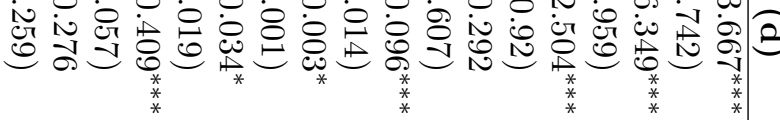

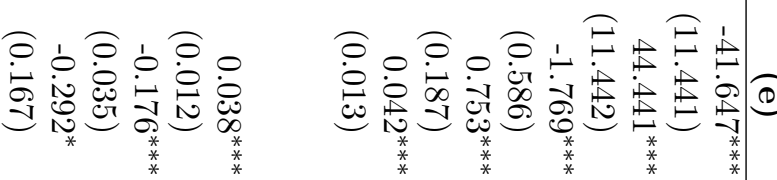
Oें



官 :

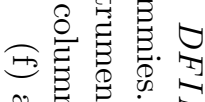

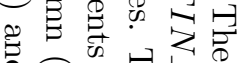

टลิ

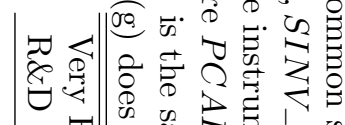

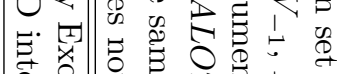

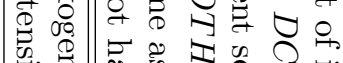
氧.

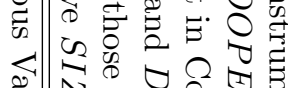

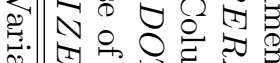

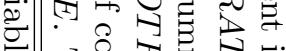

当完材式

4. है

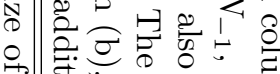

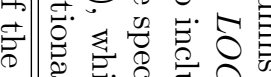

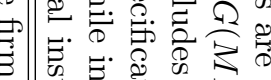

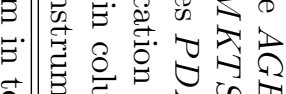

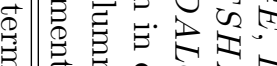

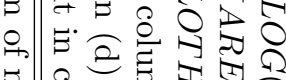

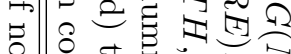

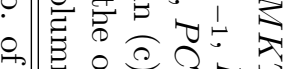

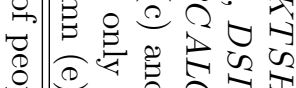

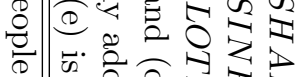

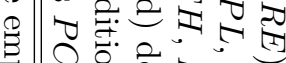

- 28 8 $\forall-$

过司讨

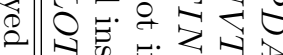

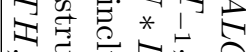

ঊ

E. 원 ब ज. 012

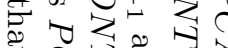

- 2 절 저용

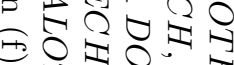

牙牙 क्ष

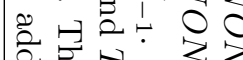

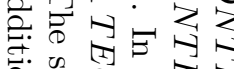

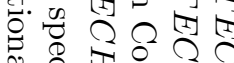

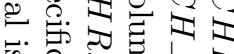
ط.

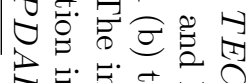

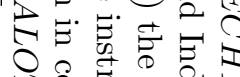

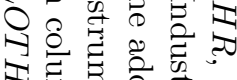

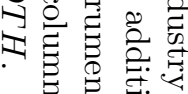
(c) 要 


\section{Table 3.4: Specification for Financial Constraint}

The set of instruments in all columns contains DOTH, DOTH $-1, A G E, D S I N P L$, LOG(MKTSHARE), LOG(MKTSHARE -1$)$, DCOOPERATION ${ }_{-1}$, PDOTH, PDALOTH, PCALOTH, PCOTH, SINV $V_{-1}$, DNONTECH, DNONTECH $H_{-1}$, lagged size, and sectoral dummies.

\begin{tabular}{|c|c|c|c|c|}
\hline \multicolumn{5}{|c|}{$\begin{array}{l}\text { Very Exogenous Variable: Log of Size } \\
\text { Dependent Variable: DFIN: Binary Variable indicating } \\
\text { if the firm was Financially Constrained or not }\end{array}$} \\
\hline & (a) & (b) & (c) & (d) \\
\hline$S I N V$ & $\begin{array}{r}0.36 \\
(0.35)\end{array}$ & $\begin{array}{c}-0.06 \\
(0.59)\end{array}$ & & \\
\hline$S I N V_{-1}$ & & $\begin{array}{r}22.61 \\
(25.9)\end{array}$ & $\begin{array}{r}20.6 \\
(15.18)\end{array}$ & $\begin{array}{r}20.87 \\
(15.1)\end{array}$ \\
\hline DOTH & $\begin{array}{l}-15.25^{*} \\
(9.36)\end{array}$ & $\begin{array}{r}-13.09 \\
(9.67)\end{array}$ & $\begin{array}{l}-13.46 \\
(8.87)\end{array}$ & $\begin{array}{l}-13.31 \\
(8.84)\end{array}$ \\
\hline$A G E$ & $\begin{array}{l}-0.96^{* * *} \\
(0.24)\end{array}$ & $\begin{array}{l}-0.94^{* * *} \\
(0.24)\end{array}$ & $\begin{array}{l}-0.95^{\text {*** }} \\
(0.24)\end{array}$ & $\begin{array}{l}-0.95^{\text {*** }} \\
(0.24)\end{array}$ \\
\hline$L O G(M K T S H A R E)$ & $\begin{array}{r}0.16 \\
(1.38)\end{array}$ & $\begin{array}{r}0.27 \\
(1.38)\end{array}$ & $\begin{array}{r}0.25 \\
(1.36)\end{array}$ & \\
\hline$D S I N P L$ & $\begin{array}{l}17.45^{\text {*** }} \\
(5.54)\end{array}$ & $\begin{array}{l}17.65^{* * *} \\
(5.53)\end{array}$ & $\begin{array}{l}17.62^{\text {*** }} \\
(5.53)\end{array}$ & $\begin{array}{l}17.54^{* * *} \\
(5.51)\end{array}$ \\
\hline Sargan Test & 13.23 & 12.51 & 12.52 & 12.55 \\
\hline Degrees of Freedom & 10 & 9 & 10 & 11 \\
\hline P-value & 0.21 & 0.19 & 0.25 & 0.32 \\
\hline
\end{tabular}

Significance levels : $\quad *: 10 \% \quad * *: 5 \% \quad * * *: 1 \%$ 



\section{Financial Constraints and Other Obstacles: Are They a}

\section{Threat to Innovation Activity}

\subsection{Introduction}

The Lisbon Strategy launched in March 2000 by the heads of State or Government and aimed at making the European Union the most competitive economy in the world and achieving full employment by 2010 emphasizes in the first pillar the need to adapt constantly to changes in the information society and to boost research and development. The importance of innovative activity by firms for securing economic growth and welfare is generally recognized and widely documented in the scientific literature. While insisting on the necessity of more investment in $\mathrm{R} \& \mathrm{D}$ and more innovations to get Europe on a high growth path, Aghion (2006) emphasizes the need of "a comprehensive and coherent strategy which also involves: (i) more competition and entry on product market; (ii) more investment in higher education; (iii) more developed financial sectors and markets and more flexible labour markets; (iv) a more proactive macroeconomic policy over the business cycle" ${ }^{1 "}$.

Financial problems are particularly acute in the case of innovation activities due to some of their inherent characteristics(see Hall (2002) for a discussion). First of all, innovation projects are riskier than physical investment projects and therefore outside investors require a risk premium for the financing of innovation activities. Secondly, because of problems of appropriability innovators are reluctant to share with outside investors information about their innovations. This asymmetric information problem hampers the financing of innovation. Providing convincing signals about the quality of the innovation project is costly (see Bhattacharya and Ritter (1983) on this point) and sometimes leads to market failure (due to the lemon's problem). Thirdly, the difficulty of using intangible assets as collateral also leads to increased costs of external capital in the form of a risk premium. Because of the differences between internal and external costs of capital in the case of

\footnotetext{
${ }^{1}$ A critical assessment of Aghion's recent work on these issues can be found in Brouwer (2007).
} 
innovation, we observe the pecking order theory of finance, where firms prefer to use internal funds over external debt and finally new equity to finance innovation investments (see e.g. Myers and Majluf, 1984). The riskiness of innovation projects may raise other financial problems, especially in the case of young and small and medium sized firms. Some innovation projects may not be started, delayed or abandoned because of the risk of bankruptcy and the low value of intangibles in case of liquidation (see Gomes et al. (2006) for a modeling of this issue). Attracting additional equity to finance an innovative activity is hampered as this is likely to aggravate the agency problem and the moral hazard on the part of the inventor (reluctance to invest in risky projects due to risk aversion) arising from the separation of ownership and management of the firm (see e.g. Jensen and Meckling 1976). Information asymmetry, moral hazard and tax considerations (different tax treatment of external finance and financing by retained earnings) explain the positive gap between external and internal costs of capital and the preference of financing innovative activities by internal capital. The objective of this contribution is threefold. First, in Section 4.2 we provide some evidence about the importance and the effect of financial and other constraints on innovations in Dutch firms using the data from the Dutch Community Innovation Survey CIS 3.5. Second, in Section 4.3, we compare this evidence with some other evidence about the importance of financial and other constraints on innovation from empirical studies on Dutch and other country data. Third, we discuss in Section 4.4 the policy implications of the empirical findings as well as some alternative solutions to remove or to by-pass these obstacles. Finally, in Section 4.5, some concluding remarks will be presented.

\subsection{Obstacles to Innovation and their Impact: Some Facts}

In the Dutch CIS 3.5 survey, covering the years 2000-2002, participating innovative or potentially innovative firms were requested to answer some detailed questions about the hampering factors and their consequences for innovative projects. The hampering factors included in the survey questionnaire are the lack of appropriate sources of finance, but also too high innovation costs, too much uncertainty of future benefits and costs, lack of qualified personnel, lack of knowledge on technologies needed, organizational rigidities within the enterprise, uncertainty of future market developments and the existence of regulation [see e.g. Statistics Netherlands, Community Innovation Survey 20002002 (CIS 3.5), 2002, question 9]. The firms had to answer whether in the period 2000-2002 one or several among the above obstacles lead to seriously delaying, prematurely stopping, abandoning and/or not starting innovation projects. The questions had to be answered by the innovative firms (i.e. firms that introduced or tried but failed or were still in the process of introducing a new product 
Table 4.1: Frequency Distribution of being Hampered

\begin{tabular}{lcc}
\hline \hline & Hampered & Not Hampered \\
\hline Financial Constraints & 401 & 820 \\
Cost Too High & 410 & 811 \\
Economic Uncertanity & 529 & 692 \\
Shortage of Personnel & 373 & 848 \\
Shortage of Knowledge & 287 & 934 \\
Organistional Rigidities & 322 & 899 \\
Marrket Uncertanities & 472 & 749 \\
Regulations & 194 & 1,027 \\
Other Factors & 187 & 1,034 \\
\hline Total No. of Firms & 2: 10592 \\
Total No. of Potential Innovators: 3456 & \\
Total No. of Hampered Firms: 1221 & \\
\hline
\end{tabular}

or a new process into the market during this period) but also by firms which stated that they did not engage in activities aimed at technological improvements despite the fact these activities were needed (question 8, CIS 3.5). Among the 10,592 firms which answered the questionnaire were 3,456 (potential) innovators. Among the (potential) innovators, 1,221 firms (11.52\% of the firms in CIS 3.5) indicated that they were hampered in one way or the other. Of the reported potential innovators that number 3,456, 264 were non-innovators who could not take up any kind of innovative activity since they were hampered by one factor or another. In Table 4.1, the frequency distribution between being hampered or not is given for each hampering factor. The row totals are 1,221.

Table 4.2: Contribution of various Factors towards Abandoning, Prematurely Stopping, Seriously Slowing Down and Not Starting of at least one R\&D Project

\begin{tabular}{lcccc}
\hline \hline & Abandoned & $\begin{array}{c}\text { Prematurely } \\
\text { Stopped/Abandoned }\end{array}$ & $\begin{array}{c}\text { Seriously } \\
\text { Slowed Down }\end{array}$ & $\begin{array}{c}\text { Did Not } \\
\text { Start }\end{array}$ \\
\hline Financial Constraints & 162 & 135 & 220 & 264 \\
Cost Too High & 203 & 185 & 231 & 266 \\
Economic Risk & 266 & 238 & 275 & 327 \\
Shortage of Personnel & 151 & 113 & 246 & 220 \\
Shortage of Knowledge & 117 & 83 & 195 & 152 \\
Organizational Rigidities & 124 & 100 & 191 & 193 \\
Market Uncertainty & 232 & 187 & 280 & 265 \\
Regulations & 82 & 64 & 110 & 129 \\
Other Factors & 53 & 35 & 107 & 92 \\
\hline
\end{tabular}

Total No. of Firms that reported Abandoning of R\&D Projects: 737

Total No. of Firms that reported Prematurely Stopping/Abandoning of R\&D Projects: 353

Total No. of Firms that reported Seriously Slowing Down of R\&D Projects: 654

Total No. of Firms that reported Not Starting of R\&D Projects: 553 
The frequencies of being hampered are fairly high across all hampering factors. Obviously, firms do not only experience financial constraints. They appear to have been hampered in various ways with costs too high, economic uncertainty and market uncertainty mentioned more often as a hampering factor than financial constraints. Even organizational rigidities are mentioned more frequently to constrain the execution of innovative activities than financial constraints. Economic uncertainty (43.30\% of the firms) and market uncertainty (38.65\%) are the most frequently listed obstacles. Of course, the obstacles are not mutually exclusive. For instance, market and economic uncertainty are likely to be closely related to the occurrence of financial constraints. It is instructive to link the occurrence of hampering factors to consequences regarding the smooth realization of innovation projects. This is done in Table $4.2^{3}$. From Table 4.2 it appears that the various hampering factors lead most frequently to failure of starting a project. Financial constraints, cost considerations and economic uncertainty, organizational rigidities and regulations are the reasons most often mentioned for not starting a project. This finding makes sense as firms are likely not to start projects for which the financing issue has not been resolved, the costs are too high, returns too uncertain, organizational rigidities and regulations are prohibitive. Shortage of personnel, shortage of knowledge, market uncertainty and other factors most frequently lead to seriously slowing down a project. Economic uncertainty and market uncertainty appear to be the leading obstacles for the four types of decisions.

To measure the impact of the obstacles on each of the four decisions ${ }^{4}$ of abandoning $(A B)$, prematurely stopping (ps), seriously slowing down $(S S D)$, or not starting $(N S)$ a project, we use a probit model with sample selection. The first equation models each of these decisions separately for innovative firms. The equation explains the probability that an innovative firm takes one of these four decisions given dummy variables for three types of obstacles, financial constraints $(B F I N)$, economic uncertainty $(B E C)$ and market uncertainty $(B I N F)$, and controlling for firm size $(L S I Z E)$ measured in terms of number of employees. We decided not to include costs too high, shortage of knowledge and shortage of personnel because we felt that they were somehow related to financial constraints. We excluded regulations and other factors because, as shown in Table 4.1, they were relatively minor. However, economic uncertainty and market uncertainty are forward looking and assess the future potential benefits that a firm can receive from undertaking an R\&D project. Hence these factors are about certain fundamentals that affect the firm and its R\&D project. Also included

\footnotetext{
${ }^{3}$ Addition of the figures across the various actions for different types of constraints in Table 4.2 will not lead to the figure of the total number of hampered firms in Table 1 for different types of constraints. The reason is that a firm can have more that one project, and a single constraint can lead to different types of actions for different projects.

${ }^{4}$ The decisions "Abandoning" and "Prematurely stopping" refer to two different questions asked to the firm. While the former refers to a question asked directly to the firm, the later refers to the kind of action taken as a consequence of being faced by a hampering factor.
} 
are sectoral dummy variables for several sectors and an intercept (The results for the sectoral dummies and the intercept are not in Table 4.3). We allow size, economic uncertainty and market uncertainty to be interacted with dummies for being or not being financially constrained (denoted by $-F$ and $-N F$, respectively). For instance, $B E C-F$ is the interaction between the dummy variables of being hampered by economic uncertainty and being financially constrained. The selection equation explains the probability that a firm is an innovator using the following explanatory variables: the logarithm of size, the age of the firm, the market share $(R L S A L E)$, a dummy variable for being a single plant firm $(D-L P)$, dummies for some sectors and an intercept (not reported). The estimation results for each type of action separately for CIS 3.5 data using the maximum likelihood method are given in Table 4.3. Coefficient estimates and their standard-errors are reported in Table 4.3 for the main probit equation and for the selection equation that explains the probability of being an innovator. The number of observations is 10,592 with 3,456 being uncensored (innovators and potential innovators). We also report estimates of $\rho$, the correlation coefficient between the disturbances of the two equations, and its standard-errors. Using the $\chi_{(1)}^{2}$ statistic this coefficient is found to be significantly different from zero. The $\chi_{(15)}^{2}$ statistic tests the joint nullity of the coefficients in the first equation.

The marginal effects for the main probit equation of some of the explanatory variables, evaluated at their means and at $B F I N=1$, and their standard-errors are given in Table 4.4. The marginal effects are in general smaller than the coefficient estimates of the underlying probit equation and fewer marginal effects than coefficients of the probit equation are significant. This is not surprising given that the marginal effects are evaluated at sample means. The findings for the marginal effects basically confirm the conclusions from the estimation results in Table 4.3. The estimation results show clearly that financial constraints, BFIN, have a significant and positive impact on the three probabilities of prematurely stopping, seriously slowing down and not starting a project, but not on that of abandoning a project. Financial constraints affect the least the decision of abandoning a project, which is also what Table 4.2 revealed. This result is also reported with firm data by Savignac (2006) and by Canepa and Stoneman (2002)for a cross-section of 15 European countries from the CIS2 survey.

It is likely that firms that encounter financial constraints for their innovative activities face simultaneously other hampering factors. Therefore, when we allow for different coefficients for these other obstacles depending on whether or not financial obstacles are perceived as constraining, in most cases the other obstacles (economic and market uncertainty) have less of an effect on the timely realization of the innovative projects when financial constraints are present, and this difference has 
Table 4.3: Determinants OF Abandoning ( $A B)$, Prematurely Stopping $(P S)$, Seriously Slowing Down $(S S D)$, and Not Starting $(N S)$ R\&D Projects

\begin{tabular}{lcccc}
\hline \hline & $A B$ & $P S$ & $S S D$ & $N S$ \\
\hline BFIN & 0.385 & $0.918^{* * *}$ & $0.912^{* * *}$ & $1.079^{* * *}$ \\
& $(0.257)$ & $(0.301)$ & $(0.259)$ & $(0.286)$ \\
$B E C-F$ & 0.087 & $0.353^{* * *}$ & $-0.297^{* *}$ & $0.622^{* * *}$ \\
& $(0.135)$ & $(0.135)$ & $(0.132)$ & $(0.146)$ \\
BINF-F & 0.161 & 0.083 & $0.338^{* * *}$ & 0.126 \\
& $(0.132)$ & $(0.124)$ & $(0.13)$ & $(0.142)$ \\
BEC-NF & $0.747^{* * *}$ & $1.291^{* * *}$ & $0.654^{* * *}$ & $1.26^{* * *}$ \\
& $(0.098)$ & $(0.17)$ & $(0.101)$ & $(0.112)$ \\
BINF-NF & $0.593^{* * *}$ & $0.674^{* * *}$ & $1.016^{* * *}$ & $0.733^{* * *}$ \\
& $(0.096)$ & $(0.115)$ & $(0.125)$ & $(0.107)$ \\
LSIZE-F & $0.174^{* * *}$ & 0.049 & 0.071 & $0.133^{* *}$ \\
& $(0.064)$ & $(0.064)$ & $(0.063)$ & $(0.065)$ \\
LSIZE-NF & $0.107^{* *}$ & 0.001 & -0.027 & 0.0003 \\
& $(0.044)$ & $(0.057)$ & $(0.048)$ & $(0.049)$ \\
\hline Selection & & & & \\
\hline$L S I Z E$ & $0.175^{* * *}$ & $0.177^{* * *}$ & $0.179^{* * *}$ & $0.177^{* * *}$ \\
& $(0.014)$ & $(0.014)$ & $(0.014)$ & $(0.014)$ \\
$A G E$ & $-0.003^{* * *}$ & $-0.003^{* * *}$ & $-0.003^{* * *}$ & $-0.003^{* *}$ \\
& $(0.001)$ & $(0.001)$ & $(0.001)$ & $(0.001)$ \\
$R L S A L E$ & $0.083^{* * *}$ & $0.083^{* * *}$ & $0.081^{* * *}$ & $0.082^{* * *}$ \\
& $(0.008)$ & $(0.008)$ & $(0.008)$ & $(0.008)$ \\
$D-L P$ & $-0.053^{*}$ & -0.039 & -0.044 & $-0.047^{*}$ \\
& $(0.027)$ & $(0.028)$ & $(0.027)$ & $(0.028)$ \\
\hline$\rho$ & -0.469 & -0.642 & -0.562 & 0.311 \\
& $(0.147)$ & $(0.158)$ & $(0.18)$ & $(0.253)$ \\
$\chi_{(1)}^{2}: \rho=0$ & 6.33 & 6.01 & 5.11 & 1.16 \\
Prob. & 0.012 & 0.014 & 0.024 & 0.281 \\
$\chi_{(15)}^{2}$ & 251.12 & 368.61 & 537.6 & 849.21 \\
Prob. & 0 & 0 & 0 & 0 \\
\hline & & & &
\end{tabular}


Table 4.4: Marginal Effects of the Explanatory Variables evaluated at their Means and $B F I N=1$ for the Probit Equation

\begin{tabular}{lcccc}
\hline \hline & $A B$ & $P S$ & $S S D$ & $N S$ \\
\hline$B F I N$ & 0.153 & 0.362 & 0.328 & 0.358 \\
$B E C-F$ & $(0.105)$ & $(0.305)$ & $(0.087)$ & $(0.17)$ \\
& 0.034 & 0.139 & -0.107 & 0.206 \\
$B I N F-F$ & $(0.054)$ & $(0.119)$ & $(0.05)$ & $(0.072)$ \\
& 0.064 & 0.033 & 0.122 & 0.042 \\
$B E C-N F$ & $(0.052)$ & $(0.055)$ & $(0.053)$ & $(0.047)$ \\
& 0.297 & 0.509 & 0.236 & 0.418 \\
$B I N F-N F$ & $(0.038)$ & $(0.395)$ & $(0.055)$ & $(0.116)$ \\
& 0.235 & 0.266 & 0.366 & 0.243 \\
LSIZE-F & $(0.038)$ & $(0.208)$ & $(0.079)$ & $(0.075)$ \\
& 0.069 & 0.019 & 0.026 & 0.044 \\
LSIZE-NF & $(0.024)$ & $(0.028)$ & $(0.026)$ & $(0.014)$ \\
& 0.042 & 0 & -0.010 & 0.0001 \\
& $(0.017)$ & $(0.022)$ & $(0.017)$ & $(0.016)$ \\
\hline
\end{tabular}

The figures in the parenthesis are the standard errors of the estimates.

been tested to be significant. It is only when the firm is financially well off that fundamentals such as market uncertainty and market uncertainty become relevant. Financial constraints also matter indirectly by reinforcing the hampering effect of other obstacles. With the exception of the impact of economic uncertainty on the decision to seriously slow down a project, the simultaneous presence of financial and other constraints whenever significant has a positive sign, implying that financial constraints reinforce, or are reinforced by the other constraints. The equations for the four types of decisions have also been estimated jointly by maximum likelihood in an ordered probit model and in a multinomial logit model with sample selection. Our main finding that the effects of financial obstacles and their interactions with market and economic uncertainty are significant and positive is basically confirmed.

\subsection{Review of Empirical Evidence on Financial and other Obstacles to Innovation}

The existence of financial constraints to innovation is frequently studied by examining the sensitivity of R\&D investment to financial factors. Himmelberg and Petersen (1994)find a large and significant relationship between R\&D and internal finance for small US firms in the high-tech industries. Similar results have been obtained by Mulkay et al. (2001) for French and US firms.Bond et al. (2003)find 
that cash flow is not informative about the flow of R\&D for panels of German and UK firms. They interpret their findings as indicating that UK firms face a higher wedge between the cost of external and internal finance than German firms. Actually, Stockdale (2002)reports findings from the third CIS for the UK showing that the presence of financial constraints is the second most important inhibiting factor for innovation active firms, next to high innovation costs. However, Kaplan and Zingales $(1997,2000)$ and Cleary (1999) provide evidence that cash flow sensitivity of investments need not identify liquidity constraints. Cash flow may also be indicative of high demand and expectations of future profits. Several studies have regressed R\&D, innovation activities, and/or innovation output, measured by the share in total sales of the sales of new products, on innovation obstacles. The typical, at first sight, counterintuitive result is that innovation is positively correlated with perceived obstacles. At second thought this result can be explained by the fact that innovating firms are more likely than non-innovating firms to perceive the various obstacles that stand in their way. In other words, the perception of hampering factors is itself endogenous and co-determined by some of the same factors that condition innovation. Corrections for the endogeneity of innovation obstacles has been done in a study on French manufacturing firms by Savignac (2006) and on Dutch firm data by Tiwari et al. (2008). Savignac (2006) reports that for all firms with more than 500 employees and a sample of small business firms $17.25 \%$ of the firms suffer from financing constraints. In the electrical and electronic equipment sector this proportion reaches $30.18 \%$. She estimates that financing constraints reduce by $22 \%$ the probability to implement innovation projects, that the existence of financial constraints on innovation decreases with firm size, and that financing problems also depend on sectors, ex-ante financing structure and past economic performance. Tiwari et al. (2008) using the Dutch CIS3.5 data conclude that financial constraints adversely affect R\&D, and that financial constraints are the major stumbling block in the pursuit of R\&D. They also find that older firms and firms that do belong to a group are less likely to be financially constrained. Using CIS 2 data for European countries, Canepa and Stoneman (2002) find that financial constraints have more of an impact on not starting, delaying or postponing projects than other internal or external hampering factors. Financial constraints are found to matter more in market based systems than in bank based systems (a finding that is in line with that of Bond et al. (2003) for Germany and the UK) and the more the riskier and newer industries are. Both Savignac (2006) and Canepa and Stoneman (2002) confirm our finding reported in Section 4.2 that financial constraints lead less often to the abandonment of projects than to them not being started or being delayed. Another sort of evidence that $R \& D$ is constrained by financing difficulties are the studies conducted in many countries 
about the effectiveness of $R \& D$ tax incentives. In a recent econometric study on the effectiveness of the Dutch WBSO scheme (Wet bevordering speuren ontwikkelingswerk) Lokshin and Mohnen (2007) conclude that the WBSO program has been effective in reducing the user cost of R\&D and therefore successful in stimulating firm R\&D expenditures. According to their results WBSO has the largest impact in the first period after which the effect of the tax incentives declines. They find that the effect is larger for the smaller firms and is smaller for the larger firms. The R\&D additionality of WBSO points to the existence of financial constraints. By lowering the cost of conducting $\mathrm{R} \& \mathrm{D}$, the $\mathrm{R} \& \mathrm{D}$ incentive scheme stimulates additional $\mathrm{R} \& \mathrm{D}$ expenditures by private business firms. Financial constraints as a hampering factor for innovations has been extensively dealt with in the literature. Other obstacles to innovations have received some attention too in the theoretical and empirical literature. For instance, Aghion et al. $(2005,2006)$ provide evidence on the increased beneficial effects of competition and entry respectively on innovative activity in industries close to the technology frontier. Aghion et al. (2006) find positive effects on entry of new firms and their post-entry growth of financial development, regulations affecting start-up costs and regulations on hiring and firing employees. As these other obstacles have been found to have a significant impact on innovative activity, they deserve more attention by researchers.

\subsection{Discussion of the Empirical Findings and of their Policy Impli- cation}

The finding that about $11.52 \%$ of the firms that answered the questionnaire reported to have been hampered in one way or the other and that about $3.8 \%$ reported to have been financially constrained may be reassuring, especially when it is compared to the $17.25 \%$ of firms found by Savignac (2006) to be financially constrained in France. Realizing that almost one out of three innovative or potentially innovative firms (i.e. 1,221 out of 3,456 firms or $35.3 \%$ ) have been hampered and $15.3 \%$ of innovative firms (529 out of 3,456 firms) have been hampered by at least one factor and that the major hampering factors were found to have a significant detrimental impact on decisions of abandoning, prematurely stopping, seriously slowing down or not starting innovative projects (See Table 4.3) should be reason for serious concern. There is even more reason for being concerned when one realizes that these figures might underestimate the true proportions of constrained innovative firms. Reasons for underestimation are the likely higher attrition rate among constrained firms leading to a survivorship bias of unconstrained firms. Another reason might be that because a combination 
of a census of large enterprises (firms with 250 or more employees) and a stratified random sample of small firms is used for the CIS are under represented in the survey. Small firms often face more severe constraints than large enterprises so that figures for the complete survey are not necessarily representative for the population of small firms. To assess the importance of the figures on financial constraints, one has to realize that policy measures have been taken long ago and that venture capital and other forms of private equity have become a major source of financing of innovation activities. Since long tax subsidies are provided through expensing R\&D in many countries, special financing schemes are available for small, innovative enterprises in many countries (e.g. the US SBIR/SBIC programs, financing of patent projects by the Swedish government, see Svensson 2007). Moreover, in the last decade venture capitalists have provided an increasing share of the financing of early stage investment. For instance, Engel and Keilbach (2007) state that between 1995 and 2000 the volume of newly closed deals by venture capital in Germany increased by a factor of 8 , in the years between 2001 and 2004, however, it decreased. Kortum and Lerner (2000) provide evidence that while the ratio of venture capital to R\&D averaged less than 3\% from 1983 to 1992, venture capital may have accounted for $8 \%$ of innovations in the same period. Venture capital provides financing and contributes to reducing the information asymmetry and the moral hazard through active involvement with the enterprise and through increased leverage (see e.g. Kaplan and Stromberg (2000) on the complexity of the venture capital contracts and Gompers (1995) on the structure of staged venture capital investments when agency and monitoring costs exist). Hellmann and Puri (2002) provide evidence for Silicon Valley start-ups that venture capitalists play important roles in the professionalisation of these start-ups over and beyond those of traditional financial intermediaries. However, venture capital is not the panacea. The findings for German firms by Engel and Keilbach (2007), which are somewhat at variance with those of Kortum and Lerner (2000), suggest that the higher innovativeness and growth rates of venture-funded enterprises is due to the selection process by venture capitalists using patent applications as a selection criterion. This would mean that venture capital is not available for firms that are not able to convincingly signal growth perspectives to an external investor by providing patent applications. The importance of patents as signals to attract venture capital is also documented for Quebec biotechnology firms by Niosi et al. (2002). Gompers et al. (2007) document the venture capitalist industry's volatility over the period 1975-1998 and show that its investments are closely tied to valuations in public stock markets, i.e. they increase when signals of public stock markets become favorable. Rates of return on venture capital appear to be highly correlated with those on public stock markets (see also Ljungqvist and Richardson 2003; Cochrane 
2005; Kaplan and Schoar 2005). More generally, as shown by Black and Gilson (1997) and Rajan and Zingales (2001) venture capital works best when there is an active equity market which allows investors to exit by selling their shares. Another policy aspect that has been shown to be important by looking at the responses to the obstacles to innovation is the issue of complementarity of innovation policies, something that is also called "the policy mix" in current discussions in European policy circles. Indeed, as the descriptive statistics reported in Section 4.2 have shown, firms face a number of obstacles in their attempts to innovate. If only one obstacle was important, the problem would be easy to solve, but if various obstacles co-exist, it is necessary to introduce a policy package, taking into account the complementarity and substitution between various policies. In two similar studies examining the joint occurrence of reported innovation obstacles in innovation surveys, Mohnen and Rosa (2002) on Canadian data and Galia and Legros (2004) on French data conclude that many signs exist of complementarity between obstacles, in the sense that obstacles tend to be reported jointly even after controlling for other covariates. Mohnen and Roller (2005) consider the obstacles to innovation as indications of failures or weaknesses in the corresponding innovation policies. They examine whether innovation policies are complements or substitutes in the sense of reinforcing their negative effect on innovation behavior and innovation output. They conclude that the two phases of innovation, i.e. the probability of becoming an innovator and the intensity of innovation, are subject to different constraints. The evidence seems to suggest that substitutability among policies is more often the norm as far as the intensity of innovation is concerned and complementarity as far as making firms innovative is concerned. When it comes to turn non-innovators into innovators, it is important to remove a bunch of obstacles at the same time. Governments should adopt a mix of policies, for instance easing access to finance and allowing firms to cooperate with other firms and technological institutions, or increasing the amount of skilled personnel and reducing the regulatory burden. When it comes to increasing the amount of innovation, one or the other policy will do: easing access to finance, making more skilled labor available, or allowing for more collaborations.

\subsection{Conclusion}

In this chapter we have analyzed the nature and the degree of obstacles, in particular financial constraints, to innovative activity using statistical information from CIS 3.5 for the Netherlands. We have studied the impact on firm decisions to abandoning, prematurely stopping, seriously slowing down or desisting from starting an innovative project as a result from the occurrence of hampering factors. Our analysis leads us to conclude that the constraints faced by innovative firms are important 
and have had a major negative impact on innovative activity. Financial constraints continue to hamper innovative activity despite the fact that the tax treatment of $R \& D$ is favorable to innovations, that there exist programs to support small innovative firms and that the venture capital sector experienced a significant growth over recent decades. Other ways of financing innovations such as business angel finance contribute to mitigate the financing problem of many young, small firms but in terms of size this type of finance is of less importance than venture capital (see Berger and Udell, 1998). Our empirical findings are very much in line with the conclusions by Aghion (2006) about the important beneficial effects on economic growth of the absence of barriers to competition and entry, of spending on education reducing the shortage of qualified labor, of financial development or appropriate fiscal policy providing the required finance to innovative activity and of increased flexibility of labor market and reduction of regulation affecting start-up costs. Hampering factors such as shortage of qualified human resources have received less attention in the innovation literature than financial constraints. This is an unjustified omission which calls for more research into the obstacles to innovative activity and economic growth and also for collecting more refined statistical information on these obstacles and their economic impact. 


\section{5}

\section{Capital Structure, Innovation, and Agency: A Contingent Claim Analysis}

\subsection{Introduction}

Hall (1993,1994), Opler and Titman (1993, 1994), Blass and Yosha (2001), and Alderson and Betker (1996) are some of the papers that provide empirical evidence that R\&D intensive firms are less leveraged than those that are not. More recently, Brown, Fazzari, and Petersen (2009), find similar evidence for a panel of R\&D performing US firms. Brown, Fazzari, and Petersen (2009) draw out a financing hierarchy for $R \& D$ intensive firms, where equity might be preferred to debt as a means of financing R\&D, especially for young firms. Hall and Lerner (2010) argue that although leverage may be a useful tool for reducing agency costs within a firm, it is of limited value for R\&D-intensive firms. Because the knowledge asset created by $R \& D$ investment is intangible, partly embedded in human capital, and ordinarily very specialized to the particular firm in which it resides, the capital structure of R\&D-intensive firms customarily exhibits considerably less leverage than that of other firms. Williamson (1988) points out that "redeployable" assets (that is, assets whose value in an alternative use is almost as high as in their current use) are more suited to the governance structures associated with debt. Titman and Wessels (1988) report that having "unique" assets is associated with lower debt levels. The logic is, first, that consumers will only buy unique products if they are confident that the firm will survive to provide after-sales service. Second, the lack of a secondary market for $R \& D$ and the non-collaterability of $R \& D$ activity mitigates against debt-financed $R \& D$ activity.

Aboody and Lev (2000) find that the extent of information asymmetry associated with R\&D is larger than that associated with tangible (e.g., property, plant, and equipment) and financial investments because of the relative uniqueness (idiosyncrasy) of R\&D. This is because the relative uniqueness of $R \& D$ investments makes it difficult for outsiders to learn about the productivity and 
value of a given firm's R\&D from the performance and products of other firms in the industry, thereby contributing to information asymmetry. Shi (2003) finds evidence that R\&D activity, which increases the market value of equity, also increases bond default risk and debt risk premia. Bond holders, ceteris paribus, may be unwilling to hold the risks associated with greater R\&D activity.

Because of (a) the intangibility and the uniqueness of the assets involved and created, and (b) various sort of uncertainties, such as the technical uncertainty in successfully completing the R\&D project, the uncertainty about the future cash flows from a successfully completed R\&D project, and risk of obsolescence, make R\&D activity a risky venture. Pindyck (1993), Childs and Triantis (1999), Schwartz and Moon (2000), Berk, Green, and Naik (2004) and Miltersen and Schwartz (2004) are some of the papers that study $R \& D$ process as a contingent claim on the value of an underlying asset, which happens to be the present value of the expected cash flows from a successfully completed and implemented R\&D program. Some of these papers, for example Berk, Green, and Naik (2004), incorporate the above mentioned uncertainties in a very comprehensive way. However, these papers either treat the R\&D project in isolation or as "pure growth" firms and not as a project which an existing firm, facing a threat of liquidation, might undertake. Also, these papers do not study the implications of the risk associated with $R \& D$ on the debt valuation of the firm and the attendant agency conflict between the bond holders and the equity holders over R\&D investment policy of the firm.

The aim of the chapter is twin fold:

(I) given bankruptcy costs and limited liability of the equity holders, to explore the sources of potential agency conflict between the bond holders and equity holders that could arise in R\&D investment decision, and

(II) to compare $\mathrm{R} \& \mathrm{D}$ investment to that of scale expansion program which involves employing the existing technology, and which is inefficient as compared to the successfully implemented R\&D output.

Some of the papers that use real-options models to analyze financing and investment decisions of firms are Mello and Parsons (1992), Leland (1994), Mella-Barral and Perraudin (1997), Mella-Barral (1999), Leland (1998), Mauer and Sarkar (2004), Childs, Mauer, and Ott (2005), Lambrecht and Myers (2008), and Egami (2009). These paper differ in their scope and the issues they address. Apart from Lambrecht and Myers (2008) who study the agency problem between managers and stockholders, the central issue studied in these papers is the agency conflict between the bond holders and the stock holders of the firm over investment decisions of the firm. Given bankruptcy costs and 
limited liability the agency problem these papers study is either the problem of risk-shifting or the problem of underinvestment. The investment decision considered in these papers is either that of asset substitution or scale expansion, but not $R \& D$ investment which is risky due to the various kinds of uncertainties mentioned above and due to the fact that in the event of liquidation its intangible asset base is lost.

This chapter studies sequential R\&D investment in a real-option framework. While R\&D could be about developing a new product, the problem we consider in this chapter is $R \& D$ investment for development of a more efficient technology for production, which could either supplement existing operation or subsequently replace it. The problem faced by the firm is first to start the R\&D project and then continue to invest in the project which will be completed at an uncertain date. Starting an $R \& D$ project involves spending a lump sum investment cost. Subsequently, after having started the $\mathrm{R} \& \mathrm{D}$ project, in order to complete the project the firm has to incur additional investment cost. The firm also has the option to mothball the project if the cash flows to be realized from the project are low. Apart from the problem of investing the firm also has the option to liquidate both before and after starting the R\&D project. The problem we study is analogous to the two sided optimal stopping time in Egami (2009).

The model gives results on the maximum amount of default risk-free debt that the firm can sustain before and after starting the $\mathrm{R} \& \mathrm{D}$ project. The maximum amount of default risk-free debt sustainable by the firm, both before and after starting the R\&D project, among other things, is a function of the degree of intangibility of the assets the firm employs to carry on the R\&D project and the intensity of successfully completing the R\&D project.

We find that if the net revenue of the firm at liquidation is positive, or in other words, if the closure value and going-concern value of the firm move together, then the maximum amount of default risk-free debt sustainable before and after starting the R\&D project differ. If the degree of intangibility of the assets employed is high and if the intensity of successfully completing the R\&D project is low, then the maximum amount of default risk-free debt sustainable, after having started the $R \& D$ project, is lower than some debt levels that are deemed safe before starting the $R \& D$ project. This implies that if the firm undertakes R\&D investment, then certain levels of debt, which are deemed safe before starting the $R \& D$ project, turn risky upon starting the $R \& D$ project, with the result that bondholders claim on the firm is reduced once the $R \& D$ project is undertaken. Moreover, in such a situation the equity holders of the firm, protected by limited liability, maximizing their claim overinvest and shift the burden or risk on to the bond holders. On the other hand, if assets 
employed to conduct R\&D involves greater tangibility and if the intensity with which the firm can complete the $\mathrm{R} \& \mathrm{D}$ program is high, then the firm can increase its preexisting default risk-free debt to higher level.

The chapter also compares scale expansion, in which the firm employs the old existing technology, to that of R\&D investment. Scale expansion mainly involves employment of physical assets whose resale value in the event of liquidation is high as compared to intellectual capital employed in R\&D. In comparing the two, we are able to provide some answer to why $R \& D$ is desirable as compared to scale expansion that uses old technology, and yet - as documented in many empirical findings difficult to finance with debt.

The rest of the chapter is organized as follows: Section 2 describes the model, where there is a description of the $R \& D$ project, debt characteristics, the cash flows realized before and after $R \& D$ investment, and the liquidation value of the firm before and after R\&D investment. In Section 3 we discuss equity and firm valuation when before and after $R \& D$ investment and the outcomes in terms of trigger thresholds at which the firm invests and liquidates when the level of outstanding debt is default risk free. Section 4 discusses the valuation and outcomes when debt is risky. Section 5 compares scale expansion to that of R\&D investment and, finally, Section 6 concludes.

\subsection{The Model}

\subsubsection{Description of the R\&D Project}

The growth of the firm comes through a $R \& D$ project the firm wishes to undertake. That is, all discretionary investments of the firm is related to the $R \& D$ project. The $R \& D$ project, generates a stream of stochastic cash flows $\pi x_{t}$ after the firm successfully completes the R\&D project. $\pi$ is the constant revenue parameter and $x_{t}$ represents exogenous demand, which follows a geometric Brownian motion

$$
d x_{t}=\alpha x_{t} d t+\sigma x_{t} d w_{t}
$$

Without loss of generality we assume $\pi$ to be equal to 1 . Since in this chapter we deal with R\&D investment for more efficient technology, the demand $x_{t}$ of the produce from a successfully implemented $\mathrm{R} \& \mathrm{D}$ project is the same as the demand for the output from its existing operation. Consequently, even if the project is not complete the firm can still observe $x_{t}$, the potential cash flows from the $R \& D$ project it wishes to undertake. 
To start the R\&D project, the firm requires an initial investment of $I$. Having started the R\&D project, to successfully complete the project, we assume that an investment cost of $a+b x_{t}$ has to be paid per instant of time. $a$ being the fixed component of the investment cost and $b x_{t}$ the variable component of the cost. $\mathcal{I}(t)$ is the investment decision variable, that takes value 1 if the firm decides to continue with the ongoing $\mathrm{R} \& \mathrm{D}$ project and 0 if it decides to mothball the $\mathrm{R} \& \mathrm{D}$ project. In states of nature when the R\&D project has to be mothballed, the investment costs, $a+b x_{t}$, are not incurred. For sake of simplicity, we assume that there are no maintenance costs involved in maintaining a mothballed $R \& D$ project.

Successfully completing an $R \& D$ project requires time. When the firm is active with the $R \& D$ project, investing $a+b x_{t}$ per unit of time, the firm does not know with certainty when it can successfully complete the R\&D project. We assume, like Miltersen and Schwartz (2004), that the firm will successfully complete the $R \& D$ project at some random date $\tau$, where $\tau$ is exponentially distributed with intensity, $\lambda$, and that the time to completion is independent of the process, $\left\{x_{t}\right\}_{t \in[0, \infty)}$. Hence, the expected time to completion, $T_{p}$ is $1 / \lambda$. After the firm has successfully completed the $\mathrm{R} \& \mathrm{D}$ project at the random date, $\tau$, it has the option to pay a fixed investment cost, $K$, required to implement the project. $\zeta(t)$ is an indicator function indicating whether the R\&D project has been successfully completed or not, that is

$$
\zeta(s)= \begin{cases}1 & \text { if the } \mathrm{R} \& \mathrm{D} \text { project has been completed } \\ 0 & \text { if the } \mathrm{R} \& \mathrm{D} \text { project is still uncompleted }\end{cases}
$$

The initial investment, $I$, needed to start the R\&D project is the amount spent in building a capacity to do research and development. This capacity or the asset, which the firm needs to acquire, comprises both of physical as well as intellectual capital. The extent of intangibility of $I$, though is likely to be high, is also firm and $R \& D$ project specific. Building a capacity to conduct $R \& D$, among other, requires setting up an administrative organization that can ensure smooth functioning of $\mathrm{R} \& \mathrm{D}$ activity and creating mechanisms to monitor the progress of $\mathrm{R} \& \mathrm{D}$ activity. Moreover, there are adjustment costs involved in hiring scientific personnel and staff. By spending resources on the above mentioned activities the firm is able to earn intellectual capital, in form of ideas and knowledge of scientists and engineers, required for R\&D activity. Now, it is well known that the second hand market for intangibles is fraught with friction and generally do not exist. Hence, after having invested the amount $I$, if the firm liquidates itself, only a fraction of $I$ can be recouped, which can be very low. We denote this fraction as $f$. The lower $f$ is, higher is the intangibility of $I$. This is one reason 
that makes R\&D activity a risky venture.

The second reason why $R \& D$ activity is risky is because of the uncertainty involved in successfully completing the R\&D program. Following Miltersen and Schwartz (2004), we have modelled the interarrival time of success in R\&D activity as a Poisson Process with parameter $\lambda$. This implies that both the expected time, $T_{p}$, at which success can be realized as well as the variance of that time increases as $\lambda$ becomes low. Thus, if expected time to complete the R\&D project is large, it might happen that before successfully completing the project, the firm may experience a down fall in the cash flows, forcing it to liquidate, during which it stands to loose a large fraction of $I$.

\subsubsection{Income/Cash Flows of the Firm and Firm Valuation}

Assume that the owner of the firm in question derives an income/cash flow of $\psi x_{t}$, where $\psi$ is strictly less than $\pi=1$, and $x_{t}$ follows the Brownian motion described above. We can assume that $\psi$ is a constant revenue parameter and $x_{t}$ represents exogenous demand ${ }^{1}$. Hence, if the owner of the firm manages to be successful in its $R \& D$ endeavor and manages to implement the R\&D project, it receives a cash flow of $(\psi+1) x_{t}$ per instant of time.

Let $V^{b}\left(x_{t}\right)$ be the present value at time, $t$, of the cash flows from the operation that yields a cash flow of $\psi x_{t}$ per instant of time, and $V^{p}\left(x_{\tau}\right)$ the present value of the cash flows from the R\&D project after it has been successfully completed at the random date $\tau$. To obtain the values $V^{b}\left(x_{t}\right)$ and $V^{p}\left(x_{\tau}\right)$, consider an asset or dynamic portfolio of assets that is perfectly correlated with $x$. Let $p$ be the price of this asset or dynamic portfolio of assets, where $p$ follows a geometric Brownian motion, given by

$$
d p_{t}=\alpha_{p} p_{t} d t+\sigma p_{t} d w_{t}
$$

Now, according to CAPM $\alpha_{p}$ should reflect the asset's systematic risk. Hence $\alpha_{p}$ is given by

$$
\alpha_{p}=r+\phi \sigma \rho_{p m}
$$

where $r$ is the risk-free rate of return, $\rho_{p m}$ is the coefficient of correlation between $p$ the price of the asset or the dynamic portfolio of assets that tracks $x$ and the market portfolio, and $\phi$ is the market price of risk. Assume that $\alpha_{p}>\alpha$. Let $\rho_{x m}$ be the coefficient of correlation between $x$ and the market

\footnotetext{
${ }^{1}$ There could be a fixed cost, $f$, incurred while reaping a revenue of $\psi x_{t}$ per instant of time. If only to keep the algebra simple we normalize it to zero.
} 
portfolio. Since $x$ is perfectly correlated with $p$ we have $\rho_{x m}=\rho_{p m}$. Since no one would be willing to hold $x$, unless $\delta=\left(\alpha_{p}-\alpha\right)>0$, accrues as some kind of dividend ${ }^{2}$ for holding $x$ or convenience yield on $x$. The risk adjusted rate of return on the cash flows, $x$, defined as $\mu$, is given by

$$
\mu=\alpha-\phi \sigma \rho_{x m}
$$

then

$$
\mu=\alpha-\phi \sigma \rho_{x m}=r-\left[\left(r+\phi \sigma \rho_{x m}\right)-\alpha\right]=r-\left[\alpha_{p}-\alpha\right]=r-\delta
$$

The present value, $V^{b}\left(x_{t}\right)$, of the expected cash flows from the operation that yields a cash flow of $\psi x_{t}$ per instant of time is then given by:

$$
V^{b}\left(x_{t}\right)=\int_{t}^{\infty} E_{t}\left(\psi x_{s}\right) e^{-\alpha_{p} s} d s=\int_{t}^{\infty} \psi_{1} x_{t} e^{\alpha s} e^{-\alpha_{p} s} d s=\frac{\psi_{1} x_{t}}{\alpha_{p}-\alpha}=\frac{\psi_{1} x_{t}}{r-\mu}
$$

The value of the $R \& D$ project after it has been successfully completed at the random date $\tau$ is given by:

$$
V^{p}\left(x_{\tau}\right)=\int_{\tau}^{\infty} E_{\tau}\left(x_{s}\right) e^{-\alpha_{p} s} d s=\int_{\tau}^{\infty} x_{\tau} e^{\alpha s} e^{-\alpha_{p} s} d s=\frac{x_{\tau}}{\alpha_{p}-\alpha}=\frac{x_{\tau}}{r-\mu}
$$

Since the firm has option to pay final (fixed) investment costs $K$ in order to obtain the present value of $V^{p}\left(x_{\tau}\right)$ at the random completion date, $\tau$, the value of firm's cash flows, $V^{a}\left(x_{\tau}\right)$, after successfully completing the $\mathrm{R} \& \mathrm{D}$ project at $\tau$ is given by

$$
V^{a}\left(x_{\tau}\right)=V^{b}\left(x_{\tau}\right)+\max \left\{0, V^{p}\left(x_{\tau}\right)-K\right\}
$$

\subsubsection{Debt Characteristic}

Assume that the firm has issued perpetual debt with principal $D$ and debt service $r D$. The market value of the debt is $B(x)$. When the debt is default risk-free, $B(x)=D$. The values of the levered firm and the levered equity are $V(x)$ and $E(x)$, where the value of the equity is given by the identity: $E(x)=V(x)-B(x)$. In our setup shareholders are also the managers of the firm. The firm or the borrowers cannot extract concessions from the banks or bondholders, so that lenders get the full

\footnotetext{
${ }^{2}$ Note that the economy has an asset or a portfolio of assets, $p$, which has the same volatility, $\sigma$, as $x$ but has a higher return, $\alpha_{p}$, than $\alpha$, the return on $x$.
} 
debt service $r D$ as long as the firm continues as a going concern. Failure to service the debt allows lenders to take over. Lenders are willing to advance financing only if they have property rights to the firm's assets when it defaults. Their property rights can be protected by laws against fraudulent conveyance and by covenants. We assume these laws and covenants are effective and that lenders are protected against purely dilutive debt issues.

We assume that debt covenants prohibit distribution of collateral or the proceeds of additional debt issues to shareholders, unless existing lenders are compensated for any decrease in the value of their claims. This assumption does not prevent risky debt issues if the proceeds are invested or if existing lenders are made whole. It does rule out liquidating dividends that would distribute the value of the firm's assets to managers or shareholders. The assumption also prevents the firm's from piling on additional debt if the only motive is to harm existing lenders.

\subsubsection{Liquidation}

Now, at any instant when the firm is operating, if it realizes that the profits from the current operation is not sufficient, it might want to liquidate the firm. Although the set of physical assets could be operated forever, the firm has the alternative to abandon operations and sell these assets. That is, usually a set of physical assets has worthwhile alternative uses in the hands of competitors. This is because the assets of the firm in the hands of other market participants could yield an alternative period income flow. At any time these alternative uses determine competitors' willingness to pay for the firm's assets. To simplify, as in Mella-Barall (1999), we consider that partial asset sales destroy existing economies of scale. If a fraction of the assets of the firm are sold, the remaining income flow from operations is reduced by more than this fraction. Therefore, gradually selling the assets through a sequence of auctions is not profitable, and the assets of the firm are best sold simultaneously. Selling the assets is an irreversible decision, so that when the incumbents decide to do so, they essentially liquidate the firm. Overall, once it is constituted, the firm consists of a set of physical assets which (i) are currently operated but (ii) could alternatively be irreversibly liquidated.

The value of the firm at closure, after it has embarked on the R\&D project but before successful realization of the $\mathrm{R} \& \mathrm{D}$ endeavor is given by $\phi_{0}+\frac{\phi_{1} x}{r-\mu}$, where $\phi_{1}<\psi, \phi_{0}=\phi_{f}+\phi_{p}$ and $\phi_{p}=f I . \phi_{f}$ is the constant liquidation value at closure that results from that operation of the firm, which yields $\psi x_{t}$ per unit instant of time and $\phi_{p}$ is the constant liquidation value at closure accruing from the $\mathrm{R} \& \mathrm{D}$ investment project. $\phi_{p}$ is assumed to be a fraction, $f$, of the initial investment, $I$, required to embark upon the project. If the firm liquidates itself prior to the starting of the R\&D project, then 
its value at liquidation is given by $\phi_{f}+\frac{\phi_{1} x}{r-\mu}$.

The restriction $\phi_{1}<\psi$ is necessary for the existence of a unique optimal closure threshold. If $\phi_{1}=0$, value at closure is constant and there is no link between closure value and the demand variable $x$ that drives the value of the going concern. This could be thought of as the liquidation case, where assets are sold off piecemeal and scrapped or put to entirely new uses. If $\phi_{1}>0$, closure value and going-concern value move together. This is plausible if, say, the assets are used to produce a different product in the same industry, or if the values of all assets depend on some common macroeconomic factor. $f$, the fraction of the firm's initial investment, $I$, that can be recouped in the event of liquidation is a function of the degree of intangibility of the assets $I$. If the extent of intangibility involved is high, as is likely to the case in R\&D investment, then the fraction $f$ is likely to be low. As we will see, if $f$ is high then the firm is able to borrow more. This is due to the fact that a large part of the asset, $I$, can be recaptured by lenders in liquidation states. However, if $f$ is low and if $\phi_{1}>0$, then existing debt levels that are deemed safe before the starting of the R\&D project can potentially turn risky.

\subsection{Valuation of the Levered Firm: Valuation when Debt is Safe}

\subsubsection{Mothballing and Resuming of the R\&D Project: The Switching Problem}

Assume that firm has already embarked upon the R\&D project by paying a lump sum cost $I$, and that it has debt in place, that has a principal value of $D_{s w}$. Assume that the firm's managers are also the shareholders, and that they maximize their equity. Since the investment project can be switched from an active investment phase to a passive investment phase and vise-versa, the owner of the investment project can temporarily suspend investing in the project and mothball the R\&D investment project. When the investment project is suspended, both the on-going investment costs rate, $a+b x_{t}$, and the intensity of completion, $\lambda$, switch to zero. For simplicity, we assume that there are no costs involved in keeping the project alive in a mothballed state. Clearly, in this model it would never be optimal to abandon the investment project since there are no costs of keeping alive the $\mathrm{R} \& \mathrm{D}$ project in a passive state.

Given the above, the value of the firm's Equity is given by the solution to the following stochastic control problem: 


$$
\begin{aligned}
E\left(x_{t}\right) & =\sup _{\mathcal{I}(s), \mathcal{L}(s), \mathrm{I}(\mathrm{s}) \in\{0,1\}, s \in(t, T)} \mathbb{E}_{t}^{Q}\left\{\int _ { t } ^ { T } e ^ { - r ( s - t ) } \left[( 1 - \mathcal { L } ( s ) ) \left[(1-\zeta(s))\left(\psi x_{s}-r D_{s w}-\mathcal{I}(s)\left(a+b x_{s}\right)\right)\right.\right.\right. \\
& \left.\left.\left.+\mathrm{I}(\mathrm{s}) \zeta(s)\left(\psi x_{s}+x_{s}-r K-r D_{s w}\right)\right]+\mathcal{L}(s)\left[\max \left\{0,\left(r \phi_{0}+\phi_{1} x_{s}-r D_{s w}\right)\right\}\right]\right] d s+e^{-r(T-t)} E\left(x_{T}\right)\right\},
\end{aligned}
$$

where $T$ is an arbitrary point in the future, $\mathbb{E}^{Q}$ is the expectation under the risk-neutral measure $Q$. $\zeta(s)$ is an indicator variable that takes value 1 if the firm successfully completes its R\&D project and 0 otherwise. $\mathcal{I}(s), \mathcal{L}(s)$, and $\mathrm{I}(\mathrm{s})$ respectively, are defined as follows

$$
\begin{gathered}
\mathcal{I}(s)= \begin{cases}1 & \text { is the decision to continue } \backslash \text { invest } \\
0 & \text { is the decision to mothball the project }\end{cases} \\
\mathcal{L}(s)= \begin{cases}1 & \text { is the decision to liquidate } \\
0 & \text { is the decision to continue }\end{cases}
\end{gathered}
$$

and $\mathrm{I}(\mathrm{s})$ is defined as

$$
I(s)=\left\{\begin{aligned}
1 & \text { if the firm decides to pay the fixed investment cost, } K, \\
& \text { required to implement the completed project } \\
0 & \text { if the firm decides to discard the completed project. }
\end{aligned}\right.
$$

$\psi x_{s}-r D_{s w}-\left(a+b x_{s}\right)$ in the above expression is the net revenue of the firm if the firm decides to invest in the project that it has embarked upon. $r D_{s w}$ is the amount paid out to the creditors per instant of time. If no debt restructuring were to take place at the time of the implementation of the $\mathrm{R} \& \mathrm{D}$ project, then debt service after implementation of the project remains $r D_{s w}$. In such a case, $\psi x_{s}+x_{s}-r K-r D_{s w}$, in the above expression is the net flow of revenue per instant of time after the implementation of the successfully completed R\&D project.

In the control problem we study, we do not consider the possibility of liquidation after the firm has successfully completed its $R \& D$ project and implemented the outcome of the project to reap the additional cash flows. We assume that the firm continues indefinitely after implementation ${ }^{3}$.

\footnotetext{
${ }^{3}$ Liquidating the firm after the firm has successfully completed and implemented the R\&D project is uninteresting and does not present any new insights. Liquidation after the firm has successfully completed and implemented the $\mathrm{R} \& \mathrm{D}$ project requires, respectively, the following value matching and smooth pasting conditions

$$
C x^{\theta}+\frac{x(1+\psi)}{r-\mu}-D_{s w}=\phi_{0}^{\prime}+\frac{\phi_{1}^{\prime} x_{l}}{r-\mu}-D_{s w}
$$
}


Now, we know that the firm always has the option to mothball the project, which it can do without incurring any cost, if it knows that the project will finish out of the money, and that the firm will be active, investing $a+b x_{t}$ at every instant $t$, when the $\mathrm{R} \& \mathrm{D}$ investment project finishes in the money, that is, when $E^{p}\left(x_{\tau}\right)=V^{p}\left(x_{\tau}\right)-D_{s w}>K$. This implies that the firm never abandons the R\&D project, and that, when the firm is active, it always pay the strike price, $K$, to implement the $\mathrm{R} \& \mathrm{D}$ project that it successfully completes with intensity $\lambda$. Hence, the investment decision, $\mathrm{I}(\mathrm{s})$, becomes redundant and the control problem can be written as follows:

$$
\begin{aligned}
E\left(x_{t}\right)=\sup _{\mathcal{I}(s), \mathcal{L}(s) \in\{0,1\}, s \in(t, T)} & \mathbb{E}_{t}^{Q}\left\{\int _ { t } ^ { T } e ^ { - r ( s - t ) } \left[(1-\mathcal{L}(s))\left(\psi x_{s}-r D_{s w}-\mathcal{I}(s)\left(a+b x_{s}\right)\right)\right.\right. \\
& \left.\left.+\mathcal{L}(s)\left[\max \left\{0,\left(r \phi_{0}+\phi_{1} x_{s}-r D_{s w}\right)\right\}\right]\right] d s+e^{-r(T-t)} E\left(x_{T}\right)\right\}
\end{aligned}
$$

Thus, in the above optimization problem, the only two decision that the owners of the firm have to take are, (1) whether to invest $a+b x_{t}$ at time period $t$ and (2) whether to liquidate the firm or not. The Hamilton-Jacobi-Bellman equation ${ }^{4}$ corresponding to the above problem is given by

$$
\begin{array}{r}
\frac{1}{2} x^{2} \sigma^{2} E_{x x}\left(x_{s}\right)+\mu x E_{x}\left(x_{s}\right)-r E\left(x_{s}\right)+ \\
\sup _{\mathcal{I}(s), \mathcal{L}(s) \in\{0,1\}}\left\{(1-\mathcal{L}(s)) \mathcal{I}(s)\left\{\lambda\left(\left[E^{a}\left(x_{s}\right)-K\right]-E\left(x_{s}\right)\right)+\psi x_{s}-\left(a+b x_{s}\right)-r D_{s w}\right\}+\right. \\
\left.\mathcal{L}(s)\left[\max \left\{0,\left(r \phi_{0}+\phi_{1} x(s)-r D_{s w}\right)\right\}\right]\right\}=0
\end{array}
$$

where $E^{a}\left(x_{s}\right)-K=\left(V^{a}\left(x_{s}\right)-D_{s w}\right)-K$, is the value of the firm's equity after the completion of the project minus the fixed cost (strike price) to implement the project and is equal to the present value of the perpetual income flow of $\psi x_{s}+x_{s}-r K$.

Assume that the firm is still in the hands of the owners of the firm. Now, the firm's ex post optimal liquidation trigger level of exogenous demand $x_{t}$, which we denote by $x_{l}$, is essentially a point, such that, if $x_{t}$ falls below $x_{l}$ then it is optimal for the firm to irreversibly exchange their current claim for their residual one: $\max \left\{0,\left(\phi_{0}+\frac{\phi_{1} x_{l}}{r-\mu}-D_{s w}\right)\right\}$. The maximum between 0 and

$$
\theta C x^{\theta-1}+\frac{1+\psi}{r-\mu}=\frac{\phi_{1}^{\prime}}{r-\mu}
$$

to hold when debt is safe. Assuming $\phi_{0}^{\prime} \geq \phi_{0}$ and $\phi_{1}^{\prime} \geq \phi_{1}$ reflects the fact that the constant liquidation value and the value of the firm as a going concern at liquidation might be higher after the firm has successfully completed and implemented its R\&D project. Not to mention, $C x^{\theta}$ is the value of the option of the firm to liquidate it self. Liquidation after implementing the $\mathrm{R} \& \mathrm{D}$ project when debt is risky requires, $C x^{\theta}+\frac{x(1+\psi)}{r-\mu}-D_{s w}=0$ and $\theta C x^{\theta-1}+\frac{1+\psi}{r-\mu}=0$, and the valuation of risky debt.

${ }^{4}$ The derivation of the Hamilton-Jacobi-Bellman equation is provided in Appendix 1. 
$\phi_{0}+\frac{\phi_{1} x_{l}}{r-\mu}-D_{s w}$ ensures that there are no violations of limited liability of the shareholders. Since here we are assuming that the debt level, $D_{s w}$, is default risk-free, in the event of liquidation, $\max \left\{0,\left(\phi_{0}+\frac{\phi_{1} x_{l}}{r-\mu}-D_{s w}\right)\right\}=\phi_{0}+\frac{\phi_{1} x_{l}}{r-\mu}-D_{s w}$. Thus, the maximum level of debt, such that, $D_{s w}$ is default risk-free is, $D_{s w}^{*}=\phi_{0}+\frac{\phi_{1} x_{l}}{r-\mu}$.

At time $t$, conditional on $\mathcal{L}(s)=0$, or in other words when $x_{t}>x_{l}$, the value of the control that maximizes equation (11) is either $\mathcal{I}(s)=1$ or $\mathcal{I}(s)=0$. When the R\&D investment project is in a passive state there is no possibility of completion, therefore, there will be a threshold level, $x^{*}$, such that, if the exogenous demand, $x_{t}$, is above this threshold at a certain date, then it would be optimal for the firm to resume the R\&D project, and if $x_{t}$ is below $x^{*}$, then it is optimal for the firm to remain in the passive state at that date. Since there are no costs involved in maintaining the $R \& D$ project in the passive state, the threshold level at which the firm resumes with the $R \& D$ project and the threshold level at which it mothballs the project coincide. In the region where the firm does not invest, $\mathcal{I}(s)=0$, that is, when the firm mothballs the R\&D project, the evolution of the value is driven entirely by the dynamics of $x_{t}$. Define $E_{m}(x)$ as the value of the firm's equity in the "mothball region".

In the region in which the firm chooses to invest, $\mathcal{I}(s)=1$, which we will call the "continuation region", the terms that capture the consequences of investment must be included. With probability $\lambda$, over the next instant the firm will achieve a technical breakthrough and the value of the firm's equity will jump from $E_{c}(x)$ to $E^{a}(x)-K$, where $E_{c}(x)$ is the value of the firm's equity in the continuation region. Thus the value of the firm's equity in the various regions implied by the thresholds $x_{l}$ and $x^{*}$ can be written as

$$
E(x)= \begin{cases}E_{c}(x) & \text { if } x \geq x^{*}: \zeta(s)=0, \mathcal{L}(s)=0, \mathcal{I}(s)=1 \\ E_{m}(x) & \text { if } x_{l}<x<x^{*}: \zeta(s)=0, \mathcal{L}(s)=0, \mathcal{I}(s)=0 \\ E_{l}(x) & \text { if } x \leq x_{l}: \zeta(s)=0, \mathcal{L}(s)=1, \mathcal{I}(s)=0\end{cases}
$$

where $E_{l}(x)$ is the residual claim of the owners after liquidation. The above implies that the value of the firm's equity in the continuation region, the mothball region and after liquidation, respectively 
satisfy the following set of differential equations:

$$
\begin{gathered}
\frac{1}{2} x^{2} \sigma^{2} E_{c_{x x}}(x)+\mu x E_{c_{x}}(x)-r E_{c}(x)+\lambda\left(\frac{x}{r-\mu}-K+\frac{\psi x}{r-\mu}-E_{c}(x)-D_{s w}\right)+ \\
\psi x-(a+b x)-r D_{s w}=0 \text { if } x \geq x^{*}, \\
\frac{1}{2} x^{2} \sigma^{2} E_{m_{x x}}(x)+\mu x E_{m_{x}}(x)-r E_{m}(x)+\psi x-r D_{s w}=0 \text { if } x_{l} \leq x \leq x^{*},
\end{gathered}
$$

and

$$
\frac{1}{2} x^{2} \sigma^{2} E_{l_{x x}}(x)+\mu x E_{l_{x}}(x)-r E_{l}(x)+\max \left\{0,\left(r \phi_{0}+\phi_{1} x-r D_{s w}\right)\right\}=0 \text { if } x \leq x_{l} .
$$

Equation (2-4) describes the value of the investment project when it is active. Since we know that the investment project would be in the money when it is active, this equation reflects the fact that with intensity $\lambda$, the value of the investment project would jump to the completion value, $E^{a}(x)-K=\left(V^{a}(x)-D_{s w}\right)-K^{5}$. At the same time, at completion, the firm looses $E_{c}(x)$, the value of the firm in the continuation region, an inevitable consequence of completion. The term $\psi x-(a+b x)-r D_{s w}$ reflects the fact that the owner earns $\psi x$ per instant of time, pays an investment costs at the rate $a+b x$ per unit of time, and services debt of the amount $r D_{s w}$. Equation (2-5) describes the value of the investment project when it is passive. This equation reflects the fact that as long as the investment project is passive, i.e., $\mathcal{I}(s)=0$ there is no chance that the project will be completed, i.e., $\lambda=0$.

Debt is safe or default risk-free if the value of the firm at liquidation is more than or equal to the value of debt principal at closure, that is, if $\phi_{0}+\frac{\phi_{1} x_{l}}{r-\mu}-D_{s w} \geq 0$. Thus for safe debt, equation (2-6) becomes

$$
\frac{1}{2} x^{2} \sigma^{2} E_{l_{x x}}(x)+\mu x E_{l_{x}}(x)-r E_{l}(x)+r \phi_{0}+\phi_{1} x-r D_{s w}=0 \text { if } x \leq x_{l}
$$

The above equations, (2-4), (2-5), and (2-6), are $2^{\text {nd }}$ order Non-Homogeneous Cauchy Euler differ-

\footnotetext{
${ }^{5}$ Though we have postulated that the value of the equity after the implementation of the successfully completed project is $E^{a}(x)=\frac{(\psi+1) x}{r-\mu}-D_{s w}$, ideally this value should be $C x^{\theta}+\frac{(\psi+1) x}{r-\mu}-D_{s w}$ in case of safe debt as was alluded in Footnote $3, C x^{\theta}$, being the value of the option to liquidate the firm after implementation. In case of risky debt the value of equity after the implementation of the completed $\mathrm{R} \& \mathrm{D}$ project is $E^{a}(x)=C x^{\theta}+\frac{(\psi+1) x}{r-\mu}-B(x), B(x)$ being the value of debt after implementation. However, if only to keep matters simple, we abstain from the issue of liquidation and default after the implementation of the successfully completed R\&D project and assume that firm operates indefinitely after implementation. This assumption also implies that debt, which might be risky during the completion of the R\&D project, is no longer risky after implementation and has a value of $D_{s w}$.
} 
ential equations. The solution to (2-4) is given by:

$$
C_{1 c} x^{\kappa}+C_{2 c} x^{\gamma}+\frac{\psi x}{r-\mu}+\frac{\lambda x}{(r-\mu)(\lambda+r-\mu)}-\frac{\lambda K}{\lambda+r}-\frac{b x}{\lambda+r-\mu}-\frac{a}{\lambda+r}-D_{s w},
$$

where $\kappa$ and $\gamma$ are the roots of the characteristic polynomial,

$$
\frac{1}{2} \sigma^{2} \eta^{2}+\left[\mu-\frac{1}{2} \sigma^{2}\right] \eta-(r+\lambda)=0
$$

As it turns out, $\kappa=\frac{-\left[\mu-\frac{1}{2} \sigma^{2}\right]+\left\{\left[\mu-\frac{1}{2} \sigma^{2}\right]^{2}+2 \sigma^{2}(r+\lambda)\right\}^{1 / 2}}{\sigma^{2}}>1$, and $\gamma=\frac{-\left[\mu-\frac{1}{2} \sigma^{2}\right]-\left\{\left[\mu-\frac{1}{2} \sigma^{2}\right]^{2}+2 \sigma^{2}(r+\lambda)\right\}^{1 / 2}}{\sigma^{2}}<0$.

The solutions to (2-5) and (2-7) respectively are given by:

$$
\begin{gathered}
C_{1 m} x^{\beta}+C_{2 m} x^{\theta}+\frac{\psi x}{r-\mu}-D_{s w} \\
C_{1 l} x^{\beta}+C_{2 l} x^{\theta}+\phi_{0}+\frac{\phi_{1} x}{r-\mu}-D_{s w},
\end{gathered}
$$

where $\beta$ and $\theta$ are the roots of the characteristic polynomial,

$$
\begin{gathered}
\frac{1}{2} \sigma^{2} \eta^{2}+\left[\mu-\frac{1}{2} \sigma^{2}\right] \eta-r=0 . \\
\beta=\frac{-\left[\mu-\frac{1}{2} \sigma^{2}\right]+\left\{\left[\mu-\frac{1}{2} \sigma^{2}\right]^{2}+2 \sigma^{2} r\right\}^{1 / 2}}{\sigma^{2}}>1, \text { and } \theta=\frac{-\left[\mu-\frac{1}{2} \sigma^{2}\right]-\left\{\left[\mu-\frac{1}{2} \sigma^{2}\right]^{2}+2 \sigma^{2} r\right\}^{1 / 2}}{\sigma^{2}}<0 .
\end{gathered}
$$

Thus, we are left with the constants, $C_{1 c}, C_{2 c}, C_{1 m}, C_{2 m}, C_{1 l}$, and $C_{2 l}$ and the two threshold level of exogenous demand or the free boundaries, $x^{*}$ and $x_{l}$, which we determine using boundary conditions. The first boundary condition that we consider is the following:

$$
\lim _{x \rightarrow \infty} E(x) \propto x
$$

Now, it might happen that as $x \rightarrow \infty$, then people might value the asset, above its fundamentals if they expect to be able to resell it later at a sufficient capital gain. Equation (2-11) precisely rules out such speculative bubbles as $x \rightarrow \infty$. The boundary condition in (2-11) in particular is pertinent to value of equity in the continuation region, $E_{c}(x)$. We know that the solution to the differential equation applicable to the continuation region is given by (2-8). Since, $\kappa>1$, therefore we require 
that $C_{1 c}=0$, else we will face a violation of the boundary condition $(2-11)$. Thus

$$
E_{c}(x)=C_{2 c} x^{\gamma}+\frac{\psi x}{r-\mu}+\frac{\lambda x}{(r-\mu)(\lambda+r-\mu)}-\frac{\lambda K}{\lambda+r}-\frac{b x}{\lambda+r-\mu}-\frac{a}{\lambda+r}-D_{s w},
$$

where $C_{2 c} x^{\gamma}$ is the value of the option to mothball the project and $\frac{\psi x}{r-\mu}+\frac{\lambda x}{(r-\mu)(\lambda+r-\mu)}-\frac{\lambda K}{\lambda+r}-\frac{b x}{\lambda+r-\mu}-$ $\frac{a}{\lambda+r}$ is value of the firm's equity to continue forever without the option to mothball the project.

Since $E_{m}(x)$ is the value of the firm's equity when it is not actively engaged in R\&D investment, hence $E_{m}(x)$ constitutes of the value of the option for the firm to invest $a+b x_{t}$, and the value of the option to close all operations and liquidate the firm. Also, since $E_{m}(x)$ is the value of the firm in the mothball region, that is, when $x$ lies between $x^{*}$ and $x_{l}$, and since the boundaries $x^{*}$ and $x_{l}$ are positive and finite, $C_{1 m}$ and $C_{2 m}$ are both non zero. Since the firm receives as cash flow of $\psi x_{t}$ per instant of time from its existing operation, $\frac{\psi x}{r-\mu}$ is the claim on, or the value of the firm arising out of the cash flow of $\psi x_{t}$. Hence,

$$
E_{m}(x)=C_{1 m} x^{\beta}+C_{2 m} x^{\theta}+\frac{\psi x}{r-\mu}-D_{s w} .
$$

Now, we know that the value of the firm's equity at liquidation, $E_{l}\left(x_{l}\right)$, satisfies the following condition:

$$
E_{l}\left(x_{l}\right)=C_{1 l} x_{l}^{\beta}+C_{2 l} x_{l}^{\theta}+\phi_{0}+\frac{\phi_{1} x_{l}}{r-\mu}-D_{s w}=\phi_{0}+\frac{\phi_{1} x_{l}}{r-\mu}-D_{s w} .
$$

Hence, the above implies that $C_{1 l}=C_{2 l}=0^{6}$. Thus, we have

$$
E_{l}(x)=\phi_{0}+\frac{\phi_{1} x}{r-\mu}-D_{s w}
$$

Thus we are left with five unknowns $C_{2 c}, C_{1 m}, C_{2 m}, x^{*}$, and $x_{l}$. These can be determine by two value matching, two smooth pasting, and a super contact condition. The value matching conditions, (2-16) and (2-17), respectively reflect the fact that the value function should be continuous respectively at the switching point, $x^{*}$, where the differential equations (2-4) and (2-5) meet, and at the liquidation point, $x_{l}$, where the differential equations (2-5) and (2-7) meet.

$$
E_{m}\left(x^{*}\right)=E_{c}\left(x^{*}\right)
$$

\footnotetext{
${ }^{6}$ Proof: Suppose that $C_{1 l} \neq C_{2 l} \neq 0$, then $\frac{C_{1 l}}{C_{2 l}}=-x^{\theta-\beta} \forall x$. Since $\theta \neq \beta$, this implies that $\frac{C_{1 l}}{C_{2 l}}$ is not constant, a contradiction.
} 


$$
E_{l}\left(x_{l}\right)=E_{m}\left(x_{l}\right)
$$

The smooth pasting conditions, (2-18) and (2-19)

$$
\begin{aligned}
& \frac{\partial E_{m}\left(x^{*}\right)}{\partial x}=\frac{\partial E_{c}\left(x^{*}\right)}{\partial x} \\
& \frac{\partial E_{l}\left(x_{l}\right)}{\partial x}=\frac{\partial E_{m}\left(x_{l}\right)}{\partial x},
\end{aligned}
$$

respectively reflect the fact that the value function should be differentiable respectively at the switching point, $x^{*}$, and at the liquidation point, $x_{l}$. Equation $(2-20)$ is the super contact condition.

$$
\frac{\partial^{2} E_{m}\left(x^{*}\right)}{\partial x^{2}}=\frac{\partial^{2} E_{c}\left(x^{*}\right)}{\partial x^{2}}
$$

The condition is based on the following instantaneous trade-off argument,

$$
\lambda\left(\frac{x^{*}}{r-\mu}-K\right)=\lambda E_{c}^{p}\left(x^{*}\right)+\left(a+b x^{*}\right)
$$

where $E_{c}^{p}\left(x^{*}\right)=\left[E_{c}\left(x^{*}\right)-\left(\frac{\psi x^{*}}{r-\mu}-D_{s w}\right)\right]$ is the value of the $\mathrm{R} \& \mathrm{D}$ investment project in the continuation region. This value is equal to the value of the equity in the continuation region, $E_{c}\left(x^{*}\right)$, less the value of the equity that accrues from its exiting operation, $\frac{\psi x^{*}}{r-\mu}-D_{s w}$. The left hand side of the equation (2-21) is the increased instantaneous benefits from switching from a passive state to an active state. The instantaneous benefit is the increased intensity of completion which has a value flow of $\lambda\left(\frac{x^{*}}{r-\mu}-K\right)$ per unit of time. The right hand side is the increased instantaneous costs of switching and comprises of: (i) the increased intensity of loosing the investment project (an inevitable consequence of completion), which has a flow value of $\lambda E_{c}^{p}\left(x^{*}\right)=\lambda\left[E_{c}\left(x^{*}\right)-\left(\frac{\psi x^{*}}{r-\mu}-D_{s w}\right)\right]$ per unit of time and (ii) the increased on-going investment costs at the rate $\left(a+b x^{*}\right)$ per unit of time. Substituting the value of $\lambda\left(\frac{x^{*}}{r-\mu}-K\right)$ as implied by equation (2-21) in to equation (2-4) at $x^{*}$ we obtain,

$$
\frac{1}{2}\left(x^{*}\right)^{2} \sigma^{2} E_{c_{x x}}\left(x^{*}\right)=-\mu x^{*} E_{c_{x}}\left(x^{*}\right)+r E_{c}\left(x^{*}\right)-\psi x^{*}+r D_{s w} .
$$

We also know from equation (2-5) that at $x^{*}$,

$$
\frac{1}{2}\left(x^{*}\right)^{2} \sigma^{2} E_{m_{x x}}\left(x^{*}\right)=-\mu x^{*} E_{m_{x}}\left(x^{*}\right)+r E_{m}\left(x^{*}\right)-\psi x^{*}+r D_{s w} .
$$


Since, $E_{c}\left(x^{*}\right)=E_{m}\left(x^{*}\right)$, (value matching condition) and $E_{c_{x}}\left(x^{*}\right)=E_{m_{x}}\left(x^{*}\right)$, (smooth pasting condition), the right hand side of equations (2-4a) and (2-5a) are equal. This implies that the left hand side of (2-4a) and (2-5a) are equal, giving rise to the super contact condition (2-20).

Given the value of equity in the continuation region, the mothball region, and the value of the equity at liquidation, the value matching, smooth pasting, and the super contact condition at $x^{*}$ and the value matching and the smooth pasting condition at $x_{l}$ respectively can be written as:

$$
\begin{gathered}
C_{1 m} x^{* \beta}+C_{2 m} x^{* \theta}+\frac{\psi x^{*}}{r-\mu}-D_{s w}=C_{2 c} x^{* \gamma}+\frac{\psi x^{*}}{r-\mu}+\frac{\lambda x^{*}}{(r-\mu)(\lambda+r-\mu)} \\
-\frac{\lambda K}{\lambda+r}-\frac{b x^{*}}{\lambda+r-\mu}-\frac{a}{\lambda+r}-D_{s w} \\
\beta C_{1 m} x^{*(\beta-1)}+\theta C_{2 m} x^{*(\theta-1)}+\frac{\psi}{r-\mu}=\gamma C_{2 c} x^{*(\gamma-1)}+\frac{\psi}{r-\mu}+\frac{\lambda}{(r-\mu)(\lambda+r-\mu)}-\frac{b}{\lambda+r-\mu} \\
\beta(\beta-1) C_{1 m} x^{*(\beta-2)}+\theta(\theta-1) C_{2 m} x^{*(\theta-2)}=\gamma(\gamma-1) C_{2 c} x^{*(\gamma-2)} \\
C_{1 m} x_{l}^{\beta}+C_{2 m} x_{l}^{\theta}+\frac{\psi x_{l}}{r-\mu}-D_{s w}=\phi_{f}+f I+\frac{\phi_{1} x_{l}}{r-\mu}-D_{s w} \\
\beta C_{1 m} x_{l}^{(\beta-1)}+\theta C_{2 m} x_{l}^{(\theta-1)}+\frac{\psi}{r-\mu}=\frac{\phi_{1}}{r-\mu} .
\end{gathered}
$$

Five equations, (2-22), (2-23), (2-24), (2-25), and (2-26) determine the five unknowns $C_{2 c}, C_{1 m}, C_{2 m}$, $x^{*}$, and $x_{l}$. Since no analytical solution exits to the above set of equations, we have to resort to numerical techniques. Table 1 below lists the parameter values chosen to solve the above system of equations.

Table 5.1: Parameter Values

$$
\begin{array}{cc}
r=0.06 & b=0.1 \\
\mu=0.03 & a=1 \\
\sigma=0.3 & K=125 \\
\psi=0.80 & I=50 \\
\phi_{0}=200 & \lambda=0.5 \\
\phi_{1}=0.50 &
\end{array}
$$


We set $\phi_{1}=0.5$, which implies that, given $\psi=0.8$, net revenue, post liquidation, is $62.5 \%$ of its pre-closure value in the best alternative use of assets ${ }^{7}$. For the above chosen parameter values we solve the non-linear system of equations for different values of $f$, starting from 0.5 to 0 . As discussed earlier, $f$ is the fraction of the initial investment that can be recouped in the event of liquidation. Figure 1 below plots $x^{*}$, the trigger point at which the firm resumes its R\&D investment from the inactive state, and $x_{l}$, the trigger point at which the firm liquidates from the inactive state for different values of $f$. We find that both $x^{*}$ and $x_{l}$ increases with, $f$, the degree of tangibility of the asset, $I$, needed to embark on the R\&D project ${ }^{8}$.

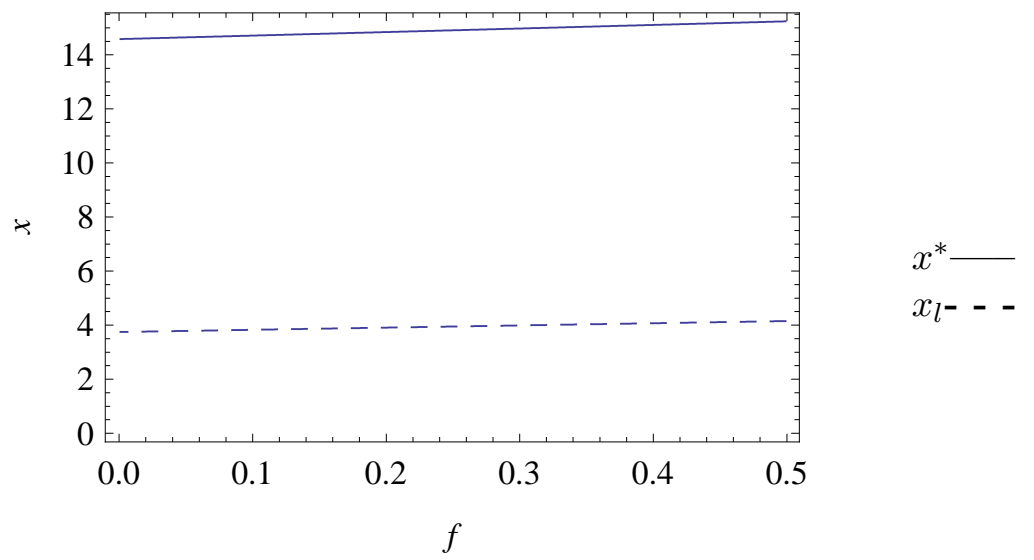

Figure 5.1: Mothballing/Resuming threshold, $x^{*}$, and Liquidation threshold, $x_{l}$.

Let $f^{\prime}$ and $\hat{f}$ be two levels of fraction of the initial investment, $I$, that can be retained in the event of liquidation, where $f^{\prime}>\hat{f}$. For the above two values of $f$, we find that $x^{*}\left(f^{\prime}\right)>x^{*}(\hat{f})$. To understand the above result, suppose the current level of exogenous demand, $x$, is such that $x^{*}(\hat{f})<x<x^{*}\left(f^{\prime}\right)$. At $x$, it is clear that the firm with an R\&D project involving higher $f$ has mothballed the $R \& D$ project. What the result in Figure 1 says, is that the firm with an $R \& D$ project with higher $f$ waits longer to resume investment from the state of inaction. This is because, if starting from $x$, the cash flows do start falling to the point that the firm eventually has to liquidate itself, in the event of liquidation, the firm with higher $f$ is able retain a higher fraction of the initial investment. This fact gives an advantage to the firm with higher $f$, thereby making it possible for it to wait longer before resuming with the $R \& D$ project, with the result that at the completion of the

\footnotetext{
${ }^{7}$ Lambrecht and Myres (2007) assume net revenue, post liquidation, to be $70 \%$ of the pre-closure value in the best alternative use of assets. The net revenue of the firm as a going concern, post liquidation, $\phi_{1}$, also affects the optimal strategy of a firm, our numerical results show that $\frac{\partial x^{*}}{\partial \phi_{1}}>0$ and $\frac{\partial x_{l}}{\partial \phi_{1}}>0$.

${ }^{8}$ It can be shown analytically that $\frac{\partial x^{*}}{\partial f}=\frac{\frac{-I}{(\beta-\theta)}\left[\beta\left(\frac{x^{*}}{x_{l}}\right)^{\theta}-\theta\left(\frac{x^{*}}{x_{l}}\right)^{\beta}\right]}{\frac{1}{x^{*}}\left[(\gamma-1) C_{2 c} x^{* \gamma}-\frac{r K}{(r+\lambda)}-\frac{r a}{\lambda(r+\lambda)}\right]}>0$, and $\frac{\partial x_{l}}{\partial f}=\frac{\partial x^{*}}{\partial f} \frac{x_{l}}{x^{*}}$. However, the
} proof is not interesting and has been omitted from the text. 
R\&D project the firm with a higher $f$ has a higher chance of completing the project in the money. Also, by waiting more avoids paying the investment cost, $a+b x$.

The result also suggests that for $f^{\prime}>\hat{f}, x_{l}\left(f^{\prime}\right)>x_{l}(\hat{f})$. This is because, having already invested $I$ to start the $R \& D$ project, if in the event of liquidation the fraction, $f$, of the initial investment that can be recouped is small, then the firm in question would like to wait longer before it liquidates, hoping that $x$ might eventually rise. We know that the maximum amount of default risk-free debt, $D^{*}$, is $D^{*}=\phi_{f}+f I+\frac{\phi_{1} x_{l}}{r-\mu}$. Thus, as a result of both lower $f$ and lower $x_{l}$ as consequence of lower $f$, the maximum amount of default risk-free debt the firm can incur is lower.

The value of debt in the continuation region and the value of debt in the mothball region are denoted respectively by $B_{c}(x)$ and $B_{m}(x)$. Debt level, $D_{s w}$, being default risk-free, the value of debt in the both the regions is equal to the debt principal $D_{s w}$. The value of the firm in the continuation region, $V_{c}^{s}(x)$, when debt is safe is then given by,

$$
\begin{aligned}
V_{c}(x) & =E_{c}(x)+B_{c}(x) \\
& =E_{c}(x)+D_{s w} \\
& =C_{2 c} x^{\gamma}+\frac{\psi x}{r-\mu}+\frac{\lambda x}{(r-\mu)(\lambda+r-\mu)}-\frac{\lambda K}{\lambda+r}-\frac{b x}{\lambda+r-\mu}-\frac{a}{\lambda+r},
\end{aligned}
$$

and the value of the firm in the mothball region, $V_{m}^{s}(x)$, is given by,

$$
V_{m}(x)=E_{m}(x)+B_{m}(x)=E_{m}(x)+D_{s w}=C_{1 m} x^{\beta}+C_{2 m} x^{\theta}+\frac{\psi x}{r-\mu},
$$

where $C_{2 c}, C_{1 m}$ and $C_{2 m}$ are obtained by solving the system of equations (2-22)-(2-26).

\subsubsection{Starting the R\&D Project: The Irreversible Investment Problem}

Let $D_{i r}$ be the level of outstanding debt when the firm is planning to start the R\&D project, but has not started as yet. As mentioned earlier, at the point in time when the firm embarks on the R\&D project it can restructure its debt to $D_{s w}$. Since the firm is not going to invest if after investing $I$, it lands up in the mothball region, the gain from investing $I$ is $E_{c}(x)-I$, where $E_{c}(x)$ is the value of the firm's equity in the continuation region of the switching problem, post starting the R\&D project.

At the time when the firm is contemplating starting $R \& D$ project, the value of the equity is given 
by the following optimization problem:

$$
\begin{array}{r}
E\left(x_{t}\right)=\max \left\{E_{c}\left(x_{t}\right)-I, \max _{\mathcal{L}(s) \in\{0,1\}, s \in(t, t+d t)} \mathbb{E}_{t}^{Q}\left\{\int _ { t } ^ { t + d t } e ^ { - r ( s - t ) } \left[(1-\mathcal{L}(s))\left(\psi x_{s}-r D_{i r}\right)\right.\right.\right. \\
\left.\left.\left.+\mathcal{L}(s) \max \left\{0,\left(r \phi_{f}+\phi_{1} x_{s}-r D_{i r}\right)\right\}\right] d s+e^{-r d t} E\left(x_{t+d t}\right)\right\}\right\} .
\end{array}
$$

Since the firm is not going to invest if after investing $I$ it has to mothball the R\&D project, it needs to value the decision to continue without investing for a small period of time, $d t$, against $E_{c}(x)-I$, and then again review the situation after the elapse of that time interval. Continuing without investing, during the small period of time $d t$, it receives a cash flow of $\psi x_{t}$ from its existing operation, and also maintains the option to liquidate itself if the cash flows of the firm fall down sufficiently. Let $x^{I}$ denote the threshold level of exogenous demand at which the firm invests $I$, and let $x^{L I}$ be the threshold level of exogenous demand at which the firm liquidates itself.

Assume that after having started the R\&D project, the debt level, $D_{s w}$, for the next stage switching problem continues to be default risk-free. The debt level, $D_{i r}$ before having started the $\mathrm{R} \& \mathrm{D}$ project, is default risk-free when the value of the firm at liquidation is higher than the value of debt, that is, when $\phi_{f}+\frac{\phi_{1} x^{L I}}{r-\mu} \geq D_{i r}$. Define $E_{d}(x)$ as the value of the firm's equity when the firm is deciding whether to embark upon the $R \& D$ project or to liquidate. As before let $E_{l}(x)$ be the value of the firm at/after liquidation. Thus the value of equity, for the firm can be written as follows

$$
E(x)= \begin{cases}V_{c}(x)-I-D_{s w} & \text { if } x \geq x^{I} ; \mathcal{L}(s)=0 \\ E_{d}(x) & \text { if } x^{L I}<x<x^{I} ; \mathcal{L}(s)=0 \\ E_{l}(x) & \text { if } x \leq x^{L I} ; \mathcal{L}(s)=1,\end{cases}
$$

where $E(x)=V_{c}(x)-I-D_{s w}$ when $x \geq x^{I}$ follows from the fact that $D_{s w}$, for the next stage switching problem continues to be default risk-free. Thus we have,

$$
\begin{aligned}
E(x) & =E_{c}(x)-I \\
& =\frac{\psi x}{r-\mu}+C_{2 c} x^{\gamma}+\frac{\lambda x}{(r-\mu)(\lambda+r-\mu)}-\frac{\lambda K}{\lambda+r}-\frac{b x}{\lambda+r-\mu}-\frac{a}{\lambda+r}-I-D_{s w} .
\end{aligned}
$$

Then, for the irreversible investment problem or the starting of the R\&D project problem we need to solve for the value of the firm's equity in the decision region, $E_{d}(x)$, when the firm is deciding 
between liquidating itself and starting the R\&D project, and the value of the firm at/after liquidation. To obtain the differential equation governing the value of the equity in the decision region we employ Itô's lemma to get

$$
e^{-r(d t)} E\left(x_{T}\right)=E\left(x_{t}\right)+\int_{t}^{t+d t} e^{-r(s-t)}\left[\mathcal{D} E\left(x_{s}\right)-r E\left(x_{s}\right)\right] d s+\int_{t}^{t+d t} e^{-r(s-t)}\left[E_{x}\left(x_{s}\right) \sigma d w_{s}\right]
$$

where

$$
\mathcal{D} E(x)=\frac{1}{2} x^{2} \sigma^{2} E_{x x}(x)+\mu x E_{x}(x) .
$$

Taking expectations with respect to the risk neutral measure we obtain

$$
E\left(x_{t}\right)=\mathbb{E}_{t}^{Q}\left\{e^{-r(d t)} E\left(x_{T}\right)-\int_{t}^{t+d t} e^{-r(s-t)}\left[\mathcal{D}\left(x_{s}\right)-r E\left(x_{s}\right)\right] d s\right\}
$$

Now, when it is neither optimal to liquidate the firm nor start the R\&D project, then equation (2-29) becomes

$$
E\left(x_{t}\right)=\mathbb{E}_{t}^{Q}\left\{\int_{t}^{t+d t} e^{-r(s-t)}\left[\left(\psi x_{s}-r D_{i r}\right)\right] d s+e^{-r d t} E\left(x_{t+d t}\right)\right\}
$$

Comparing equation (2-29a) and equation (2-31) we obtain the differential equation governing the value of equity, $E_{d}(x)$, in the decision region

$$
\frac{1}{2} x^{2} \sigma^{2} E_{d_{x x}}(x)+\mu x E_{d_{x}}(x)-r E_{d}(x)+\psi x-r D_{i r}=0, x^{L I} \leq x \leq x^{I} .
$$

We know that the solution to the above differential equation is given by

$$
E_{d}(x)=C_{1 d} x^{\beta}+C_{2 d} x^{\theta}+\frac{\psi x}{r-\mu}-D_{i r}
$$

where $\beta>1$ and $\theta<0$ are the roots of the characteristic polynomial, $\frac{1}{2} \sigma^{2} \eta^{2}+\left[\mu-\frac{1}{2} \sigma^{2}\right] \eta-r=0$. Analogous to the case of safe debt for the switching problem, the value of equity at/after liquidation, $E_{l}(x)$ is given by:

$$
E_{l}(x)=\phi_{f}+\frac{\phi_{1} x}{r-\mu}-D_{i r}
$$

where $\phi_{f}$ is the constant liquidation value at closure from the operation of the firm, which yields $\psi x_{t}$ 
per unit instant of time.

Thus we have four unknowns $C_{1 d}, C_{2 d}, x^{I}$, and $x^{L I}$ which we can determine by the boundary conditions the value matching and smooth pasting conditions. Assuming that debt, $D_{s w}$, is safe after investment $I$, the value matching conditions,

$$
E_{d}\left(x^{I}\right)-\left(D_{s w}-D_{i r}\right)=E_{c}\left(x^{I}\right)-I
$$

and

$$
E_{d}\left(x^{L I}\right)=E_{l}\left(x^{L I}\right)
$$

respectively reflect the fact that the value function $E(x)$ should be continuous respectively at the trigger point for investing, $x^{I}$, and at the liquidation point, $x^{L I}$. The additional term, $D_{s w}-D_{i r}$ on the LHS of (2-35), reflect the fact that at $x^{I}$, when the firm embarks on the project, it restructures its debt level to $D_{s w}$ and consequently the equity holders loose a claim of the amount $D_{s w}-D_{i r}$ on the value of the firm. The smooth pasting conditions,

$$
\frac{\partial E_{d}\left(x^{I}\right)}{\partial x}=\frac{\partial E_{c}\left(x^{I}\right)}{\partial x}
$$

and

$$
\frac{\partial E_{d}\left(x^{L I}\right)}{\partial x}=\frac{\partial E_{l}\left(x^{L I}\right)}{\partial x}
$$

respectively reflect the fact that the value function should be differentiable respectively at the switching point, $x^{I}$, and at the liquidation point, $x^{L I}$.

Given the value functions, $E_{c}(x), E_{d}(x)$ and $E_{l}(x)$, the above boundary conditions, (2-35) to (2-38), respectively, can be written as

$$
\begin{aligned}
C_{1 d}\left(x^{I}\right)^{\beta}+C_{2 d}\left(x^{I}\right)^{\theta}+\frac{\psi x^{I}}{r-\mu}-D_{s w}= & C_{2 c}\left(x^{I}\right)^{\gamma}+\frac{\psi x^{I}}{r-\mu}+\frac{\lambda x^{I}}{(r-\mu)(\lambda+r-\mu)} \\
& -\frac{\lambda K}{\lambda+r}-\frac{b x^{I}}{\lambda+r-\mu}-\frac{a}{\lambda+r}-D_{s w}-I
\end{aligned}
$$




$$
\begin{gathered}
C_{1 d}\left(x^{L I}\right)^{\beta}+C_{2 d}\left(x^{L I}\right)^{\theta}+\frac{\psi x^{L I}}{r-\mu}-D_{i r}=\phi_{f}+\frac{\phi_{1} x^{L I}}{r-\mu}-D_{i r} \\
\beta C_{1 d}\left(x^{I}\right)^{\beta-1}+\theta C_{2 d}\left(x^{I}\right)^{\theta-1}+\frac{\psi}{r-\mu}=\gamma C_{2 c}\left(x^{I}\right)^{\gamma-1}+\frac{\psi}{r-\mu}+ \\
\frac{\lambda}{(r-\mu)(\lambda+r-\mu)}-\frac{b}{\lambda+r-\mu} \\
\beta C_{1 d}\left(x^{L I}\right)^{\beta-1}+\theta C_{2 d}\left(x^{L I}\right)^{\theta-1}+\frac{\psi}{r-\mu}=\frac{\phi_{1}}{r-\mu}
\end{gathered}
$$

Since no analytical solution exits for the above set of nonlinear set of equations we have to resort to numerical techniques to solve them. We solve the above system of equations for different values of $f$, the degree of tangibility of asset $I$. Though $f$ does not enter the above system of equations, (2-39) to (2-42), it does affect the system through the term, $C_{2 c}$, determined in the second stage switching problem. Figure 2 illustrates $x^{I}$ and $x^{L I}$ obtained from numerical solution for different values of $f$.

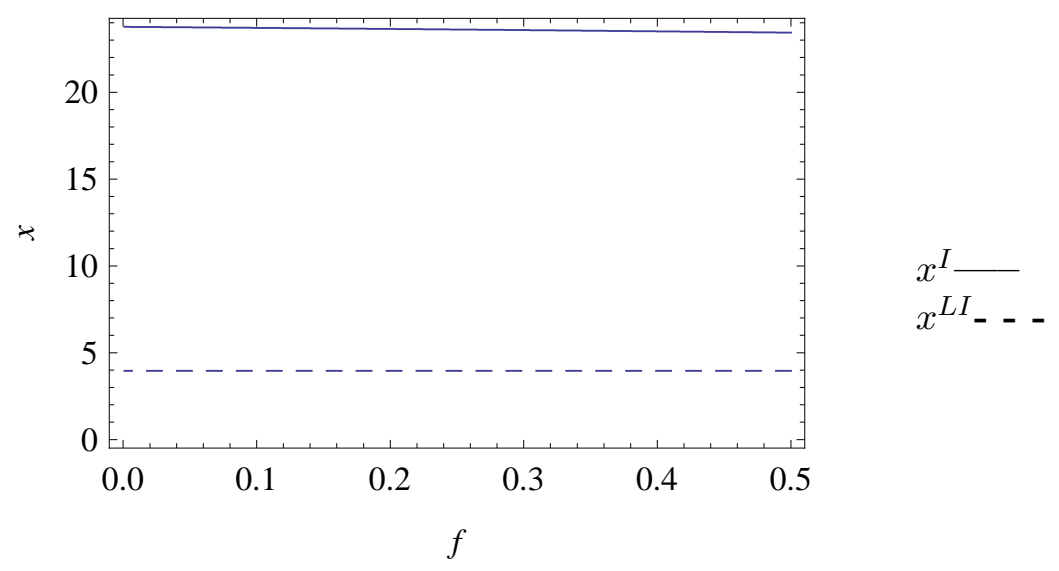

Figure 5.2: Starting the R\&D project threshold, $x^{I}$, and liquidation threshold, $x_{L I}$, before starting the project.

For debt level $D_{i r}$, which is default risk-free before the starting of the R\&D and debt level $D_{s w}$ that is default risk-free after embarking on the $\mathrm{R} \& \mathrm{D}$ project, $x^{I}$, the trigger point at which the firm starts its $\mathrm{R} \& \mathrm{D}$ project and $x^{L I}$, the trigger point at which the firm closes, both decrease as the degree of tangibility of $I$, required to embark upon the R\&D project increases. That is, for $f^{\prime}>\hat{f}$, $x^{I}\left(f^{\prime}\right)<x^{I}(\hat{f})$. This is because if $f$ is high then, if after investment, demand eventually does fall so 
that the firm has to liquidate then the loss, $\left(1-f^{\prime}\right) I$, is less than $(1-\hat{f}) I$. Knowing this, the firm with a higher $f$ would rather embark early than late. Also to be noted is the fact that for $f^{\prime}>\hat{f}$, $x^{L I}\left(f^{\prime}\right)<x^{L I}(\hat{f})$. This is to be expected, since, given the fact that the probability of success is same for all $f$, then stakes are low after investment for firms with R\&D project that involve higher degree of tangibles. Therefore, the firm with $\mathrm{R} \& \mathrm{D}$ project with higher $f$ would be willing to wait more before eventually liquidating the firm hoping that $x$ the level of exogenous demand might rise in the near future to the point where it can start the $R \& D$ project. However as Figure 2 suggests, the rate of decrease of $x^{L I}$ with increasing $f$ is very small. For the parameter values in Table 1, our numerical solution suggests that the difference between $x^{L I}(f=0)$ and $x^{L I}(f=0.5)$ is only of the order of 0.11 percent. This only suggests that, before having started the R\&D project if the cash flows of the firm and the cash flows from the potential $R \& D$ project is low, then the firm with an $R \& D$ project that involves a higher degree of tangibles does have an incentive to wait longer before eventually liquidating the firm, however, this incentive is very small compared to a firm with an R\&D project that involves lesser amount of tangibles.

For a firm that wishes to start the R\&D project, assuming that the level of debt, $D_{s w}$, remains default risk-free after embarking on the R\&D project, the maximum level of safe debt, $D^{I}$, before embarking on the R\&D program is defined as $D^{I}=\phi_{f}+\frac{\phi_{1} x^{L I}}{r-\mu}$. Given that $\frac{\partial x^{L I}}{\partial f}<0$, for $\mathrm{R} \& \mathrm{D}$ projects involving higher levels of $f$, the maximum level of default risk-free debt is less compared to firms with projects that involve lower $f$ or higher amount of intangibles. However, as our numerical results suggests, the difference is very small: the difference between $D^{I}(f=0)$ and $D^{I}(f=.5)$ is 0.03 percent.

In Figure 3 we plot $x^{*}, x^{I}, x_{l}$, and $x^{L I}$ against $f$. These trigger threshold were obtained, assuming that the debt in place is default risk-free for both the starting as well as the switching problem.

We find that the investment threshold $x^{I}$ is much higher than the mothballing/resuming threshold $x^{*}$. This is because starting the R\&D project involves sinking an initial amount of investment $I$. Hence, the firm would begin the R\&D program only when it is sure that the cash flows to be reaped from the project is sufficiently high. Having invested $I$, if the cash flows were to subsequently fall, then the firm mothballs the project at $x^{*}$. Also, the liquidation threshold, $x_{l}$, after sinking the initial amount $I$ varies more with $f$ as compared to $x^{L I}$, and the former increases with $f$ while the later decreases with $f$. This, as explained earlier, is due to the fact that having sunk the initial investment, $I$, if in the event of liquidation the amount of initial investment $I$ that can be recouped is small, then the firm would like to wait more - hoping that demand for its product might eventually rise - before 


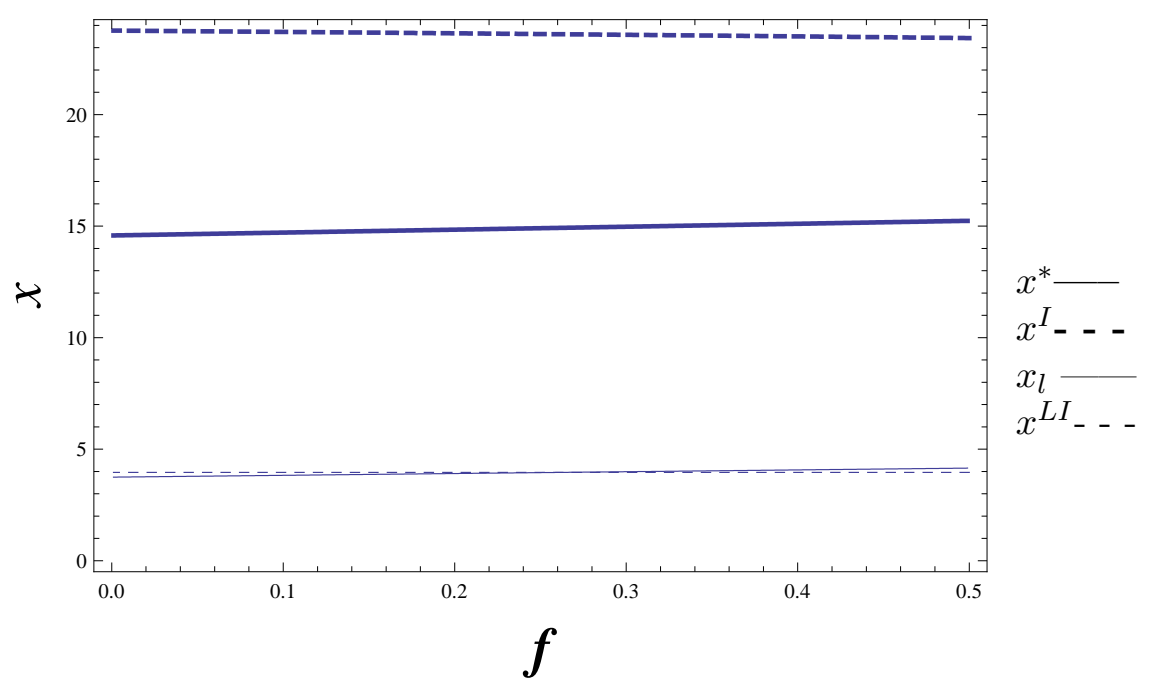

Figure 5.3: Starting the R\&D Project Threshold, $x^{I}$, and Liquidation Threshold, $x_{L I}$

finally liquidating the firm. On the other hand prior to sinking $I$ for a firm with higher $f$ the stakes are low after investing $I$. Therefore, the firm with R\&D project with higher $f$ would be willing to wait more before eventually liquidating the firm hoping that $x$ the level of exogenous demand might rise in the near future to the point where it can start the $R \& D$ project. The implication of this is that, in our framework, the maximum level of default risk-free debt that a firm can afford, before and after starting the R\&D project differ. This is illustrated in Figure 4.



Figure 5.4: Maximum level of safe debt after starting the R\&D project, $D^{*}$, and before starting the project, $D^{I}$, as a function of the fraction, $f$, of the initial investment, $I$, that can be retained in the event of liquidation.

The result suggests that there exits an $\bar{f}$, such that, for all $f>\bar{f},\left(D^{*}>D^{I}\right)$, and that for $f \leq \bar{f}$, $\left(D^{*} \leq D^{I}\right)$. In other words, if the asset, $I$, needed to start the R\&D program involves investing more in tangibles, then ceteris paribus, the firm can borrow more, up to $D^{*}$, after having started the 
R\&D project without facing the risk of default. On the other hand, ceteris paribus, if $f$ is low, that is, if the investment needed to start the project involves large amount of intangible assets, then the existing debt level which is deemed safe before starting the project, becomes risky upon embarking on the $R \& D$ project. What drives this result is the fact that when $f$ is low, the firm before starting the $R \& D$ project, if it has to liquidate itself, liquidates early, while after having started the R\&D project, if the firm has to liquidate, liquidates itself late. This behavior of the firm can potentially give rise to agency issues between the firm and the bond holder, where the firm by investing in $\mathrm{R} \& \mathrm{D}$ can turn existing default risk-free debt into risky debt. As we will see later, assuming that the level of debt remains the same before and after starting the $\mathrm{R} \& \mathrm{D}$ project, that is if $D_{s w}=D_{i r}=D$, and if the pair $(D, f)$ is such that it lies in Area 4, then the equity holders of the firm invest early, that is overinvest, turning existing level of safe debt into risky. Analogous to the risk-shifting problem of Jensen and Meckling (1976), this occurs because, with limited liability, equity holders can transfer the risk of prematurely starting the $\mathrm{R} \& \mathrm{D}$ project to the bondholders while preserving the upside potential. However, after having started the $\mathrm{R} \& \mathrm{D}$ project with $D$ now risky the firm faces another kind of agency issue. Risky debt, as we know imposes costs both by introducing direct bankruptcy costs and by creating agency-theoretic "underinvestment" problems of the kind discussed by Myers (1977).

Before we proceed further, we discuss the implication of varying $\lambda$ for the maximum amount of default risk-free debt that the firm can incur before starting the R\&D project and when the project is operational. We know that higher the intensity $\lambda$, lower is the expected time to completion. Figure 5 below illustrates $D^{*}$ and $D^{I}$ for (a) $\lambda=0.8$, (b) $\lambda=0.5$, and (c) $\lambda=0.2$. We find that as the expected time to completion, $T_{p}=\frac{1}{\lambda}$, increases, "Area 4" becomes larger. As we can see from Figure $5, \bar{f}$, the critical level of $f$, below which $D^{*}<D^{I}$, also increases with declining $\lambda$. This suggests that as the expected time to successful completion of the R\&D program increases, intangibility of asset, $I$, employed to embark on the R\&D program becomes a more pressing concern. Moreover, as can be evinced from Figure 5, the maximum amount of safe debt prior to starting the R\&D project, $D^{I}$, increases with decreasing $\lambda$ for all $f$. This is because if the firm knows that the expected time to completion is large, and if the cash flows from the existing operation and the potential cash flows from the outcome of the $R \& D$ project are low, then the firm prior to starting the R\&D program will be all too eager to liquidate it self early. With increasing $T_{p}=\frac{1}{\lambda}$, the same is true of $D^{*}$, however, since $\bar{f}$ too increases, the over all effect of declining $\lambda$ is a larger difference between $D^{I}$ and $D^{*}$ for each value of $f$ below $\bar{f}$. 


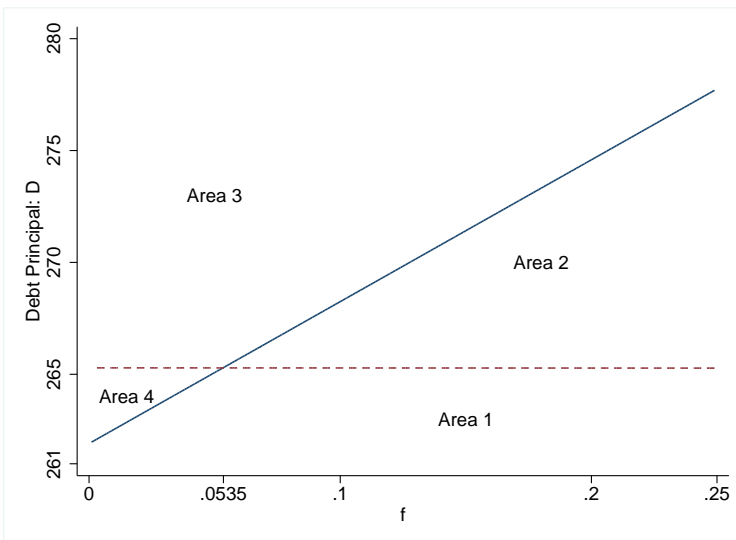

(a)



(c)

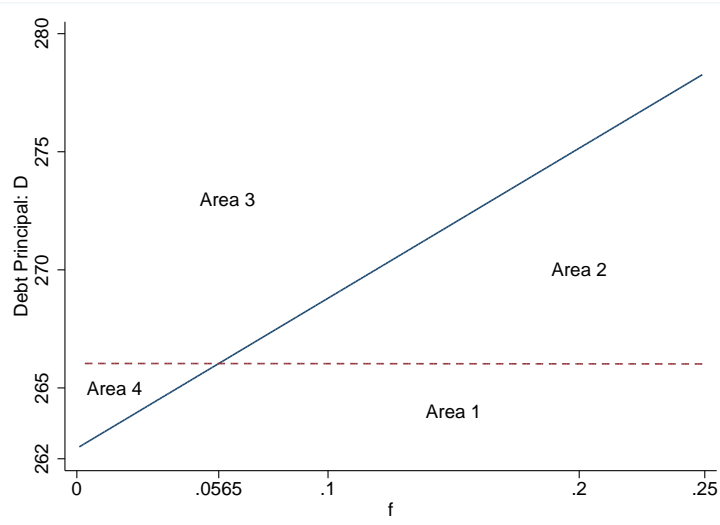

(b)

Figure 5.5: $D^{*}$ and $D^{I}$ for (a) $\lambda=0.8$, (b) $\lambda=0.5$, (c) $\lambda=0.2$

A third factor that increases the wedge between $D^{I}$ and $D^{*}$ is, $\phi_{1}$, the net revenue earned by the firm as a going concern post liquidation. Figure 6 plots $D^{I}$ and $D^{*}$ for $\phi_{1}=0.50$ and $\phi_{1}=0.65$. Our results suggests that for any given $f$, both $\frac{\partial x_{l}}{\partial \phi_{1}}>0$ and $\frac{\partial x^{L I}}{\partial \phi_{1}}>0$. This is because if the net revenue in the liquidation states of the firm as a going concern increases then, given every thing else, the firm is going to going to liquidate it self early both before and after embarking on the R\&D project. This implies that if the value of the firm as a going concern is high in liquidation states, then the firm can borrow more to finance itself, yet keeping the debt default risk-free. Also, we find is that the $f$ at which $x_{l}(f)$ and $x^{L I}(f)$ intersect shifts to the right as $\phi_{1}$ increases, which implies that the rate at which $x^{L I}$ increases with $\phi_{1}$ is faster than the rate at which $x_{l}$ increases. The net effect of increase in $\phi_{1}$ is that Area 4 shifts up and becomes larger. As the value of the firm as a going concern at liquidation approaches zero, at $\phi_{1}=0$, the existing debt levels $D_{i r}$ that are safe prior to starting 


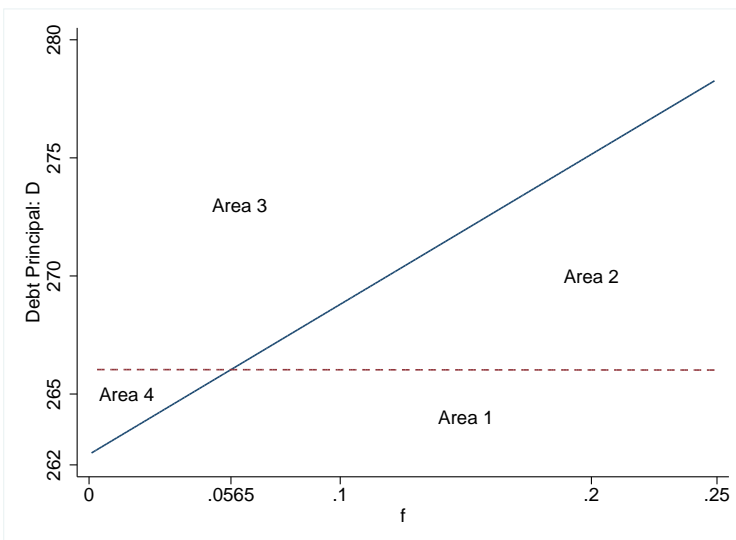

(a)

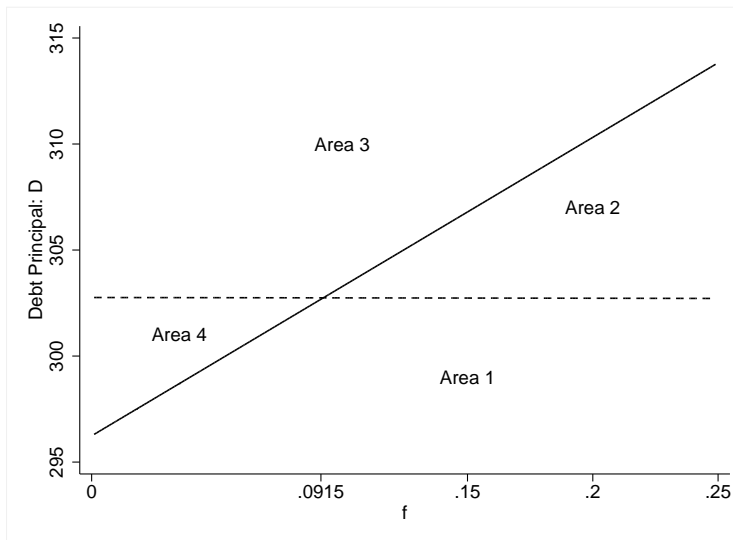

(b)

$D^{*}-$

Figure 5.6: $D^{*}$ and $D^{I}$ for (a) $\phi_{1}=0.5$, (b) $\phi_{1}=0.65$

of the $\mathrm{R} \& \mathrm{D}$ project do not turn risky after embarking on the project, regardless of the fact that $x^{L I}>x_{l}$ for low values of $f$. This is because when $\phi_{1}=0$, the maximum level of default risk-free debt is equal to the constant liquidation value of the firm: $\phi_{f}+f I$ after starting the $\mathrm{R} \& \mathrm{D}$ project and $\phi_{f}$ before staring of the $\mathrm{R} \& \mathrm{D}$ project.

The fact that, for $\phi_{1}>0, D^{*}$ being less than $D^{I}$ for low values of $f$, may create a problems for the firms. This is because for certain levels of existing debt levels that are default risk-free prior to starting of the R\&D program, turn risky after, there by reducing the value of debt. With debt becoming risky, we know that under certain states of nature, bankruptcy and the attendant costs to be incurred becomes a real possibility. To avoid bankruptcy in some states of nature, the firm may renegotiate or restructure its debt.

In sum, what we find is that when $\phi_{1}>0$, both the expected time to successful completion of the $R \& D$ program and the extent of intangibility of the asset involved in conducting $R \& D$ can give rise to potential agency problem between the equity holders and the bond holders. As we will discuss in detail in the next section, the agency issue can involve both risk-shifting, of the type discussed in Jensen and Meckling (1976), and the underinvestment due debt overhang as discussed in Myers (1977). 


\subsection{Valuation when Debt is Risky}

\subsubsection{Mothballing and Resuming of the R\&D Project: The Switching Problem}

Debt is risky when $D_{s w}>D^{*}=\phi_{0}+\frac{\phi_{1} x_{l}}{r-\mu}$, where $D^{*}$ is the maximum level of safe debt. For risky debt the value of the firm at closure is less than the value of debt, that is, $\phi_{0}+\frac{\phi_{1} x_{b}}{r-\mu}<D_{s w}$, where $x_{b}$ is the trigger point at which the firm owners declare bankruptcy. Since at closure the seniority of claim of the creditors is respected, the creditors in the event of bankruptcy receive

$$
(1-\delta)\left[\phi_{0}+\frac{\phi_{1} x_{b}}{r-\mu}\right]
$$

where, $\delta,(0 \leq \delta \leq 1)$, is the fraction of the firm's value that is destroyed when the firm defaults on its debt at closure. Being protected by limited liability the share holder's claim, $E(x)$, in the event of default at closure is given by $E(x)=0$. Since the pay off to the shareholders in the event of default is zero when debt, $D_{s w}$, is risky, the optimization problem (2-2) can be written as:

$$
\begin{array}{r}
E\left(x_{t}\right)=\sup _{\mathcal{I}(s), \mathcal{L}(s) \in\{0,1\}, s \in(t, T)} \mathbb{E}_{t}^{Q}\left\{\int _ { t } ^ { T } e ^ { - r ( s - t ) } \left[(1-\mathcal{L}(s))\left(\psi x_{s}-r D_{s w}-\mathcal{I}(s)\left(a+b x_{s}\right)\right)\right.\right. \\
\left.+\mathcal{L}(s)[0]] d s+e^{-r(T-t)} E\left(x_{T}\right)\right\} .
\end{array}
$$

In the above optimization problem, the two decision that the owners of the firm have to take are, (a) whether to resume operation on R\&D by investing $a+b x_{s}$ at time period $s, \mathcal{I}(s)=1$, or to suspend operation, $\mathcal{I}(s)=0$, and (b) whether to default on the firm's obligation, $\mathcal{L}(s)=1$, in which case the equity holders of the firm receive a payoff of 0 , or to continue $\mathcal{L}(s)=0$. The Hamilton-Jacobi-Bellman equation corresponding to the above problem is given by:

$$
\begin{array}{r}
\frac{1}{2} x^{2} \sigma^{2} E_{x x}\left(x_{s}\right)+\mu x E_{x}\left(x_{s}\right)-r E\left(x_{s}\right)+ \\
\sup _{\mathcal{I}(s), \mathcal{L}(s) \in\{0,1\}}\left\{(1-\mathcal{L}(s)) \mathcal{I}(s)\left\{\lambda\left(\left[E^{a}\left(x_{s}\right)-K\right]-E\left(x_{s}\right)\right)+\psi x_{s}-\left(a+b x_{s}\right)-r D_{s w}\right\}+\right. \\
\mathcal{L}(s)[0]\}=0,
\end{array}
$$

where $E^{a}\left(x_{s}\right)-K=\left(V^{a}\left(x_{s}\right)-D_{s w}\right)-K$, is the value of the firm's equity after the completion of the project minus the fixed cost (strike price) to implement the project and is equal to the present value of the perpetual income flow of $\psi x_{s}+x_{s}-r K-r D_{s w}$. Let $x_{b}$ be the trigger threshold of demand, such that, if the exogenous demand, $x_{t}$ falls below $x_{b}$ then firm defaults and bankruptcy is declared. 
Let $\hat{x}^{*}$ be the threshold level of exogenous demand such that if $x_{t}$ rises above this level then the firm resumes operation on the $\mathrm{R} \& \mathrm{D}$ and if $x_{t}$ is below then it mothballs the $\mathrm{R} \& \mathrm{D}$ project. Thus, as in the case of safe debt, we have the mothball region defined as $\left(x_{b}, \hat{x}^{*}\right)$, the continuation region defined as $\left[\hat{x}^{*}, \infty\right)$, and the region in which the firm is likely to default, $\left[0, x_{b}\right]$.

To distinguish the value of equity when debt is risky as compared to the value when debt is safe, we denote the value of equity in the mothball region as $E_{m}^{r}(x)$ and the value of equity in the continuation region as $E_{c}^{r}(x)$. When the level of exogenous demand $x_{t}$ is such that, $x_{t}$ lies in the continuation region region, then it is optimal for the firm to invest $a+b x_{t}$ per instant of time, in which case $\mathcal{I}(s)=1$. Given the HJB equation, the value of the firm in the continuation region is governed by the following differential equation:

$$
\begin{array}{r}
\frac{1}{2} x^{2} \sigma^{2} E_{c_{x x}}^{r}(x)+\mu x E_{c_{x}}^{r}(x)-r E_{c}^{r}(x)+\lambda\left(\frac{x}{r-\mu}-K+\frac{\psi x}{r-\mu}-E_{c}^{r}(x)-D_{s w}\right)+ \\
\psi x-(a+b x)-r D_{s w}=0 \text { if } x \geq \hat{x}^{*}
\end{array}
$$

When $x_{t}$ is such that, $x_{t}$ lies in the mothball region region, then optimally $\mathcal{I}(s)=0$, and given the HJB equation, the value of the firm in the mothball region is governed by the differential equation:

$$
\frac{1}{2} x^{2} \sigma^{2} E_{m_{x x}}^{r}(x)+\mu x E_{m_{x}}^{r}(x)-r E_{m}^{r}(x)+\psi x-r D_{s w}=0 \text { if } x_{b} \leq x \leq \hat{x}^{*}
$$

We know that the solution to the above two differential equation (3-4) and (3-5) respectively are given by:

$$
E_{c}^{r}(x)=\tilde{C}_{1 c} x^{\kappa}+\tilde{C}_{2 c} x^{\gamma}+\frac{\psi x}{r-\mu}+\frac{\lambda x}{(r-\mu)(\lambda+r-\mu)}-\frac{\lambda K}{\lambda+r}-\frac{b x}{\lambda+r-\mu}-\frac{a}{\lambda+r}-D_{s w}
$$

and

$$
E_{m}^{r}(x)=\tilde{C}_{1 m} x^{\beta}+\tilde{C}_{2 m} x^{\theta}+\frac{\psi x}{r-\mu}-D_{s w}
$$

where the constants $\tilde{C}_{1 c}, \tilde{C}_{2 c}, \tilde{C}_{1 m}$, and $\tilde{C}_{2 m}$ are to be determined. The boundary condition, (2-11), implies that $\tilde{C}_{1 c}=0$. Hence the value of the firm in the continuation region becomes:

$$
E_{c}^{r}(x)=\tilde{C}_{2 c} x^{\gamma}+\frac{\psi x}{r-\mu}+\frac{\lambda x}{(r-\mu)(\lambda+r-\mu)}-\frac{\lambda K}{\lambda+r}-\frac{b x}{\lambda+r-\mu}-\frac{a}{\lambda+r}-D_{s w} .
$$

Thus we are left with five unknowns, $\tilde{C}_{2 c}, \tilde{C}_{1 m}, \tilde{C}_{2 m}$ and the two threshold levels of exogenous 
demand or the free boundaries $x_{b}$ and $\hat{x}^{*}$. These are determined by the boundary conditions at the free boundaries $x_{b}$ and $\hat{x}^{*}$.

The boundary conditions at $\hat{x}^{*}$ are the value matching, smooth pasting, and the super contact conditions, which we have discussed earlier. These boundary conditions respectively at $\hat{x}^{*}$ are given by:

$$
\begin{gathered}
E_{c}^{r}\left(\hat{x}^{*}\right)=E_{m}^{r}\left(x^{*}\right), \\
\frac{\partial E_{c}^{r}\left(\hat{x}^{*}\right)}{\partial x}=\frac{\partial E_{m}^{r}\left(\hat{x}^{*}\right)}{\partial x},
\end{gathered}
$$

and

$$
\frac{\partial^{2} E_{c}^{r}\left(\hat{x}^{*}\right)}{\partial x^{2}}=\frac{\partial^{2} E_{m}^{r}\left(\hat{x}^{*}\right)}{\partial x^{2}}
$$

The standard boundary conditions, the value matching and smooth pasting conditions respectively at $x_{b}$ are respectively given by:

$$
E_{m}^{r}\left(x_{b}\right)=\tilde{C}_{1 m} x_{b}^{\beta}+\tilde{C}_{2 m} x_{b}^{\theta}+\frac{\psi x_{b}}{r-\mu}-D_{s w}=0
$$

and

$$
\frac{\partial E_{m}^{r}\left(x_{b}\right)}{\partial x}=\beta \tilde{C}_{1 m} x_{b}^{(\beta-1)}+\theta \tilde{C}_{2 m} x_{b}^{(\theta-1)}+\frac{\psi}{r-\mu}=0 .
$$

Given the value functions $E_{c}^{r}(x)$ and $E_{m}^{r}(x)$ the above boundary conditions, respectively can be written as:

$$
\begin{gathered}
\tilde{C}_{1 m} \hat{x}^{* \beta}+\tilde{C}_{2 m} \hat{x}^{* \theta}+\frac{\psi \hat{x}^{*}}{r-\mu}-D_{s w}=\tilde{C}_{2 c} \hat{x}^{* \gamma}+\frac{\psi \hat{x}^{*}}{r-\mu}+\frac{\lambda \hat{x}^{*}}{(r-\mu)(\lambda+r-\mu)} \\
-\frac{\lambda K}{\lambda+r}-\frac{b \hat{x}^{*}}{\lambda+r-\mu}-\frac{a}{\lambda+r}-D_{s w} \\
\beta \tilde{C}_{1 m} \hat{x}^{*(\beta-1)}+\theta \tilde{C}_{2 m} \hat{x}^{*(\theta-1)}+\frac{\psi}{r-\mu}=\gamma \tilde{C}_{2 c} x^{*(\gamma-1)}+\frac{\psi}{r-\mu}+\frac{\lambda}{(r-\mu)(\lambda+r-\mu)}-\frac{b}{\lambda+r-\mu}
\end{gathered}
$$




$$
\begin{gathered}
\beta(\beta-1) \tilde{C}_{1 m} \hat{x}^{*(\beta-2)}+\theta(\theta-1) \tilde{C}_{2 m} \hat{x}^{*(\theta-2)}=\gamma(\gamma-1) \tilde{C}_{2 c} \hat{x}^{*(\gamma-2)} \\
\tilde{C}_{1 m} x_{b}^{\beta}+\tilde{C}_{2 m} x_{b}^{\theta}+\frac{\psi x_{b}}{r-\mu}-D_{s w}=0 \\
\beta \tilde{C}_{1 m} x_{b}^{(\beta-1)}+\theta \tilde{C}_{2 m} x_{b}^{(\theta-1)} \frac{\psi}{r-\mu}=0 .
\end{gathered}
$$

Again, as in the case of safe debt no closed form solution of the above set of equation exits, hence we have to rely on numerical techniques to obtain the value of equity in the continuation and mothball region. From our analysis in Section 3, we know that the maximum amount of default risk-free debt $D^{*}$ is a function of $f$, the fraction of the initial investment, $I$, that can be retained in the event of liquidation. Therefore, in order to see the effect of the presence of debt levels higher than the maximum amount of safe debt sustainable by a firm, we need to fix the value of $f$ at some particular value, say $\tilde{f}$. For our numerical analysis we assume $\tilde{f}=0.1$, while the other parameters are the same as in Table 1. In considering the valuation of the firm when debt is risky, we consider the two cases: (a) when the net revenue of the firm as going concern in the event of liquidation is positive, $\phi_{1}>0$, and (b) when value of the firm in the event of liquidation is constant, $\phi_{1}=0$. The results of the numerical analysis are illustrated in Figure 7. The bold and the thin solid lines respectively are the motballing/resuming threshold and the liquidation threshold when $\phi_{1}=0$ and the debt level, $D_{s w}$, is such that it is default risk free. The bold and the thin dotted lines respectively are the motballing/resuming threshold and the liquidation threshold when $\phi_{1}=0.5$ and the debt level, $D_{s w}$, is such that it is default risk free. The bold and the thin dashed lines respectively are the motballing/resuming threshold and the default threshold when debt is risky.

The maximum level of safe debt, $D^{*}$, when $\phi_{1}=0$ is $D^{*}\left(\tilde{f}, \phi_{1}=0\right)=205.5$, and the maximum level of safe debt when $\phi_{1}=0.5$ turns out to be $D^{*}\left(\tilde{f}, \phi_{1}=0.5\right)=268.8$. The vertical line in the figure is drawn at $D^{*}\left(\tilde{f}, \phi_{1}=0.5\right)=268.8$. As can be seen from the figure, when $\phi_{1}$ increases, both the mothballing/resuming and the liquidation threshold increases and so does the maximum amount of default risk-free debt that the firm can borrow. When $\phi_{1}=0$ is as stated earlier, $D^{*}\left(\tilde{f}, \phi_{1}=0\right)=$ $\phi_{f}+\tilde{f} I$. As we increase $D_{s w}$ above this level, we find that both $\hat{x}^{*}\left(D_{s w}\right)$ and $x_{b}\left(D_{s w}\right)$ increase. That is, as the level of risky debt in place increase we find that mothballing/resuming threshold and the liquidation increases. When $\phi_{1}>0$, then for all risky debt levels $D_{s w}>D^{*}(f), \hat{x}^{*}>x^{*}$. Thus, we find that when the firm is financed with risky debt, since, $\hat{x}^{*}>x^{*}$, in some states of nature, 


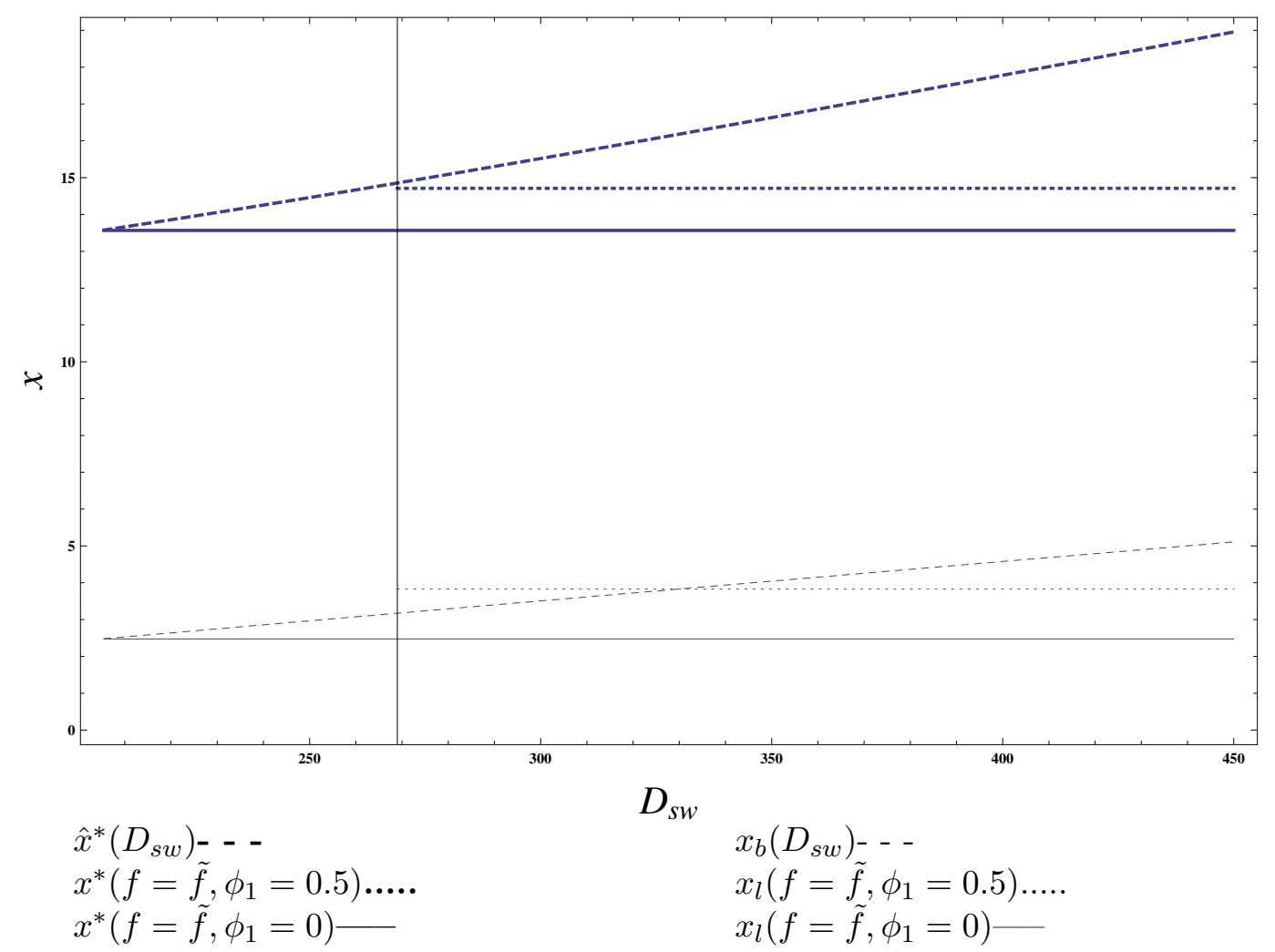

Figure 5.7: Mothballing/Resuming threshold and Default threshold for Risky Debt as compared to Mothballing/Resuming threshold and Liquidation threshold for Safe Debt at a fixed value of $f$.

it passes up valuable investment opportunities which could make a positive net contribution to the market value of the firm, and since, $\frac{\partial \hat{x}^{*}}{\partial D_{s w}}>0$, the debt overhang problem becomes more severe as debt becomes riskier ${ }^{9}$.

As far as the default threshold is concerned when $\phi_{1}>0$, as can be evinced from Figure 7, there exists a risky debt level $\tilde{D}, \tilde{D}>D^{*}$, such that $x_{b}=x_{l}$ when the risky debt level $D_{s w}=\tilde{D}$. For $D^{*}<D_{s w}<\tilde{D}, x_{b}<x_{l}$ and for $D \geq \tilde{D}, x_{b} \geq x_{l}$. This is due to the fact that the rate at which liquidation threshold, $x_{l}$, increases in response to increase in $\phi_{1}$ is higher than the rate at which the default threshold, $x_{b}$, increases in response to increase in $D_{s w}$. This in effect implies that for $\phi_{1}>0$, when $D_{s w}$ increases above $D^{*}\left(\tilde{f}, \phi_{1}=0.5\right)=\phi_{f}+\tilde{f} I+\frac{\phi_{1} x_{l}}{r-\mu}$, for some levels of debt, the default threshold, $x_{b}$, might even be lower than the closure threshold,$x_{l}$, when debt is default risk-free. This result essentially follows from the fact that when debt is risky, in the event of default shareholders receive nothing, consequently their optimal default threshold is determined by the burden of debt

${ }^{9}$ It can be shown analytically that $\frac{\partial \hat{x}^{*}}{\partial D_{s w}}=\frac{\frac{-1}{(\beta-\theta)}\left[\beta\left(\frac{\hat{x}^{*}}{x_{b}}\right)^{\theta}-\theta\left(\frac{\hat{x}^{*}}{x_{b}}\right)^{\beta}\right]}{\frac{1}{\hat{x}^{*}}\left[(\gamma-1) \tilde{C}_{2 c}\left(\hat{x}^{*}\right)^{\gamma}-\frac{r K}{(r+\lambda)}-\frac{r a}{\lambda(r+\lambda)}\right]}>0$ and that $\frac{\partial x_{b}}{\partial D_{s w}}=\frac{\partial \hat{x}^{*}}{\partial D_{s w}} \frac{x_{b}}{\hat{x}^{*}}$. 
service. In doing so the firm ignores the net revenue of the firm as a going concern in liquidation states. Thus, when the burden of debt services are low, the firm defaults late and when they are high the firm defaults early.

We now, turn to the valuation of risky debt. Let the value of debt in the mothball region and the continuation region be denoted respectively by $B_{m}\left(x_{t}\right)$ and $B_{c}\left(x_{t}\right)$. Using Itó's formula and standard hedging argument we know that the value of debt in the mothball region satisfies the following differential equation:

$$
\frac{1}{2} x^{2} \sigma^{2} B_{m_{x x}}(x)+\mu x B_{m_{x}}(x)-r B_{m}(x)+r D_{s w}=0, x_{b} \leq x \leq \hat{x}^{*}
$$

while the equation governing the value of debt in the continuation region is given by

$$
\frac{1}{2} x^{2} \sigma^{2} B_{c_{x x}}(x)+\mu x B_{c_{x}}(x)-r B_{c}(x)+r D_{s w}+\lambda\left(D_{s w}-B_{c}(x)\right)=0 \text { for } x \geq \hat{x}^{*} .
$$

The term $\lambda\left(D_{s w}-B_{c}(x)\right)$ in the above equation is due to the fact that with intensity $\lambda$, the value of debt in the continuation region jumps from $B_{c}(x)$ to $D_{s w}$. This because we assume that the firm carries on indefinitely after implementation of the successfully completed R\&D project, (see footnote7). Without the risk of closure or default after implementation of the R\&D project, the value of debt is always $D_{s w}$.

The solution to equation (3-13) and (3-14) respectively are given by

$$
\begin{aligned}
& B_{1 m} x^{\beta}+B_{2 m} x^{\theta}+D_{s w} \\
& B_{1 c} x^{\kappa}+B_{2 c} x^{\gamma}+D_{s w}
\end{aligned}
$$

where $\beta$ and $\theta$ are the roots of the characteristic polynomial, $\frac{1}{2} \sigma^{2} \eta^{2}+\left[\mu-\frac{1}{2} \sigma^{2}\right] \eta-r=0$, and $\kappa$ and $\gamma$ are the roots of the characteristic polynomial, $\frac{1}{2} \sigma^{2} \eta^{2}+\left[\mu-\frac{1}{2} \sigma^{2}\right] \eta-(r+\lambda)=0 . B_{1 m}, B_{2 m}, B_{1 c}$, and $B_{2 c}$ are constants to be determined by the boundary conditions.

The first boundary condition that we consider is absence of speculative bubbles:

$$
\lim _{x \rightarrow \infty} B(x)=D_{s w} .
$$

The condition states that as the value of the underling exogenous demand for the product of the firm 
goes to infinity the value of debt converges to $D_{s w}$, the debt principal. This is due to the fact that for high values of $x$, the firm is easily able to service its debt and hence quite unlikely to default. However, this boundary condition is only pertinent to the value of debt in the continuation region. This because, given

$$
B(x)= \begin{cases}B_{c}(x) & \text { if } x \geq \hat{x}^{*} \\ B_{m}(x) & \text { if } x_{b} \leq x \leq \hat{x}^{*},\end{cases}
$$

the continuation region is bounded below by $\hat{x}^{*}$ but is not bounded above, but the mothball region is bounded below and above by $x_{b}$ and $\hat{x}^{*}$ respectively. The boundary condition (3-17) implies that, $B_{1 c}=0$, since $B_{1 c}$ is the coefficient of $x^{\kappa}$ and $\kappa>1$. Thus the value of debt in the continuation region is given by

$$
B_{c}(x)=B_{2 c} x^{\gamma}+D_{s w}
$$

The mothball region, however, being bounded by $x_{b}$ and $\hat{x}^{*}$, and $\hat{x}^{*}>x_{b}>0$ the value of debt in the mothball region is given by

$$
B_{m}(x)=B_{1 m} x^{\beta}+B_{2 m} x^{\theta}+D_{s w}
$$

Thus we are left with three constants $B_{1 m}, B_{2 m}$, and $B_{2 c}$, which we can determine from the value matching and smooth pasting conditions at the free boundaries $x_{b}$ and $\hat{x}^{*} . x_{b}$ and $\hat{x}^{*}$, as we know were determined earlier as a solution to the system of equations (3-8a)-(3-12a). The value matching and smooth pasting conditions respectively at $x_{b}$ are the following:

$$
\begin{gathered}
B_{m}\left(x_{b}\right)=B_{1 m} x_{b}^{\beta}+B_{2 m} x_{b}^{\theta}+D_{s w}=(1-\delta)\left[\phi_{0}+\frac{\phi_{1} x_{b}}{r-\mu}\right] \\
\frac{\partial B_{m}\left(x_{b}\right)}{\partial x}=\beta B_{1 m} x_{b}^{(\beta-1)}+\theta B_{2 m} x_{b}^{(\theta-1)}=\frac{(1-\delta) \phi_{1}}{r-\mu} .
\end{gathered}
$$

The value matching condition (3-20) states that when the firm defaults at $x_{b}$, the creditors receive $(1-\delta)\left[\phi_{0}+\frac{\phi_{1} x_{b}}{r-\mu}\right]$, where, $\delta$, as explained earlier is the fraction of the value of the firm that gets destroyed during bankruptcy. Since, the above two set of equations, (3-20) and (3-21), are sufficient to determine $B_{1 m}$ and $B_{1 m}$, the only remaining constant $B_{2 c}$ can be determined by the value matching 
condition at $\hat{x}^{*}$, given by:

$$
B_{m}\left(\hat{x}^{*}\right)=B_{1 m} \hat{x}^{* \beta}+B_{2 m} \hat{x}^{* \theta}+D_{s w}=B_{2 c} \hat{x}^{* \gamma}+D_{s w}=B_{c}\left(\hat{x}^{*}\right) .
$$

Given $x_{b}$ and $\hat{x}^{*}$, using equation (3-20) and (3-21) to solve for $B_{1 m}$ and $B_{2 m}$, we find

$$
B_{1 m}=-\frac{1}{\beta-\theta}\left\{-\theta\left[D_{s w}-(1-\delta)\left(\phi_{0}+\frac{\phi_{1} x_{b}}{(r-\mu)}\right)\right]-\frac{(1-\delta) \phi_{1} x_{b}}{(r-\mu)}\right\}\left(\frac{1}{x_{b}}\right)^{\beta}
$$

and

$$
B_{2 m}=-\frac{1}{\beta-\theta}\left\{\beta\left[D_{s w}-(1-\delta)\left(\phi_{0}+\frac{\phi_{1} x_{b}}{(r-\mu)}\right)\right]+\frac{(1-\delta) \phi_{1} x_{b}}{(r-\mu)}\right\}\left(\frac{1}{x_{b}}\right)^{\theta}
$$

Thus we arrive at the value of debt in the mothball region, $B_{m}(x)=B_{m}\left(x, D_{s w}\right)$, given by

$$
\begin{array}{r}
B_{m}\left(x, D_{s w}\right)=D_{s w}-\left\{D_{s w}-(1-\delta)\left[\phi_{0}+\frac{\phi_{1} x_{b}}{(r-\mu)}\right]\right\}\left\{\frac{\beta}{\beta-\theta}\left(\frac{x}{x_{b}}\right)^{\theta}+\frac{\theta}{\theta-\beta}\left(\frac{x}{x_{b}}\right)^{\beta}\right\} \\
-\left[\frac{(1-\delta) \phi_{1} x_{b}}{(r-\mu)(\beta-\theta)}\right]\left\{\left(\frac{x}{x_{b}}\right)^{\theta}-\left(\frac{x}{x_{b}}\right)^{\beta}\right\} .
\end{array}
$$

It can be easily verified that $\left\{D_{s w}-(1-\delta)\left[\phi_{0}+\frac{\phi_{1} x_{b}}{(r-\mu)}\right]\right\}\left\{\frac{\beta}{\beta-\theta}\left(\frac{x}{x_{b}}\right)^{\theta}+\frac{\theta}{\theta-\beta}\left(\frac{x}{x_{b}}\right)^{\beta}\right\}>0$, and that $\left[\frac{(1-\delta) \phi_{1} x_{b}}{(r-\mu)(\beta-\theta)}\right]\left\{\left(\frac{x}{x_{b}}\right)^{\theta}-\left(\frac{x}{x_{b}}\right)^{\beta}\right\}>0$. This implies that when $D_{s w}$ is risky, the value of debt is less than the debt principal. Given $B_{m}(x)$, equation (3-22) yields the value of debt in the continuation region, $B_{c}(x)=B_{c}\left(x, D_{s w}\right)$,

$$
\begin{array}{r}
B_{c}\left(x, D_{s w}\right)=D_{s w}-\left\{\left\{D_{s w}-(1-\delta)\left[\phi_{0}+\frac{\phi_{1} x_{b}}{(r-\mu)}\right]\right\}\left\{\frac{\beta}{\beta-\theta}\left(\frac{x}{x_{b}}\right)^{\theta}+\frac{\theta}{\theta-\beta}\left(\frac{x}{x_{b}}\right)^{\beta}\right\}\right. \\
\left.-\left[\frac{(1-\delta) \phi_{1} x_{b}}{(r-\mu)(\beta-\theta)}\right]\left\{\left(\frac{x}{x_{b}}\right)^{\theta}-\left(\frac{x}{x_{b}}\right)^{\beta}\right\}\right\}\left(\frac{x}{\hat{x}^{*}}\right)^{\gamma}
\end{array}
$$

For risky debt the value of the firm in the mothball region, $V_{m}^{r}(x)$ is given by

$$
V_{m}^{r}(x)=E_{m}^{r}(x)+B_{m}\left(x, D_{s w}\right)=\left(\tilde{C}_{1 m}+B_{1 m}\right) x^{\beta}+\left(\tilde{C}_{2 m}+B_{2 m}\right) x^{\theta}+\frac{\psi x}{r-\mu}
$$


and the value of the firm in the continuation region is given by

$$
\begin{aligned}
V_{c}^{r}(x)=E_{c}^{r}(x)+ & B_{c}\left(x, D_{s w}\right)=\left[\frac{B_{1 m} \hat{x}^{* \beta}+B_{2 m} x_{r}^{* \theta}}{\hat{x}^{* \gamma}}+\tilde{C}_{2 c}\right] x^{\gamma}+\frac{\psi x}{r-\mu} \\
& +\frac{\lambda x}{(r-\mu)(\lambda+r-\mu)}-\frac{\lambda K}{\lambda+r}-\frac{b x}{\lambda+r-\mu}-\frac{a}{\lambda+r}
\end{aligned}
$$

\subsubsection{Starting the R\&D Project: The Irreversible Investment Problem}

As discussed earlier, depending on $f$, the fraction of the initial investment, $I$, recouped in the event of liquidation, the maximum amount of safe debt sustainable before and after starting the R\&D project differ. Depending on the amount of existing debt in place and $f$, Figure 4 delineates 4 cases, represented by Area 1 to Area 4 . In this section we assume that $D_{s w}=D_{i r}=D$. While it is possible that the firm can restructure its debt level when the firm embarks on $R \& D$ program, this assumes that the firm is in a favorable position to reduce or increase its debt level. Here we show what the likely outcomes can be when existing debt levels can not be renegotiated ${ }^{10}$. We have already analyzed in detail the outcome for the starting of the R\&D project when the level of debt for the switching problem and the first stage starting, both, were default risk-free. This leaves us to discuss the outcomes for the first stage when $f$ is such that existing levels of debt are (a) safe for the second stage switching but risky for the first stage starting of the R\&D, (Area 2), (b) risky for the second and risky for the first, (Area 3), and (c) safe for the first stage but risky for the second stage switching, (Area 4). The subsections to follow discuss these various cases.

Debt is risky when $D>D^{I}=\phi_{f}+\frac{\phi_{1} x^{L I}}{r-\mu}$, where $D^{I}$ as defined earlier is the maximum level of safe debt for a firm wishing to embark upon an R\&D project and $x^{L I}$ is the liquidation threshold when the level of debt $D$ is default risk-free. For risky debt the value of the firm at closure is less than the value of debt, that is, $\phi_{f}+\frac{\phi_{1} x^{B}}{r-\mu}<D$, where $x^{B}$ is the trigger point at which the firm owners declare bankruptcy. Since, at closure the seniority of claim of the creditors is respected, the creditors in the event of bankruptcy receive

$$
(1-\delta)\left[\phi_{f}+\frac{\phi_{1} x^{B}}{r-\mu}\right]
$$

where $\delta$, as defined earlier, is the fraction of the firm's value that is destroyed during bankruptcy. Since the shareholders receive nothing, the value of equity, $E_{l}(x)$, at liquidation is zero.

\footnotetext{
${ }^{10}$ At the time of the starting of the R\&D project the firm may increase its debt level to finance its R\&D project, the possibility for reduction depends on many factors and is outside the scope of the chapter.
} 


\section{Debt levels Default Risk-Free for Switching, Risky for Starting}

In this section we discuss the implication of having, for a given $f$, debt level $D$ such that the pair $(D, f)$ lie in Area 2 of Figure 4. We fix $f$ at $f=0.25$. Debt level, $D$, is risky for the first stage problem but default risk-free for the second stage switching when $D$ is such that, $D^{I}(f)<D \leq D^{*}(f)$. Now, for any given $f$, we know what the switching and liquidation thresholds for the second stage switching problems are. It remains to find out the investment, $\hat{x}^{I}$, and the liquidation, $\hat{x}^{L I}$, threshold for the first stage, when $D^{I}(f)<D \leq D^{*}(f)$.

From our analysis of the switching and the starting problem with default risk-free debt, we know that the value of equity in the what we had defined as the decision region takes the form of

$$
E_{d}(x)=\tilde{C}_{1 d}(x)^{\beta}+\tilde{C}_{2 d}(x)^{\theta}+\frac{\psi x}{r-\mu}-D \text { if } x^{B} \leq x \leq \hat{x}^{I}
$$

Prior to starting of the R\&D project or when the firm is in the decision region, with risky debt in place, if the firm defaults on its obligation we know that at default the firm receives nothing. This implies that the value of the firm's equity at the boundary $x^{B}$ satisfies the following value matching and smooth pasting conditions respectively

$$
E_{d}\left(x^{B}\right)=\tilde{C}_{1 d}\left(x^{B}\right)^{\beta}+\tilde{C}_{2 d}\left(x^{B}\right)^{\theta}+\frac{\psi x^{B}}{r-\mu}-D=0=E_{l}\left(x^{B}\right)
$$

and

$$
\frac{\partial E_{d}\left(x^{B}\right)}{\partial x}=\beta \tilde{C}_{1 d}\left(x^{B}\right)^{\beta-1}+\theta \tilde{C}_{2 d}\left(x^{B}\right)^{\theta-1}+\frac{\psi}{r-\mu}=0=\frac{\partial E_{l}\left(x^{B}\right)}{\partial x} .
$$

We denote by $\hat{x}^{I}$, the investment threshold when $D$ is risky. Since the firm invests $I$ only when it is sure that after having invested it will be able to continue with the project, and since after investing, the existing level of debt turns default risk-free, at the investment threshold $\hat{x}^{I}$, the value of equity in the decision region is matched with the value of equity in the continuation region, $E_{c}(x)$. The value matching and the smooth pasting condition at $\hat{x}^{I}$ respectively are:

$$
\tilde{C}_{1 d}\left(\hat{x}^{I}\right)^{\beta}+\tilde{C}_{2 d}\left(\hat{x}^{I}\right)^{\theta}+\frac{\psi \hat{x}^{I}}{r-\mu}-D=E_{c}\left(\hat{x}^{I}\right)-I
$$


and

$$
\beta \tilde{C}_{1 d}\left(\hat{x}^{I}\right)^{\beta-1}+\theta \tilde{C}_{2 d}\left(\hat{x}^{I}\right)^{\theta-1}+\frac{\psi}{r-\mu}=\frac{\partial E_{c}\left(\hat{x}^{I}\right)}{\partial x} .
$$

Now, from the analysis of the second stage switching problem for safe debt, we know, $E_{c}(x)$, the value of equity in the continuation region. Thus, the four unknowns $\tilde{C}_{1 d}, \tilde{C}_{2 d}, \hat{x}^{I}$, and $x^{B}$ are determined by the above four equations, (3-28) to (3-31).

For a given $f$, which we assume to be $f=0.25$, Figure 8 , illustrates the outcomes for the first stage for different values of $D$, where $D^{I}(f)<D \leq D^{*}(f)$. The range of $D$ in the figure is bounded below by $D^{I}(f)$ and above by $D^{*}(f)$. Figure 8 (a) compares the trigger demand threshold level, $x^{I}$, for starting of the R\&D project when $D \leq D^{I}(f)$ with the trigger demand threshold level, $\hat{x}^{I}$, for starting of the R\&D project when $D^{I}(f)<D \leq D^{*}(f)$. We know that when $D \leq D^{I}(f), x^{I}(f)$ is constant for a given $f$. When $D^{I}(f)<D \leq D^{*}(f)$, we find that $x^{I}(f)<\hat{x}^{I}(f, D)$ and that $\hat{x}^{I}(f, D)$ increases with $D$. In other words, we find that when debt levels are risky prior to starting of the

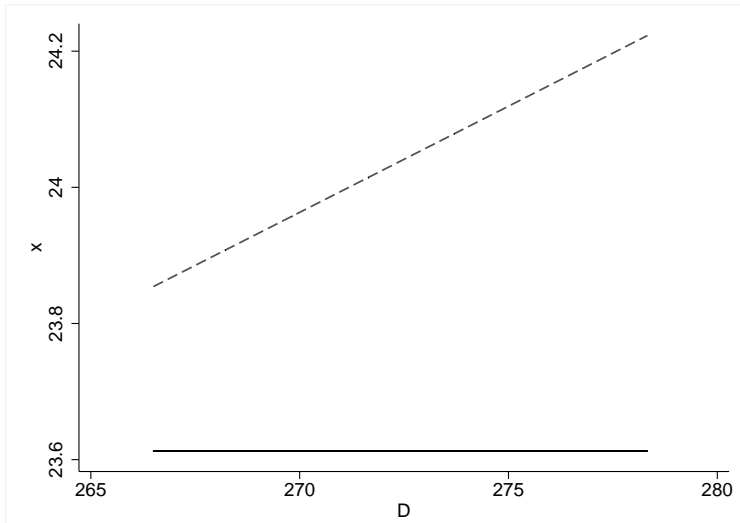

(a)

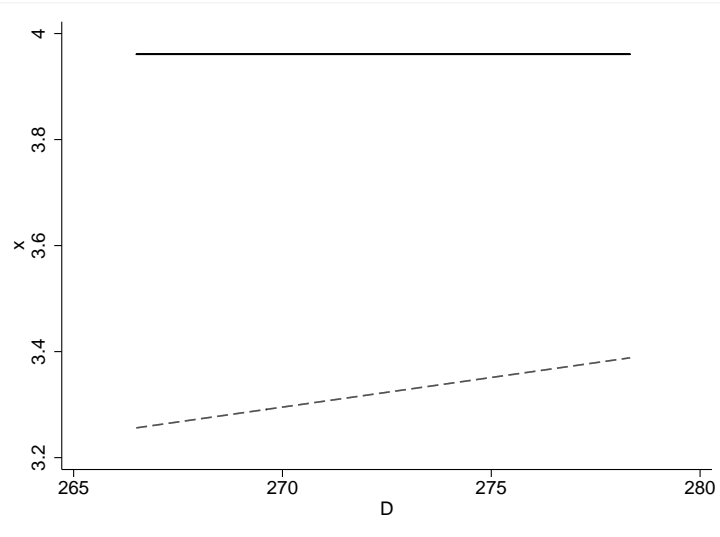

(b)

$x^{I}(f)-$

$\hat{x}^{I}(f, D)-\cdots$

$$
\begin{aligned}
& x^{L I}(f)- \\
& x^{B}(f, D)-\cdot-
\end{aligned}
$$

Figure 5.8: (a) Investment Threshold when Debt levels are Default Risk-Free for Switching and Risky for Starting as compared to when Debt levels are Default Risk-Free for both Switching and Starting, (b) Liquidation Threshold when Debt levels are Default Risk-Free for Switching and Risky for Starting as compared to when Debt levels are Default Risk-Free for both Switching and Starting

$\mathrm{R} \& \mathrm{D}$ project, the trigger threshold level $\hat{x}^{I}(f, D)$ at which the firm starts the $\mathrm{R} \& \mathrm{D}$ project becomes higher. That is, with risky debt in place, the outcome, $x^{I}(f)<\hat{x}^{I}(f, D)$, reflects the fact that the firm decides to wait more before investing, $I$, to start the $\mathrm{R} \& \mathrm{D}$ project, thus foregoing valuable investment opportunity. This is reflects the debt overhang problem due to risky debt in place. 
As far as the default threshold $x^{B}(f, D)$ is concerned, we find that there is a discrete jump downwards from $x^{L I}(f)$ as soon as soon as $D$ becomes greater than $D^{I}(f)$. We also find that $x^{B}(f, D)$ increases as $D$ increases. This is due to the fact that with risky debt in place, equity holders of the firm ignore the net revenue of the firm in liquidation states and the optimal reaction is based only on the extent of debt burden. For the range of values of $D$ for which $D$ is risky prior to starting up of the R\&D project and default risk-free-after, the the optimal default threshold increases with higher debt burden, but the burden is not high enough to make the firm default earlier as compared to $x^{L I}$, the closure threshold level had the debt, level, $D$, been such that it was default risk-free. Thus we find that when the pair $(D, f)$ is such that, the pair lies in Area 2, then $x^{B}(f, D)<x^{L I}(f)$ and $\hat{x}^{I}(f, D)>x^{I}(f)$.

However, what is interesting here is that if $f>\bar{f}$ and the level of $D$ is such that it is default risk-free before having started the $R \& D$ project and if it is possible to restructure the debt level at the time of investing $I$, then it would be possible for the firm to borrow more, up to $D^{*}$, without risking default.

To obtain the value of risky debt in place, we know that, by using Itó's formula and standard hedging argument, the value of debt in the decision region satisfies the following differential equation:

$$
\frac{1}{2} x^{2} \sigma^{2} B_{d_{x x}}(x)+\mu x B_{d_{x}}(x)-r B_{d}(x)+r D=0, x_{b} \leq x \leq \hat{x}^{*} .
$$

The solution to the above equation is given by:

$$
B_{1 d} x^{\beta}+B_{2 d} x^{\theta}+D
$$

where $B_{1 d}$ and $B_{2 d}$ are constants to be determined. These can be easily determined by employing the value matching and smooth pasting conditions either at $x^{B}(f, D)$ or at $\hat{x}^{I}(f, D)$.

\section{Debt levels Risky for Switching, Risky for Starting}

To solve for the outcomes in Area 3, where the level of existing debt is such that it is risky, both, prior to starting of the $R \& D$ project and after starting the $R \& D$ project we solve the following four equation.

$$
\tilde{C}_{1 d}\left(\hat{x}^{I}\right)^{\beta}+\tilde{C}_{2 d}\left(\hat{x}^{I}\right)^{\theta}+\frac{\psi \hat{x}^{I}}{r-\mu}-D=E_{c}^{r}\left(\hat{x}^{I}\right)-I
$$




$$
\begin{gathered}
\beta \tilde{C}_{1 d}\left(\hat{x}^{I}\right)^{\beta-1}+\theta \tilde{C}_{2 d}\left(\hat{x}^{I}\right)^{\theta-1}+\frac{\psi}{r-\mu}=\frac{\partial E_{c}^{r}\left(\hat{x}^{I}\right)}{\partial x} \\
E_{d}\left(x^{B}\right)=\tilde{C}_{1 d}\left(x^{B}\right)^{\beta}+\tilde{C}_{2 d}\left(x^{B}\right)^{\theta}+\frac{\psi x^{B}}{r-\mu}-D=0=E_{l}\left(x^{B}\right) \\
\frac{\partial E_{d}\left(x^{B}\right)}{\partial x}=\beta \tilde{C}_{1 d}\left(x^{B}\right)^{\beta-1}+\theta \tilde{C}_{2 d}\left(x^{B}\right)^{\theta-1}+\frac{\psi}{r-\mu}=0=\frac{\partial E_{l}\left(x^{B}\right)}{\partial x} .
\end{gathered}
$$

Equation (3-34) and (3-35) are respectively the value matching and the smooth pasting conditions at $\hat{x}^{I}$ and (3-36) and (3-37) are respectively the value matching and smooth pasting conditions at $x^{B}$. It should be noted here that at $\hat{x}^{I}$, the value of equity in the decision region is equated with the value of equity in the continuation region $E_{c}^{r}\left(\hat{x}^{I}\right)$, which is the value when debt is risky after the starting of the R\&D project. The system of four equations solves for $\hat{x}^{I}, x^{B}, \tilde{C}_{1 d}$, and $\tilde{C}_{2 d}$. Figure

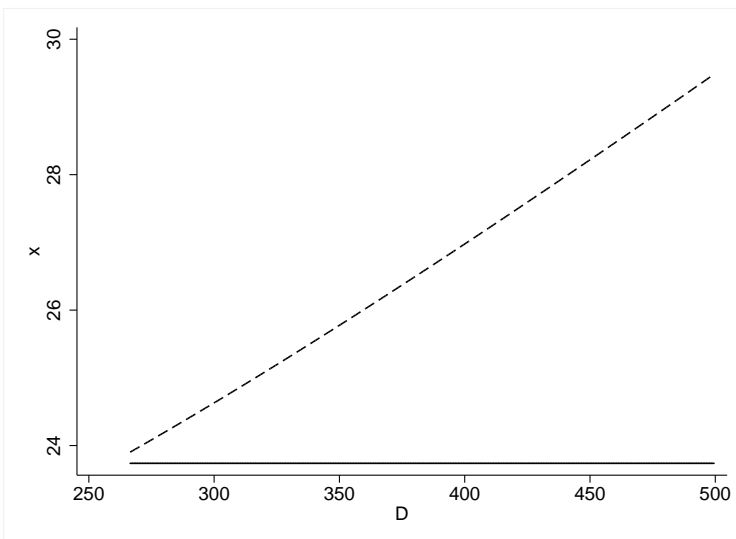

(a)

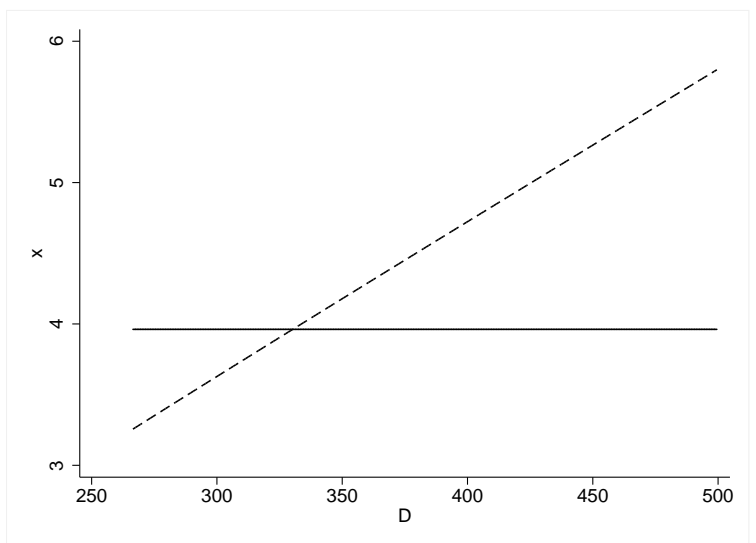

(b)

$x^{I}(f)-$ $\hat{x}^{I}(f, D)--$

$$
\begin{aligned}
& x^{L I}(f)- \\
& x^{B}(f, D)--
\end{aligned}
$$

Figure 5.9: (a) Investment Threshold when Debt levels are Risky for both Switching and Starting as compared to when Debt levels are Default Risk-Free for both Switching and Starting,

(b) Liquidation Threshold when Debt levels are Risky for both Switching and Starting as compared to when Debt levels are Default Risk-Free for both Switching and Starting

9 (a) compares $\hat{x}^{I}(f, D)$ to $x^{I}(f)$, where $f$ has been fixed at $f=0.25$. The range of $D$ in the figure is $D \geq D^{*}$. This is because with $f=0.25>\bar{f}, D$ is risky both for the switching and the starting problem only when $D>D^{*}$. Had we fixed $f$ at some value, where $f<\bar{f}, D$ would be risky for both the switching and the starting problem for all $D>D^{I}$. Since $x^{I}(f)$ is only a function of $f$, and since $f$ has been fixed, $x^{I}(f)$ is constant. As can be seen from the figure, for a given $f$, as $D$ increases, 
$\hat{x}^{I}(f, D)$ increases. That is, with risky debt in place, the firm postpones investment as compared to $x^{I}(f)$. This is due to debt overhang problem of having excessive debt in place, because of which firms in some states of nature forego investing in projects which otherwise could have been undertaken to the benefit of the firm.

As far as the default threshold $x^{B}(f, D)$ is concerned, we find that for certain values of $D$ the firm defaults late as compared to when debt is default risk-free, and for higher values of $D$, the firm defaults earlier as compared to when $D$ is default risk free. The default phenomena for the first stage starting of the R\&D problem, observed when $D$ is risky for both the first as well as the second stage is the same as that for the second stage switching problem. The reasons for observing this phenomena is essentially the same as that for the switching problem, and are not mentioned here. However, we do note that when the level of risky debt $D$ is high, above a certain threshold, the debt overhang problem is also reflected in the early default of the firm as compared to the situation when debt is default risk-free. The value of debt is obtained exactly in the same manner as stated in the last section.

\section{Debt level Risky for Switching, Default Risk-Free for Starting}

We denote by $\bar{x}^{I}$ the investment threshold and by $\bar{x}^{L I}$ the liquidation threshold when the pair $(D, f)$ are such that they lie in Area 4. For any $f$, below $\bar{f}$, in Area 4 where $D$ is such that $D^{*}(f)<D \leq D^{I}(f)$, debt level that is safe prior to starting of the R\&D project become risky after starting the R\&D project. To solve for the outcomes $\bar{x}^{I}$ and $\bar{x}^{L I}$ we solve the system of equations:

$$
\begin{gathered}
C_{1 d}\left(\bar{x}^{I}\right)^{\beta}+C_{2 d}\left(\bar{x}^{I}\right)^{\theta}+\frac{\psi \bar{x}^{I}}{r-\mu}=E_{c}^{r}\left(\bar{x}^{I}\right)-I, \\
\beta C_{1 d}\left(\bar{x}^{I}\right)^{\beta-1}+\theta C_{2 d}\left(\bar{x}^{I}\right)^{\theta-1}+\frac{\psi}{r-\mu}=\frac{\partial E_{c}^{r}\left(\bar{x}^{I}\right)}{\partial x}, \\
C_{1 d}\left(\bar{x}^{L I}\right)^{\beta}+C_{2 d}\left(\bar{x}^{L I}\right)^{\theta}+\frac{\psi \bar{x}^{L I}}{r-\mu}=\phi_{f}+\frac{\phi_{1} \bar{x}^{L I}}{r-\mu},
\end{gathered}
$$

and

$$
\beta C_{1 d}\left(\bar{x}^{L I}\right)^{\beta-1}+\theta C_{2 d}\left(\bar{x}^{L I}\right)^{\theta-1}+\frac{\psi}{r-\mu}=\frac{\phi_{1}}{r-\mu} .
$$


Equation (3-38) and (3-39) are the value matching and smooth pasting conditions at $\bar{x}^{I}$, while (3-40) and (3-41) are the value matching and smooth pasting conditions at $\bar{x}^{L I}$. Note that at $\bar{x}^{I}$ the value of the firm's equity in decision region is equated with value of the firm's equity in the continuation region, $E_{c}^{r}\left(\hat{x}^{I}\right)$, which is the value of equity in the continuation region when debt is risky for the second stage switching problem. Along with $\bar{x}^{I}$ and $\bar{x}^{L I}$ we also obtain the values of $C_{1 d}$ and $C_{2 d}$. To solve the above system of equations numerically, we assume $\phi_{1}=0.65$ and $f=0.05$. The results of the numerical solution are illustrated in Figure 10. For a given $f$, the figure $\operatorname{plots} \bar{x}^{I}(f, D)$ and

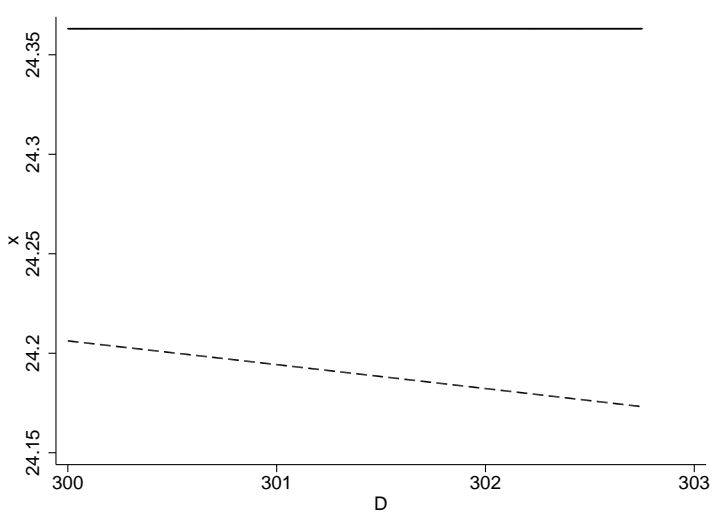

(a)

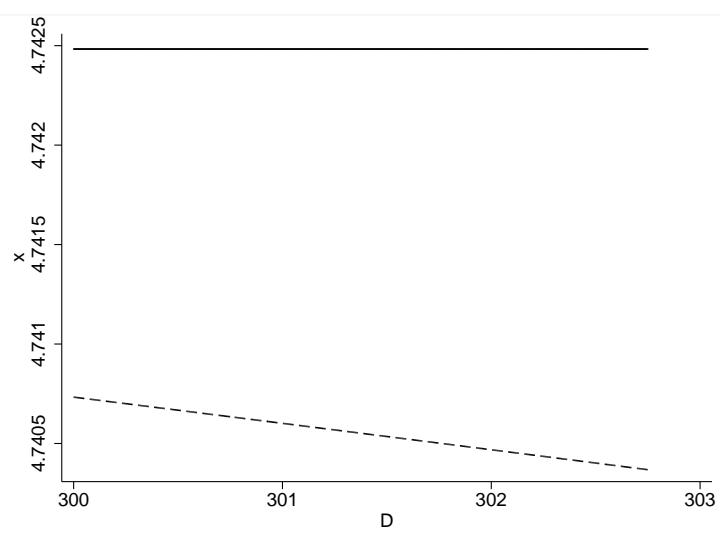

(b)

$x^{I}(f)-$

$x^{L I}(f)$

$\bar{x}^{I}(f, D)-\cdots$

$\bar{x}^{L I}(f, D)--$

Figure 5.10: (a) Investment Threshold when Debt levels are Risky for Switching and Default RiskFree for Starting as compared to when Debt levels are Default Risk-Free for both Switching and Starting,

(b) Liquidation Threshold when Debt levels are Risky for Switching and Default Risk-Free for Starting as compared to when Debt levels are Default Risk-Free for both Switching and Starting

$\bar{x}^{L I}(f, D)$ over the range of $D, D^{*}(f)<D \leq D^{I}(f)$. Figure $10\left(\right.$ a) compares $\bar{x}^{I}(f, D)$ and $x^{I}(f)$. We find that the investment threshold, $\bar{x}^{I}(f, D)$, is lower than $x^{I}(f)$ and that $\bar{x}^{I}(f, D)$ decreases as $D$ decreases. In other words, when the pair $(D, f)$ is such that it lies in Area 4 the equity holders of the firm overinvest. The incentive of equity holders to exercise the investment option early relative to the case when $D$ is default risk-free for both the first and the second stage is explained as follows. Equity holders have a strong incentive to exercise the investment option quickly and reap the benefits of a successfully implemented $\mathrm{R} \& \mathrm{D}$ project if the project is successfully completed prior to any liquidation. This incentive is higher for higher levels of $D$ since equity holders are not concerned about the welfare of bondholders, and are therefore indifferent to the increased risk of bankruptcy resulting from their early exercise decision. Having limited liability, equity holders shift the burden 
of default risk of an early exercise decision on to the bondholders, while simultaneously enjoying a real possibility of reaping higher cash flows form a successfully implemented R\&D output, which can then reduce their debt burden of a high debt service.

We also find that $\bar{x}^{L I}(f, D)$ is lower as compared to when debt is default risk free before and after investing in R\&D and decreases as the level of debt increases. Choosing to liquidate at a later time is also symptomatic of overinvestment. By waiting longer to liquidate, it could happen that low realization of cash flows might eventually turn up to the point, $\bar{x}^{I}(f, D)$, at which the firm can invest in R\&D.

Thus, what is important about Area 4, the region in the $f, D$ plain where $f$ low, is that even when $D$ is default risk-free prior to starting of the $\mathrm{R} \& \mathrm{D}$ project it turns risky upon embarking on the $R \& D$ project. This implies that after having started the $R \& D$ project, unless the firm lowers its debt level, the value of the existing debt falls. Thus when $f$ is low, unless the existing debt levels are very low, the firm may not be able to finance its $R \& D$ project with additional debt at the time when it starts the $R \& D$ project. Also, in this situation, after having embarked on the R\&D project early, when the firm has to continue with the R\&D project, it is beset with the agency problem of underinvestment with debt overhang.

\subsection{Comparison with Scale Expansion}

In this section we contrast $R \& D$ investment with scale expansion of the firm, where the firm employs the old existing technology that that yields a revenue of $\psi x_{t}$ per instant of time, which is less than, $x_{t}$, the revenue earned from the successfully implemented R\&D project. Equity holders of the firm can chose to invest in $R \& D$ activity or expand the scale of the operation by employing the existing technology that yields a revenue of $\psi x_{t}$ every instant of time. R\&D activity, as discussed earlier because of the intangibility of the assets involved and the uncertainty in developing a new process or a product - is a risky venture. We emphasize here that, the parameters, the expected time to completion, $T_{p}=\frac{1}{\lambda}$, and the degree of tangibility, $f$, are technologically specified and fixed ${ }^{11}$. That is, these parameters can not be affected by the firm nor does the economy, at an point in time, has available many technologies that vary in the parameters mentioned above.

Consider a firm with an option to expand the scale of its operation by employing the existing technology that yields a cash flow of $\psi x_{t}$ per instant of time. In expanding the scale of its operation

\footnotetext{
${ }^{11}$ It is possible that the economy has available many technologies with different cost. However, we do model the choice of technology here.
} 
the firm can consider two possibilities: (a) expand the scale of its operation by using the same amount of investment $\mathbb{I}=I$ as needed to start the $R \& D$ activity or (b) by employing some level of investment II to achieve the same level of cash flows, $(1+\psi) x_{t}$, as the successfully completed R\&D activity yields.

Let us first consider possibility (a), where the firm expands the scale of its operation by installing a capital of the amount, $I$, precisely the amount needed to start the $R \& D$ project. The question is by how much is the scale of operation increased if the firm invests $\mathbb{I}=I$. To answer this question, we assume that a fraction $r$ of $\mathbb{I}$ involves physical capital, while $1-r$ of $\mathbb{I}$ is used up in training, administrative and adjustment costs. In the event of liquidation a fraction $f$ of $r \mathbb{I}$ is lost. On the other hand, in the event of closure, all of $(1-r) \mathbb{I}$ is lost. We also assume that the existing technology, that yields a profit of $\psi x_{t}$ per instant of time, is a constant returns to scale technology. That is, if the existing capital stock is doubled then the profit every instant doubles to $2 \psi x_{t}$.

Note that the constant liquidation value of existing operation of the firm that yields a cash flow of $\psi x_{t}$ per instant of time is $\phi_{f}$. If $\phi_{f}$ is the value of physical capital, employed by the firm in liquidation states, then the value of physical capital when the firm is operating is $\phi_{f} / \underline{f}$. Therefore, if the firm spends an amount, $r \mathbb{I}=r I$, of physical capital for scale expansion, then the scale by which the existing operation of the firm is expanded ${ }^{12}$ is given by $s=\frac{f r \mathbb{I}}{\phi_{f}}$. Hence, having invested $\mathbb{I}$, the amount by which the cash flows of the firm increases, given constant returns to scale, is given by: $s \psi x=\frac{f r \mathbb{I}}{\phi_{f}} \psi x$. When the firm wants to increase the scale of its production to the point where it can reap the same cash flows as from a successfully implemented $R \& D$ project, the scale to which it needs to expand the firm can be obtained from the relation: $(1+s) \psi=(1+\psi)$. Given constant return to scale, the amount of investment, $r \mathbb{I}$, needed to achieve the scale, $s=1 / \psi$, can be computed by employing the relation: $s=\frac{f r \mathbb{I}}{\bar{\phi}_{f}}$.

Suppose the firm wants to increase the scale of its operation so as to reap a cash flow of $(1+\psi) x_{t}$ per instant of time, then we know that the firm needs to increase its scale of operation by $s=1 / \psi$. In order to compute the total amount of investment, $\mathbb{I}$, needed, we need to get an estimate of $\underline{f}$ and $r$. Cooper and Haltiwanger (2006) use the method of indirect inference to study investment irreversibility, where firms also disinvest. Assuming that the buying price of capital goods, $p_{b}$, to be equal to 1 , they compute the resale price of capital goods $p_{s}=0.975$. We assume our parameter, $\underline{f}=p_{s}$. That is, of the $r \mathbb{I}$ of the physical capital invested, in the event of liquidation, the firm loses a fraction $\left(1-p_{s}\right)=(1-\underline{f})$ of $r \mathbb{I}$.

\footnotetext{
${ }^{12}$ The implicit assumption here is that capital is perfectly divisible and that output of the firm can be proportionately increased for a marginal increase in capital. However, this assumption is not binding on the analysis that follows. We can specify a technology with discrete units of capital to achieve a certain scale, but this does not provide any new insight as far our analysis is concerned.
} 
Cooper and Haltiwanger (2006) also compute adjustment cost of capital, that includes both convex and non-convex cost of adjustment. They specify convex cost of adjustment as $c=\frac{\gamma}{2}\left(\frac{\mathcal{I}}{\mathcal{K}}\right)^{2} \mathcal{K}$, and non-convex cost of adjustment as $F \mathcal{K}$, where $\mathcal{I}$ is the amount of capital investment, $\mathcal{K}$ is the amount of existing capital stock, and $F$, the fixed cost of adjustment, which is independent of the level of activity of the firm, is proportional to the level of capital at the firm. Using the method of indirect inference, they estimate the adjustment cost parameters $\gamma$ and $F$ as, $\gamma=0.049$ and $F=0.039$. Since, $s=1 / \psi$ and $\underline{f}=0.975$ are known, we can compute $r \mathbb{I}$. Now, according to our assumption the investment in capital, $\mathcal{I}$, is $r \mathbb{I}$ and $\mathcal{K}=\frac{\phi_{f}}{\underline{f}}$. Thus $(1-r) \mathbb{I}$, the assumed adjustment costs incurred during scale expansion, can be computed as:

$$
(1-r) \mathbb{I}=\frac{\gamma}{2}\left(\frac{\underline{f} r \mathbb{I}}{\phi_{f}}\right)^{2} \frac{\phi_{f}}{\underline{f}}+F \frac{\phi_{f}}{\underline{f}} .
$$

With $r \mathbb{I}$ known, and given the estimate of $1-r \mathbb{I}, r$ and $\mathbb{I}$ can be computed. On the other hand, if only the total investment $\mathbb{I}$ is known, then $r$ can be obtained by solving the above quadratic equation. Thus in the event of liquidation, of the total amount of investment, $\mathbb{I}$, the firm loses $(1-r) \mathbb{I}+(1-\underline{f}) r \mathbb{I}$. We denote by $g=1-\frac{(1-r) \mathbb{I}+(1-\underline{f}) r \mathbb{I}}{\mathbb{I}}=\underline{f} r$, the fraction of the investment, $\mathbb{I}$, that can be regained by the firm in the event of liquidation.

The problem facing a firm that intends to expand its scale of operation constitutes of essentially three decisions: (i) when to optimally expand its scale of operation, (ii) when to optimally liquidate the firm after having increased its size, and (iii) if the expansion has not yet taken place, when to optimally liquidate itself if the cash flows of the firm happen to fall prior to sinking $\mathbb{I}$. Assume that the firm has debt, $D$ in place, which is default risk-free before and after scale expansion. Suppose the firm has not yet expanded its scale of operation, and is earning a profit of $\psi x_{t}$ per instant of time and retains the options to expand itself or to liquidate itself. If demand rises and crosses a certain a limit the firm would expend resources of the amount $\mathbb{I}$ to expand the scale of its production. Let $x_{e}$ be the optimal threshold level, such that if demand crosses $x_{e}$, then the firm expands its scale of operation. If however, demand falls below a certain threshold then the firm liquidates itself. Let $x_{l b}$ be the optimal closure threshold at which firm liquidates itself before having expanded its scale of operation. After having expanded the scale of its operation, it is quite likely that demand for the firm's produce falls down. In which case the firm at a certain lower threshold will call for closure. We denote the optimal closure threshold at which the firm liquidates itself after having expanded it's scale operation as $x_{l a}$.

For the scale expansion problem, the value of the firm at the closure threshold, $x_{l b}$, before the 
firm invests, $\mathbb{I}$, to expand the scale of its operation is given by,

$$
E_{l}\left(x_{l b}\right)=\phi_{f}+\frac{\phi_{1} x_{l b}}{r-\mu}-D \geq 0
$$

where $\frac{\phi_{1} x_{l b}}{r-\mu}$ is the value of the firm as a going concern at the liquidation threshold $x_{l b}$. At the liquidation threshold $x_{l a}$, after the firms has expanded the scale of its operation, the value of the equity is given by:

$$
E_{l}\left(x_{l a}\right)=\phi_{f}+\underline{f} r \mathbb{I}+\frac{\phi_{1}^{\prime} x_{l a}}{r-\mu}-D \geq 0
$$

where $\phi_{1}^{\prime}$ is the net revenue earned by the firm as a going concern in the event of closure after the scale expansion. The above two equation (4-4) and (4-5) imply that the maximum level of default risk-free debt, $D_{b}$, before and, $D_{a}$, after scale expansion are respectively given by:

$$
\begin{gathered}
D_{b}=\phi_{f}+\frac{\phi_{1} x_{l b}}{r-\mu} \\
D_{a}=\phi_{f}+\underline{f} r \mathbb{I}+\frac{\phi_{1}^{\prime} x_{l a}}{r-\mu} .
\end{gathered}
$$

We are now left with computing the value of equity before and after scale expansion. Without writing the optimization problem of the firm, standard option theoretic argument tells us that the value of the firm's equity before having expanded the scale of operation, $E_{b}(x)$, is governed by the differential equation,

$$
\frac{1}{2} x^{2} \sigma^{2} E_{b_{x x}}(x)+\mu x E_{b_{x}}(x)-r E_{b}(x)+\psi x-r D=0, x_{l b} \leq x \leq x_{e},
$$

and the differential equation governing the value of the firm's equity after the scale expansion is given by:

$$
\frac{1}{2} x^{2} \sigma^{2} E_{a_{x x}}(x)+\mu x E_{a_{x}}(x)-r E_{b}(x)+(1+s) \psi x-r D=0, x \geq x_{e} .
$$

We know that the solutions to the above differential equations, (4-5) and (4-6), are respectively given 
by:

$$
E_{b}(x)=A_{b 1} x^{\beta}+A_{b 2} x^{\theta}+\frac{\psi x}{r-\mu}-D
$$

and

$$
E_{a}(x)=A_{a 1} x^{\beta}+A_{a 2} x^{\theta}+\frac{(s+1) \psi x}{r-\mu}-D
$$

where $\theta<0$ and $\beta>1$ are of the roots of the characteristic equation, $\frac{1}{2} \sigma^{2} \eta^{2}+\left[\mu-\frac{1}{2} \sigma^{2}\right] \eta-r=0$. The constants $A_{b 1}, A_{b 2}, A_{a 1}$ and $A_{a 2}$ are determined using boundary conditions. The first boundary condition that we consider is one stated in (2-11):

$$
\lim _{x \rightarrow \infty} E_{a}(x) \propto x
$$

the explanation for which has been provided earlier. This implies that, since $\beta>1, A_{a 1}=0$. Thus we are left with three constants: $A_{b 1}, A_{b 2}$, and $A_{a 2}$, which can be determined by the boundary conditions, the value matching and the smooth pasting, at the free boundaries $x_{e}, x_{l a}$, and $x_{l b}$. The value matching and smooth pasting conditions respectively at $x_{e}$ are given by equations (4-9) and (4-10). The same conditions at $x_{l b}$ and $x_{l a}$ respectively are given by equations (4-11)-(4-12) and $(4-13)-(4-14)$.

$$
\begin{gathered}
A_{b 1} x_{e}^{\beta}+A_{b 2} x_{e}^{\theta}+\frac{\psi x_{e}}{r-\mu}-D=A_{a 2} x_{e}^{\theta}-\mathbb{I}+\frac{(s+1) \psi x_{e}}{r-\mu}-D \\
\beta A_{b 1} x_{e}^{\beta-1}+\theta A_{b 2} x_{e}^{\theta-1}+\frac{\psi}{r-\mu}=\theta A_{a 2} x_{e}^{\theta-1}+\frac{(s+1) \psi}{r-\mu} \\
A_{b 1} x_{l b}^{\beta}+A_{b 2} x_{l b}^{\theta}+\frac{\psi x_{l b}}{r-\mu}-D=\phi_{f}+\frac{\phi_{1} x_{l b}}{r-\mu}-D \\
\beta A_{b 1} x_{l b}^{\beta-1}+\theta A_{b 2} x_{l b}^{\theta-1}+\frac{\psi}{r-\mu}=\frac{\phi_{1}}{r-\mu} \\
\phi_{f}+\underline{f r} r+\frac{\phi_{1}^{\prime} x_{l a}}{r-\mu}-D=A_{a 2} x_{l a}^{\theta}+\frac{(s+1) \psi x_{l a}}{r-\mu}-D
\end{gathered}
$$




$$
\frac{\phi_{1}^{\prime}}{r-\mu}=\theta A_{a 2} x_{l a}^{\theta-1}+\frac{(s+1) \psi}{r-\mu}
$$

Since no analytical solutions for the above system of equations exists, we resort to numerical solution. While all the parameters remain the same as in Table 1, for the scale expansion problem, there are five additional parameters: $\phi_{1}^{\prime}, s, r, \underline{f}$, and $\mathbb{I}$. Assume that the firm by spending some amount $\mathbb{I}$, wants to expand the scale of operation so as to reap the same amount of cash flows from a successfully completed $\mathrm{R} \& \mathrm{D}$. For such a case we know that $s=1 / \psi$, where $\psi$ is given in Table 1 . We assume $\underline{f}=0.975$, the relative resale price of capital goods as estimated in Cooper and Haltiwanger (2006). Given $s$ and $f$, as discussed earlier we can compute $r \mathbb{I}$, the amount of capital investment needed for scale expansion. As it turns out, the amount of capital investment $r \mathbb{I}$ needed to achieve the same amount cash flows as from a successfully completed $R \& D$ project is $r \mathbb{I}=256.4$. In order to compute the total gross investment, $\mathbb{I}$, needed we have to compute the amount of adjustment costs $(1-r) \mathbb{I}$ needed to install $r \mathbb{I}$ of capital. Given $(4-1), \gamma=0.049$ and $F=0.039$, it turns out that $(1-r) \mathbb{I}=15.852$ and $g=\underline{f} r=0.92=\bar{g}$. Given our assumptions about the scale expansion parameters, it turns out that the total amount of investment needed for $\mathrm{R} \& \mathrm{D}, I+K$, to achieve a cash flow of $(\psi+1) x_{t}$ per instant of time is about $63 \%$ of the total investment, $\mathbb{I}$, needed to achieve the same cash flows through scale expansion.

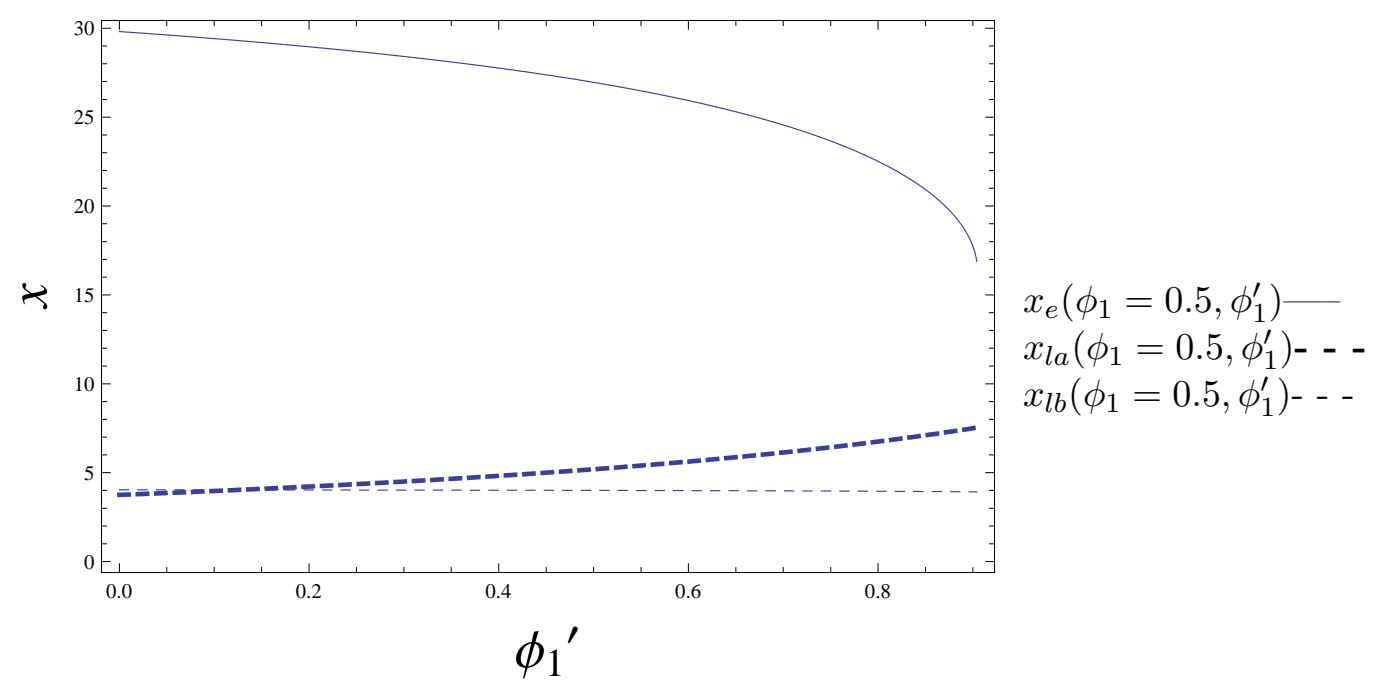

Figure 5.11: Scale expansion threshold, $x_{e}$, liquidation threshold before investing in scale expansion, $x_{l b}$, and liquidation threshold after investing in scale expansion, $x_{l b}$.

While we could determine $s, r, \underline{f}$, and $\mathbb{I}$, for $\phi_{1}^{\prime}$ we need to assume a value. Given $\phi_{1}=0.5$, Figure 11 plots $x_{e}, x_{l b}$, and $x_{l a}$ as a function of $\phi_{1}^{\prime}$. We find that as $\phi_{1}^{\prime}$ increases $x_{e}\left(\phi_{1}=0.5, \phi_{1}^{\prime}\right)$ decreases and asymptotes downwards at some higher value of $\phi_{1}^{\prime}$. That is to say, if the firm perceives 
that post scale expansion the net revenue of the firm as a going concern will be high, then the firm will be only too eager to expand the scale of its operation. This is because having increased the scale of its operation, if the net revenue of the firm in liquidation states is high and if the fraction, $g$, of the initial investment, $\mathbb{I}$, that can be retained is high, then in the event of liquidation equity holders of the firm obtain a higher value for the firm ${ }^{13}$. Thus, if $\phi_{1}^{\prime}$ is high then the incentive to expand the scale of its operation is high too. We also find that the liquidation threshold, $x_{l a}$, post scale expansion, increases with $\phi_{1}^{\prime}$, while the liquidation threshold, $x_{l b}$, prior to expansion decreases with $\phi_{1}^{\prime}$. Post scale expansion, if the cash flows of the firm does fall down and if $\phi_{1}^{\prime}$ is high, then the value received by the firm at liquidation will be high. Therefore, with $\phi_{1}^{\prime}$ being high, the gains to be made by liquidating early are higher than continuing. The importance of net revenue, $\phi_{1}^{\prime}$, earned by the firm as going concern in liquidation states, post scale expansion, is also reflected by the fact that the liquidation threshold, $x_{l b}$, prior to scale expansion decreases as $\phi_{1}^{\prime}$ increases. This is because, if the firm knows today that after scale expansion the liquidation value of the firm will be high, then it would rather wait longer to liquidate today when it has not yet expanded the scale of its operation.

Figure 12 compares the optimal trigger threshold level of demand at which the firm expands its scale of operation $x_{e}\left(g=\bar{g}, \phi_{1}^{\prime}\right)$ and the trigger threshold at which the firm embarks on the R\&D program, $x^{I}(f)$. While the $x^{I}(f)$ is computed for all values of $f, g$, the fraction of investment $\mathbb{I}$

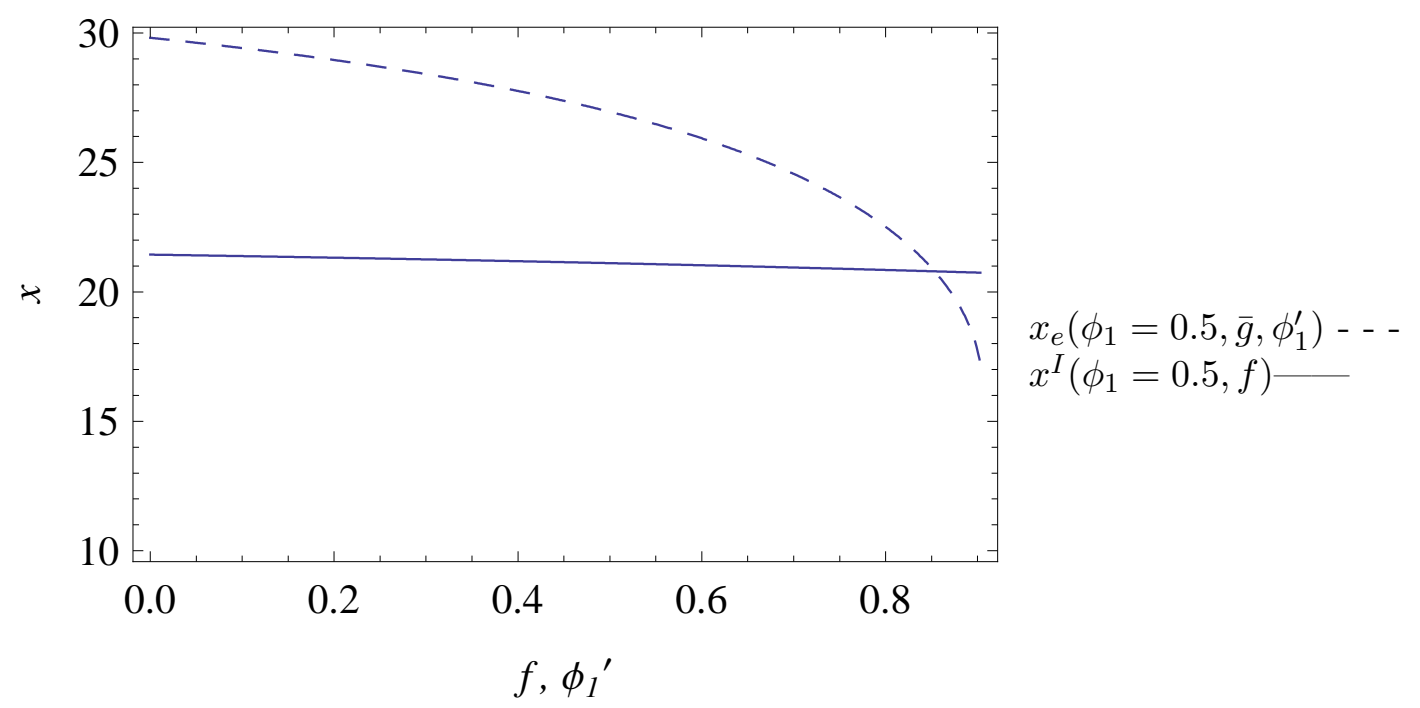

Figure 5.12: Scale Expansion threshold, $x_{e}$, and Starting of R\&D Project threshold, $x^{I}$.

retained in the event of liquidation has been fixed at $g=0.92=\bar{g}$ and $\phi_{1}^{\prime}$ is varied. We find that for any given $f, x^{I}(f)$ is smaller that $x_{e}\left(\phi_{1}^{\prime}\right)$ for most values of $\phi_{1}^{\prime}$, and that for any given $f$, the

\footnotetext{
${ }^{13}$ As $g$ declines we find that $x_{e}\left(\phi_{1}=0.5, g, \phi_{1}^{\prime}\right)$ asymptotically decreases at higher value of $\phi_{1}^{\prime}$.
} 
difference between $x_{e}\left(\phi_{1}^{\prime}\right)$ and $x^{I}(f)$ narrows down as $\phi_{1}^{\prime}$ becomes larger. For any given $\phi_{1}^{\prime}$ the difference between $x_{e}\left(\phi_{1}^{\prime}\right)$ and $x^{I}(f)$ becomes smaller as $f$ decreases. This suggests that for a given $f, \mathrm{R} \& \mathrm{D}$ investment is more desirable when $\phi_{1}^{\prime}$ is low. This is because when $\phi_{1}^{\prime}$ is low, the level of exogenous demand needed to trigger scale expansion, $x_{e}$, is higher than $x^{I}$. Figure 12 also suggests that for any given $f$, there exists a $\bar{\phi}_{1}^{\prime}$ such that $x_{e}\left(\bar{\phi}_{1}^{\prime}\right)=x^{I}(f)$. Let $f_{a}$ and $f_{b}$ be two levels of fraction $f$ that can be retained of the initial investment $I$ required to start the R\&D program, such that, $f_{a}<f_{b}$. Then as Figure 12 suggests, $\bar{\phi}_{1_{a}}^{\prime}<\bar{\phi}_{1_{b}}^{\prime}$, where $x_{e}\left(\bar{\phi}_{1_{a}}^{\prime}\right)=x^{I}\left(f_{a}\right)$ and $x_{e}\left(\bar{\phi}_{1_{b}}^{\prime}\right)=x^{I}\left(f_{b}\right)$. This implies that if there is a situation, such that, $f=f_{a}$ and $\phi_{1}^{\prime}=\bar{\phi}_{1_{b}}^{\prime}$, then at these values of $f$ and $\phi_{1}^{\prime}$, the firm will chose to expand its scale of operation rather than invest in R\&D. Since, for these values of $f$ and $\phi_{1}^{\prime}, x_{e}\left(\bar{\phi}_{1_{b}}^{\prime}\right)<x^{I}\left(f_{a}\right)$.

As discussed earlier, for any given $f$, there exists a $\bar{\phi}_{1}^{\prime}$ such that $x_{e}\left(\bar{\phi}_{1}^{\prime}\right)=x^{I}(f)$ at which a firm is indifferent between investing or expanding the scale of operation. For a given $f$, if $\phi_{1}^{\prime}$ is lower that $\bar{\phi}_{1}^{\prime}$, we find that the trigger threshold level of exogenous demand, $x_{e}\left(\bar{g}, \phi_{1}^{\prime}\right)$, at which the firm opts to expand the scale of operation is higher than $x^{I}(f)$, the optimal trigger threshold level of demand at which the firm embarks on the $R \& D$ project. This is due to the fact that scale expansion involves using an inefficient technology as compared to the outcome of an R\&D endeavor. Thus, unless demand for the firm's produce is high enough, the firm is does not expand the scale of operation. On the other hand by investing a lower amount, $I$, where $I<\mathbb{I}$, if the firm successfully completes the R\&D project, the firm is able to capture the same amount of cash flows as from expanding the scale of its operation. For any given $f$, as stated earlier, as $\phi_{1}^{\prime}$ increases the higher incentive of receiving a higher value for the firm at liquidation post scale expansion, starts overriding the efficiency concern $^{14}$. Also, ceteris paribus, if the fraction, $f$, of initial investment that can be retained in the event of liquidation is high, then the firm embarks upon the R\&D project even earlier. This is due to the fact that with higher $f$ the costs associated with starting the R\&D project is low, and the extent of tangibility involved in starting the $R \& D$ project is high, making the $R \& D$ undertaking a less risky endeavor.

As stated earlier, $x_{l b}$ is the optimal closure threshold of a firm that has the option to expand the scale of operation but has not expanded the scale as yet. Figure 13 (a) below illustrates the optimal closure threshold of demand for such a firm before scale expansion and the optimal closure threshold, $x^{L I}$, of the firm that is contemplating to conduct $\mathrm{R} \& \mathrm{D}$ but has not embarked on the project as yet.

\footnotetext{
${ }^{14}$ Note, in all the analysis we have kept $\phi_{1}$, the net revenue of the firm as a going concern at liquidation prior to scale expansion or R\&D investment, fixed at $\phi_{1}=0.5$. Changing $\phi_{1}$ shifts both the curves $x_{e}\left(\phi_{1}^{\prime}\right)$ and $x^{I}(f)$ upwards or downwards. However, since the shifts are almost in the same proportion, the difference between $x_{e}\left(\phi_{1}^{\prime}\right)$ and $x^{I}(f)$ remains almost the same.
} 
We find that the optimal closure threshold of the firm with an option to do $R \& D$, that has not been exercised as yet, is lower as compared to the closure threshold of the firm with an option to expand the scale of operation. We obtain this result even when the constant liquidation value in liquidation

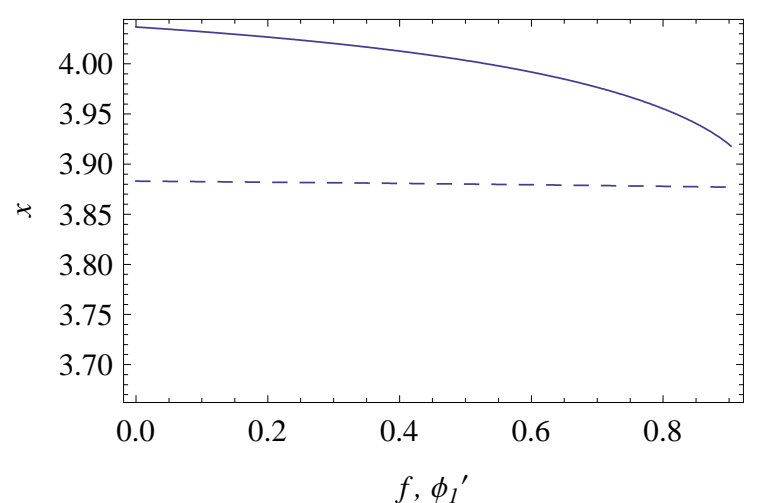

(a)

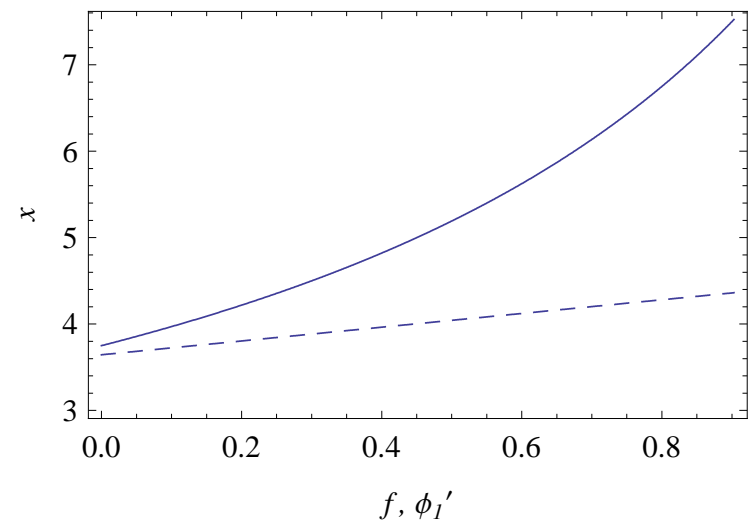

(b)

$x_{l b}\left(\bar{g}, \phi_{1}^{\prime}\right)$

$x_{l a}\left(\bar{g}, \phi_{1}^{\prime}\right)$

$x_{l}(f)--$

Figure 5.13: (a) Liquidation threshold before scale expansion, $x_{l b}\left(\bar{g}, \phi_{1}^{\prime}\right)$, and before starting the R\&D project, $x^{L I}$. (b) Liquidation threshold after scale expansion, $x_{l a}\left(\bar{g}, \phi_{1}^{\prime}\right)$, and after starting the R\&D project, $x_{l}(f)$.

states is same for both the firms. This can only be possible if at $x_{l b}\left(\bar{g}, \phi_{1}^{\prime}\right)$, for any given $\phi_{1}^{\prime}$, the value of equity to continue without liquidating, $E_{d}\left(x_{l b}\left(\bar{g}, \phi_{1}^{\prime}\right)\right)$, of the firm that seeks to engage in $\mathrm{R} \& \mathrm{D}$ is higher than the liquidation value of the same firm at $x_{l b}\left(\bar{g}, \phi_{1}^{\prime}\right)$. In other words, at $x_{l b}\left(\bar{g}, \phi_{1}^{\prime}\right)$ the value of the firm to continue without liquidating and maintain the value of the option to start the $R \& D$ project is higher than the value the firm could have earned by liquidating itself. This in a way confirms the importance of $\mathrm{R} \& \mathrm{D}$ activity: at the level of exogenous demand, $x_{l b}\left(\bar{g}, \phi_{1}^{\prime}\right)$, when a firm is likely to give up its option to expand the scale of its operation, the value of the option to start $R \& D$ for a firm that seeks to invest in $R \& D$ is still valuable enough, so as not to seek closure and wait longer. This again is due to the fact that, with a certain degree of uncertainty, a firm with relatively low investment in $\mathrm{R} \& \mathrm{D}$ is able to reap higher profits ${ }^{15}$.

Figure 13 (b), illustrates the optimal trigger threshold, $x_{l a}\left(\bar{g}, \phi_{1}^{\prime}\right)$, at which a firm that has already expanded the scale of its operation liquidates itself, and $x_{l}(f)$, the trigger threshold at which a firm

\footnotetext{
${ }^{15}$ This result is however conditional on the choice of $\lambda$, the intensity with which the R\&D project can be completed. We find that when $\lambda$ is low then it is possible that the closure threshold for the R\&D project, $x^{L I}$, prior to starting the $\mathrm{R} \& \mathrm{D}$ project, lies above the closure threshold for the scale expansion program, $x_{l b}$. In other words, for low values of $\lambda$ the value of the option to invest in $\mathrm{R} \& \mathrm{D}$ may not be high enough to continue at some low level of demand. As $\lambda$ falls down, we also find that $x^{I}$ increases, which implies that the difference between the starting threshold for the scale expansion program and the starting threshold for the R\&D project narrows down.
} 
that has embarked on the R\&D program liquidates itself. As can be seen from the figure, whether the liquidation thresholds $x_{l a}\left(\bar{g}, \phi_{1}^{\prime}\right)$ and $x_{l}(f)$ are higher or lower compared to each other depends on the particular combination of $\phi_{1}^{\prime}$ and $f$. Let us first consider $\phi_{1}^{\prime}=0$. For $\phi_{1}^{\prime}=0$, as can be evinced from the figure that there exists a $f_{0}$, such that $x_{l a}\left(\bar{g}, \phi_{1}^{\prime}=0\right)=x_{l}\left(f_{0}\right)$. For all $f$ greater than $f_{0}$, the firm that invests in $\mathrm{R} \& \mathrm{D}$ liquidates earlier than the firm that has expanded the scale of its operation and whose net revenue as a going concern at liquidation, post scale expansion, is 0 . On the other hand, for all $f$ less than $f_{0}$, the firm that invests in $\mathrm{R} \& \mathrm{D}$ liquidates it self earlier than the firm that expanded the scale of its operation, even when the only value that it receives happens to be the constant liquidation value. Now consider the maximum value of $f=f_{m}$. For $f=f_{m}$, as the figure suggests, there exists a $\phi_{1}^{\prime}=\phi_{1_{m}}^{\prime}$, such that, $x_{l a}\left(\bar{g}, \phi_{1_{m}}^{\prime}\right)=x_{l}\left(f_{m}\right)$. For all $\phi_{1}^{\prime}>\phi_{1_{m}}^{\prime}$, the liquidation threshold of the firm that expands the scale of its operation is higher than the firm that invests in R\&D for all values of $f$.

For all values of $f \in\left(f_{0}, f_{m}\right)$, there exists a $\tilde{\phi}_{1}^{\prime}$, such that, $x_{l}(f)=x_{l a}\left(\bar{g}, \tilde{\phi}_{1}^{\prime}\right)$. For that particular value of $f$, at all $\phi_{1}^{\prime}$ lower that $\tilde{\phi}_{1}^{\prime}$ the firm that has expanded the scale of operation liquidates itself late as compared to the firm that invests in $\mathrm{R} \& \mathrm{D}$, and for all values of $\phi_{1}^{\prime}$ greater that $\tilde{\phi}_{1}^{\prime}$ the firm that expands the scale of its operation liquidates it self early than the firm that invests in R\&D. To cut the long story short, when $f$ is low, $f<f_{0}$, for all values of $\phi_{1}^{\prime}$, the firms that has expanded the scale of its operation closes much earlier than the firm that has expended resources to start the $R \& D$ program. This is due to the fact that on one hand, the firm that expands it's scale of operation invests largely in physical assets, whose resale value is high as compared to an $R \& D$ performing firm that invests $I$ to start the R\&D project, but loses almost all of $I, f<f_{0}$, at liquidation prior to successfully completing the R\&D. To put in other words, when $f$ is low then the fraction of the initial investment, $I$, retained in the event of liquidation is low, which implies that the degree of investment irreversibility associated with investing in $R \& D$ is high. Therefore when $f$ is low, the firm waits longer, during which demand may rise so that it may resume on with the R\&D activity, or eventually liquidate at a lower value of $x$. On the other hand, as $\phi_{1}^{\prime}$, the net revenue of the firm as a going concern at liquidation, post scale expansion, increases, the incentive of the firm to liquidate the firm at higher levels of exogenous demand becomes larger, to the extent that when $\phi_{1}^{\prime}>\phi_{1_{m}}^{\prime}$, the firm that has expanded the scale of its operation liquidates early compared to a firm that invests in $\mathrm{R} \& \mathrm{D}$, no matter how large $f$ is.

Early liquidation for the firm that has expanded the scale of its operation could also be due to the fact that, after having expanded the scale of its operation, the firm has no further option to 
invest. On the other hand the firm that has invested in $R \& D$, since $R \& D$ efforts leads to higher cash flows with lower investment, at $x_{l a}\left(\bar{g}, \phi_{1}^{\prime}\right)$, at which the firm with an R\&D project has mothballed the project, the value of the firm's option to resume investing and continue with R\&D is high enough so as not to call for closure.

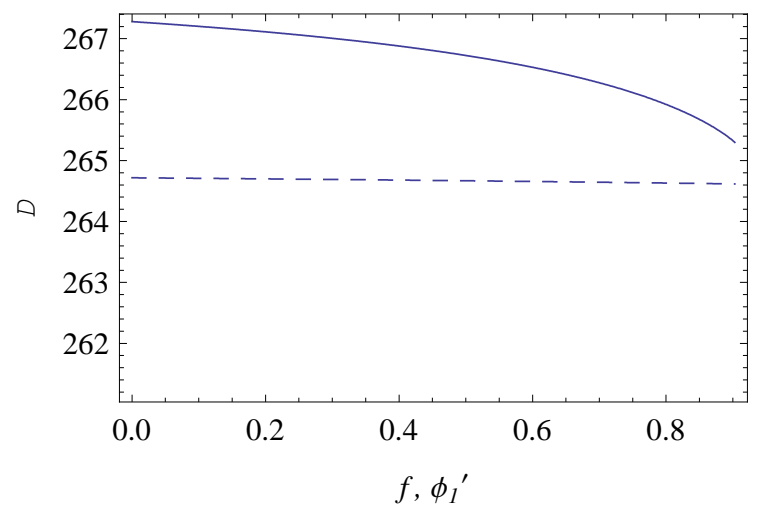

(a)

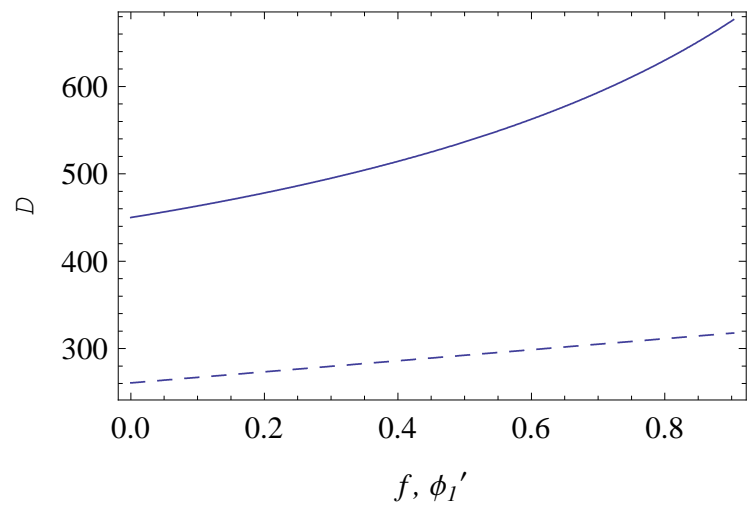

(b)

$D_{b}-$

$D_{a}-$

$D^{I}-$

$D^{*}-$ -

Figure 5.14: (a) Maximum amount of risk-free debt before scale expansion, $D_{b}$, and before investing in $\mathrm{R} \& \mathrm{D}, D^{I}$. (b) Maximum amount of risk-free debt after scale expansion, $D_{a}$, and $D^{*}$, the maximum amount of safe debt after having invested $I$ to start the R\&D project.

The implication of various closure thresholds, before and after investment, either for scale expansion or R\&D, on the maximum amount of risk-free assets are shown in Figure 14. Figure 14 (a) illustrates the maximum amount of default risk-free debt that can be incurred before either scale expansion or starting up of the R\&D project. Before scale expansion or starting of the R\&D project, the constant liquidation value of the firm as well as the value of the firm as a going concern is same for both type of firms. The difference between the two is only explained by the respective difference in the optimal closure thresholds. As explained earlier, since R\&D achieves the same amount of cash flows as the scale expansion with a lesser investment, the firm that maintains the option to invest in R\&D finds the option valuable enough to maintain it for a longer period of time before eventually liquidating. However, this also implies a lower debt capacity if the equity holders of the firm wish to avoid bankruptcy.

Figure 14 (b) illustrates the maximum level of default risk-free debt that the two types of firm can sustain after scale expansion and after investing in $R \& D$. We find that the maximum amount of default risk-free debt that the firm that expands the scale of its operation can sustain is higher than the maximum that the firm that invests in $R \& D$ can. As can be seen from the figure, the difference is higher when $f$ is low and when $\phi_{1}^{\prime}$ is high. Part of the difference is due to the fact that the constant 
liquidation value of the firm that expands the scale of its operation is higher than that of R\&D: $\phi_{f}+\underline{f r} \mathbb{I}>\phi_{f}+f I$. The difference is also due to the fact that closure threshold after scale expansion and after investing in $\mathrm{R} \& \mathrm{D}$ differ. As explained earlier, for any given $f$, when $\phi_{1}^{\prime}$ is greater than a certain threshold, the firm that has expanded the scale of its operation liquidates earlier than the firm that has invested in R\&D.

In order to see only the effect of the differences in the liquidation thresholds, $x_{l a}\left(\bar{g}, \phi_{1}^{\prime}\right)$ and $x_{l}(f)$, on the maximum amount of safe debt for the scale expansion and the R\&D program, we set $\mathbb{I}=I$. Given our assumption, this implies that the extent to which the scale is expanded is less than $(1+\psi) x_{t}$, the revenue generated from a successful R\&D program. Given our assumptions, when $\mathbb{I}=I$, the scale by which the equity holders expand the scale of operation is about $s=0.20$. Now, the maximum amount of risk-free debt after scale expansion, $D_{a}$, is given by $D_{a}=\phi_{f}+\bar{g} I+\frac{\phi_{1}^{\prime} x_{l a}}{r-\mu}$, and that after starting the R\&D project is given by $D^{*}=\phi_{f}+f I+\frac{\phi_{1} x_{l}}{r-\mu}$. We have already fixed $\bar{g}$ and $\phi_{1}$, therefore for any given $f$, as Figure 15 (c) suggests, we can find a $\bar{\phi}_{1}^{\prime}$, such that $D_{a}=D^{*}$. For all $\phi_{1}^{\prime}>\bar{\phi}_{1}^{\prime}$, we find that $D_{a}>D^{*}$. What essentially drives this result is the kind of incentive the firm that expands its scale of operation and the firm that invests in R\&D face. When $\phi_{1}^{\prime}$ is high, then the incentive to liquidate early for the firm that expands is higher, and when $f$ is low, for a firm that invests in $R \& D$, it has a higher incentive to liquidate late than early.

Now let us assume that the both the type of firms, the firm with an option to embark on the $\mathrm{R} \& \mathrm{D}$ program and the firm with an option to expand the scale of its operation, can restructure their debt at the time of starting the $R \& D$ project or at the time of expanding the scale of its operation. Let us also assume that $\mathbb{I}=I$ and the net revenue of the firm as a going concern at liquidation after scale expansion is the same as the net revenue of the firm as a going concern at liquidation for the R\&D, i.e., when $\phi_{1}^{\prime}=\phi_{1}=0.5$. Given our assumption about constant returns to scale and divisibility of capital we find that when $\mathbb{I}=I$ the scale, $s$, by which the firm expands its scale of operation is, $s=0.20$. At these values, as is evident from Figure 15 (a), the threshold level of demand, $x_{e}\left(\bar{g}, \phi_{1}^{\prime}=0.5\right)$, needed to start scale expansion is much higher as compared to the threshold level of demand needed to start the R\&D program $x^{I}$ for almost all values of $f$. The liquidation threshold, $x_{l a}\left(\bar{g}, \phi_{1}^{\prime}=0.5\right)$, for the scale expansion program is also greater than $x_{l}(f)$. The same is true of $D_{a}\left(\phi_{1}^{\prime}=0.5\right)$ as compared to $D^{*}$. Thus we find that even when the option to invest in $\mathrm{R} \& \mathrm{D}$ in more valuable, the amount of default risk-free debt that it can borrow is less than the firm with an scale expansion program. As II increases, since the fraction of $\mathbb{I}$ that can be retained in the event of liquidation is high, $D_{a}$, becomes even larger - compare Figure 15 (c) and 14 (b). At the debt 


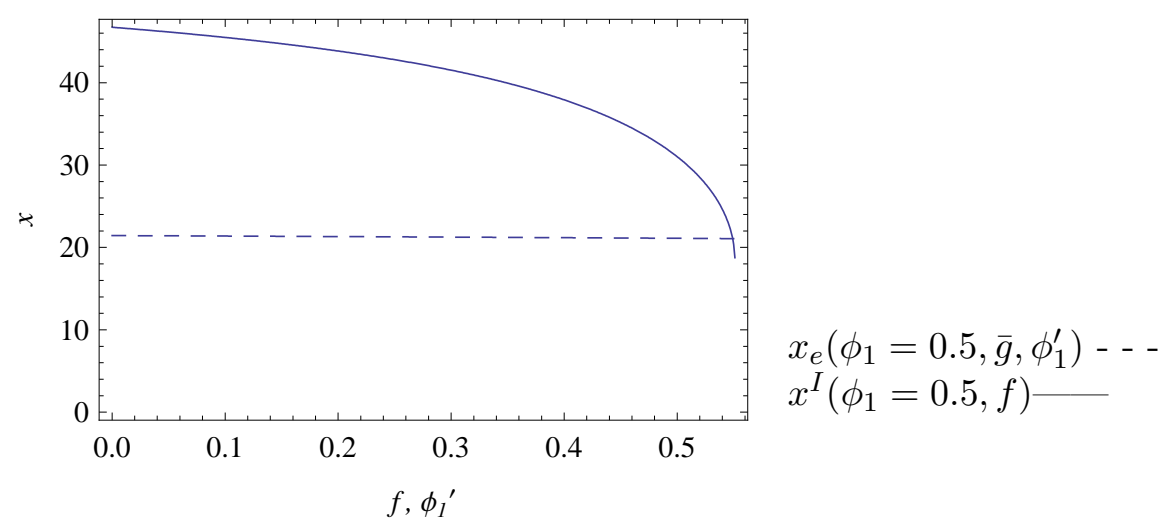

(a)

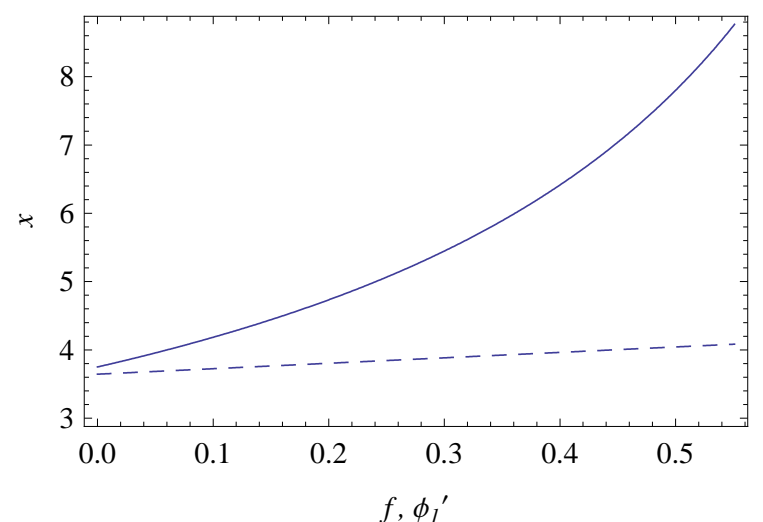

(b)

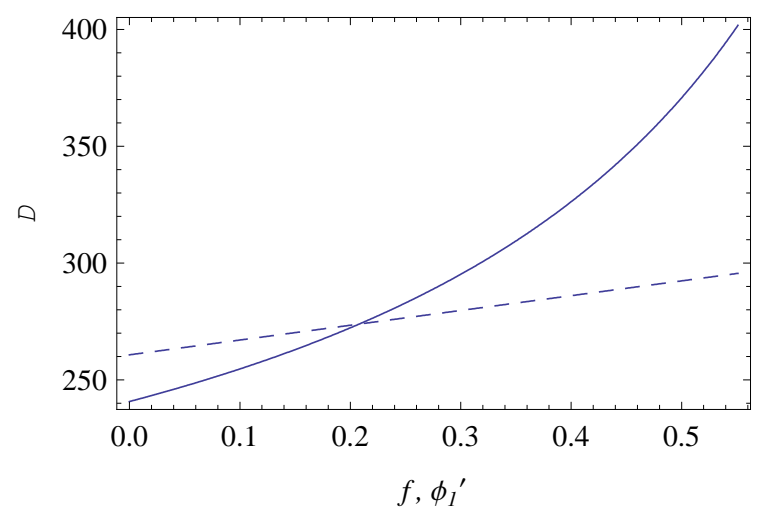

(c)

$x_{l a}\left(\bar{g}, \phi_{1}^{\prime}\right)-$

$D_{a}$

$x_{l}(f)--$

$D^{*}-$

Figure 5.15: (a) Scale Expansion threshold, $x_{e}$, and starting of R\&D Project threshold, $x^{I}$. (b) Liquidation threshold after scale expansion, $x_{l a}\left(\bar{g}, \phi_{1}^{\prime}\right)$, and after starting the R\&D project, $x_{l}(f)$. (c) Maximum amount of risk-free debt after scale expansion, $D_{a}$, and $D^{*}$, the maximum amount of safe debt after having invested $I$ to start the R\&D project.

restructuring point, when the firm embarks on the $R \& D$ program if it incurs any debt higher than $D^{*}$, the debt becomes risky and bondholders lose their claim on the firm, hence lenders are reluctant to lend to the firms with $R \& D$ program as compared to firms that expand their scale of operation. Our result thus corroborates with the many empirical papers that find that $R \& D$ intensive firms are less leveraged than non R\&D performing firms.

Thus, the main result of the comparison can be summarized as follows: Unless the value of the firm in its second best use, post scale expansion, is high, the growth option related to REDD activity is more valuable. This is because a successfully completed RED activity yields higher cash flows with lower investment as compared to scale expansion. On the other hand since R\&D activity mainly 
involves investment in intangible assets, whose value in the event of liquidation is low, the optimal reaction of the firm, when demand falls after having started the REDD project, is to wait longer before eventually liquidating itself. Both the facts, lower value of the initial investment, I, that can be retained in the event of liquidation and lower liquidation threshold imply that the maximum level of default risk-free debt is lower for RED as compared to scale expansion program.

\subsection{Conclusion}

In this chapter we study the implication of risk associated with $R \& D$ investment for agency conflict between bond holders and equity holders of the firm. The riskiness for R\&D investment is primarily derived from the intangibility of assets employed in conducting $R \& D$, which is lost in the event of liquidation, and the technical uncertainty associated with successful completion of the project. We have found that when intangibility of assets involved is high and the intensity with which R\&D can be completed is low the equity holders of the firm in maximizing their claim overinvest, thus shifting the burden of risk on to the bondholders. To our knowledge, we have not seen any paper that explore the agency problem between different class of claimants over R\&D investment policy of the firm.

However, the result presented only indicates the existence of the potential agency problem that can arise between the bond holders and the owners of the firm. We are currently working on quantifying the amount of agency cost due to the risk involved in R\&D project and its implication for loan commitment.

We also recognize that a richer model for $\mathrm{R} \& \mathrm{D}$, incorporating learning, an option to abandon the R\&D project prior to liquidation, and accumulation of intellectual capital stock over time could have some bearing on the results we report. For our future work we intend to incorporate such features into our model.

The chapter also compares scale expansion program to that of $R \& D$ investment. We find that under quite reasonable circumstance $\mathrm{R} \& \mathrm{D}$ investment to find a more efficient technology is more desirable than scale expansion and yet might be difficult to finance with debt. Our model for scale expansion, however, does not incorporate time to build. It would be interesting to compare R\&D and scale expansion with additional features of scale expansion and R\&D included. There is also a larger question of agency issue over investment decision where the firm irreversibly opts either for the scale expansion program or R\&D investment. We leave these for future research. 


\subsection{Appendix}

\section{A Derivation of the Hamilton-Bellman-Jacobi Equation: The Switch- ing Problem}

After having started the R\&D project when the firm has still not liquidated itself, that is when $\mathcal{L}(s)=0$, Itô's Lemma imply that

$$
\begin{array}{r}
e^{-r(T-t)} E\left(x_{T}\right)=E\left(x_{t}\right)+\int_{t}^{T} e^{-r(s-t)}\left[\mathcal{D} E\left(x_{s}\right)-r E\left(x_{s}\right)\right] d s \\
\int_{t}^{T} e^{-r(s-t)}\left[E_{x}\left(x_{s}\right) \sigma d w_{s}\right]+\int_{t}^{T} e^{-r(s-t)}\left[E^{b}\left(x_{s}\right)+\max \left\{0, E^{p}\left(x_{s}\right)-K\right\}-E\left(x_{s}\right)\right] d q_{s},
\end{array}
$$

where $E\left(x_{s}\right)$, as stated earlier, is the value of the firm's equity, $E^{b}\left(x_{s}\right)$ and $E^{p}\left(x_{s}\right)-K$ have been defined in the main text above. $q_{t}$ denotes a jump process that jumps on success and its intensity is given by $\lambda \mathcal{I}(s)$ and

$$
\mathcal{D} E(x)=\frac{1}{2} x^{2} \sigma^{2} E_{x x}(x)+\mu x E_{x}(x) .
$$

Taking expectations (under the risk neutral measure) on both sides of the equation (A-1) and after some rearrangement with the observation that the project always ends up in the money, i.e., $\max \left\{0, E^{p}\left(x_{s}\right)-K\right\}=E^{p}\left(x_{s}\right)-K$, and

$$
\mathbb{E}_{t}^{Q}\left\{\int_{t}^{T} e^{-r(s-t)} E_{x}\left(x_{s}\right) \sigma d w_{s}\right\}=0
$$

we obtain

$$
E\left(x_{t}\right)=\mathbb{E}_{t}^{Q}\left\{e^{-r(T-t)} E\left(x_{T}\right)-\int_{t}^{T} e^{-r(s-t)}\left[\mathcal{D}\left(x_{s}, n\right)-r E\left(x_{s}\right)+\lambda \mathcal{I}(s)\left(E^{a}\left(x_{s}\right)-K-E\left(x_{s}\right)\right)\right] d s\right\}
$$

where $E^{a}\left(x_{s}\right)=E^{b}\left(x_{s}\right)+E^{p}\left(x_{s}\right)$. Comparing equation (A-1) and equation (2-2) we obtain the H-B-J equation

$$
\psi x_{s}-\mathcal{I}(s)\left(a+b x_{s}\right)-r D=-\left[\mathcal{D} E\left(x_{s}\right)-r E\left(x_{s}\right)+\lambda \mathcal{I}(s)\left(E^{a}\left(x_{s}\right)-K-E\left(x_{s}\right)\right)\right] .
$$


For $\mathcal{L}(s)=1$, Itô's lemma implies that

$$
e^{-r(T-t)} E\left(x_{T}\right)=E\left(x_{t}\right)+\int_{t}^{T} e^{-r(s-t)}\left[\mathcal{D} E\left(x_{s}\right)-r E\left(x_{s}\right)\right] d s \int_{t}^{T} e^{-r(s-t)}\left[E_{x}\left(x_{s}\right) \sigma d w_{s}\right] .
$$

Since after liquidation the firm has lost the option to invest or continue with the R\&D project the term that accounts for the jump in value of the firm's equity upon success is absent. Again taking expectations with respect to the risk neutral measure we obtain

$$
E\left(x_{t}\right)=\mathbb{E}_{t}^{Q}\left\{e^{-r(T-t)} E\left(x_{T}\right)-\int_{t}^{T} e^{-r(s-t)}\left[\mathcal{D}\left(x_{s}, n\right)-r E\left(x_{s}\right)\right] d s\right\}
$$

Comparing equation (A-5) and equation $(2-2)$ for $\mathcal{L}(s)=1$ and for safe debt, i.e. when $\max \left\{0,\left(r \phi_{0}+\right.\right.$ $\left.\left.\phi_{1} x_{s}-r D\right)\right\}=\left(r \phi_{0}+\phi_{1} x_{s}-r D\right)$, we obtain the H-B-J equation

$$
r \phi_{0}+\phi_{1} x_{s}-r D=-\left[\mathcal{D} E\left(x_{s}\right)-r E\left(x_{s}\right)\right]
$$





\section{Financial Constraints, Capital Structure and Innovation:}

\section{An Empirical Investigation}

\subsection{Introduction}

Empirically, the study of the effect of financing frictions on investment has broadly followed two approaches. One approach is to ad hoc classify firms into those that are financially constrained and those that are not, see Fazzari, Hubbard, and Petersen (1988) and Kaplan and Zingales (1997), and specify a reduced form accelerator type model for the constrained and unconstrained firms. The extent of financing frictions, controlling for the investment opportunity, is judged by the sensitivity of investment to cash flows, where cash flows realized is taken as measure of internal wealth. Another approach, which is more structural, is to construct an index of financial constraints based on a standard intertemporal investment model augmented to account for financial frictions, where external financing constraints affect the intertemporal substitution of investment today for investment tomorrow, via the shadow value of scarce external funds, Whited and $\mathrm{Wu}(2005)$. The approach relies on specifying a smooth functional form for adjustment costs of adjusting capital, and specifying the shadow value of external funds as a function of financial state variables. The small number of empirical studies on financing frictions and R\&D investment, documented in an excellent review by Hall and Lerner (2010), broadly speaking, follow the two above mentioned approaches.

In this chapter we assess the impact of financial constraints on $R \& D$ expenditure, and what firm characteristics are associated with a firm being financially constrained, where firms themselves report if they are financially constrained or not with respect to R\&D activity. Using firm's assessment of being financially constrained avoids the need to construct an index of financial constraint. This implies that we do not know whether these firms are constrained due to high cost of external finance or feel constrained because their access to funds is less than what is needed to finance their investment, which a priori classification usually imply: see Moyen (2004) and Hennessy and Whited (2007). 
However, this also implies that using firm's assessment of being financially constrained allows us to test how important are the classification criteria that distinguish firms as constrained and not constrained.

Secondly, since the test of financing frictions relies on assessing the impact of financial constraints on $\mathrm{R} \& \mathrm{D}$ expenditure, ours is a departure from the reduced form accelerator type models, where the extent of financing frictions is measured by the sensitivity of investment to cash flows for constrained and unconstrained firms, and about which questions have been raised as to whether such a procedure can indeed identify the extent of financing frictions: see for example, Kaplan and Zingales (1997), Gomes (2001), and Hennessy and Whited (2007). In other words, in contrast to reduced form models, ours is a more structural approach, where conditional on firm characteristics, R\&D investment is determined by financing frictions and the future expected profitability from R\&D investment. The financing frictions as summarized by the reported financial constraints faced by the firms could be either due to high cost of external sources of funds or due to the fact that the access to funds is less than what is needed to finance their investment. We find that the impact of financial constraints can be substantial, reducing the R\&D intensity, measured by $R \& D$ expenditure to capital asset ratio, of an average firm by more than half. Thirdly, using the information on financial constraint as reported by firms, not only allows us to assess the effect of financing frictions on R\&D investment, but also, using the framework of switching regression model, allows us to investigate how firms with different characteristics such as maturity and degree of monopoly, behave with respect to innovation and R\&D investment under financial constraints and under no financial constraints.

Moreover, papers that a priori classify firms as constrained and unconstrained, take the financial constraints faced by firms as exogenous to investment decisions. However, we know that financial constraints and investment expenditures are determined simultaneously, see Section 6.3 for a detailed discussion. Using information on financial constraints, which are a function of financial state variables and firm characteristics, as reported by firms, allows us to endogenize financial constraints while explaining R\&D investment. We do this by specifying a financial constraint equation, whose error term is correlated with the error term of the $\mathrm{R} \& \mathrm{D}$ equation, and by allowing a common time invariant individual effect to affect both the financial constraints faced by the firm and its decision on how much to invest in R\&D.

$R \& D$ expenditure in our data, however, is observed only for firms that are classified as innovators. Hence, we have to confront the problem of endogenous sample selection. To control for the bias that arises when estimating the $\mathrm{R} \& \mathrm{D}$ equation, due to endogenous sample selection, we specify a 
selection/innovation equation, the idiosyncratic component of which is correlated with those of the financial constraint and the R\&D investment equation. Estimating the innovation equation allows us to test, which type of firms, given their characteristics, are more likely to take up R\&D activity. Also, since the decision to innovate and the constraints faced are determined simultaneously, joint estimation of the decision to innovate and the financial constraint faced allows us investigate the implication of financing frictions for a firm's decision to innovate.

Debt, as we know, is an important source of external financing, but given the existence of financing friction, is costly. Given the nature of R\&D, discussed in Section 6.2, debt might even be costlier when it comes to financing R\&D. Hence, choosing to be an innovator can have an important implication for its choice of capital structure. Consequently leverage, defined as the ratio of long-term debt to capital asset, will have a bearing on both the financial constraint faced by the firm as well as the decision to innovate. However, since there is simultaneity in the financing policy and investment decision of the firm, from a modeling perspective, endogeneity of debt has to be taken into account. Our empirical strategy which is a three step procedure takes into account the endogeneity of the long-term debt while estimating the structural equations relating to the decision to innovate, the financial constraint with respect to $R \& D$ that the firm faces, and its $R \& D$ expenditure, all of which, again, are endogenously determined.

Costly external finance has important consequences for the dynamics of the firm subject to technological and idiosyncratic shocks, that affect firms with different characteristics differently: see Cooley and Quadrini (2001). Hence we expect to see financing and investment/innovation policies to vary along the distribution of firms, for example, based on size, age, leverage and degree of financial constraints. Apart from assessing the impact of constraints on R\&D expenditure this chapter attempts to explore the implication of financing frictions on the choice of capital structure and the decision to innovate and how such choices or the propensity to innovate with respect to leverage vary over the distribution of firms characteristics such as maturity, size and leverage. Our results suggest that, ceteris paribus, a firm is less inclined to innovate if it is highly leveraged. The marginal propensity to innovate with respect to leverage differs when a firm is financially constrained and when it is not. We find that when a firm is not financially constrained with respect to R\&D and if it is highly leveraged, then it is more likely that it is not an innovator as compared to a firm that is financially constrained. Moreover, if the firm is not financially constrained the marginal propensity to innovate is almost constant, while the propensity to innovate with respect to leverage, when financial constraints bind, varies over the distribution of firm characteristics such as age, size 
and leverage. While there have been many papers that have studied financing and innovation policy of firms, see Section 6.2, none to our knowledge, has investigated the behavior of such firms when firms are financially constrained and when they are not, and how their financing and innovation policies vary with the distribution of firm characteristics ${ }^{1}$.

To summarize, in this chapter we model a firm's behavior, where its choice of capital structure, the decision to innovate, the financial constraint faced, and the amount spent on R\&D related activities are determined simultaneously. By doing so, we are able to assess the implication of financing decision on, controlling for other factors, the firm's decision to innovate, the financial constraints faced by the firm, and subsequently the effect of financial constraints on R\&D investment. We do this by specifying a system of four equations: (a) an R\&D intensity equation (a switching regression model), (b) a financial constraint equation, (c) a selection/innovation equation, and (d) a leverage or longterm debt to asset ratio equation. While (a), (b), and (c) are structural equations, we write (d) in reduced form. The simultaneity in all the four above is captured through the correlation of the idiosyncratic terms in each of the four equations and a common time invariant individual effect that appears in all the equations.

To estimate the above system of four equations, we employ the method of control function, see Blundell and Powell (2003), in which the estimated residuals from the first stage reduced form are used to control for the endogeneity of the debt to asset ratio in the structural equations. However, due to the presence of unobserved time invariant individual effects, of which the residuals are a function of, the residuals are not identified. To this effect, we substitute the expected a posteriori values of the individual effects based on the first stage estimates. The chapter provides the theoretical foundations for such a procedure. Before we end our introductory section, we introduce the remaining sections that follow. Section 6.2 discusses the nature of R\&D activity from an economic point of view and its implication for the choice of capital structure. The section also discusses how these innovation and financing policies can vary over the distribution of firm characteristics. In Section 6.3 we briefly review some of the theories of costly external sources of finance, and given the nature of R\&D activity, discuss the implications for financial constraint a firm engaging in $R \& D$ might face. The rest of the chapter is organized as follows: Section 6.4 discusses the data and the construction of the variables, Section 6.5 discusses the empirical strategy employed, Section 6.6 discusses the results and finally

\footnotetext{
${ }^{1}$ A likely exception is a recent paper by Brown, Fazzari, and Petersen (2009). These authors separate their sample based on age, where they argue that young firms are more likely to face financial distress than large firms. For the subsamples of mature and young firms, they fit an Euler equation augmented with financial state variables. They find that the financial variables indeed matter for young firms, thereby supporting their claim that financial constraints are binding for young firms.
} 
Section 6.7 concludes. The details of the econometric methodology are provided in Appendix A, B, and $\mathrm{C}$.

\subsection{Innovation, Capital Structure, and Firm Dynamics}

From the perspective of investment theory, $R \& D$ has a number of characteristics that make it different from ordinary investment. Holmstrom (1989) indicates that innovation, and by extension R\&D, has five unique characteristics, it is long-term in nature, high risk in terms of the probability of failure, unpredictable in outcome, labor intensive and idiosyncratic. Hall and Lerner (2010) point out that in practice fifty per cent or more of $\mathrm{R} \& \mathrm{D}$ spending is the wages and salaries of highly educated scientists and engineers, and that their efforts create an intangible asset, the firm's knowledge base, from which profits in future years will be generated. To the extent that this knowledge is tacit rather than codified, it is embedded in the human capital of the firm's employees, and is therefore lost if they leave or are fired. These characteristics, as we discuss, are potential sources of agency issues that can arise between creditors and borrowers.

The high risk involved and unpredictability of outcomes are potential sources of asymmetric information that give rise to agency issues in which the inventor frequently has better information about the likelihood of success and the nature of the contemplated innovation project than the potential investors. Therefore, the marketplace for financing the development of innovative ideas looks like the "lemons" market modelled by Akerlof (1970), and accordingly a higher premium might be charged on the external funds offered. In case of $R \& D$, given its nature, the adverse selection problem can even be more severe, and accordingly, the "lemons" premium for $\mathrm{R} \& \mathrm{D}$ can be higher than that for ordinary investment. This is because investors have more difficulty distinguishing good or low risk projects from bad ones when they are long-term in nature than when they are more short-term (Leland and Pyle, 1977). Due to the ease of imitation of inventive ideas, reducing information asymmetry via fuller disclosure is of limited effectiveness. Firms are reluctant to reveal their innovative ideas to the marketplace and the fact that there could be a substantial cost to revealing information to their competitors reduces the quality of the signal they can make about a potential project: Bhattacharya and Ritter (1983) and Anton and Yao (1998). Thus the implication of asymmetric information coupled with the costliness of mitigating the problem is that firms and inventors will face a higher cost of external than internal capital for R\&D due to the "lemons" premium.

Hall (1993,1994), Opler and Titman (1993, 1994), Blass and Yosha (2001), and Alderson and 
Betker (1996) are some of the papers that provide empirical evidence that R\&D intensive firms are less leveraged than those that are not. More recently, Brown, Fazzari, and Petersen (2009), find similar evidence for a panel of R\&D performing US firms. Brown, Fazzari, and Petersen (2009) draw out a financing hierarchy for R\&D intensive firms, where equity might be preferred to debt as a means of financing $R \& D$, especially for young firms. Although leverage may be a useful tool for reducing agency costs within a firm, it is of limited value for R\&D-intensive firms. Because the knowledge asset created by R\&D investment is intangible, partly embedded in human capital, and ordinarily very specialized to the particular firm in which it resides, the capital structure of R\&D-intensive firms customarily exhibits considerably less leverage than that of other firms. Williamson (1988), points out that "redeployable" assets (that is, assets whose value in an alternative use is almost as high as in their current use) are more suited to the governance structures associated with debt. Titman and Wessels (1988) report that having "unique" assets is associated with lower debt levels. The logic is, first, that consumers will only buy unique products if they are confident that the firm will survive to provide after-sales service. Second, the lack of a secondary market for R\&D and the non-collaterability of R\&D activity mitigates against debt-financed R\&D activity. Also, as Aboody and Lev (2000) argue, the extent of information asymmetry associated with $\mathrm{R} \& \mathrm{D}$, however, is larger than that associated with tangible (e.g., property, plant, and equipment) and financial investments because of the relative uniqueness (idiosyncrasy) of R\&D. Thus, for example, a failure of a drug under development to pass Phase I clinical tests is a unique event not shared by other pharmaceutical companies. In contrast, a downturn in demand for commercial property for example, will exert a strong common effect on the property values of all real estate companies operating in a given geographical region. Similarly, interest-rate changes will affect systematically the values of bond and stock portfolios of companies. Thus, the relative uniqueness of $R \& D$ investments makes it difficult for outsiders to learn about the productivity and value of a given firm's R\&D from the performance and products of other firms in the industry, thereby contributing to information asymmetry. Shi (2003) finds evidence that R\&D activity, which increases the market value of equity, also increases bond default risk and debt risk premia. Bond holders, ceteris paribus, may be unwilling to hold the risks associated with greater R\&D activity.

Given the nature of R\&D activity, the capital structure of a firm (debt to asset ratio) amongst other things also contains information on the type of activity a firm is engaged in. After controlling for various factors, such as size, age, degree of monopoly, profitability of the firm and other determinants of capital structure related to corporate governance or reasons related to tax consideration, we would 
expect that more levered firms, for reasons stated above, are less likely to engage in R\&D related activity.

The above discussion relating asymmetric information pertinent to the nature of $\mathrm{R} \& \mathrm{D}$ activity and leverage holds for any given firm. Since, empirically there exists certain regularities in the financial characteristics of firms that are related to their size and age, Cooley and Quadrini (2001) point out that it is important to link patterns of firm growth with their financial decisions. They introduce financial frictions in a standard model of industry dynamics that generates results which match the empirical findings. Some of the results related to growth and financing are that small and young firms (a) experience higher growth and volatility of growth, (b) invest relatively more and exhibit higher risk taking behavior, (c) take on more debt and pay less dividends. Cooley and Quadrini (2001) explain, that in order to understand these phenomena, one has to consider the trade-off that firms face in deciding the optimal amount of debt. On the one hand, more debt allows them to expand the production scale and increase their expected profits; on the other, the expansion of the production scale implies a higher volatility of profits and a higher probability of failure. Given that a large fraction of profits is reinvested, and the firm's future value, by their assumption, is a concave function of equity, the firm's objective is a concave function of profits. This implies that the volatility of profits has a negative impact on the firm's value. Therefore, in deciding whether to expand the scale of production by borrowing more, the firm compares the marginal increase in the expected profits with the marginal increase in its volatility (and therefore, in the volatility of next period equity). Due to diminishing returns, as the firm increases its equity and implements larger production plans, the marginal expected profits from further increasing the production scale decrease. The firm becomes more concerned about the volatility of profits and borrows less in proportion to its equity. Consequently, as the firm grows, the composition of the sources of finance changes in favor of internal sources. As a consequence of higher borrowing, small firms face a higher probability of default. Cooley and Quadrini (2001) model heterogeneity as difference in productivity level. For firms with higher productivity level, the marginal expected profit is higher for each production scale. Consequently, the firm is willing to face higher risk by borrowing more, and expands the scale of production. However, the essential trade off between profits and volatility is still faced.

Our findings that, (i) mature firms are less likely to be innovators, (ii) younger firms are more financially constrained, (iii) marginal propensity to innovate with respect to leverage declines with age, (iv) under binding financial constraints the propensity to innovate with respect to leverage varies with the distribution of firm characteristics such as age, size, and leverage, and (v) that large and 
mature firms are less R\&D intensive, suggest that decisions to innovate, financing choices, and firm dynamics are not independent. Though we do not study financing choices along the distribution of firm characteristics, some of our findings, for example, small and young firms being more R\&D intensive, match the empirical regularities of the Cooley and Quadrini (2001) study. However, R\&D investment is different from scale expansion, in the sense that $R \& D$ activity is both risky and the productivity increasing. Therefore it might be interesting to incorporate R\&D investment in Cooley and Quadarini's (2001) model. For example, suppose a large firm is as R\&D intensive as a small firm, and there are decreasing returns to $\mathrm{R} \& \mathrm{D}$ capital, which is quite plausible, then the large firm will be at a proportionately higher risk than the small firm, since not only is it more subject to exogenous shocks, given an undiversified scale of its operation, which increases the volatility of profits, but also, since it has tied up more capital in risky $R \& D$ ventures, it becomes more default prone. Thus, being an innovator could also affect the amount of debt it can procure for its scale expansion activity.

On the other hand, for small and young firms, entry, survival and subsequent growth depends on how innovative they are. Recent research on industry evolution has shown that entry and exit in any given industry are typically high, that new firms start on a very small scale but also that they are not able to remain small forever, and that survival depends on heterogeneous mechanisms which include crucial innovation and growth: see, Audretsch (1995) and Huergo and Jaumandreu (2004). Literature on industrial organization treat entry of firms as the way in which firms explore the value of new ideas in an uncertain context. Entry, the likelihood of survival, and subsequent growth are determined by barriers to survival. In this framework, entry is innovative and increases with uncertainty, the likelihood of survival is lower the higher the risk is, and the growth subsequent to successful innovation is higher the higher barriers to survival are.

\subsection{R\&D Investment and Financial Constraints}

Firms are financially constrained when they face a shortage of internal funds needed for their investment and are forced to resort to external sources of financing, which simply may not be available or may be costly in the sense that firms are required to pay a high premium on external finance due to capital market imperfections. These capital market imperfections can be a due to a variety of agency and information asymmetry problems, some of which, related to R\&D investment, have been discussed above.

Myers and Majluf (1984), Myers (1984) and Greenwald, Stiglitz, and Weiss (1984), have pointed out that raising equity externally may be costly due to the kind of adverse selection problem identified 
by Akerlof (1970). Inability to raise new equity would not be a problem if firms could frictionlessly raise unlimited amounts of debt to finance their investment. However, a variety of theories suggest that this is unlikely to be the case. Now, since at any given interest rate managers will be more likely to borrow if their private information suggests that they are relatively prone to default, hence the market for debt could also be subject to the adverse selection problem that afflicts equity market. It is also possible that there can be moral hazard problems, whereby those managers who borrow have an increased incentive to take risks that lead to default. These considerations, as has been shown by Stiglitz and Weiss $(1981,1983)$ can lead to credit rationing, whereby firms are unable to obtain all the debt financing they would like at the prevailing market interest rate.

Debt overhang as Myers (1977) points out can limit debt finance. Large debt can be a burden on a firm's balance sheet, which can discourage further new investment, particularly if this new investment is financed by issuing claims that are junior to the existing debt. This is because if the existing debt is trading at less than face value, it acts as a tax on the proceeds of the new investment: part of any increase in value generated by the new investment goes to the existing lenders, they being the first claimants, and therefore is unavailable to repay those claimants who put up the new money. Debt overhang models can have two different implications: ex post (once the debt burden is in place) they suggest that highly leveraged firms will be particularly prone to underinvestment. Ex ante, they offer a reason why even more modestly-levered firms, particularly those with attractive future investment opportunities, may be reluctant to raise much debt in the first place, even if this means foregoing some current investment projects. Jensen and Meckling (1976) offer another reason why firms might be unwilling to take on too much debt ex ante: the so-called asset substitution effect, whereby an excessive debt burden can create incentives for managers, acting on behalf of shareholders, to take on risky negative-NPV projects at the expense of lenders.

The above-discussed models of debt and equity finance take the existence of these types of financial claims as given, and then go on to derive implications for investment, capital structure, etc. Another branch of the literature seeks to endogenize the financial contract, typically by positing some specific agency problem (e.g., managers penchant for diverting the firms cashflow to themselves) and asking what sort of claim represents an optimal response to this agency problem. These agency issues as discussed earlier are likely to be even more acute for $R \& D$ financing. In much of this work, the optimal contract that emerges resembles a standard debt contract, and there is no outside equity financing. Early examples include Townsend (1979) and Gale and Hellwig (1985), who assume that outside investors can only verify a firm's cash flows by paying some fixed auditing cost. As long as 
the manager turns over the stipulated debt payments, there is no audit, and the manager gets to keep the rest of the firm's cashflow. However, if the manager/entrepreneur defaults on its obligation, the lender audits, and keeps everything he finds; this can be interpreted as costly bankruptcy. The implications for investment is that, the less wealth the manager/entrepreneur is able to put up, the more he must borrow, and hence the greater is the likelihood of the auditing/bankruptcy cost being incurred. The default cost increases the cost of borrowing. This is because, for a given value of equity, the probability of default increases when the firm borrows more, because then it is more vulnerable to idiosyncratic shocks. This increases the expected default cost and the financial intermediary will, accordingly, demand a higher interest rate.

However, in the above mentioned papers, the borrowing constraints faced by the firms when deriving the optimal contract is specified exogenously. More recent papers seek to endogenize the borrowing constraints faced by the firms. Examples include Hart and Moore (1994), Almeida and Campello (2002), and Albuquerque and Hopenhayn (2004). In Hart and Moore (1994) the threat of repudiation by the entrepreneur sets an upper bound on the value of debt and debt payments are subject to a cash-flow constraint. In Almeida and Campello (2002), borrowing constraints are endogenized by conditioning on the firm's ability to raise external finance on its investment spending, while in Albuquerque and Hopenhayn (2004), the borrowing constraints are endogenously derived from limited enforceability problems.

The notion of financial constraint that we employ is one of borrowing constraints, that is, firms are financially constrained when they reach their debt capacity. Depending on the amount of internally available funds, the degree of market imperfection it faces, and the amount of existing debt it services, a firm may or may not have reached its debt capacity. Given the nature of R\&D, such as the intangibility and uniqueness of assets and the unpredictability of outcomes, the degree of market imperfections for R\&D activity is expected to be even higher. This would imply that external sources of finance could be even more costly when it comes to R\&D related activity. Albuquerque and Hopenhayn's (2004) analysis indicates that riskier projects could face tighter constraints. Secondly, due to intangibility and uniqueness of assets, there is a lack of a secondary market for R\&D activity and therefore $R \& D$ activity and its assets are generally not pledgeable, this naturally reduces the borrowing capacity of an R\&D intensive firm. Also, given the uncertainty involved with respect to successfully inventing a new product or idea, the market may not respond favorably at the initial stages of the development of the product. Thus, lower valuation of the firm at initial stages of the development of the project, may also lower the borrowing capacity of the firm. 
In general, as some of the above mentioned theories on investment and costly external finance imply, we would expect that, given everything else, a more leveraged firm and a firm with a lower level of internally available funds to be more financially constrained. Opler and Titman (1994) too find that firms with specialized products are especially vulnerable to financial distress, and that highly leveraged firms that engage in $\mathrm{R} \& \mathrm{D}$ suffer most in economically distressed periods. Here we test, given everything else, whether the presence of higher leverage causes a firm to be financially constrained, whether internal sources of financing relax the borrowing constraint, and how higher cost of external finance, as summarized by the reported financial constraints, affects $R \& D$ related expenditures.

\subsection{Data and Construction of Variables}

As stated earlier, to assess the impact of financial constraints on R\&D expenditure and to assess the impact of the evolution of financial state variables on a firm being financially constrained with respect to $R \& D$ activities, we have to merge two data sets for those years for which information on $\mathrm{R} \& \mathrm{D}$ is available. The data on information related to $\mathrm{R} \& \mathrm{D}$ is obtained from the Dutch Community Innovation Surveys which are conducted every two years. The Innovation Survey data are collected at the enterprise level. A combination of a census and a stratified random sampling is used to collect the data. First, the frame population for the innovation surveys are determined. For enterprises employing 50 persons or more, a census is used. For enterprises employing 10 to 50 persons, a sample is drawn from the general business register. A census of large (250 or more employees) enterprises, and stratified random sample for small and medium sized enterprises from the frame population is used to construct the data set for every survey. The stratum variables are the economic activity and the size of an enterprise, where the economic activity is given by the Dutch standard industrial classification. For our empirical analysis we use three waves of innovation survey data: CIS2.5, CIS3, and CIS3.5 pertaining respectively to the years 1996-98, 1998-2000, and 2000-02.

Information related to financial status of the firms is available at the firm level, which could be constituted of many enterprises consolidated within the firm. The financial data is from the balance sheet of the SFGO (Financial Statistics for Large) and SFKO (Financial Statistics for Small - reported assets less than 23 million Euros - Companies) firms. The data for the SFGO firms are collected by the Central Bureau of Statistics through a questionnaire, consequently the SFGO data is more detailed than the SFKO data, which are compiled from the information sent to the Tax Collectors Office. 
However, the SFGO and SFKO data, which are at the company/firm level do not have any information on $R \& D$ activity. As mentioned earlier information related to $R \& D$ are obtained from the Innovation Surveys. For any given year, our problem here is to infer the size of the relevant R\&D variables for a firm when not all enterprises belonging to the firm have been surveyed. To achieve this end, we use the information on the sampling design for the stratified random sampling done by the Central Bureau of Statistics (CBS) of The Netherlands. Below we outline the procedure.

For any given year, let $N_{T}$ be the total population of the enterprises in the Netherlands and let $N$ be the population of R\&D performing enterprises. CBS determines $N$ based on, $(a)$ size class and (b) activity class. Outside $N$, or the Frame Population, as is referred to by the CBS, any enterprise is hardly likely to indulge in any R\&D activity. From this frame population a stratified random sampling is done. These strata are again based on size and the activity class. Let $S$ be the total number of strata, and each stratum is indexed by $s=1,2, \cdots, S$. Then, $\sum_{s=1}^{S} N_{s}=N$, where $N_{s}$ is the population size of R\&D performing enterprise belonging to stratum $s$. Let $n_{s}$ be the sample size of each stratum and let $\Theta_{s}=\left\{1,2, \cdots, i, \cdots, i_{s}\right\}$ be the set of enterprises for the $s^{\text {th }}$ stratum, that is $\left|\Theta_{s}\right|=n_{s}$.

Let $x$ be the variable of interest and $x_{i}$ the value of $x$ for the $i^{t h}$ observation in the $s^{\text {th }}$ stratum. The mean value of $x$ for an enterprise belonging to the $s^{\text {th }}$ stratum is $\bar{x}_{s}=\left(\sum_{i \in \Theta_{s}} x_{i}\right) / n_{s}$. Now consider a firm $f$. Let $N_{f s}$ be the number of enterprises belonging to the firm $f$ and stratum $s$ and $n_{f s}$ be the number of enterprises belonging to the firm $f$ and stratum $s$ that have been surveyed.

Then the estimated value of $x$ for the firm $f, \hat{x}_{f}$ is given by

$$
\hat{x}_{f}=\sum_{s=1}^{S}\left(N_{f s}-n_{f s}\right) \bar{x}_{s}+\sum_{s=1}^{S} \sum_{k=1}^{n_{f s}} x_{f s k}
$$

where $x_{f s k}$ is the value of $x$ for the $k^{\text {th }}$ enterprise belonging to the $s^{t h}$ stratum and firm $f$ that has been surveyed and $N_{f s}-n_{f s}$ are the number of enterprise of the $f^{\text {th }}$ firm in stratum $s$ that have not been surveyed. It can be shown under appropriate conditions that $\hat{x}_{f}$ is an unbiased estimator of the expected value of $x$ for firm $f^{2}$. Table 6.1 below gives, based on size class and 2 digit Dutch Standard Industry Classification (SBI), the number of strata, between which the enterprises surveyed in the

\footnotetext{
${ }^{2}$ Proof:

The proof is based on the assumption that the distribution of $x$ in terms of its expected value is the same for each enterprise in a particular stratum. Let $\mu_{x f}$ the population mean of $x$ for the firm $f$ and let $\mu_{x s}$ the population mean of $x$ for an enterprise belonging to stratum $s$. Given our assumption, we know that $\bar{x}_{s}$ is an unbiased estimator of $\mu_{x s}$, that $\mu_{x f}=\sum_{s=1}^{S} N_{f s} \mu_{x s}$, and that the expected value of $\sum_{s=1}^{S} \sum_{k=1}^{n_{f s}} x_{f s k}$, the second term on the RHS of equation (1), is $\sum_{s=1}^{S} n_{f s} \mu_{x s}$. Taking expectations in (1) and substituting the expected value of $\mathrm{E}\left(\sum_{s=1}^{S} \sum_{k=1}^{n_{f s}} x_{f s k}\right)=\sum_{s=1}^{S} n_{f s} \mu_{x s}$ and noting that $\mathrm{E}\left(\sum_{s=1}^{S} n_{f s} \bar{x}_{s}\right)=\sum_{s=1}^{S} n_{f s} \mu_{x s}$, we get $\mathrm{E}\left(\hat{x}_{f}\right)=\mu_{x f}=\sum_{s=1}^{S} N_{f s} \mu_{x s}$.
} 
CIS surveys were divided.

Table 6.1: Number of Enterprises and Number of Strata

\begin{tabular}{|l|c|c|c|}
\hline & CIS2.5 & CSI3 & CIS3.5 \\
\hline Total no. of enterprises & 13465 & 10750 & 10533 \\
\hline Total no. of strata & 240 & 249 & 280 \\
\hline \multicolumn{2}{|l|}{ These figures are from the original/raw data set. } \\
\hline
\end{tabular}

The sample of firms used in the estimation are only those for which at least one R\&D performing enterprise is present in the innovation surveys. Also, those R\&D performing enterprises for whom no firm information was available - firms not present in the SFGO and SFKO data - had to be dropped. Table 6. 8 in Appendix E tabulates, for the sample of firms used in estimation, $N_{f}=\sum_{s=1}^{S} N_{f s}$ for each of the three waves, $N_{f}$ being the total number of potentially R\&D performing enterprises belonging to the firm $f$. The table also shows for each $N_{f}$, the number of firms for which, $N_{f}=n_{f}$, where $n_{f}$ is the total number enterprise belonging to the firm $f$ that were surveyed. It also shows the number of firms for which, $\left(N_{f}-n_{f}\right)>0$. This tells us the number of firms for which the above procedure was used to get an estimate of the relevant variables for the firm. Here, we would like to point out that the information on $N_{f}$ was obtained form the Frame Population constructed by the CBS and of course the information on $n_{f}$ from the CIS surveys. As can be seen from the table, for the sample of firms used for estimation, for 18.06 percent of the total number of firms in CIS2.5, equation (1) was used to get the estimates of the relevant variables for the firms, while these percentages for CIS3 and CIS3.5 were 24.62 and 23.75 respectively. The table also shows that the majority of the firms happen to be single $R \& D$ performing enterprises. At least for these firms the above procedure, summarized by equation (1), is not applicable. For our sample, the percentage of $\mathrm{R} \& \mathrm{D}$ firms with single $\mathrm{R} \& \mathrm{D}$ performing enterprise are $78.97,74.01$, and 73.87 respectively for CIS2.5, CIS3, and CIS3.5.

The two R\&D variables of interest for which the above procedure was used to get an estimate at the firm level are the $R \& D$ expenditure and the share of innovative sales in the total sales of the enterprise. Here we would like to mention that we do not have any information on R\&D expenditure of those firms that have been categorized as non-innovator, while the share of innovative sales by definition does not exist for non-innovating firms. In order to estimate $\bar{x}_{s}$ for $\mathrm{R} \& \mathrm{D}$ expenditure, for each stratum $s$, we have assumed that the $\mathrm{R} \& \mathrm{D}$ expenditure is zero for those enterprises that have been classified as non innovators in the survey ${ }^{3}$.

\footnotetext{
${ }^{3}$ This assumption could possibly lead to a bias in the estimates of R\&D expenditure for those firms, for which not all enterprises have been surveyed.
} 
While $R \& D$ expenditure and the share of innovative sales are continuous variables, we also had to infer about two binary variables for the firm, given the information about these for the enterprises constituting the firm. The two categorical variables happen to be (1) a dummy variable on the enterprise being financially constrained with respect to $R \& D$ activities and (2) a dummy variable on the decision for an enterprise to be an innovator. Characterizing a firm to be financially constrained was straight forward - a firm is financially constrained if any one of the enterprise is financially constrained with respect to the R\&D activities.

Before we discuss the criterion that characterizes a firm as being an innovator or a non-innovator using information on the constituent enterprises being a innovator or a non-innovator, we briefly mention the survey criteria that classify an enterprise as an innovating or non-innovating enterprise. An enterprise is innovating if it satisfies one of the following criteria: (a) If the enterprise has introduced a new product to the market, (b) If the enterprise has introduced a new process to the market, (c) If the enterprise has some unfinished $R \& D$ project and (d) If the enterprise, began on a R\&D project, and abandoned it during the time period that the survey covers. To characterize a firm as an innovator or a non-innovator the following criterion was used. If all the enterprises of a firm have been surveyed and if all the enterprises report themselves to be a non-innovator then the firm is classified as being a non-innovator. If the number of enterprises present in a firm are more than the number of enterprises that have been surveyed, that is, if $N_{f}>n_{f}$, and if one the enterprises surveyed, reports that it has engaged in R\&D activities, then we classify this firm to be an innovator. However, if $N_{f}>n_{f}$, and if none of the enterprises sampled reported to be an innovator, then if any one of the remaining enterprises that have not been surveyed is to be found in a stratum that, based on the CIS survey, has been classified as an innovating stratum, then the firm has been classified as an innovator.

The total number of employees as a measure of the size of the firm was also constructed using information from the CIS data and the General Business Register. As far as the number of employees in a firm is concerned, if all the enterprises belonging to a firm are surveyed, that is if $N_{f}=n_{f}$, then we simply add up the number employees of each of the constituent enterprises. However, when $N_{f}>n_{f}$, for those enterprise/s that has/have not been surveyed we take the mid point of the size class of those enterprises that have not been surveyed. The size class to which an enterprise belongs to is available from the General Business Register for every year.

Table 6.2 below shows the number of innovators and number of non-innovators for each of the 
three waves, and the number firms that are financially constrained with respect to R\&D activities ${ }^{4}$. We would also like to point out that most of the information contained in the Innovation Surveys,

Table 6.2: Total number Innovating Firms, Non-Innovating Firms, and Financially Constrained Firms

\begin{tabular}{|l|c|c|c|}
\hline & CIS2.5 & CIS3 & CIS3.5 \\
\hline No. of Non-Innovators & 2,405 & 1,495 & 2,221 \\
\hline No. of Innovators & 2,987 & 1,933 & 2,011 \\
\hline No. of Financially Constrained firms & 536 & 416 & 188 \\
\hline \hline These figures are for the Data Set used in Estimation
\end{tabular}

These figures are for the Data Set used in Estimation

cover three time periods. For example, if any enterprise present in CIS3.5, classifies itself to being an innovator, then this implies that over the course of the three years 2000-02, the enterprise carried out any of the R\&D related activities that are necessary for it to be classified as an innovator. The same is true of financial constraint, that is, an enterprise if it reports that it is financially constrained, then it is true that in either of the three years, covered by the survey, the enterprise found itself being financially constrained in the proper implementation of any of its R\&D projects. This implies that there is an overlapping year between every CIS survey. Hence, if the reporting has to be consistent, then an enterprise reporting itself to be financially constrained, say in CIS3, covering years 1998-2000, should also report itself as being financially constrained in CIS3.5, covering the years 2000-2002, the year 2000 being the overlapping year. However, we do not find this to be the case. Therefore we proceed as if that the CIS surveys cover two time periods, that is, say for CIS3.5, the time period covered are from the end of 2000 till the end of 2002, covering the years 2001 and 2002. Thus, if a firm reports itself as being innovative or being financially constrained, then we assume that it has been innovating or has been financially constrained for two time periods. The share of innovative sales in the total sales of the enterprise also covers two time periods. However, the figures on R\&D expenditure are only for the last year of the two years covered by any of the innovation surveys. Thus, given the nature of the data, we make the assumption that the last year of the two years covered by any of the innovation surveys, is period $t$ and the year preceding it is period $t-1$ and that without knowing in which of the two periods it was an innovator and which of the two periods it was financially constrained, we make the assumption that the enterprise had been innovating in both periods and that it was financially constrained in both periods. Also, that the share of innovative sales in the total sales of the enterprise had been the same for the two time periods. The figure below elucidates the above discussion and the time line along which the stock and flow variables are

\footnotetext{
${ }^{4}$ For CIS2.5 information on financial constraint is available only for the innovators.
} 
realized $^{5}$. The vertical lines, at $t-1, t$, and $t+1$, indicate the beginning of the respective time periods. Having drawn the time line and given the fact that $R \& D$ expenditure is reported only for the last year of the two periods that any CIS covers, then according to the time line defined, this implies that if the last two periods in our data is indexed $T$ and $T-1$, the R\&D expenditure is observed for time periods, $T$, but not period $T-1$, for time period $T-2$ but not for $T-3$ and so on.

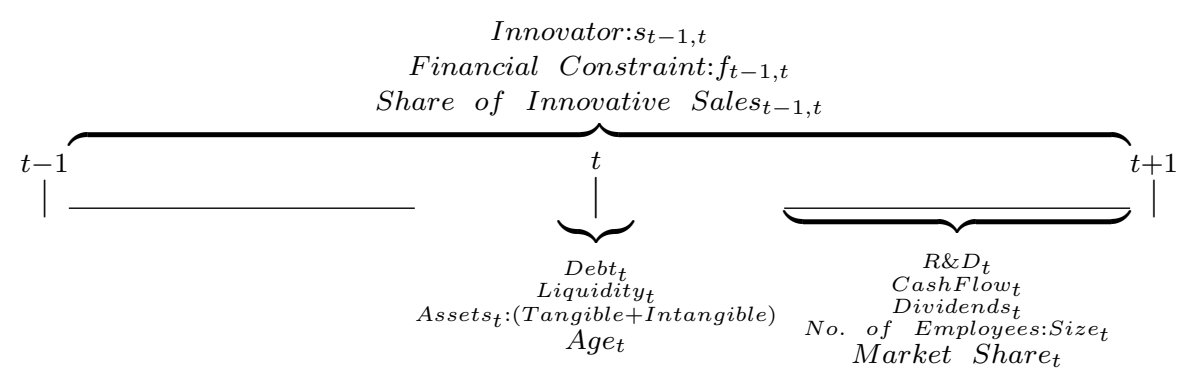

R\&D expenditure, the constructed dummy variable on a firm being financially constrained, and the constructed dummy variable indicating whether the firm is an innovator or not, are three among the four endogenous variables. Our fourth endogenous variable is long-term debt, about which we learn from the SFGO and SFKO data set, which as mentioned earlier is available at the firm level. We discuss the set of our assumed exogenous variables in the text following this.

\subsection{Empirical Strategy}

\subsubsection{R\&D Investment, Endogenous Financial Constraint and Endogenous Se- lection with Endogenous Long-Term Debt: A Three step Procedure}

To study the choice of capital structure of $R \& D$ intensive firms, the effect of financial constraints on $\mathrm{R} \& \mathrm{D}$ expenditure and to account for the features of the data, where $\mathrm{R} \& \mathrm{D}$ expenditure is known only for firms that opt to innovate and we consider a four equation system

$$
\begin{aligned}
r_{i t} & =\mathbf{z}_{i t}^{r \prime} \beta+S I N S_{i t} \beta_{s}+\mu \alpha_{i} \\
& +f_{i t} \beta_{f}+\left(f_{i t} \times C F_{i t}\right) \beta_{c 1}+\left(\left(1-f_{i t}\right) \times C F_{i t}\right) \beta_{c 0} \\
& +\left(f_{i t} \times D I V_{i t}\right) \beta_{D 1}+\left(\left(1-f_{i t}\right) \times D I V_{i t}\right) \beta_{D 0}+\eta_{i t},
\end{aligned}
$$

\footnotetext{
${ }^{5}$ While the number of employees of a firm is a stock variable, the enterprises reported the figures on it for the accounting period, hence the figures on employment are the year end values on the number of employees.
} 


$$
\begin{gathered}
f_{i t}^{*}=\mathbf{z}_{i t}^{f \prime} \varphi+d_{i t} \varphi_{d}+\lambda \alpha_{i}+\zeta_{i t}, \\
s_{i t}^{*}=\mathbf{z}_{i t}^{s \prime} \gamma+d_{i t} \gamma_{d}+\theta \alpha_{i}+v_{i t}, \\
d_{i t}=\mathbf{z}_{i t}^{\prime} \delta+\alpha_{i}+\epsilon_{i t},
\end{gathered}
$$

where $r_{i t}$ in equation (2) is the ratio of total R\&D expenditure to total capital, (tangible + intangible), assets of the firm and $\mathbf{z}_{i t}^{r}$, is vector of strictly exogenous variables. We term equation (2) as the R\&D equation. $f_{i t}$, a binary variable that indicates, with value 1 , if the firm is financially constrained with respect to innovation or $\mathrm{R} \& \mathrm{D}$ activities in period $t$ and $t-1 . C F_{i t}$ is the cash flows of the firm in period $t$ and $D I V_{i t}$ is a dummy variable for positive dividends. We interact, $C F_{i t}$ and $D I V_{i t}$ with the dummy variables $f_{i t}$ and $1-f_{i t}$. SIN $S_{i t}$ is the share of innovative sales in the total sales of the firm $i$, for the period $t-1$ and period $t$. A detailed discussion of the specification for the R\&D equation is carried out later when we discuss the third stage estimation.

$f_{i t}^{*}$ is the latent variable underlying $f_{i t}$, that is $f_{i t}$ takes value 1 if $f_{i t}^{*}$ crosses a certain threshold. We term, equation (3) as the financial constraint equation. $\mathbf{z}_{i t}^{f}$ is a vector of strictly exogenous variables in equation (3). The specification for financial constraint includes the ratio of outstanding long term debt to book value of capital (tangible + intangible) asset, $d_{i t}$, which is endogenous since the choice of leverage and the financial constraint facing the firm, if we interpret the underlying latent variable $f_{i t}^{*}$ as the shadow price of debt, are determined simultaneously. As we have mentioned above, R\&D investment is observed only for the innovators. To rule out possible sample selection bias that could arise because some component (observed or unobserved) of the decision to innovate also determines the outcome - here R\&D expenditure - we specify a selection equation, equation (4), where the idiosyncratic error term appearing in the selection equation is correlated with the idiosyncratic error terms appearing in the R\&D equation and the financial constraint equations. $s_{i t}^{*}$ is the latent variable underlying the decision to innovate, $s_{i t}$, which takes value 1 if the firm decides to innovate and 0 otherwise. $s_{i t}$ takes value 1 if $s_{i t}^{*}$ crosses a certain threshold, which could be $0 . \mathbf{z}_{i}^{s}$, is a vector of strictly exogenous variables. The specification for the selection equation includes the endogenous variable, $d_{i t}$. Equation (5) specifies the reduced form for debt to capital ratio, where $\mathbf{z}_{i t}$ is a vector of exogenous variables appearing in (5).

Our discussion on R\&D investment, financial constraints and debt limits, and the discussion on 
the decision to innovate and choice of capital structure in the preceding two sections imply that R\&D investment, financial constraints, the decision to innovate and leverage are determined simultaneously. Here we also mention that the specification for the financial constraint equation and the selection equation include the stock of liquid assets, $L Q_{i t}$, dummy for dividend payout, $D I V_{i t}$, and share of innovative sales. While these variables could possibly be endogenous or predetermined to the system of equations,(2), (3), (4), and (5), here we assume them to be exogenously given. Hence, subsequently we will assume $\mathbf{z}_{i t}^{r}, \mathbf{z}_{i t}^{f}, \mathbf{z}_{i t}^{s}$, and $\mathbf{z}_{i t}$ to include $L Q_{i t}, D I V_{i t}$, and $S I N S_{i t}{ }^{6}$.

Let $Z_{i t}$ be the union of the exogenous variables appearing in $\mathbf{z}_{i t}^{r}, \mathbf{z}_{i t}^{f}$, $\mathbf{z}_{i t}^{s}$, and $\mathbf{z}_{i t}$ and $Z_{i}=$ $\left(Z_{i 1}^{\prime} \ldots Z_{i T_{i}}^{\prime}\right)^{\prime} . \quad \alpha_{i}$ is the unobserved individual effect, which we model as a random effect that is normally distributed with mean 0 and variance $\sigma_{\alpha}$, is assumed to be independent of $Z_{i}$ and is also assumed to be mean independent of $\eta_{i t}, \zeta_{i t}, v_{i t}$ and $\epsilon_{i t}$. Now, it is possible that the unobserved individual specific effect affecting leverage, that is, the choice of capital structure also affects the decision to innovate, the firm's realization that it is financially constrained with respect to R\&D activity, and how much R\&D expenditure to incur. The factor loadings, $\mu, \lambda$ and $\theta$ allow for such a possibility.

The endogeneity of the financial constraint, long-term debt and selection are captured through the following error structure, where conditional on $Z_{i}$,

$$
\left(\begin{array}{c}
\eta_{i t} \\
\zeta_{i t} \\
v_{i t} \\
\epsilon_{i t}
\end{array}\right) \sim N\left[\left(\begin{array}{l}
0 \\
0 \\
0 \\
0
\end{array}\right)\left(\begin{array}{cccc}
\sigma_{\eta}^{2} & \rho_{\eta \zeta} \sigma_{\eta} \sigma_{\zeta} & \rho_{\eta v} \sigma_{\eta} \sigma_{v} & \rho_{\eta \epsilon} \sigma_{\eta} \sigma_{\epsilon} \\
& \sigma_{\zeta}^{2} & \rho_{\zeta v} \sigma_{\zeta} \sigma_{v} & \rho_{\zeta \epsilon} \sigma_{\zeta} \sigma_{\epsilon} \\
& & \sigma_{v}^{2} & \rho_{v \epsilon} \sigma_{v} \sigma_{\epsilon} \\
& & & \sigma_{\epsilon}^{2}
\end{array}\right)\right]
$$

We also assume that, each of the error terms, $\eta_{i t}, \zeta_{i t}, v_{i t}$, and $\epsilon_{i t}$ are independently and identically distributed.

We extend the model for $R \& D$ expenditure, equation (2), to that of endogenous switching regression model. In this model a switching equation, here the financial constraint equation, sorts the firms over two different regimes, depending on whether $I_{f_{i t}^{*}>0}$, with only one regime observed. $I_{f_{i t}^{*}>0}$ is an indicator variable, that takes value 1 if $f_{i t}^{*}>0$. Thus, we have

$$
r_{1 i t}=\mathbf{z}_{i t}^{r \prime} \beta+\beta_{f}+C F_{i t} \beta_{c 1}+D I V_{i t} \beta_{D 1}+S I N S_{i t} \beta_{s}+\mu \alpha_{i}+\eta_{1 i t}
$$

\footnotetext{
${ }^{6}$ As an extension of this work we intend to endogenize dividends, share of innovative sales and liquidity by specifying a reduced form for all these variables along with long term debt and condition the idiosyncratic error term of the structural equations (2), (3), and (4) on the vector of reduced form idiosyncratic error term which are correlated to those of the structural form.
} 
if $f_{i t}^{*}>0$, and

$$
r_{0 i t}=\mathbf{z}_{i t}^{r \prime} \beta+C F_{i t} \beta_{c 0}+D I V_{i t} \beta_{D 0}+S I N S_{i t} \beta_{s}+\mu \alpha_{i}+\eta_{0 i t}
$$

if $f_{i t}^{*} \leq 0$, where $\eta_{1 i t}$ denotes the idiosyncratic term in regime 1 , when the firm is financially constrained and $\eta_{0 i t}$ denotes the idiosyncratic term when the firm is not, regime 0 . Thus, we have

$$
\begin{aligned}
r_{i t} & =f_{i t} r_{1 i t}+\left(1-f_{i t}\right) r_{0 i t} \\
& =\mathbf{z}_{i t}^{r \prime} \beta+f_{i t} \beta_{f}+f_{i t} \beta_{1}(.)+\left(1-f_{i t}\right) \beta_{0}(.)+\mu \alpha_{i}+f_{i t} \eta_{1 i t}+\left(1-f_{i t}\right) \eta_{0 i t},
\end{aligned}
$$

where $\beta_{1}()=.\left(C F_{i t} \beta_{c 1}+D I V_{i t} \beta_{D 1}\right)$ and $\beta_{0}()=.\left(C F_{i t} \beta_{c 0}+D I V_{i t} \beta_{D 0}\right)$ and $S I N S_{i t}$ has been subsumed into $\mathbf{z}_{i t}^{r \prime}$.

The distribution of the error terms of the system of equations (2a), (2b), (3), (4), and (5) is now given by:

$$
\left(\begin{array}{c}
\eta_{1 i t} \\
\eta_{0 i t} \\
\zeta_{i t} \\
v_{i t} \\
\epsilon_{i t}
\end{array}\right) \sim N\left[\left(\begin{array}{l}
0 \\
0 \\
0 \\
0 \\
0
\end{array}\right)\left(\begin{array}{ccccc}
\sigma_{\eta_{1}}^{2} & \rho_{\eta_{1} \eta_{0}} \sigma_{\eta_{1}} \sigma_{\eta_{0}} & \rho_{\eta_{1} \zeta} \sigma_{\eta_{1}} \sigma_{\zeta} & \rho_{\eta_{1} v} \sigma_{\eta_{1}} \sigma_{v} & \rho_{\eta_{1} \epsilon} \sigma_{\eta_{1}} \sigma_{\epsilon} \\
& \sigma_{\eta_{0}}^{2} & \rho_{\eta_{0} \zeta} \sigma_{\eta_{0}} \sigma_{\zeta} & \rho_{\eta_{0} v} \sigma_{\eta_{0}} \sigma_{v} & \rho_{\eta_{0} \epsilon} \sigma_{\eta_{0}} \sigma_{\epsilon} \\
& & \sigma_{\zeta}^{2} & \rho_{\zeta v} \sigma_{\zeta} \sigma_{v} & \rho_{\zeta \epsilon} \sigma_{\zeta} \sigma_{\epsilon} \\
& & & \sigma_{v}^{2} & \rho_{v \epsilon} \sigma_{v} \sigma_{\epsilon} \\
& & & & \sigma_{\epsilon}^{2}
\end{array}\right)\right] \text {. }
$$

We note here that $\rho_{\eta_{1} \eta_{0}}$ is not identified, since we do not observe the pair $\left(r_{1 i t}, r_{0 i t}\right)$ together, but only either one of them. We also restrict $\sigma_{\zeta}^{2}$ and $\sigma_{v}^{2}$ to be 1 .

To estimate the above model, given by equation (2a), (2b), (3), (4), and (5), we use a three step estimation procedure as an extension of Heckman's classical two step estimation to multivariate selection problems. Heckman (1979) corrects the bias caused by the sample selection using the control function approach, namely, by adding the inverse Mills ratio to main regression equation, obtained from the first stage selection equation. Here we are dealing with two selection problems. One is the endogenous switching and the other one is the sample selection, not to mention, also, the endogeneity of long term debt. To consistently estimate the parameters of equations (2a) and (2b), in Appendix $\mathrm{B}$, we derive the three correction terms. The first term corrects for the bias due to the endogeneity of long-term debt, while the other two correct for the bias due to endogenous switching and the bias due to endogenous sample selection. These correction terms are obtained for each firm-year observation. Adding these correction terms for each observation, we obtain consistent estimates for the structural equations, (2a) and (2b), using corresponding subsamples. 
To define these correction terms, we first consider the conditional distribution of $r_{i t}, f_{i t}^{*}$ and $s_{i t}^{*}$ given $\epsilon_{i t}$. Since $\eta_{1 i t}, \eta_{0 i t}, \zeta_{i t}, v_{i t}$ and $\epsilon_{i t}$ follow a joint normal distribution, the linear projections of $\eta_{1 i t}, \eta_{0 i t}, \zeta_{i t}$ and $v_{i t}$ in error form, given $\epsilon_{i t}$ are given by

$$
\eta_{1 i t}=\rho_{\eta_{1}} \epsilon \frac{\sigma_{\eta_{1}}}{\sigma_{\epsilon}} \epsilon_{i t}+\bar{\eta}_{1 i t}, \quad \eta_{0 i t}=\rho_{\eta_{0} \epsilon} \frac{\sigma_{\eta_{0}}}{\sigma_{\epsilon}} \epsilon_{i t}+\bar{\eta}_{0 i t}, \quad \zeta_{i t}=\rho_{\zeta \epsilon} \frac{\epsilon_{i t}}{\sigma_{\epsilon}}+\bar{\zeta}_{i t}, \quad v_{i t}=\rho_{v \epsilon} \frac{\epsilon_{i t}}{\sigma_{\epsilon}}+\bar{v}_{i t},
$$

where

$$
\left(\begin{array}{c}
\bar{\eta}_{1 i t} \\
\bar{\eta}_{0 i t} \\
\bar{\zeta}_{i t} \\
\bar{v}_{i t}
\end{array}\right) \sim N\left[\left(\begin{array}{l}
0 \\
0 \\
0 \\
0
\end{array}\right)\left(\begin{array}{cccc}
\sigma_{\bar{\eta}_{1}}^{2} & \rho_{\bar{\eta}_{1} \bar{\eta}_{0}} \sigma_{\bar{\eta}_{1}} \sigma_{\bar{\eta}_{0}} & \rho_{\bar{\eta}_{1} \bar{\zeta}} \sigma_{\bar{\eta}_{1}} \sigma_{\bar{\zeta}} & \rho_{\bar{\eta}_{1} \bar{v}} \sigma_{\bar{\eta}_{1}} \sigma_{\bar{v}} \\
& \sigma_{\bar{\eta}_{0}}^{2} & \rho_{\bar{\eta}_{0} \bar{\zeta}} \sigma_{\bar{\eta}_{0}} \sigma_{\bar{\zeta}} & \rho_{\bar{\eta}_{0} \bar{v}} \sigma_{\bar{\eta}_{0}} \sigma_{\bar{v}} \\
& & \sigma_{\bar{\zeta}}^{2} & \rho_{\bar{\zeta} \bar{v}} \sigma_{\bar{\zeta}} \sigma_{\bar{v}} \\
& & & \sigma_{\bar{v}}^{2}
\end{array}\right)\right]
$$

and are independent of $Z_{i} d_{i}$ and $\alpha_{i}{ }^{7}$.

The above then implies that the distribution of $r_{1 i t}, r_{0 i t}, f_{i t}^{*}$ and $s_{i t}^{*}$ given $\epsilon_{i t}$ is then given by

$$
r_{1 i t}=\mathbf{z}_{i t}^{\prime \prime} \beta+\beta_{f}+\beta_{1}(.)+\mu \alpha_{i}+\rho_{\eta_{1} \epsilon} \frac{\sigma_{\eta_{1}}}{\sigma_{\epsilon}} \epsilon_{i t}+\bar{\eta}_{1 i t},
$$

if $f_{i t}^{*}>0$,

$$
r_{0 i t}=\mathbf{z}_{i t}^{r \prime} \beta+\beta_{0}(.)+\mu \alpha_{i}+\rho_{\eta_{0} \epsilon} \frac{\sigma_{\eta_{0}}}{\sigma_{\epsilon}} \epsilon_{i t}+\bar{\eta}_{0 i t}
$$

if $f_{i t}^{*} \leq 0$, and

$$
f_{i t}^{*}=\mathbf{z}_{i t}^{f \prime} \varphi+d_{i t} \varphi_{d}+\lambda \alpha_{i}+\rho_{\zeta \epsilon} \frac{\epsilon_{i t}}{\sigma_{\epsilon}}+\bar{\zeta}_{i t}=\varphi\left(\mathbf{z}_{i t}^{f \prime}, d_{i t}, \alpha_{i}\right)+\rho_{\zeta \epsilon} \frac{\epsilon_{i t}}{\sigma_{\epsilon}}+\bar{\zeta}_{i t}
$$

and

$$
s_{i t}^{*}=\mathbf{z}_{i t}^{s \prime} \gamma+d_{i t} \gamma_{d}+\theta \alpha_{i}+\rho_{v \epsilon} \frac{\epsilon_{i t}}{\sigma_{\epsilon}}+\bar{v}_{i t}=\gamma\left(\mathbf{z}_{i t}^{s \prime}, d_{i t}, \alpha_{i}\right)+\rho_{v \epsilon} \frac{\epsilon_{i t}}{\sigma_{\epsilon}}+\bar{v}_{i t}
$$

Conditioning the endogenous variables of interest on $\epsilon_{i t}$ allows us to control for the endogeneity of $d_{i t}$, the long-term debt to asset ratio. To estimate the above system of equation, the standard technique is to replace $\epsilon_{i t}$ by the residuals from the first stage reduced form regression, here equation

\footnotetext{
${ }^{7}$ Given the joint distribution of $\eta_{1 i t}, \eta_{0 i t}, \zeta_{i t}, v_{i t}$ and $\epsilon_{i t}$, the conditional variance covariance matrix of $\eta_{1 i t}, \eta_{0 i t}, \zeta_{i t}$, and $v_{i t}$, given $\epsilon_{i t}$ can be computed. However, as we will see later the elements of this conditional variance covariance matrix are not estimated.
} 
(5). However, since $\mathrm{E}\left(\epsilon_{i t} \mid d_{i}, Z_{i}, \alpha_{i}\right)=d_{i t}-\mathbf{z}_{i t}^{\prime} \delta-\alpha_{i}$, the residuals from the first stage regression are not identified, this is because the $\alpha_{i}$ 's remain unobserved, even though $\delta$ and $\sigma_{\epsilon}$ can be consistently estimated. To estimate the above system of equations, we show in Appendix A that

$$
\begin{aligned}
E\left(r_{1 i t} \mid d_{i}, Z_{i}\right) & =\int \mathrm{E}\left(r_{1 i t} \mid d_{i}, Z_{i}, \alpha_{i}\right) f\left(\alpha_{i} \mid d_{i}, Z_{i}\right) d \alpha_{i}=\mathbf{z}_{i t}^{r \prime} \beta+\beta_{f}+\beta_{1}(.)+\mu \hat{\alpha}_{i}+\rho_{\eta_{1} \epsilon} \frac{\sigma_{\eta_{1}}}{\sigma_{\epsilon}} \hat{\epsilon}_{i t} \\
& =\mathrm{E}\left(r_{1 i t} \mid d_{i}, Z_{i}, \hat{\alpha}_{i}, \hat{\epsilon}_{i t}\right)
\end{aligned}
$$

if $f_{i t}^{*}>0$, and

$$
\begin{aligned}
E\left(r_{0 i t} \mid d_{i}, Z_{i}\right) & =\int \mathrm{E}\left(r_{0 i t} \mid d_{i}, Z_{i}, \alpha_{i}\right) f\left(\alpha_{i} \mid d_{i}, Z_{i}\right) d \alpha_{i}=\mathbf{z}_{i t}^{r^{\prime}} \beta+\beta_{0}(.)+\mu \hat{\alpha}_{i}+\rho_{\eta_{0}} \epsilon \frac{\sigma_{\eta_{0}}}{\sigma_{\epsilon}} \hat{\epsilon}_{i t} \\
& =\mathrm{E}\left(r_{0 i t} \mid d_{i}, Z_{i}, \hat{\alpha}_{i}, \hat{\epsilon}_{i t}\right)
\end{aligned}
$$

if $f_{i t}^{*} \leq 0$.

$$
\begin{aligned}
E\left(f_{i t}^{*} \mid d_{i}, Z_{i}\right) & =\int \mathrm{E}\left(f_{i t}^{*} \mid d_{i}, Z_{i}, \alpha_{i}\right) f\left(\alpha_{i} \mid d_{i}, Z_{i}\right) d \alpha_{i}=\varphi\left(\mathbf{z}_{i t}^{f \prime}, d_{i t}, \hat{\alpha}_{i}\right)+\rho_{\zeta \epsilon} \frac{\hat{\epsilon}_{i t}}{\sigma_{\epsilon}} \\
& =\mathrm{E}\left(f_{i t}^{*} \mid d_{i}, Z_{i}, \hat{\alpha}_{i}, \hat{\epsilon}_{i t}\right),
\end{aligned}
$$

and

$$
\begin{aligned}
E\left(s_{i t}^{*} \mid d_{i}, Z_{i}\right) & =\int \mathrm{E}\left(s_{i t}^{*} \mid d_{i}, Z_{i}, \alpha_{i}\right) f\left(\alpha_{i} \mid d_{i}, Z_{i}\right) d \alpha_{i}=\gamma\left(\mathbf{z}_{i t}^{s \prime}, d_{i t}, \hat{\alpha}_{i}\right)+\rho_{v \epsilon} \frac{\hat{\epsilon}_{i t}}{\sigma_{\epsilon}} \\
& =\mathrm{E}\left(s_{i t}^{*} \mid d_{i}, Z_{i}, \hat{\alpha}_{i}, \hat{\epsilon}_{i t}\right)
\end{aligned}
$$

where $\hat{\epsilon}_{i t}=\left(d_{i t}-\mathbf{z}_{i t}^{\prime} \delta-\hat{\alpha}_{i}\right)$ and $\hat{\alpha}_{i} \equiv \hat{\alpha}_{i}\left(d_{i}, Z_{i}, \delta, \sigma_{\epsilon}, \sigma_{\alpha}\right)$ is the expected a posteriori value of $\alpha_{i}$, that are based on the results of the first stage estimation, which we discuss in a later section. To estimate the expected values of $r_{1 i t}, r_{0 i t}, f_{i t}^{*}$ and $s_{i t}^{*}$ given $d_{i}$ and $Z_{i}$ we write the linear projection of $r_{1 i t}, r_{0 i t}$, $f_{i t}^{*}$ and $s_{i t}^{*}$ in error form given $d_{i}$ and $Z_{i}$ respectively as:

$$
r_{i t}=f_{i t} r_{1 i t}+\left(1-f_{i t}\right) r_{0 i t},
$$


where

$$
r_{1 i t}=\mathbf{z}_{i t}^{r \prime} \beta+\beta_{f}+\beta_{1}(.)+\mu \hat{\alpha}_{i}+\rho_{\eta_{1} \epsilon} \frac{\sigma_{\eta_{1}}}{\sigma_{\epsilon}} \hat{\epsilon}_{i t}+\underline{\eta}_{1 i t},
$$

if $f_{i t}^{*}>0$,

$$
r_{0 i t}=\mathbf{z}_{i t}^{r \prime} \beta+\beta_{0}(.)+\mu \hat{\alpha}_{i}+\rho_{\eta_{0} \epsilon} \frac{\sigma_{\eta_{0}}}{\sigma_{\epsilon}} \hat{\epsilon}_{i t}+\underline{\eta}_{0 i t},
$$

if $f_{i t}^{*} \leq 0$.

$$
f_{i t}^{*}=\varphi\left(\mathbf{z}_{i t}^{f \prime}, d_{i t}, \hat{\alpha}_{i}\right)+\rho_{\zeta \epsilon} \frac{\hat{\epsilon}_{i t}}{\sigma_{\epsilon}}+\underline{\zeta}_{i t},
$$

and

$$
s_{i t}^{*}=\gamma\left(\mathbf{z}_{i t}^{s \prime}, d_{i t}, \hat{\alpha}_{i}\right)+\rho_{v \epsilon} \frac{\hat{\epsilon}_{i t}}{\sigma_{\epsilon}}+\underline{v}_{i t},
$$

where $\underline{\eta}_{1 i t}, \underline{\eta}_{0 i t} \underline{\zeta}_{i t}$ and $\underline{v}_{i t}$ have been defined in Appendix A. The variance covariance matrix of the error component in (12) to (14) is given by,

$$
\left(\begin{array}{l}
\underline{\eta}_{1 i t} \\
\underline{\eta}_{0 i t} \\
\underline{\zeta}_{i t} \\
\underline{v}_{i t}
\end{array}\right) \sim N\left[\left(\begin{array}{l}
0 \\
0 \\
0 \\
0
\end{array}\right)\left(\begin{array}{cccc}
\sigma_{\underline{\eta}_{1}}^{2} & \rho_{\underline{\eta}_{1} \underline{\eta}_{0}} \sigma_{\underline{\eta}_{1}} \sigma_{\underline{\eta}_{0}} & \rho_{\underline{\eta}_{1} \underline{\zeta}} \sigma_{\underline{\eta}_{1}} \sigma_{\underline{\zeta}} & \rho_{\underline{\eta}_{1} \underline{v}} \sigma_{\underline{\eta}_{1}} \sigma_{\underline{v}} \\
& \sigma_{\underline{\eta}_{0}}^{2} & \rho_{{\underline{\eta_{0}}}_{0}} \sigma_{\underline{\eta}_{0}} \sigma_{\underline{\zeta}} & \rho_{\underline{\eta}_{0} \underline{v}} \sigma_{\underline{\eta}_{0}} \sigma_{\underline{v}} \\
& & \sigma_{\underline{\zeta}}^{2} & \rho_{\underline{\underline{\underline{v}}}} \sigma_{\underline{\zeta}} \sigma_{\underline{v}} \\
& & & \sigma_{\underline{v}}^{2}
\end{array}\right)\right],
$$

where the respective elements of the matrix have been stated in Appendix A. Again as stated earlier, $\rho_{\underline{\eta}_{1} \underline{\eta}_{0}}$, cannot be identified since a firm cannot be at the same time in either of the two regimes. We also note here that, having specified the conditional distribution of $r_{1 i t}, r_{0 i t}, f_{i t}^{*}$ and $s_{i t}^{*}$ given $d_{i}$ and $Z_{i}$, we can no longer estimate the error structure for $\bar{\eta}_{1 i t}, \bar{\eta}_{0 i t}, \bar{\zeta}_{i t}$ and $\bar{v}_{i t}$, though the parameters of interest appearing in equations (12)-(14) can be identified.

To define the correction terms, consider the following conditional mean, $\mathrm{E}\left(r_{i t} \mid f_{i t}^{*}, s_{i t}^{*}>0, Z_{i}, d_{i}, \hat{\alpha}_{i}, \hat{\epsilon}_{i t}\right)$ : 


$$
\begin{aligned}
& \mathrm{E}\left(r_{i t} \mid f_{i t}^{*}, s_{i t}^{*}>0, Z_{i}, d_{i}, \hat{\alpha}_{i}, \hat{\epsilon}_{i t}\right)=\mathrm{E}\left(f_{i t} r_{1 i t}+\left(1-f_{i t}\right) r_{0 i t} \mid f_{i t}^{*}, s_{i t}^{*}>0, Z_{i}, d_{i}, \hat{\alpha}_{i}, \hat{\epsilon}_{i t}\right) \\
& =\mathbf{z}_{i t}^{r \prime} \beta+f_{i t} \beta_{f}+f_{i t}\left(\beta_{1}(.)+\rho_{\eta_{1}} \frac{\sigma_{\eta_{1}}}{\sigma_{\epsilon}} \hat{\epsilon}_{i t}\right)+\left(1-f_{i t}\right)\left(\beta_{0}(.)+\rho_{\eta_{0} \epsilon} \frac{\sigma_{\eta_{0}}}{\sigma_{\epsilon}} \hat{\epsilon}_{i t}\right)+\mu \hat{\alpha}_{i} \\
& +f_{i t} \mathrm{E}\left(\underline{\eta}_{1 i t} \mid f_{i t}^{*}>0, s_{i t}^{*}>0, Z_{i}, d_{i}, \hat{\alpha}_{i}, \hat{\epsilon}_{i t}\right)+\left(1-f_{i t}\right) \mathrm{E}\left(\underline{\eta}_{0 i t} \mid f_{i t}^{*} \leq 0, s_{i t}^{*}>0, Z_{i}, d_{i}, \hat{\alpha}_{i}, \hat{\epsilon}_{i t}\right)
\end{aligned}
$$

We know that

$$
E\left(\underline{\eta}_{1 i t} \mid f_{i t}^{*}>0, s_{i t}^{*}>0, Z_{i}, d_{i}, \hat{\alpha}_{i}, \hat{\epsilon}_{i t}\right)=\mathrm{E}\left[\underline{\eta}_{1 i t} \mid \underline{\zeta}_{i t}>-\varphi\left(\mathbf{z}_{i t}^{f \prime}, d_{i t}, \hat{\alpha}_{i}\right)-\rho_{\zeta \epsilon} \frac{\hat{\epsilon}_{i t}}{\sigma_{\epsilon}}, \underline{v}_{i t}>-\gamma\left(\mathbf{z}_{i t}^{s \prime}, d_{i t}, \hat{\alpha}_{i}\right)-\rho_{v \epsilon} \frac{\hat{\epsilon}_{i t}}{\sigma_{\epsilon}}\right],
$$

and that

$$
E\left(\underline{\eta}_{0 i t} \mid f_{i t}^{*} \leq 0, s_{i t}^{*}>0, Z_{i}, d_{i}, \hat{\alpha}_{i}, \hat{\epsilon}_{i t}\right)=\mathrm{E}\left[\underline{\eta}_{0 i t} \mid \underline{\zeta}_{i t} \leq-\varphi\left(\mathbf{z}_{i t}^{f \prime}, d_{i t}, \hat{\alpha}_{i}\right)-\rho_{\zeta \epsilon} \frac{\hat{\epsilon}_{i t}}{\sigma_{\epsilon}}, \underline{v}_{i t}>-\gamma\left(\mathbf{z}_{i t}^{s \prime}, d_{i t}, \hat{\alpha}_{i}\right)-\rho_{v \epsilon} \frac{\hat{\epsilon}_{i t}}{\sigma_{\epsilon}}\right],
$$

Define $\hat{\mu}_{\zeta}=\rho_{\zeta \epsilon} \frac{\hat{\epsilon}_{i t}}{\sigma_{\epsilon}}$ and $\hat{\mu}_{v}=\rho_{v \epsilon} \frac{\hat{\epsilon}_{i t}}{\sigma_{\epsilon}}$. It has been shown in Appendix B that

$$
\begin{aligned}
& \mathrm{E}\left[\underline{\eta}_{1 i t} \mid \underline{\zeta}_{i t}>-\varphi\left(\mathbf{z}_{i t}^{f \prime}, d_{i t}, \hat{\alpha}_{i}\right)-\hat{\mu}_{\zeta}, \underline{v}_{i t}>-\gamma\left(\mathbf{z}_{i t}^{s \prime}, d_{i t}, \hat{\alpha}_{i}\right)-\hat{\mu}_{v}\right]= \\
& \sigma_{\underline{\eta}_{1}} \rho_{\underline{\eta}_{1} \underline{\zeta}} \phi\left(\frac{\varphi(.)+\hat{\mu}_{\zeta}}{\sigma_{\underline{\zeta}}}\right) \frac{\Phi\left(\left(\frac{\gamma(.)+\hat{\mu}_{v}}{\sigma_{\underline{v}}}-\rho_{\underline{\underline{\underline{v}}}} \frac{\varphi(.)+\hat{\mu}_{\underline{\zeta}}}{\sigma_{\underline{\zeta}}}\right) / \sqrt{1-\rho_{\underline{\underline{\underline{v}}}}^{2}}\right)}{\Phi_{2}\left(\frac{\varphi(.)+\hat{\mu}_{\zeta}}{\sigma_{\underline{\zeta}}}, \frac{\gamma(.)+\hat{\mu}_{v}}{\sigma_{\underline{v}}}, \rho_{\underline{\zeta} \underline{v}}\right)}
\end{aligned}
$$

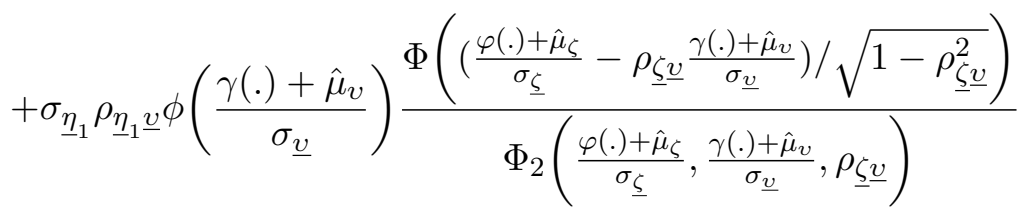

and

$$
\begin{aligned}
& \mathrm{E}\left[\underline{\eta}_{0 i t} \mid \underline{\zeta}_{i t} \leq-\varphi\left(\mathbf{z}_{i t}^{f \prime}, d_{i t}, \hat{\alpha}_{i}\right)-\hat{\mu}_{\zeta}, \underline{v}_{i t}>-\gamma\left(\mathbf{z}_{i t}^{s \prime}, d_{i t}, \hat{\alpha}_{i}\right)-\hat{\mu}_{v}\right]= \\
& -\sigma_{\underline{\eta}_{0}} \rho_{\underline{\eta}_{0} \underline{\zeta}} \phi\left(\frac{\varphi(.)+\hat{\mu}_{\zeta}}{\sigma_{\underline{\zeta}}}\right) \frac{\Phi\left(\left(\frac{\gamma(.)+\hat{\mu}_{v}}{\sigma_{\underline{v}}}-\rho_{\underline{\zeta} \underline{v}} \frac{\varphi(.)+\hat{\mu}_{\zeta}}{\sigma_{\underline{\zeta}}}\right) / \sqrt{1-\rho_{\underline{\zeta} \underline{v}}^{2}}\right)}{\Phi_{2}\left(-\frac{\varphi(.)+\hat{\mu}_{\zeta}}{\sigma_{\underline{\zeta}}}, \frac{\gamma(.)+\hat{\mu}_{v}}{\sigma_{\underline{v}}},-\rho_{\underline{\zeta} \underline{v}}\right)} \\
& +\sigma_{\underline{\eta}_{0}} \rho_{\underline{\eta}_{0} \underline{v}} \phi\left(\frac{\gamma(.)+\hat{\mu}_{v}}{\sigma_{\underline{v}}}\right) \frac{\Phi\left(\left(-\frac{\varphi(.)+\hat{\mu}_{\zeta}}{\sigma_{\underline{\zeta}}}+\rho_{\underline{\zeta} \underline{v}} \frac{\gamma(.)+\hat{\mu}_{v}}{\sigma_{\underline{v}}}\right) / \sqrt{1-\rho_{\underline{\zeta} \underline{v}}^{2}}\right)}{\Phi_{2}\left(-\frac{\varphi(.)+\hat{\mu}_{\zeta}}{\sigma_{\underline{\zeta}}}, \frac{\gamma(.)+\hat{\mu}_{v}}{\sigma_{\underline{v}}},-\rho_{\underline{\zeta} \underline{v}}\right)},
\end{aligned}
$$

where $\phi, \Phi$, and $\Phi_{2}$, respectively denote the density function of a standard normal distribution, the 
cumulative distribution function of a standard normal, and the cumulative distribution function of a standard bivariate normal.

Define the correction terms $C_{11}({ })_{i t}, C_{12}(.)_{i t}, C_{13}(.)_{i t}, C_{01}(.)_{i t}, C_{02}(.)_{i t}$, and $C_{03}(.)_{i t}$ respectively as

$$
\begin{aligned}
& C_{11}\left(\Xi, Z_{i}, d_{i}, \hat{\alpha}_{i}, \hat{\epsilon}_{i t}\right)_{i t} \equiv f_{i t} \frac{\hat{\epsilon}_{i t}}{\sigma_{\epsilon}}=f_{i t} \frac{1}{\sigma_{\epsilon}}\left(d_{i t}-\mathbf{z}_{i t}^{\prime} \delta-\hat{\alpha}_{i}\right) \\
& C_{12}\left(\Xi, Z_{i}, d_{i}, \hat{\alpha}_{i}, \hat{\epsilon}_{i t}\right)_{i t} \equiv f_{i t} \phi\left(\frac{\varphi(.)+\hat{\mu}_{\zeta}}{\sigma_{\underline{\zeta}}}\right) \frac{\Phi\left(\left(\frac{\gamma(.)+\hat{\mu}_{v}}{\sigma_{\underline{\underline{v}}}}-\rho_{\underline{\underline{\zeta}} \underline{ }} \frac{\varphi(.)+\hat{\mu}_{\zeta}}{\sigma_{\underline{\zeta}}}\right) / \sqrt{1-\rho_{\underline{\underline{\underline{v}}}}^{2}}\right)}{\Phi_{2}\left(\frac{\varphi(.)+\hat{\mu}_{\zeta}}{\sigma_{\underline{\zeta}}}, \frac{\gamma(.)+\hat{\mu}_{v}}{\sigma_{\underline{v}}}, \rho_{\underline{\underline{\underline{v}}}}\right)}, \\
& C_{13}\left(\Xi, Z_{i}, d_{i}, \hat{\alpha}_{i}, \hat{\epsilon}_{i t}\right)_{i t} \equiv f_{i t} \phi\left(\frac{\gamma(.)+\hat{\mu}_{v}}{\sigma_{\underline{v}}}\right) \frac{\Phi\left(\left(\frac{\varphi(.)+\hat{\mu}_{\zeta}}{\sigma_{\underline{\zeta}}}-\rho_{\underline{\underline{v}} \underline{\underline{v}}} \frac{\gamma(.)+\hat{\mu}_{v}}{\sigma_{\underline{v}}}\right) / \sqrt{1-\rho_{\underline{\underline{v}}}^{2}}\right)}{\Phi_{2}\left(\frac{\varphi(.)+\hat{\mu}_{\zeta}}{\sigma_{\underline{\zeta}}}, \frac{\gamma(.)+\hat{\mu}_{v}}{\sigma_{\underline{v}}}, \rho_{\underline{\underline{v}}}\right)}, \\
& C_{01}\left(\Xi, Z_{i}, d_{i}, \hat{\alpha}_{i}, \hat{\epsilon}_{i t}\right)_{i t} \equiv\left(1-f_{i t}\right) \frac{\hat{\epsilon}_{i t}}{\sigma_{\epsilon}}=\left(1-f_{i t}\right) \frac{1}{\sigma_{\epsilon}}\left(d_{i t}-\mathbf{z}_{i t}^{\prime} \delta-\hat{\alpha}_{i}\right), \\
& C_{02}\left(\Xi, Z_{i}, d_{i}, \hat{\alpha}_{i}, \hat{\epsilon}_{i t}\right)_{i t} \equiv\left(1-f_{i t}\right) \phi\left(\frac{\varphi(.)+\hat{\mu}_{\zeta}}{\sigma_{\underline{\zeta}}}\right) \frac{\Phi\left(\left(\frac{\gamma(.)+\hat{\mu}_{v}}{\sigma_{\underline{v}}}-\rho_{\underline{\zeta} \underline{v}} \frac{\varphi(.)+\hat{\mu}_{\zeta}}{\sigma_{\underline{\zeta}}}\right) / \sqrt{1-\rho_{\underline{\zeta} \underline{v}}^{2}}\right)}{\Phi_{2}\left(-\frac{\varphi(.)+\hat{\mu}_{\zeta}}{\sigma_{\underline{\zeta}}}, \frac{\gamma(.)+\hat{\mu}_{v}}{\sigma_{\underline{\underline{v}}}},-\rho_{\underline{\underline{v}} \underline{v}}\right)},
\end{aligned}
$$

and

$$
C_{03}\left(\Xi, Z_{i}, d_{i}, \hat{\alpha}_{i}, \hat{\epsilon}_{i t}\right)_{i t} \equiv\left(1-f_{i t}\right) \phi\left(\frac{\gamma(.)+\hat{\mu}_{v}}{\sigma_{\underline{v}}}\right) \frac{\Phi\left(\left(-\frac{\varphi(.)+\rho_{\zeta \epsilon} \frac{\hat{\epsilon}_{i t}}{\sigma_{\epsilon}}}{\sigma_{\underline{\zeta}}}+\rho_{\underline{\underline{\zeta}} \underline{\underline{v}}} \frac{\gamma(.)+\hat{\mu}_{v}}{\sigma_{\underline{v}}}\right) / \sqrt{1-\rho_{\underline{\underline{\underline{v}}}}^{2}}\right)}{\Phi_{2}\left(-\frac{\varphi(.)+\hat{\mu}_{\zeta}}{\sigma_{\underline{\zeta}}}, \frac{\gamma(.)+\hat{\mu}_{v}}{\sigma_{\underline{v}}},-\rho_{\underline{\underline{\underline{v}}}}\right)} .
$$

With the correction terms defined, we can now write the R\&D switching equation (12), conditional 
on $f_{i t}^{*}, s_{i t}^{*}>0, Z_{i}, d_{i}, \hat{\alpha}_{i}, \hat{\epsilon}_{i t}$ as

$$
\begin{aligned}
r_{i t} & =\mathbf{z}_{i t}^{r \prime} \beta+f_{i t} \beta_{f}+f_{i t} \beta_{1}(.)+\left(1-f_{i t}\right) \beta_{0}(.)+\mu \hat{\alpha}_{i} \\
& +f_{i t}\left(\rho_{\eta_{1} \epsilon} \sigma_{\eta_{1}} C_{11}(.)_{i t}+\rho_{\underline{\eta}_{1} \underline{\zeta}} \sigma_{\underline{\eta}_{1}} C_{12}(.)_{i t}+\rho_{\underline{\eta}_{1} \underline{\underline{v}}} \sigma_{\underline{\eta}_{1}} C_{13}(.)_{i t}\right) \\
& +\left(1-f_{i t}\right)\left(\rho_{\eta_{0} \epsilon} \sigma_{\eta_{0}} C_{01}(.)_{i t}+\rho_{\underline{\eta}_{0} \underline{\zeta}} \sigma_{\underline{\eta}_{0}} C_{02}(.)_{i t}+\rho_{\underline{\eta}_{0} \underline{\underline{v}}} \sigma_{\underline{\eta}_{0}} C_{03}(.)_{i t}\right)+\tilde{\eta}_{i t},
\end{aligned}
$$

where $\tilde{\eta}_{i t}$ conditional on $f_{i t}^{*}, s_{i t}^{*}, Z_{i}$ and $d_{i}$ is distributed with mean zero. The first and second stage of the empirical strategy, gives us estimates of $\Xi$, for constructing the correction terms , where $\Xi=\left(\varphi \frac{1}{\sigma_{\underline{\zeta}}}, \frac{\varphi_{d}}{\sigma_{\underline{\zeta}}}, \frac{\lambda}{\sigma_{\underline{\underline{G}}}} ; \gamma \frac{1}{\sigma_{\underline{v}}}, \frac{\gamma_{d}}{\sigma_{\underline{v}}}, \frac{\theta}{\sigma_{\underline{v}}} ; \delta ; \rho_{\underline{\underline{v}} \underline{ }}, \frac{\rho_{\zeta \epsilon}}{\sigma_{\underline{\zeta}}}, \frac{\rho_{v \epsilon}}{\sigma_{\underline{v}}}, \sigma_{\epsilon}\right)$. Plugging these correction terms and $\hat{\alpha}_{i}$ in the R\&D equation, (24), gives consistent estimates of the parameters of the switching model for R\&D investment. These parameters can be obtained by running a simple pooled OLS for the sample of selected or innovating firms. $C_{11}(\Xi, .)_{i t}$ and $C_{01}(\Xi, .)_{i t}$ corrects for the potential bias that can arise due to endogeneity of long-term debt when estimating equation (24). While $C_{11}(\Xi, .)_{i t}$ corrects for the bias in the subsample of firms belonging to the regime that is financially constrained, $C_{01}(\Xi \text {., })_{i t}$ corrects for the bias in the subsample of firms that are not constrained. $C_{12}(\Xi, .)_{i t}$ and $C_{13}(\Xi, .)_{i t}$ corrects for the bias that could arise due endogenous switching and endogenous selection while estimating the $\mathrm{R} \& \mathrm{D}$ equation for the firms that are financially constrained, while $C_{02}(\Xi, .)_{i t}$ and $C_{03}(\Xi, .)_{i t}$ corrects for the bias that could arise due endogenous switching and endogenous selection for the subsample of firms that are not financially constrained.

Apart from the parameters appearing in the R\&D switching equation, (12a) and (12b), the other parameters that are estimated while estimating equation (24), are the coefficients of the correction terms. These coefficients are the estimates of the correlation between the unobserved factors affecting $R \& D$ expenditure in the two regimes and the unobserved factors that affect the chances of a firm to be financially constrained $\left(\sigma_{\underline{\eta}_{1}} \rho_{\underline{\eta}_{1}}, \sigma_{\underline{\eta}_{0}} \rho_{\underline{\eta}_{0}}\right)$, the correlation between the unobserved factors affecting $\mathrm{R} \& \mathrm{D}$ expenditure and the unobserved factors affecting the choice of the firm to be an innovator $\left(\sigma_{\underline{\eta}_{1}} \rho_{\underline{\eta}_{1} \underline{v}}, \sigma_{\underline{\eta}_{0}} \rho_{\underline{\underline{\eta}}_{0} \underline{\underline{v}}}\right)$, and of course, the correlation between the unobserved factors affecting R\&D expenditure and the unobserved factors affecting the choice of capital structure, that is, the extent of leverage measured by long-term debt to capital asset ratio $\left(\rho_{\eta_{0} \epsilon} \sigma_{\eta_{0}}, \rho_{\eta_{1} \epsilon} \sigma_{\eta_{1}}\right)$.

We estimate the parameters in $\Xi$ in the first and second stage, which we discuss in detail below. In the first stage we estimate equation (5), the reduced form long-term debt equation. Using the estimates from the first stage regression, we jointly estimate equations (13) and (14), which are our conditional financial constraint equation and conditional selection equation. To estimate equations 
(13) and (14), we use the method of Maximum Likelihood. While such a procedure is quite common for cross sectional data analysis, in panel data we have to account for an unobserved firm specific individual effect, $\alpha_{i}$, which is correlated with endogenous regressors and appears in each of the equations, (2a), (2b), (3), (4) and (5). With $\hat{\alpha}_{i}$ in place, the unobserved time individual effect is controlled for and the factor loadings, $\mu, \lambda$, and $\theta$ are estimated. The details for estimating the expected a posteriori values of $\alpha_{i}$ are outlined in Appendix A.

\section{The First Stage: Reduced Form for Long-term Debt}

In the first stage of our econometric methodology we estimate equation (5), the reduced form equation for long-term debt.

$$
d_{i t}=\mathbf{z}_{i t}^{\prime} \delta+\alpha_{i}+\epsilon_{i t}
$$

The vector of exogenous variables included in $\mathbf{z}_{i t}^{\prime}$ are: (1) the ratio of cash flows of the firm in period $t$ to the capital assets (tangible +intangible) of the firm at the beginning of period $t\left(C F_{t}\right),(2)$ the market share of the firm measured by the ratio of the total sales of the firm to the industry total sales in period $t\left(M K S H_{t}\right)$, (3) the logarithm of the number of people employed $\left(S I Z E_{t}\right)$, (4) the age of the firm $(A G E),(5)$ the ratio of cash holdings of the firm to total capital assets $\left(L Q_{t}\right),(6)$ a dummy for positive dividends $\left(D I V_{t}\right),(7)$ a dummy if a firm is a multi-enterprise firm $\left(D M U L T I_{t}\right)$, (8) a dummy for negative realization of cash flows $\left(D N F C_{t}\right)$, (9) the share of innovative sales in the total sales of the firms, $\left(S I N S_{t}\right)$, (10) industry or sectoral dummies and finally (11) year dummies.

We can get the estimates of the parameters of the reduced form model, equation (5), we can either use the simple random effects model or maximize the marginal likelihood function. The marginal likelihood function for individual $i$ for the first stage estimation of the reduced form for the debt equation is given by

$$
\boldsymbol{L}_{i}\left(\delta, \sigma_{\epsilon}, \sigma_{\alpha}\right)=\int_{-\infty}^{\infty} \prod_{t=1}^{T_{i}} \frac{1}{\sigma_{\epsilon} \sqrt{2 \pi}} \exp \left\{\frac{\left(d_{i t}-\mathbf{z}_{i t}^{\prime} \delta-\sigma_{\alpha} \tilde{\alpha}_{i}\right)^{2}}{2 \sigma_{\epsilon}^{2}}\right\} \phi\left(\tilde{\alpha}_{i}\right) d \tilde{\alpha}_{i}
$$

where $\tilde{\alpha}_{i}=\frac{\alpha_{i}}{\sigma_{\alpha}}$ and $\phi$ is the standard normal density function. The estimates of the first stage estimation, thus gives us the estimate of $\delta, \sigma_{\alpha}$ and $\sigma_{\epsilon}$, which we can use to get the estimates of the expected a posteriori values of $\alpha_{i}, \hat{\alpha}_{i}$, given $d_{i}$ and $z_{i}$, that would be subsequently used for the second and the third stage estimation. 


\section{The Second Stage: Financial Constraint and Selection with Endogenous Long-term Debt}

In the second stage we jointly estimate the parameters of financial constraint equation (13) and the selection equation (14). The two equations, assuming liquidity, dividends, and the share of innovative sales to be exogenous, are stated below. While equation (5), the debt equation, has been written as a reduced form, the financial constraint equation and the selection equation are both structural equations.

$$
\begin{aligned}
& f_{i t}^{*}=\varphi\left(\mathbf{z}_{i t}^{f \prime}, d_{i t}, \hat{\alpha}_{i}\right)+\rho_{\zeta \epsilon} \frac{\hat{\epsilon}_{i t}}{\sigma_{\epsilon}}+\underline{\zeta}_{i t}, \\
& s_{i t}^{*}=\gamma\left(\mathbf{z}_{i t}^{s \prime}, d_{i t}, \hat{\alpha}_{i}\right)+\rho_{v \epsilon} \frac{\hat{\epsilon}_{i t}}{\sigma_{\epsilon}}+\underline{v}_{i t},
\end{aligned}
$$

where $\hat{\epsilon}_{i t}=\left(d_{i t}-\mathbf{z}_{i t}^{\prime} \delta-\hat{\alpha}_{i}\right)$ and $\hat{\alpha}_{i} \equiv \hat{\alpha}_{i}\left(d_{i}, Z_{i}, \delta, \sigma_{\epsilon}, \sigma_{\alpha}\right)$ is the expected a posteriori value of $\alpha_{i}$ defined at the population parameters. Given the joint distribution of $\underline{\eta}_{1 i t}, \underline{\eta}_{0 i t}, \underline{\zeta}_{i t}, \underline{v}_{i t}$, conditional on $d_{i}$ and $Z_{i}$, the marginal distribution of $\underline{\zeta}_{i t}$ and $\underline{v}_{i t}$, follows a bivariate normal given by:

$$
\left(\begin{array}{l}
\underline{\zeta}_{i t} \\
\underline{v}_{i t}
\end{array}\right) \sim N\left[\left(\begin{array}{l}
0 \\
0
\end{array}\right)\left(\begin{array}{cc}
\sigma_{\underline{\zeta}}^{2} & \sigma_{\underline{\zeta}} \sigma_{\underline{v}} \rho_{\underline{\zeta} \underline{v}} \\
& \sigma_{\underline{v}}^{2}
\end{array}\right)\right] .
$$

Thus,

$$
\begin{array}{r}
\operatorname{Pr}\left(f_{i t}=1, s_{i t}=1 \mid d_{i}, Z_{i}, \hat{\epsilon}_{i t}, \hat{\alpha}_{i}\right)=\operatorname{Pr}\left(f_{i t}^{*}>0, s_{i t}^{*}>0 \mid d_{i}, Z_{i}\right) \\
=\operatorname{Pr}\left(\underline{\zeta}_{i t}>-\varphi\left(\mathbf{z}_{i t}^{f \prime}, d_{i t}, \hat{\alpha}_{i}\right)-\rho_{v \epsilon} \frac{\hat{\epsilon}_{i t}}{\sigma_{\epsilon}}, \underline{v}_{i t}>-\gamma\left(\mathbf{z}_{i t}^{s \prime}, d_{i t}, \hat{\alpha}_{i}\right)-\rho_{v \epsilon} \frac{\hat{\epsilon}_{i t}}{\sigma_{\epsilon}} \mid d_{i}, Z_{i}\right) \\
=\Phi_{2}\left(\frac{\varphi(.)+\rho_{\zeta \epsilon} \frac{\hat{\epsilon}_{i t}}{\sigma_{\epsilon}}}{\sigma_{\underline{\zeta}}}, \frac{\gamma(.)+\rho_{v \epsilon} \frac{\hat{\epsilon}_{i t}}{\sigma_{\epsilon}}}{\sigma_{\underline{v}}}, \rho_{\underline{\underline{v}}}\right),
\end{array}
$$

where $\Phi_{2}$ is the cumulative distribution function of a standard bivariate normal. Also,

$$
\begin{aligned}
& \operatorname{Pr}\left(f_{i t}=0, s_{i t}=1 \mid d_{i}, Z_{i}, \hat{\epsilon}_{i t}, \hat{\alpha}_{i}\right)=\Phi_{2}\left(-\frac{\varphi(.)+\rho_{\zeta \epsilon} \frac{\hat{\epsilon}_{i t}}{\sigma_{\epsilon}}}{\sigma_{\underline{\zeta}}}, \frac{\gamma(.)+\rho_{v \epsilon} \frac{\hat{\epsilon}_{i t}}{\sigma_{\epsilon}}}{\sigma_{\underline{v}}},-\rho_{\underline{\underline{\zeta}}}\right), \\
& \operatorname{Pr}\left(f_{i t}=1, s_{i t}=0 \mid d_{i}, Z_{i}, \hat{\epsilon}_{i t}, \hat{\alpha}_{i}\right)=\Phi_{2}\left(\frac{\varphi(.)+\rho_{\zeta \epsilon} \frac{\hat{\epsilon}_{i t}}{\sigma_{\epsilon}}}{\sigma_{\underline{\zeta}}},-\frac{\gamma(.)+\rho_{v v \frac{\hat{\epsilon}_{i t}}{\sigma_{\epsilon}}}}{\sigma_{\underline{v}}},-\rho_{\underline{\underline{\underline{v}}}}\right),
\end{aligned}
$$


and

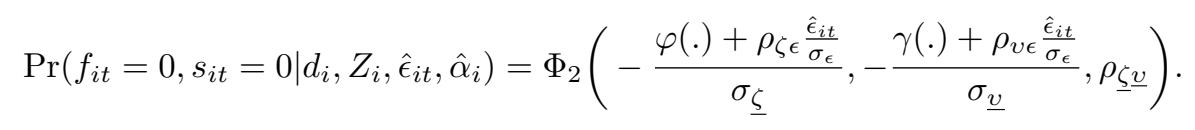

However for CIS2.5 we do not observe whether $f_{i t}$ is 1 or 0 when $s_{i t}=0$, by integrating out $\underline{\zeta}_{i t}$, we get

$$
\operatorname{Pr}\left(s_{i t}=0 \mid d_{i}, Z_{i}, \hat{\epsilon}_{i t}, \hat{\alpha}_{i}\right)=\Phi\left(\frac{-\left(\mathbf{z}_{i t}^{s \prime} \gamma+d_{i t} \gamma_{d}+\theta \hat{\alpha}_{i}+\rho_{v \epsilon} \frac{\hat{\epsilon}_{i t}}{\sigma_{\epsilon}}\right)}{\sigma_{\underline{v}}}\right)
$$

The conditional $\log$ likelihood function for individual $i$ in period $t$ given $d_{i}, Z_{i}$, if the time period $t$ corresponds to CIS3 and CIS3.5, is given by

$$
\begin{aligned}
& \boldsymbol{L}_{i t}\left(\varphi, \varphi_{d}, \rho_{\zeta \epsilon}, \lambda, \sigma_{\underline{\zeta}} ; \gamma, \gamma_{d}, \rho_{v \epsilon}, \theta, \sigma_{\underline{v}} ; \rho_{\underline{\underline{\zeta}} \underline{v}} \mid d_{i}, Z_{i}, \hat{\epsilon}_{i t}, \hat{\alpha}_{i}\right)=f s \operatorname{Pr}(f=1, s=1) \\
& +(1-f) s \operatorname{Pr}(f=0, s=1)+f(1-s) \operatorname{Pr}(f=1, s=0)+(1-f)(1-s) \operatorname{Pr}(f=0, s=0)
\end{aligned}
$$

and

$$
\begin{aligned}
\boldsymbol{L}_{i t}\left(\varphi, \varphi_{d}, \rho_{\zeta \epsilon}, \lambda, \sigma_{\underline{\underline{\zeta}}} ; \gamma, \gamma_{d}, \rho_{v \epsilon}, \theta, \sigma_{\underline{v}} ; \rho_{\underline{\underline{\underline{v}}}} \mid d_{i}, Z_{i}, \hat{\epsilon}_{i t}, \hat{\alpha}_{i}\right) & =f s \operatorname{Pr}(f=1, s=1)+(1-f) s \operatorname{Pr}(f=0, s=1) \\
& +(1-s) \operatorname{Pr}(s=0),
\end{aligned}
$$

if the time period $t$ corresponds to CIS2.5. Given that error components in (13) and (14) are i.i.d., the log likelihood for an individual $i$, is thus given by

$$
\boldsymbol{L}_{i}\left(\varphi, \varphi_{d}, \rho_{\zeta \epsilon}, \lambda, \sigma_{\underline{\zeta}} ; \gamma, \gamma_{d}, \rho_{v \epsilon}, \theta, \sigma_{\underline{v}} ; \rho_{\underline{\zeta} \underline{v}} \mid d_{i}, Z_{i}, \hat{\epsilon}_{i t}, \hat{\alpha}_{i}\right)=\sum_{t=1}^{T_{i}} \boldsymbol{L}_{i t}\left(. \mid d_{i} Z_{i}, \hat{\epsilon}_{i t}, \hat{\alpha}_{i}\right) .
$$

Now, we know that for probit models, the variance of the idiosyncratic components, $\sigma_{\underline{\zeta}}$ and $\sigma_{\underline{v}}$, are not identified and that the coefficients or the parameters of the model are estimated only up to a scale. Therefore, we can write the Log Likelihood function for an individual $i$ as $\boldsymbol{L}_{i}\left(\varphi \frac{1}{\sigma_{\underline{\zeta}}}, \frac{\varphi_{d}}{\sigma_{\underline{\zeta}}}, \frac{\lambda}{\sigma_{\underline{\zeta}}}\right.$, $\left.\frac{\rho_{\zeta \epsilon}}{\sigma_{\underline{\zeta}}} ; \gamma \frac{1}{\sigma_{\underline{v}}}, \frac{\gamma_{d}}{\sigma_{\underline{v}}}, \frac{\theta}{\sigma_{\underline{v}}}, \frac{\rho_{v \epsilon}}{\sigma_{\underline{v}}} ; \rho_{\underline{\zeta} \underline{v}} \mid d_{i}, Z_{i}, \hat{\epsilon}_{i t}, \hat{\alpha}_{i}\right)$.

As mentioned earlier, the main objective of this chapter is to assess the impact of financial constraints on $R \& D$ expenditure and to determine what causes financial constraint. We interpret financial constraints as high cost or price of external finance that a firm would be required to pay for a variety of reasons, discussed in Section 6.2 and 6.3, relating to lack of internal funds or information 
asymmetry. To this effect, $f_{i t}^{*}$, the latent variable underlying $f_{i t}$, can reflect the shadow price of external funds, $d_{i t}$, the ratio of long-term debt to capital assets. Controlling for other factors, a firm is likely to be more financially constrained or more likely to have reached its debt capacity, the higher the debt asset ratio is, and consequently face a binding borrowing constraint in optimally deciding its investment and financial policy. However, it quite possible that a firm may be financially constrained not only because of high cost of external funds, but also due to high need for funds. Quantity constraints, due to credit rationing, can be as important as cost of external finance. Kaplan and Zingales (1997) use a classification scheme that a priori distinguishes between firms that are not financially constrained, firms that are likely to be financially constrained due to high need of funds, and firms that are indeed financially constrained. The firms that are not constrained are those that have liquidity reserves more than what would be needed to finance their investment or have initiated paying dividends. Firms that are likely to be financially constrained because of need for high funds mention having difficulties in obtaining financing. For example, they include firm-year observations in which firm's postpone an equity or convertible debt offering due to adverse market conditions, or claim that they need equity capital but are waiting for improved market conditions. Generally these firms are prevented from paying dividends and have little cash available. Firms that cut dividends are more likely to fall in this category. Finally, in their classification scheme firms that are indeed financially constrained are firms that are in violation of debt covenants, have been cut out of their usual sources of credit, are renegotiating debt payments and have declared that they are forced to reduce investment because of liquidity problems. Here, we would like to mention that the information that is available with us is not as detailed as is for the firms that Kaplan and Zingales analyze. Consequently, we do not have a rich specification for the financial constraint equation that can also account for financial constraint that arises from high need of funds, and indeed, test if such variables do indicate whether firms are financially constrained on account of high need of funds. However, our specification does include variables like cash reserve and dividend payout which, to an extent, can control for the fact that firms are financially constrained due to high need for funds.

The list of exogenous variables included in $\mathbf{z}_{i t}^{f \prime}$ are: (1) the share of innovative sales in the total sales of the firm in period $t-1, t(S I N S)$, (2) the ratio of cash flows of the firm to the book value of capital assets (tangible +intangible) of the firm in period $t(C F),(3)$ the ratio of liquidity holdings to the book value of capital assets of the firm in period $t(L Q),(4)$ a dummy for positive dividends in period $t(D I V),(5)$ market share of the firm in period $t(M K S H),(6)$ the logarithm of the number of people employed in period $t(S I Z E),(7)$ a dummy for negative cash flows in period $t,(D N C F)$, 
(8) the ratio of intangible assets to the total capital asset of the firm in period $t(R A I N T)^{8}$, (9) the age of the firm $(A G E),(10)$ industry dummies and (11) year dummies.

In the specification for the financial constraint equation, we need to control for future expected profitability of the $R \& D$ related activity. This is because, if a firm finds that the $R \& D$ project for the product or the process that it is willing to undertake will reap higher profits in future, then its need for R\&D expenditure today would be high. However, if its internal funds are not sufficiently high and if capital market imperfections facing the firm are acute, then with a higher need for R\&D expenditure, the firm would find it self more likely to be facing financial constraint. We include the share of innovative sales in the total sales of the firm, (SINS), as a proxy for the future expected profitability of the firm, profitability, which is related to $R \& D$ activities. The share of innovative sales, $(S I N S)$, measures of how important R\&D activity is to a firm. Assuming, that there is a time lag between starting of an R\&D project, successful realization of the product, and incurring some fixed cost to implement or produce the new process or product, share of innovative sales in the total sales, $(S I N S)$, is a result of past innovative activity, and therefore, at most predetermined, if not strictly exogenous. This implies that the variation in $(S I N S)$ will be a result of past R\&D endeavors as well as due to high or low demand for the newly introduced product to the market. Therefore, $(S I N S)$ can potentially signal demand for R\&D related activity and investment. In other words higher percentage of innovative sales can trigger a high demand for $R \& D$ investment, which in turn implies, given every thing else, a firm is more likely to find itself reporting financial constraints.

The specification for the financial constraint equation includes cash flows, $(C F)$, and liquidity, $(L Q)$, holdings of the firm. Healthy realization of cash flows can be beneficial for firms that are financially constrained on the margin. The realized cash flows for firms that are financially constrained could be used as a source of internal equity, thus easing the constraint faced by the firm. On the other hand, since cash flows are repositories of demand signals, realized cash flows can also trigger demand for R\&D capital. Thus, increases in cash flows can also indicate a high demand for R\&D expenditures, which ceteris paribus, can lead a firm to be reporting it self as financially constrained.

Hall and Lerner (2010) and Brown, Fazzari, and Petersen (2009) point out that most of the R\&D spending is in form of payments to highly skilled workers, who often require a great deal of firm-specific knowledge and training. The effort of the skilled workers create the knowledge base of the firm, and is therefore embedded in the human capital of the firms. This knowledge base

\footnotetext{
${ }^{8}$ This variable too is likely to be predetermined if not endogenous. However, as mentioned earlier we intend to endogenize the potentially endogenous variables by specifying a system of reduced form equations for them and estimate it as system of seemingly unrelated regression.
} 
is lost once workers get laid off. The implication of this is that firms choose to smooth their R\&D spending, if only to avoid laying off their knowledge workers. This in turn implies that R\&D intensive firms behave as if they have large adjustment cost. Thus, when faced with high adjustment costs, and when it is not sure about a steady supply of positive cash flows, an R\&D intensive firm is likely to practice precautionary savings to reduce its risks of being financially constrained at any given time. This argument implies that among the R\&D intensive firms, those that maintain a liquidity reserve $(L Q)$ are less likely to be financially constrained. We include a dummy variable for dividends paid out $(D I V)$ since it is likely that cash distributions to shareholders are evidence of the availability of internally generated funds. Therefore, it is more likely that a firm that pays out dividends is unlikely to be affected by costly external finance and that at least some firms that do not distribute dividends are affected. Fama and French (2000) found the ratio of dividends to total assets to be a good predictor of profitability of the firm. Also, Fama and French (2002) point out that since it is expensive to finance investment with new risky securities, dividends are less attractive for firms with less profitable assets in place, large current and expected investments, and high leverage. Thus, controlling for other effects, more profitable firms pay out more of their earnings as dividends, indicating that such firms are less likely to be financially constrained.

We include size of the firm $(S I Z E)$ since it might be that large firms have more internal funds at their disposal to carry out $\mathrm{R} \& \mathrm{D}$ related activities, and that small firms may be typically young and less well known, hence more vulnerable to capital market imperfections. Hennessey and Whited (2007) find large differences between the cost of external funds for small and large firms. Large firms behave as if they face small indirect costs of external finance, and small firms behave as if they face large indirect costs of external finance. Market share $(M K S H)$ of the firm is included in the specification, since it may be possible that firms enjoying a higher degree of monopoly to have a better access to capital markets. While size is often correlated with market share, it may that, for certain products, relatively smaller firms enjoy a higher degree of monopoly. Now, since the secondary market for intangible asset is fraught with more frictions and generally does not exist, firms with higher percentage of intangible assets have less amount of pledgeable support to borrow. It could also be possible that such firms face higher bankruptcy costs. Thus it seems likely that firms with high ratio of intangible asset to total capital asset $(R A I N T)$ are more likely to be financially constrained. The age of the firm $(A G E)$ has been an important determinant of financial constraint as suggested by many studies: for an example, Brown, Fazzari, and Petersen (2009). Old firms, given that they have survived, have probably build reputation over the years that allow them to have 
better access to capital markets and are thus less likely to be financially constrained, given every thing else.

The specification for the selection equation includes $d_{i t}$, the long-term debt to capital asset ratio. The idea, as discussed earlier, is to test if highly leveraged firms are innovative or not. The variables that we include in $\mathbf{z}_{i t}^{s \prime}$, for the selection equation are: (1) the ratio of liquidity holdings to the capital assets of the firm $(L Q),(2)$ a dummy for positive dividends $(D I V),(3)$ the market share of the firm $(M K S H)$, (4) the logarithm of the number of people employed (SIZE), (5) a dummy that takes value 1 if the number of enterprises consolidated within a firm is more than one, (DMULTI), (6) the age of the firm $(A G E),(7)$ the ratio of intangible assets to total (tangible +intangible) assets $(R A I N T),(8)$ industry dummies, and (9) year dummies.

The liquidity holdings of the firm $(L Q)$ are included in the specification for the selection equation. For reasons related the nature of R\&D activity, R\&D intensive firms have to bear high cost of external finance, and also, as discussed earlier, to avoid high adjustment cost related to hiring and firing its knowledge workers, $R \& D$ intensive firms tend to smooth their investment spending over time. This necessitates them to maintain large amounts of cash reserves. Including $(L Q)$ in the specification allows us to test whether this is indeed true or not. Again, for reasons related to capital market imperfections faced by R\&D activity, it might be less attractive for firms indulging in R\&D activity to distribute cash as dividends $(D I V)$. We include $(R A I N T)$ in the selection/innovation equation, since for any two firms that have the same capital base, the one with more intangible asset in its capital base is more likely to be an innovator. This is because a large part of the capital of an R\&D intensive firm resides in the knowledge base of the firm which is intangible. Though, it might seem that the percentage of intangible assets in the total asset base of a firm is more of an outcome of a firm's decision to innovate rather than its having any bearing on the innovation decision of the firm. However, we know that there is persistence in innovation activity of a firm, see Wladimir et al. (2009), or in other words, innovation decision exhibits a certain degree of path dependency. RAINT being the outcome of past innovation activity, captures the persistence in the innovation decision of the the firm.

In the Schumpeterian tradition, it makes sense to include size (SIZE) as an explanatory variable in the selection equation. It can also be argued that if there are fixed costs of investing, then as Cohen and Klepper (1996) argue, large firms have a higher incentive to engage in innovative activities because they can amortize these costs by selling more units of output. Nilsen and Schiantarelli (2003) find strong statistical evidence of this relationship, including much greater incidences of zero investments 
in small versus large plants. They attribute this relevance of plant size, to the presence of fixed costs and to potential indivisibilities in investment. As stated earlier the market share $(M K S H)$ is a proxy for concentration or the degree of monopoly. We include this variable in the selection equation, since in the Schumpeterian tradition it has been argued that firms that enjoy monopoly position are more incited to innovate, if only to prevent entry of potential rivals. We also include age $(A G E)$ of the firm in the selection equation, since it is likely that young firms, in order to survive, have a larger incentive to innovate new products. Also see Section 6.2 for a detailed discussion on maturity and innovation practices of firms.

\section{The Third Stage: R\&D Investment}

In the third and the final stage we estimate the R\&D equation, equation (24), which is a switching model with the added correction terms, $C_{11}(\Xi, .)_{i t}, C_{12}(\Xi, .)_{i t}, C_{13}(\Xi, .)_{i t}, C_{01}(\Xi, .)_{i t}, C_{02}(\Xi, .)_{i t}$, and $C_{03}(\Xi, .)_{i t}$, which control for the bias that can arise due to endogeneity of debt, financial constraint and selection.

$$
\begin{aligned}
r_{i t} & =\mathbf{z}_{i t}^{r \prime} \beta+f_{i t} \beta_{f}+f_{i t} \beta_{1}(.)+\left(1-f_{i t}\right) \beta_{0}(.)+\mu \hat{\alpha}_{i} \\
& +f_{i t}\left(\rho_{\eta_{1} \epsilon} \sigma_{\eta_{1}} C_{11}(.)_{i t}+\rho_{\underline{\eta}_{1} \underline{\zeta}} \sigma_{\underline{\eta}_{1}} C_{12}(.)_{i t}+\rho_{\underline{\eta}_{1} \underline{\underline{v}}} \sigma_{\underline{\eta}_{1}} C_{13}(.)_{i t}\right) \\
& +\left(1-f_{i t}\right)\left(\rho_{\eta_{0} \epsilon} \sigma_{\eta_{0}} C_{01}(.)_{i t}+\rho_{\underline{\eta}_{0} \underline{\zeta}} \sigma_{\underline{\eta}_{0}} C_{02}(.)_{i t}+\rho_{\underline{\eta}_{0} \underline{v}} \sigma_{\underline{\eta}_{0}} C_{03}(.)_{i t}\right)+\tilde{\eta}_{i t},
\end{aligned}
$$

To control for the individual effects, $\alpha_{i}$, we substitute the expected a posteriori values, $\hat{\alpha}_{i}($.$) ,$ computed from the first stage reduced form estimation. With $\hat{\alpha}_{i}($.$) in place to control for time$ invariant individual specific effect, a simple pooled OLS, of equation (24), for the subsample of innovating firms leads to consistent estimates of the parameters.

As mentioned earlier, one of the goals of this chapter is to assess the impact of financial constraint on $\mathrm{R} \& \mathrm{D}$ investment. Interpreting $f_{i t}^{*}$ as the shadow price of external funds, implies that a firm in question finds itself being financially constrained, $f_{i t}=1$, if the price that it is required is high or if it exceeds a certain threshold. Interpreting the latent variable $f_{i t}^{*}$ as the price of external funds, underlying $f_{i t}$, allows us test whether the plethora of reasons, discussed earlier, does indeed make external financing costly and if such high cost does indeed impact R\&D activity adversely.

Following Fazzari, Hubbard, and Petersen (1988), many studies have concluded that firms, a priori classified as financially more constrained, have higher investment-cash flow sensitivities. Empirically, the existence of financial frictions for innovative firms has been investigated, either by examining 
the sensitivity of R\&D investment to financial factors, including measures of internal finance such as cash flows, that uses reduced form of accelerator type models of investment as in Fazzari, Hubbard, and Petersen (1988), or by using the structural framework of Euler equations as in Bond and Meghir (1994), see Hall and Lerner (2010) for a survey. However, Kaplan and Zingales (1997), Kaplan and Zingales (2000) and Cleary (1999) have provided evidence that cash flow sensitivity need not identify liquidity constrained firms, that is, sensitivity is not monotonic in the degree of constraints. Cash flows provide information about future investment opportunities, hence, investment cash flow sensitivity may equally occur because firms are sensitive to demand signals. On the theoretical side, Gomes (2001) and Alti (2003) simulate dynamic investment models, demonstrating that significant cash flow coefficients are not necessarily generated by financing frictions. Conversely, Gomes (2001) shows that financing frictions are not sufficient to generate significant coefficients on cash flow.

The distinguishing feature of our model is the switching regression model for R\&D expenditure that allows us endogenize financial constraint with respect to $R \& D$ related activity, which as mentioned earlier, is an information that the firms themselves report. Second, though cash flows are included in the specification and have different coefficients in the two different regimes, a test for the existence of financial frictions does not rest on the sensitivity of R\&D investment to cash flows for the financially constrained and unconstrained firms, but rather through the test of the effect of reported financial constraints on R\&D investment, and as mentioned in the last section, its implications for the decision to innovate.

Here, we would like to emphasize that in order to see the effect of firm's reportage of financial constraints on $R \& D$ investment, we would like to fix the firm's investment opportunity. Since, we do not have any information on the market valuation of the firms, we can not construct average "q" for our firms or for that matter, any such measure related to the firm's R\&D investment. To this end, in our specification we include cash flows and share of innovative sales in the total sales of the firm (SINS) which can be indicative of demand signals. Moyen (2004), simulates series from dynamic models of constrained and unconstrained firms, and pools them together to represent a theoretical sample. She does this to investigate whether some of the empirical results relating to investment cash flow sensitivity, can be replicated in her theoretical sample. Among other things, she finds that Tobin's "q" is a poor proxy for investment opportunities, cash flow is an excellent proxy, and that cash flow is an increasing function of the income shock. Since, it is quite likely that the cash flows of the firm is correlated with, or constitutes of the cash flows that emanates from R\&D related activity, accordingly, in our model the role of cash flows, $(C F)$, is to control for the R\&D investment 
opportunity of firms.

Now, the realized cash flows of the firm are not only the firm's R\&D activity. A measure to control for the investment opportunity for $R \& D$ related activity should be based on a measure such as Tobin's "q" for R\&D related activity or cash flows that result from R\&D output. However, in the absence of any such measure, we use the share of innovative sales in the total sales of the firm $(S I N S)$, which as explained in the discussion of the second stage specification, can potentially signal demand for R\&D related activity.

In our results, we do obtain different effects of changes in cash flows on R\&D investment for firms that are financially constrained and firms that are not. This could be because cash flows are correlated with investment opportunity set and observables such as (SINS), which we include in the specification to control for future expected profitability, cannot perfectly control for the firm's investment opportunity related to future expected profitability. Other reasons why the sensitivity of cash flows across constrained and unconstrained firms might differ, could be due to the nature of costs related to issuing new equity and cost of borrowing and how well proxies that classify firms as constrained or otherwise are reflective of these costs. However, within the framework of our model, we cannot test for the exact mechanism that drives the results on R\&D investment-cash flow sensitivity across constrained and unconstrained firms. For a detailed discussion on investmentcashflow sensitivity, we refer to Moyen (2004), Hennessey and Whited (2007), Whited (2008), Alti (2003), and Gomes (2001) and the references therein ${ }^{9}$.

The specification for the R\&D equation does not include any financial stock variables such as long-term debt to asset ratio or cash reserves to asset ratio. This is because in the structural model for $R \& D$ investment, $R \& D$ expenditures are determined only by the degree of constraints a firm faces and the expected profitability from R\&D investment. Therefore, it seems unlikely that leverage and cash holdings will have an independent effect, other than through financial constraints affecting the firm. However, to investigate the behavior of R\&D spending for firms paying out dividends, we do include a dummy for dividend payout $(D I V)$ during the period in which $\mathrm{R} \& \mathrm{D}$ expenditure was incurred. The other variables that are included in the specification are: size of the firm $(S I Z E)$ market share $(M K S H)$ and the age of the firm $(A G E)$. The rationale, for including these variables is essentially the same as for the selection equation. However, among the set of innovating firms, it can be possible that smaller firms invest relatively more in R\&D than larger firms. This is because,

\footnotetext{
${ }^{9}$ Though, these papers do not specifically model R\&D investment, the results in these papers can have relevance in explaining R\&D investment-cash flow coefficients, or the models in these papers could be augmented to allow for features of R\&D investment.
} 
as has been argued, smaller firms have a higher marginal "q" than large firms, which can even be true of R\&D capital. Smaller firms also experience higher growth rates than large firms and more likely to take risk than larger firms, see Cooley and Quadrini (2001), Gomes (2001) and the discussion in Section 6.2. The specification for the third stage also includes a dummy (DMULTI) that takes value 1 if the number of enterprises consolidated within a firm is more than one.

\subsubsection{Identification and Estimation of Average Partial Effects}

Estimation of average partial effects (APE) in presence of endogeneity and unobserved heterogeneity has recently been of concern in the econometric literature, see Wooldridge (2004, 2005). Our empirical strategy allows us to take into account the enodogeneity of the explanatory variables as well as unobserved heterogeneity. We do this by conditioning the endogenous variable of interest on the idiosyncratic component of the reduced form equation of the endogenous explanatory variable, thereby controlling for the endogeneity of our endogenous regressor. Estimation of the structural parameters, as we know requires substitution of the idiosyncratic component of the reduced form equation in the structural equations by their conditional expected value, the residuals from the reduced form estimation. However, the residuals, $\mathrm{E}\left(\epsilon_{i t} \mid d_{i}, Z_{i}, \alpha_{i}\right)$, from the first stage reduced form equation are not identified due to presence of time invariant individual effects, which are not observed. In Appendix A however, we have shown that even though $\mathrm{E}\left(\epsilon_{i t} \mid d_{i}, Z_{i}, \alpha_{i}\right)$ is not identified, $\mathrm{E}\left(\epsilon_{i t} \mid d_{i}, Z_{i}\right)$ is. This allows us to replace $\alpha_{i}$ with their expected a posterior values $\hat{\alpha}_{i}\left(d_{i}, Z_{i}, \hat{\delta}, \hat{\sigma}_{\alpha}, \hat{\sigma}_{\epsilon}\right)$, which helps us in identifying the parameters of interest. The details are provided in Appendix A. In this section we only state the functional form of the APE of a typical variable, continuous or categorical, for the second and the third stage estimation.

\section{Average Partial Effects for the Second Stage}

Suppose, we are interested in changes in the probability of a firm being financially constrained for small changes in $d_{i t}$ or $z_{k i t}$ where $z_{k}$ is any of the exogenous regressors that appear in the financial constraint equation. From the result on identification of parameters, discussed in Appendix A, we know that

$$
\operatorname{Pr}\left(f_{i t}=1 \mid d_{i}, Z_{i}, \hat{\epsilon}_{i t}, \hat{\alpha}_{i}\right)=\Phi\left(\mathbf{z}_{i t}^{f \prime} \tilde{\varphi}+d_{i t} \tilde{\varphi}_{d}+\tilde{\lambda} \hat{\alpha}_{i}+\tilde{\rho}_{\zeta \epsilon} \frac{\hat{\epsilon}_{i t}}{\sigma_{\epsilon}}\right)
$$


where $\tilde{\varphi}=\varphi \frac{1}{\sigma_{\underline{\zeta}}}, \tilde{\varphi}_{d}=\frac{\varphi_{d}}{\sigma_{\underline{\zeta}}}, \tilde{\lambda}=\frac{\lambda}{\sigma_{\underline{\zeta}}}, \tilde{\rho}_{\zeta \epsilon}=\frac{\rho_{\zeta \epsilon}}{\sigma_{\underline{\zeta}}}$. The APE of the change in $z_{k i t}$ from $\bar{z}_{k}$ to $\bar{z}_{k}+\kappa$ on the probability of being financially constrained given $d_{i t}=\bar{d}$ and $\mathbf{z}_{i t_{-k}}^{f}=\overline{\mathbf{z}}_{-k}^{f}$ as shown in Appendix A is given by

$$
\frac{\Delta \operatorname{Pr}\left(f_{i t}=1 \mid \bar{z}_{k}, \bar{Z}_{-k}, \bar{d}\right)}{\Delta z_{k}}=\frac{\int \Phi\left(\bar{z}_{k}+\kappa, \overline{\mathbf{z}}_{-k}^{f}, \bar{d}, \hat{\alpha}, \hat{\epsilon}\right) d G(\hat{\alpha}, \hat{\epsilon})-\int \Phi\left(\bar{z}_{k}, \overline{\mathbf{z}}_{-k}^{f}, \bar{d}, \hat{\alpha}, \hat{\epsilon}\right) d G(\hat{\alpha}, \hat{\epsilon})}{\kappa} .
$$

In the limit when $\Delta z_{k}=\kappa$ goes to zero, since the integrand is a smooth function of its arguments we can change the order of differentiation and integration, to get

$$
\frac{\partial \operatorname{Pr}\left(f_{i t}=1 \mid \bar{z}_{k}, \bar{Z}_{-k}, \bar{d}\right)}{\partial z_{k}}=\int \phi\left(\bar{z}_{k}, \overline{\mathbf{z}}_{-k}^{f}, \bar{d}, \hat{\alpha}, \hat{\epsilon}\right) \varphi_{k} d G(\hat{\alpha}, \hat{\epsilon})
$$

The sample analog of the RHS of the above equation can be computed as follows:

$$
\frac{1}{\sum_{i=1}^{N} T_{i}} \sum_{i=1}^{N} \sum_{t=1}^{T_{i}} \phi\left(\bar{z}_{k}, \overline{\mathbf{z}}_{-k}^{f}, \bar{d}, \hat{\alpha}_{i}, \hat{\epsilon}_{i t}\right) \varphi_{k}
$$

Suppose, $z_{k}$ is an exogenous dummy variable $D$ taking values 0 and 1 , then the APE of change of $D_{i t}$ from 0 to 1 on the probability of a firm being financially constrained, given other covariates, is given by

$$
\int \Phi\left(D=1, \overline{\mathbf{z}}_{-k}^{f}, \bar{d}, \hat{\alpha}, \hat{\epsilon}\right) d G(\hat{\alpha}, \hat{\epsilon})-\int \Phi\left(D=0, \overline{\mathbf{z}}_{-k}^{f}, \bar{d}, \hat{\alpha}, \hat{\epsilon}\right) d G(\hat{\alpha}, \hat{\epsilon})
$$

whose sample analog, given (34), can be computed in the same way.

We may also be interested in the APE of a variable on the conditional probability of an event or compare the APE of a variable on the probability of an event conditional on two mutually exclusive events. For example, we may be interested in the marginal effect of long-term debt to asset ratio on the probability of firm being an innovator, conditional on being financially constrained as compared to the marginal effect of long-term debt on the probability of being innovator, conditional on the firm not being financially constrained. For the above mentioned example, the APE of changing long-term debt from $d_{i t}=\bar{d}$ to $d_{i t}=\bar{d}+\kappa$ on the probability of a firm being financially constrained, conditional 
on being a innovator and given $Z_{i}=\bar{Z}$, is given by

$$
\begin{aligned}
\frac{\Delta \operatorname{Pr}\left(s_{i t}=1 \mid f_{i t}=1, \bar{d}, \bar{Z}\right)}{\Delta d} & =\left[\int\left(\frac{\Phi_{2}\left(\bar{\varphi}(\bar{d}+\kappa, .), \bar{\gamma}(\bar{d}+\kappa, .), \rho_{\underline{\underline{\underline{v}}}}\right)}{\Phi(\bar{\varphi}(\bar{d}+\kappa, .))}\right) d G(\hat{\alpha}, \hat{\epsilon})\right. \\
& \left.-\int\left(\frac{\Phi_{2}\left(\bar{\varphi}(\bar{d}, .), \bar{\gamma}(\bar{d}, .), \rho_{\underline{\underline{v}}}\right)}{\Phi(\bar{\varphi}(\bar{d}, .))}\right) d G(\hat{\alpha}, \hat{\epsilon})\right] / \kappa,
\end{aligned}
$$

where $\bar{\varphi}()=.\frac{\varphi(.)+\rho_{\zeta \epsilon} \frac{\hat{\epsilon}_{i t}}{\sigma_{\epsilon}}}{\sigma_{\underline{\zeta}}}$ and $\bar{\gamma}()=.\frac{\gamma(.)+\rho_{v \epsilon} \frac{\hat{\epsilon}_{i t}}{\sigma_{\epsilon}}}{\sigma_{\underline{v}}}$. The sample analog of which can be constructed by averaging the integrand over $\hat{\alpha}_{i}$ and $\hat{\epsilon}_{i t}$. However, in the limit as $\kappa$ tends to zero, since the integrand is a smooth function of its argument, we can change the order of differentiation and integration to obtain the APE as

$$
\frac{\partial \operatorname{Pr}\left(s_{i t}=1 \mid f_{i t}=1, \bar{d}, \bar{Z}\right)}{\partial d}=\int \frac{\partial}{\partial d}\left(\frac{\Phi_{2}\left(\bar{\varphi}(.), \bar{\gamma}(.), \rho_{\underline{\underline{v}}}\right)}{\Phi(\bar{\varphi}(.))}\right) d G(\hat{\alpha}, \hat{\epsilon})
$$

The right-hand side of the above involves taking derivative of cumulative distribution function of a standard bivariate normal with respect to $\bar{\varphi}($.$) and \bar{\gamma}($.$) . If we want to compare the APE of increase$ in leverage on the probability of being financially constrained, conditional on being a non-innovator, then we have

$$
\frac{\partial \operatorname{Pr}\left(s_{i t}=1 \mid f_{i t}=0, \bar{d}, \bar{Z}\right)}{\partial d}=\int \frac{\partial}{\partial d}\left(\frac{\Phi_{2}\left(\bar{\varphi}(.),-\bar{\gamma}(.),-\rho_{\underline{\underline{v}}}\right)}{1-\Phi(\bar{\varphi}(.))}\right) d G(\hat{\alpha}, \hat{\epsilon})
$$

The derivative of the $\Phi_{2}\left(\bar{\varphi}(),. \bar{\gamma}(),. \rho_{\underline{\underline{\underline{v}}}}\right)$ and $\Phi_{2}\left(\bar{\varphi}(),.-\bar{\gamma}(),.-\rho_{\underline{\underline{\underline{v}}}}\right)$ with respect to $\bar{\varphi}($.$) and \bar{\gamma}($.$) are$ stated in Greene (2003).

\section{Average Partial Effects for the Third Stage}

The average effect of financial constraint on $\mathrm{R} \& \mathrm{D}$ intensity, for any individual, $i$, in time period, $t$, is computed as the difference in the expected $R \& D$ expenditure between the two regimes, financially constrained and non-financially constrained, averaged over $\hat{\alpha}$ and $\hat{\epsilon}$ :

$$
\begin{aligned}
\Delta \mathrm{E}\left(r_{i t} \mid Z_{i}, d_{i}\right) & =\int \mathrm{E}\left(r_{1 i t} \mid Z_{i}, d_{i}, \hat{\alpha}, \hat{\epsilon}\right) d G(\hat{\alpha}, \hat{\epsilon}) \\
& -\int \mathrm{E}\left(r_{0 i t} \mid Z_{i}, d_{i}, \hat{\alpha}, \hat{\epsilon}\right) d G(\hat{\alpha}, \hat{\epsilon}) .
\end{aligned}
$$


From equations (8a) and (9a) we know that

$$
\mathrm{E}\left(r_{1 i t} \mid d_{i}, Z_{i}, \hat{\alpha}_{i}, \hat{\epsilon}_{i t}\right)=\mathbf{z}_{i t}^{r \prime} \beta+\beta_{f}+\beta_{1}(.)+\mu \hat{\alpha}_{i}+\rho_{\eta_{1} \epsilon} \frac{\sigma_{\eta_{1}}}{\sigma_{\epsilon}} \hat{\epsilon}_{i t}
$$

if $f_{i t}^{*}>0$, and

$$
\mathrm{E}\left(r_{0 i t} \mid d_{i}, Z_{i}, \hat{\alpha}_{i}, \hat{\epsilon}_{i t}\right)=\mathbf{z}_{i t}^{r \prime} \beta+\beta_{0}(.)+\mu \hat{\alpha}_{i}+\rho_{\eta_{0}} \frac{\sigma_{\eta_{0}}}{\sigma_{\epsilon}} \hat{\epsilon}_{i t}
$$

if $f_{i t}^{*} \leq 0$. Given the above, the average effect of financial constraint on R\&D intensity, for an individual, $i$, in time period $t$, is given by:

$$
\Delta \mathrm{E}\left(r_{i t} \mid Z_{i}, d_{i}\right)=\beta_{f}+\beta_{1}(.)-\beta_{0}(.)+\int\left(\rho_{\eta_{1} \epsilon} \frac{\sigma_{\eta_{1}}}{\sigma_{\epsilon}} \hat{\epsilon}_{i t}-\rho_{\eta_{0} \epsilon} \frac{\sigma_{\eta_{0}}}{\sigma_{\epsilon}} \hat{\epsilon}_{i t}\right) d G(\hat{\alpha}, \hat{\epsilon})
$$

Since we assume that the time invariant individual effects have the same effect in both the regimes, the $\hat{\alpha}$ term drops out. The sample analog of the above can be obtained by taking the average over $\hat{\epsilon}_{i t}$ for given $Z_{i}=\bar{Z}$ and $d_{i}=\bar{d}$.

The APE of the other variables on R\&D intensity will be different for the two regimes, defined as financially constrained and not financially constrained. The APE's are composite of the direct effect on R\&D intensity, if the variable is included in the specification for R\&D intensity, and its effect through the correction terms, that are different for the two regimes. Including the indirect effect, that comes through the correction terms, implies that APE's obtained are conditional APE's, that is, conditional on being selected. Without the indirect effect that comes through the correction terms, that correct for the bias due to sample selection, the unconditional APE's are simply the coefficient estimates.

Given the R\&D equation (24), with added correction terms, the APE, conditional on being selected, of a change in exogenous variable, $z_{k i t}$, from $\bar{z}_{k}$ to $\bar{z}_{k}+\kappa$, given $Z_{i_{-k}}=\bar{Z}_{-k}$ and $d_{i}=\bar{d}$, on $\mathrm{R} \& \mathrm{D}$ intensity for a firm, $i$, that is financially constrained in time period $t$ is given by:

$$
\begin{aligned}
& \frac{\Delta}{\Delta z_{k}} \mathrm{E}\left(r_{1} \mid f^{*}>0, s^{*}>0, \bar{z}_{k}, \bar{Z}_{-k}, \bar{d}\right)=\beta_{1 k} \\
& +\frac{\int\left[\mathrm{E}\left(\underline{\eta}_{1} \mid f^{*}>0, s^{*}>0, \bar{z}_{k}+\kappa, \bar{Z}_{-k}, \bar{d}, \hat{\alpha}, \hat{\epsilon}\right)-\mathrm{E}\left(\underline{\eta}_{1} \mid f^{*}>0, s^{*}>0, \bar{z}_{k}, \bar{Z}_{-k}, \bar{d}, \hat{\alpha}, \hat{\epsilon}\right)\right] d G(\hat{\alpha}, \hat{\epsilon})}{\kappa} .
\end{aligned}
$$


That is,

$$
\begin{aligned}
& \frac{\Delta}{\Delta z_{k}} \mathrm{E}\left(r_{1} \mid f^{*}>0, s^{*}>0, \bar{z}_{k}, \bar{Z}_{-k}, \bar{d}\right)=\beta_{1 k} \\
& +\left[\int\left(C_{12}\left(., \bar{z}_{k}+\kappa, \hat{\alpha}, \hat{\epsilon}\right) \sigma_{\underline{\eta}_{1}} \rho_{\underline{\eta}_{1} \underline{\zeta}}+C_{13}\left(., \bar{z}_{k}+\kappa, \hat{\alpha}, \hat{\epsilon}\right) \sigma_{\underline{\eta}_{1}} \rho_{\underline{\eta}_{1} \underline{v}}\right) d G(\hat{\alpha}, \hat{\epsilon})\right. \\
& \left.-\int\left(C_{12}\left(., \bar{z}_{k}, \hat{\alpha}, \hat{\epsilon}\right) \sigma_{\underline{\eta}_{1}} \rho_{\underline{\eta}_{1} \underline{\zeta}}+C_{13}\left(., \bar{z}_{k}, \hat{\alpha}, \hat{\epsilon}\right) \sigma_{\underline{\eta}_{1}} \rho_{\underline{\eta}_{1} \underline{v}}\right) d G(\hat{\alpha}, \hat{\epsilon})\right] / \kappa,
\end{aligned}
$$

where $\beta_{1 k}$ in the above two equations is the direct effect of $z_{k}$ on the R\&D intensity, and the remaining term the indirect effect. The sample analog of the RHS of (42) is given by:

$$
\begin{aligned}
& \frac{\Delta}{\Delta z_{k}} \mathrm{E}\left(r_{1} \mid f^{*}>0, s^{*}>0, \bar{z}_{k}, \bar{Z}_{-k}, \bar{d}\right)=\beta_{1 k} \\
& +\left[\frac{1}{\sum_{i=1}^{N} T_{i}} \sum_{i=1}^{N} \sum_{t=1}^{T_{i}} s_{i t}\left(C_{12}\left(., \bar{z}_{k}+\kappa, \hat{\alpha}, \hat{\epsilon}\right) \sigma_{\underline{\eta}_{1}} \rho_{\underline{\eta}_{1} \underline{\zeta}}+C_{13}\left(., \bar{z}_{k}+\kappa, \hat{\alpha}, \hat{\epsilon}\right) \sigma_{\underline{\eta}_{1}} \rho_{\underline{\eta}_{1}} \underline{v}\right)\right. \\
& \left.-\frac{1}{\sum_{i=1}^{N} T_{i}} \sum_{i=1}^{N} \sum_{t=1}^{T_{i}} s_{i t}\left(C_{12}\left(., \bar{z}_{k}, \hat{\alpha}, \hat{\epsilon}\right) \sigma_{\underline{\eta}_{1}} \rho_{\underline{\eta}_{1} \underline{\zeta}}+C_{13}\left(., \bar{z}_{k}, \hat{\alpha}, \hat{\epsilon}\right) \sigma_{\underline{\eta}_{1}} \rho_{\underline{\eta}_{1} \underline{v}}\right)\right] / \kappa .
\end{aligned}
$$

Replacing the 1's in the subscripts with 0's in the RHS of the equation gives APE of $z_{k i t}$ on R\&D intensity for a firm that belongs to the regime that is not financially constrained. Thus, we have

$$
\begin{aligned}
& \frac{\Delta}{\Delta z_{k}} \mathrm{E}\left(r \mid f^{*}, s^{*}>0, \bar{z}_{k}, \bar{Z}_{-k}, \bar{d}\right)= \\
& f \frac{\Delta}{\Delta z_{k}} \mathrm{E}\left(r_{1} \mid f^{*}>0, s^{*}>0, \bar{z}_{k}, \bar{Z}_{-k}, \bar{d}\right)+(1-f) \frac{\Delta}{\Delta z_{k}} \mathrm{E}\left(r_{0} \mid f^{*} \leq 0, s^{*}>0, \bar{z}_{k}, \bar{Z}_{-k}, \bar{d}\right) .
\end{aligned}
$$

If $z_{k}$ happens to be a binary variable, $D$, taking values 0 and 1 , then we simply replace $z_{k}+\kappa$ with $D=1$ and $z_{k}$ with $D=0$ in equations (41-42). For a continuous variable, $z_{k}$, in the limit when $\kappa$ goes to 0 , given functional form of the correction terms, which are smooth functions of their arguments, we can again change the order of integration and differentiation in (41-42) to obtain the APE.

\subsection{Results}

We discuss the results of our structural model under two subsections. In the first subsection we discuss the results of the Second Stage, in which we jointly estimate the financial constraint and sample selection equation. In the second subsection we discuss the results of the R\&D switching regression model. 


\subsubsection{Second Stage}

Table 6.3 illustrates the results of the joint estimation of the financial constraint equation and the selection equation. We present the results of three specification of the joint estimation, in which the specification for the selection or the innovation equation remains the same, but the specification for the financial constraint equation is varied. For reasons which we discuss later, our most preferred specification is the parsimonious specification presented in columns (C0) and (C1). Table 6.4 presents the APE's of the respective variables for the specification illustrated in columns (C0) and (C1). To compute the APE's, the values of all the covariates were fixed at the mean value, the mean taken over all the firms and the years. We also note here that many of the covariates are dummy variables taking values 0 's and 1's, therefore, the mean of these variables will be fractions lying between 0 and 1 .

Our results suggest that controlling for other factors, highly leveraged firms are unlikely to innovate. This validates the claim about the risky nature of $R \& D$ related activities, which in general involves assets and products that are both highly intangible in nature, and bank-based institutional lenders being more averse to provide finance to new and high risk investments. This only implies that $R \& D$ intensive firms have a preference for equity based financing, which can be outside equity or retained earnings. Allen and Gale (2000) argue that in economies that better manage asymmetric information problems $\mathrm{R} \& \mathrm{D}$ intensive firms tend to be more valuable. Also, market-based financial systems are more likely to encourage $R \& D$ activity and consequently will value $R \& D$ more highly than bank-based economies. Market-based financial systems have well developed information distribution mechanisms and are able to allocate capital to activities even when investors hold diverse views on the value of the investment. This corroborates the findings of Brown, Fazzari, and Petersen (2009), who also find a preference for equity based financing for high-tech firms and in particular firms that are young among them.

We find a significant negative coefficient for dummy for dividends, $(D I V)$. This suggests that firms that pay out dividends are less likely to innovate. Now, given the nature of R\&D activity, which makes borrowing costly, internal funds may be more preferable. Therefore, innovative firms are less likely to distribute cash as dividends. Again, for reasons related to high adjustment costs, that compels R\&D intensive firms to smooth out investment spending, and of course, the need to avert costly borrowing, we wanted to test if innovative firms maintain high cash reserves to finance a foreseeable $R \& D$ investment project in the future during which it may or may not be financially constrained. Our results suggests that innovative firms are very likely to hold cash reserves $(L Q)$. 
We find that younger firms are more innovative. This corroborates the findings of other studies that find that young firms in their bid to survive take up more innovative activity. Entry, typically in the literature on industrial organization, see Audretsch (1995) and Huergo and Jaumandreu (2004), is envisaged as the way in which firms explore the value of new ideas in an uncertain context. Entry, the likelihood of survival and subsequent conditional growth are determined by barriers to survival, which differ by industries according to technological opportunities. In this framework, entry is innovative and increases with uncertainty, the likelihood of survival is lower the higher the risk is, and the growth subsequent to successful innovation is higher the higher barriers to survival are.

Our findings also suggests that large firms are more probable to innovate. This finding, is consistent with the idea that large firms have a higher incentive to engage in innovative activities because they can amortize the large fixed costs of investing costs by selling more units of output. Moreover, larger firms can be expected to have a larger stock of knowledge base, and therefore are expected to produce more innovation than small firms. We find that firms with large market share are more innovative. This result confirms the fact that a firm is more incited to innovate if it enjoys a monopoly position to prevent entry of potential rivals. We also find that firms that have many enterprises consolidated within them, (DMULTI), are more likely to be innovative. Now, these enterprises are more or less independent entities, working under a parent firm or a company. It has been found that firms that have many enterprises consolidated within them, are more likely to be globally engaged and have better networks of customers and suppliers. Such firms are also multinational in nature. These firms are also large both in terms of employment and sales. These considerations make multi enterprise firms more likely to have better access to knowledge and also hold a larger stock of knowledge, hence such firms are more likely to be innovative. A significant positive coefficient on RAINT stress the fact that, given everything else, a firm with a higher ratio of intangible assets in the total asset base of the firm is more likely to be innovative. Now, to the extent that this ratio is a result of past innovation decisions, it captures the fact that there is persistence in the innovation decisions of the firms.

We find that the scaled correlation between $v_{i t}$, the unobserved idiosyncratic component of the selection equation and $\epsilon_{i t}$ the idiosyncratic component of the reduced form debt equation, $\frac{\rho_{v \epsilon}}{\sigma_{\underline{v}}}$, to be high and significant, suggesting strong simultaneity in the decision to innovate and the choice of leverage. In addition we also find that, $\theta$, the factor loading in the selection equation to be significant, suggesting that the unobserved individual specific term that influences the choice of capital structure also affect the decision to innovate. We find the $\chi^{2}$ test for $\rho_{\underline{\underline{\underline{v}}}}$ to be significant, suggesting a 
strong simultaneity in the decision to innovate and the financial constraint with respect to innovative activity that the firm faces. This could be because the firm's ability to access outside financing may be conditional on its innovative activity. For example, suppose there is a firm that has not been innovative in the past, but now has an $R \& D$ project that with certain degree of success, has a positive net worth. However, since the capital employed by the firm to embark on the R\&D project can be highly intangible, its value, in the event of default, in the second hand market might be significantly low. Since lenders can not observe or verify the progress or the importance of R\&D project, they are only willing to lend up to the value of the new investment at liquidation. Thus, the decision to innovate can have a bearing on the firm's ability to raise external means of financing if its wealth is not sufficiently high. While the above might be an extreme example, innovative firms with new $\mathrm{R} \& \mathrm{D}$ projects can face similar situations.

Figure 6.1 illustrates the plots of APE of long-term debt to asset ratio on the unconditional probability of innovation or selection against age, size, and leverage. We find that the APE of leverage on the probability of innovation to be negative and decreasing in the age of the firm. This suggests that once we condition on size and other covariates, older firms are more averse to engage in R\&D activity with higher debt in their capital structure as compared to young firms. This finding in a way confirms some of the findings, both theoretical and empirical, that younger firms borrow more, face higher probability of default, grow faster, and in general display risky behavior. Figure 6.1(b) plots the APE of long-term debt to asset ratio against size. We find that the effect is decreasing in absolute terms with size. This is due to the fact that large firms anyway have a higher propensity to innovate, hence a marginal increase in leverage is not as effective in affecting innovation of large firms as compared to small or intermediate sized firms. We also find that, as Figure 6.1(c) attests, the partial effect of leverage on the propensity to innovate is negative and decreasing in the size of leverage.

As stated earlier, Table 6.3 presents three specifications for the financial constraint equation. The specification in column (A0) has cash flows $(C F)$ and $R A I N T$, the ratio of intangible to total (tangible + intangible) assets. The specification in column (B0) does not include RAINT, while the specification in column (C0), has neither of them. We included RAINT in the specification for financial constraint, since secondary markets for intangible asset is fraught with more frictions and generally does not exist, hence firms with a higher percentage of intangible asset have a lower amount of pledgeable support to borrow, and thus can be expected to be more financially constrained. However, we do not find it to be significantly explaining financial constraints that a firm faces with 
respect to R\&D related activity. Moving from the specification in column (A0) to (A1), we find no change in the sign or the significance of the rest of the variables.

We had included $C F$ as measures of change in the internal networth of a firm. An increase in the cash flows of the firm was expected to ease the financial constraints faced by a firm. Instead, what we find is that cash flows, $C F$, has a significant positive sign. This can be explained by the fact that the cash flows of the firms are correlated with, or are derived from the product or the process the firm endeavors to improve or find a better substitute for. Since the cash flows realized contains signals about the demand for the firms's product, cash flows are correlated with the R\&D investment opportunity set. This in turn implies that an increase in the cash flows signals a higher demand for R\&D investment, thus ceteris paribus, an increase in cash flows can lead to a firm reporting itself being financially constrained, especially since we control for negative realization of cash flows.

Though cash flows can signal demand for investment needs of a firm, a measure of how important R\&D activity is to a firm, as explained when discussing the specification of the second stage estimation, is the share of innovative sales in the total sales of the firm $(S I N S)$, which can signal demand for R\&D related activity and investment. In other words, a higher percentage of innovative sales can be indicative of a high demand for R\&D investment, which in turn implies, given every thing else, a firm is more likely to find itself reporting financial constraints. Also, since SINS is positive only for innovators, its inclusion in the financial constraint equation controls for the fact that it is the innovators who are the ones who mostly report financial constraints with respect to $\mathrm{R} \& \mathrm{D}^{10}$. Since the dummy for negative cash flows, $D N C F$, is derived from the realized cash flows, removing cash flows from the specification results in a significant coefficient for $D N C F$. That is, we find that negative realization of cash flows, leads to a significant increase in the probability of a firm being financially constrained. We also tried a specification where we removed $D N C F$. This resulted in cash flows being marginally significant with a positive sign.

Now, we began with the question whether "shifts" in the supply of internal equity finance, that is, whether changes in the cash flows realized, can affect the financing constraints faced by the firms. Instead, what we find is that realized cash flows proxies shifts in demand for investment, which given everything else, leads a firm to report it self as financially constrained. However, given the fact that negative realization of cash flows leads a firm to report itself as more financially constrained, it seems that the dummy for negative cash flows does a better job in accounting for shifts in supply of internal finance than cash flows. This is because, while on the margin a small positive income

\footnotetext{
${ }^{10}$ Not including $(S I N S)$ in specification for the financial constraint equation resulted in some of the variable turning insignificant and some becoming marginally significant.
} 
shock can turn negative realization of cash flows into positive realization, on the average a very large income shock, which is an extreme event, will be need to turn negative realization of cash flows into positive realization. The point, therefore, is that dummy variable $D N C F$ is by and large purged of the demand signals, and hence performs as a better variable in accounting for shifts in the supply of internal equity finance. To the extent that the share of innovative sales (SINS) can control for the demand signals and $D N C F$ can account for the shifts in supply of internal funds, our preferred specification for the second stage is the one in columns (C0) and (C1).

Though it is true that innovative firms are averse to debt financing, it may be that it does not have the requisite amount of internal finance to finance their $R \& D$ activity. In such a situation a firm has to resort to external sources of financing. Borrowing, as we know, is a prevalent means of financing investment, but is costly due to capital market imperfections. Given the nature of $\mathrm{R} \& \mathrm{D}$, such as the intangibility and uniqueness of assets and the unpredictability of outcomes, the degree of market imperfection related $R \& D$ is expected to be even higher, implying that external sources of finance could be even more costly when it comes to R\&D related activity. The notion of financial constraint that we employ is one of borrowing constraints, that is, firms are financially constrained when they reach their debt capacity. Depending on the amount of internally available funds, the degree of market imperfection it faces, and the amount of existing debt it services, a firm may or may not have reached its debt capacity. As stated earlier, we assume the latent variable $f_{i t}^{*}$, underlying $f_{i t}$, as the shadow price of debt. This implies that if borrowing constraints for R\&D firms are indeed binding, then controlling for other factors, $f_{i t}^{*}$ will be high. Now, controlling for other factors, a firm with higher leverage is more likely to have reached its debt limit, which makes the borrowing constraints more binding. Our results suggests that this is indeed the case, that is, we find a highly leveraged firm more likely to be financially constrained. We find that the scaled correlation between $\zeta_{i t}$, the unobserved idiosyncratic component of the financial constraint equation, and $\epsilon_{i t}$, the idiosyncratic component of the reduced form debt equation, $\frac{\rho_{\zeta \epsilon}}{\sigma_{\zeta}}$, to be significant, suggesting a strong simultaneity in the choice of leverage/capital structure and the financial constraint with respect to R\&D investment. This should not be surprising, since after all, we are talking about the shadow price of external finance related to endogenous borrowing constraints in the firm's optimal financing and real decisions.

We also find that firms that maintain a higher amount of liquidity reserve are less financially constrained. In anticipation of financing needs and the need to avoid costly external means of finance, firms do practice precautionary savings. Given that nature of $R \& D$, as discussed earlier, 
the need to finance $R \& D$ investment, through retained earnings might even be higher. However, it is also possible that high cash holdings simply reflect the fact that these firms are profitable firms with holdings in excess of their financing needs for real investment. We also find that firms that pay dividends are significantly less constrained, indicating that such firms are profitable firms with internally generated funds more than the financing needs of the firm.

In our specification for financial constraint equation we also included market share, size and age of the firm as a proxy for degree of informational asymmetry, which we would like to control for. Firms that are large, mature and enjoy a high degree of monopoly are generally well placed to mitigate informational asymmetry problems such as adverse selection. Hennessey and Whited (2007) find that large firms face small cost of external finance as compared to small firms. However, what we find is that size has a significant positive sign, indicating that large firms are more financially constrained. Here we would like to point out that it is mostly the innovators who answer to the questions relating to financial constraints: $100 \%$ for CIS2.5, $82 \%$ for CIS3, and $83 \%$ for CIS3.5. Therefore, somehow we need to control for the fact that the information on being financially constrained reported is the constraint with respect to $\mathrm{R} \& \mathrm{D}$, which only the innovators are more likely to answer. The strong positive sign for size in the financial constraint equation is due to the fact that size of the firm, to a large extent explains the innovation decision of the firm, and is therefore able to control for the fact that it is the innovators who mostly report on being financially constrained. To confirm this, we drop size, not reported here. Since size and age of firms are positively correlated, dropping size, results in age being significantly positive.

Our results suggests that firms with a large market share are less financially constrained with respect to R\&D. Higher degree of monopoly implies that demand for its product will be more inelastic, which in turn can enable the firm to be more profitable by exercising discretionary pricing. Also, firms enjoying a higher degree of monopoly could have a better access to capital markets. We also find that matured firms are less financially constrained. This is for the simple reason that old firms having survived through time have built reputation over the years, and are therefore less likely to face adverse information asymmetry problems, as compared to young firms.

Finally, we discuss a result that pertains to Figure 6.2. Figure 6.2 plots the average partial effect of leverage on the propensity to innovate conditional on being financially constrained and conditional being financially unconstrained. We plot the APE of leverage against size, age and leverage. We find that conditional on not being financially constrained, the APE of leverage on innovation to be negative and almost constant over the distribution of size, age and leverage. In contrast, the 
APE of leverage on innovation conditional on being financially constrained varies widely over the distribution of age, size and leverage, and is less in absolute terms when compared to the APE of leverage on innovation conditional on not being financially constrained. This indicates that under no financial constraints innovative firms, regardless of size, maturity, and existing level of debt, would uniformly, given the nature of $\mathrm{R} \& \mathrm{D}$ related activity, be less inclined to finance themselves with debt. In other words, when borrowing constraints do not bind and debt is accessible on easier terms, and if for some reason the firm has to finance itself with debt, then it is very unlikely that it will do it for innovation purposes or it is unlikely that it is an innovating firm. The following scenario might explain this: suppose there is a profitable firm, that has a substantial amount of cash holdings, that it can distribute to its share holders. Being profitable, it is likely that it has a rather large debt capacity and suppose its existing debt levels are such that it has not reached its debt capacity. In such a situation, the firm can distribute cash and borrow more to finance its investment. However, if it decides to innovate or spend more on $R \& D$ related activity, then as our results suggests, it would be less inclined to distribute cash as dividends, be more inclined to maintain a high cash reserves and not borrow more, in other words, finance itself with retained earnings.

When financial constraints set in, innovating firms, though still averse to debt financing, do borrow as is reflected in the relatively higher marginal propensity to innovate with respect to marginal increase in leverage as compared to the marginal propensity to innovate of the unconstrained firms. Now, under financial constraints, as Lambrecht and Myers (2008) explain, there can be two possibilities: (a) postpone investment or (b) borrow more to invest. Given the fact that most of the firms that report being financially constrained are innovators, it is true that these firms have not entirely abandoned innovative activity. Therefore, given our result that under constraint, the propensity to innovate with respect to leverage is relatively higher than under no financial constraints, it suggests that some projects might have been valuable enough to pursue by borrowing, even if that implied a higher cost. However, what we find is that the marginal propensity to innovate with respect to leverage varies with the distribution of size, age and leverage conditional on being constrained. This is because under financial constraints, the relative cost of external financing perceived by the firm depends on its age, size and the existing levels of debt. Take for example, the age of the firm, now even though we find that younger firms are more financially constrained, it is the young firms that are more innovative. This is because for younger firms survival and subsequent growth depends on their innovation. Hence, under financial constraints young firms are more willing to borrow than matured firms. Consequently, we find the marginal propensity to innovate with respect to leverage, 
though negative, is higher compared to a matured firm. Another line of reasoning supporting this finding is that of Cooley and Quadrini (2001), who argue that young firms typically operate on a smaller scale compared to mature firms, and therefore younger firm's profit are less susceptible to exogenous shocks as compared to mature firms. Given that a firm's objective function is concave in profits, higher volatility in profits imply a lower valuation of the firm, which makes further borrowing by matured firms operating on larger scale more problematic.

Conditional on being financially constrained, the marginal or the partial propensity to innovate with respect to marginal increase in leverage, asymptotes to zero as size of the firm increases. This is because, conditional on other covariates, as the size of the firm increases, for reasons discussed earlier, a firm becomes more certain to innovate and consequently financial constraints and marginal increase in leverage have little effect on the marginal propensity to innovate. In other words as the size of the firm increases, the effect of size dominates. However, under constraint small and medium sized firms, are still quite unlikely to engage in $R \& D$ activity with higher debt in their capital structure.

\subsubsection{Third Stage: R\&D Switching Regression}

In this section we discuss the structural estimates of the R\&D equation switching model. The obtained coefficients are shown in Table 6.5 and the APE's of the variables in Table 6. As explained earlier, the switching regression model is augmented with correction terms, obtained after first and second stage estimation. The correction terms correct for the bias arising due to endogeneity of the choice of leverage, financial constraints faced and the decision to innovate. The correction terms constructed are on the basis of first stage reduced form regression, discussed earlier, and second stage specification, columns $(\mathbf{C 0})$ and $(\mathbf{C 1})$ reported in Table 6.3.

We find that financial constraints do adversely and significantly affect $R \& D$ expenditure of firms. Given our interpretation of $f_{i t}^{*}$ as shadow price of external finance, faced with borrowing constraints, the result suggests that costly external sources of finance do have a bearing on R\&D activity. Table 6.5 also shows that for financially constrained firms $R \& D$ investment is more sensitive to cash flows as compared to the firms that are not financially constrained. The sensitivity of R\&D investment to cash flows is significant for the constrained firms but not for the unconstrained firms. However, as stressed in an earlier discussion, the test for the impact of financing frictions on investment expenditure in our model does not rely on the comparison of sensitivity of investment to cash flows for the constrained and unconstrained firms. Such differences in the sensitivity of investment to cash flows can arise, since, as Gomes (2001) argues constrained firms have a higher marginal productivity 
of capital and invest more than those unconstrained. They also have a higher value of Tobin's "q" on average. Also, as Hennessy and Whited (2007) point out, the inability of proxies, in our model the share of innovative sales in the total sales of the firms, SINS, to perfectly control for investment opportunity can give predictive power to cash flows in investment regression equations, when cash flows are correlated to the investment opportunity set of the firms. Therefore, instead of interpreting the higher and significant coefficient of cash flows for financially constrained firms, it should be interpreted as controlling for investment opportunity for constrained firms.

We find that firms whose current share of innovative sales are high, are more likely to be $R \& D$ intensive. Not including $S I N S$ in the specification, not reported here, resulted in a larger coefficient for cash flow, insignificant positive sign for $f_{i t}$, and insignificant coefficients for some of the correction terms. This suggests that the share of innovative sales in the total sales of the firm (SINS) among others, is a also a function of demand signals or income shocks ${ }^{11}$.

We also find that firms that payout dividends invest less in $R \& D$. This seems to be more true for firms that are financially constrained with respect to $R \& D$ related activity. This corroborates the result of the negative relation between dividend payout and innovation obtained in the second stage. The prime reason for the negative correlation being that innovation is a risky venture, and therefore lenders demand a premium on loans offered. Consequently, R\&D intensive firms prefer internal source of financing, which makes them much less likely to distribute cash. The argument, it seems is strengthened by the fact that firms that are financially constrained with respect to innovative activity, and if for some reasons are distributing cash, then such firms are even less up R\&D intensive.

We also find that firms with a large market share invest more in $R \& D$, if only to maintain their monopoly position in the market. However, as suggested by the APE's in column (b) of Table 6.6, under financial constraints firms enjoying monopoly power could also be less R\&D intensive. We find that large firms are less $R \& D$ intensive, even though as the second stage results suggest, they are more likely to be innovators. This should not be surprising, since smaller firms are the ones that are more profitable and experience higher growth. In their bid to grow, they exhibit risky behavior both in terms of investment and borrowing, and consequently also experience higher volatility of growth. Also, for larger firms, investing as-much-as or proportionately more would imply subjecting themselves to higher risk. Since large firms operate on a larger scale and are therefore more subject to exogenous shocks, investing as-much-as or proportionately more than small firms would imply, tying up more capital in some risky venture, when they already are more subject to exigencies of

\footnotetext{
${ }^{11}$ We also estimated the system of equations with $S I N S_{i t, t+1}$, reducing the number of observations to about half, however, the results remained qualitatively the same.
} 
nature. Our findings also suggests that young firms are more R\&D intensive, corroborating the result of the second stage, where we found them to more innovative. The arguments presented earlier in the discussion of the second stage results, for young firms being more innovative, also apply here. Firms that have a number of enterprises consolidated within them, DMULTI, are more likely to be R\&D intensive. Now, such firms can be large, but as stated earlier, the various enterprises constituting the firm are more or less legal entities, with a certain degree of autonomy. These enterprises can have their innovation own policy. Thus, such firms are expected to be engaged in diverse activity and products. Hence, such firms, even if large, are found to be more R\&D intensive. However, as the APE's in column (b) of Table 6.6 suggests, the DMULTI firms, under financial constraints, can behave otherwise.

In our analysis we also find that the various correlation term as $\rho_{\eta_{1} \epsilon} \sigma_{\eta_{1}}, \sigma_{\underline{\eta}_{1}} \rho_{\underline{\eta}_{1} \underline{\zeta}}, \sigma_{\underline{\eta}_{1}} \rho_{\underline{\eta}_{1} \underline{v}}, \rho_{\eta_{0} \epsilon} \sigma_{\eta_{0}}$, $\sigma_{\underline{\eta}_{0}} \rho_{\underline{\eta}_{0} \underline{\zeta}}$, and $\sigma_{\underline{\eta}_{0}} \rho_{\underline{\eta}_{0} \underline{\underline{v}}}$ are significant, suggesting strong simultaneity in the decision to innovate, the choice of capital structure and the amount of $R \& D$ expenditure. The significance of $\mu$, the factor loading in the switching model also suggests that time invariant individual effect that affects the decision to innovate and the choice of capital structure also affects the decision on the amount of $\mathrm{R} \& \mathrm{D}$ expenditure.

\subsection{Conclusion}

In this chapter we presented an empirical strategy for modelling a firm that chooses to be an innovator, decides on the extent leverage, and how much it wants to spend on $R \& D$, where all these decisions are determined endogenously. In its decision to innovate and in deciding how much to spend on R\&D activity, the firm faces endogenous financial constraints. The strategy entails estimating a system of four simultaneous equations, estimated in three steps. The first step being, estimation of the reduced form leverage equation. The second step involves, conditional on first step estimates, joint estimation of the structural equations relating to the decision to innovate and the financial constraints faced. Finally, in the third stage we estimate a switching regression model for R\&D investment, conditional on being an innovator and the first and second stage estimates. While such a multi-step procedure is not uncommon for cross sectional data, in panel data one has to account for common time invariant individual effect that affects all of the firm's decisions and the financial constraints it faces. Our approach, in which we replace the time invariant individual effect in the structural equations by its expected a posteriori value, obtained from the first stage estimates, allows us to consistently estimate the parameters of the subsequent stages. 
Econometric methodology aside, the aim of the chapter has been to study what firm characteristics are associated with a firm's decision to innovate and the financial constraints it faces with respect to R\&D activity and how financial constraints affect R\&D investment. Among other firm characteristics, the chapter investigates, how firm's leverage is related to the firms's decision to innovate and the financial constraints it faces with respect to R\&D activity. We find that a highly leveraged firm is less likely to be an innovator and more likely to be financially constrained. We find that financial constraints adversely affects a firm's R\&D expenditure, reducing the $R \& D$ expenditure by almost two thirds, for an average firm.

We find that large, young and firms enjoying a higher degree of monopoly are more likely to be innovators. Also, firms that have many enterprises consolidated within them are more likely to be innovators. We also find that young firms are more likely to be facing financial constraints, while firms that enjoy a monopoly position are less constrained. As far a R\&D investment is concerned, we find that it is the small and young firms that are more $R \& D$ intensive than large and mature firms and that firms with large market share and multi-enterprise firms are more R\&D intensive.

Also, the behavior of firms, conditional on being financially constrained and conditional on being unconstrained, with regard to innovation and $\mathrm{R} \& \mathrm{D}$ intensity can be characteristically different. Under no financial constraints, the propensity to innovate with respect to leverage is negative and lower as compared to a situation in which firms find them selves financially constrained. Also, the propensity to innovate under no financial constraints, barely varies with firm characteristics such as maturity, size and leverage, while under financial constraints, the propensity to innovate with respect to leverage varies with the distribution of firm characteristics. As far as R\&D intensity is concerned, while unconditionally multi-enterprise and firms enjoying monopoly power are likely to be highly $\mathrm{R} \& \mathrm{D}$ intensive, under constraints the $\mathrm{R} \& \mathrm{D}$ intensity of such firms decreases. The results help us in understanding how incentives to innovate and capital market imperfections, with respect to financing R\&D activity, facing the firms interact, and how these are distributed across firm characteristics.

Finally, given our results that financial constraints adversely affect R\&D investment, and the fact that we have utilized almost a third of the CIS data, it seems to us that the effect of financial constraints for aggregate $R \& D$ investment for the economy can be considerable, which in turn can impediment aggregate growth.

For future research, within the econometric technique we have developed, we seek to endogenize some of the variables that could be potentially endogenous and compute the standard errors of the APE. 


\subsection{Appendix}

\section{A Identification of Structural Parameters with Expected a Posteriori Values of Individual Effects}

In this section we discuss the identification of the parameters for the second stage. Though the second stage estimation involves a joint estimation of the probability of a firm being financially constrained and the probability of the firm being an innovator, here we discuss identification only for the parameters that are pertinent to the financial constraint equation. The arguments carry over to the joint estimation of the financial constraint and the selection equations and the third stage R\&D switching regression model.

Suppose, we are interested only in the financial constraint affecting R\&D, where the firm's leverage explains the financial constraint the firm faces. To obtain the structural estimates for financial constraint, consider the financial constraint equation, equation (3), and the reduced form debt equation, equation (5),

$$
\begin{gathered}
f_{i t}^{*}=\mathbf{z}_{i t}^{\prime \prime} \varphi+d_{i t} \varphi_{d}+\lambda \alpha_{i}+\zeta_{i t} \\
d_{i t}=\mathbf{z}_{i t}^{\prime} \delta+\alpha_{i}+\epsilon_{i t} .
\end{gathered}
$$

Since leverage is endogenous to the financial constraint that the firm faces, the idiosyncratic components $\zeta_{i t}$ and $\epsilon_{i t}$ are correlated. To obtain the structural estimates of the financial constraint equation, a two step procedure can be employed, in which consistent estimates of the reduced form parameters obtained in the first stage can be used to obtain parameters of the structural equation in the second stage by conditional likelihood or any other method of moment.

Now, given that $\zeta_{i t}$ and $\epsilon_{i t}$ follow a normal distribution with correlation $\rho_{\zeta \epsilon}$, we can write the linear projection of $\zeta_{i t}$ on $\epsilon_{i t}$ in error form as $\zeta_{i t}=\rho_{\zeta \epsilon} \frac{\epsilon_{i t}}{\sigma_{\epsilon}}+\bar{\zeta}_{i t}$. Then conditional on $d_{i}=\left\{d_{i 1}, \ldots, d_{i T_{i}}\right\}^{\prime}$, $Z_{i}=\left\{Z_{i 1}^{\prime}, \ldots, Z_{i T_{i}}^{\prime}\right\}^{\prime}, \epsilon_{i t}$ and $\alpha_{i}$ the projection of $f_{i t}^{*}$, can be written as

$$
f_{i t}^{*}=\mathbf{z}_{i t}^{f \prime} \varphi+d_{i t} \varphi_{d}+\lambda \alpha_{i}+\rho_{\zeta \epsilon} \frac{\epsilon_{i t}}{\sigma_{\epsilon}}+\bar{\zeta}_{i t}
$$

where $\bar{\zeta}_{i t}$ is independent of $d_{i}, Z_{i}, \epsilon_{i t}$, and $\alpha_{i}$, and is normally distributed with mean zero and variance $\left(1-\rho_{\zeta \epsilon}^{2}\right)^{12}$. The probability of a firm being financially constrained in period $t$, conditional on $d_{i}, Z_{i}$,

\footnotetext{
${ }^{12}$ This essentially implies that conditional on $\epsilon_{i t}, \zeta_{i t}$ is independent of $d_{i t}$.
} 
$\alpha_{i}$, and $\epsilon_{i t}$, is then given by

$$
\begin{aligned}
\operatorname{Pr}\left(f_{i t}=1 \mid d_{i}, Z_{i}, \alpha_{i}, \epsilon_{i t}\right) & =\Phi\left(\frac{\mathbf{z}_{i t}^{f \prime} \varphi+d_{i t} \varphi_{d}+\lambda \alpha_{i}+\rho_{\zeta \epsilon} \frac{\epsilon_{i t}}{\sigma_{\epsilon}}}{\sqrt{\left(1-\rho_{\zeta \epsilon}^{2}\right)}}\right) \\
& =\Phi\left(\frac{\mathbf{z}_{i t}^{f \prime} \varphi+d_{i t} \varphi_{d}+\lambda \alpha_{i}+\rho_{\zeta \epsilon}\left(\frac{d_{i t}-\mathbf{z}_{i t}^{\prime} \delta-\alpha_{i}}{\sigma_{\epsilon}}\right)}{\sqrt{\left(1-\rho_{\zeta \epsilon}^{2}\right)}}\right),
\end{aligned}
$$

where $\Phi$ is cumulative density function of a standard normal. The log likelihood function of a firm being financially constrained in period $t$ is given by

$$
\begin{aligned}
\boldsymbol{L}_{i t f}\left(\varphi, \varphi_{d}, \rho_{\zeta \epsilon}, \lambda ; \delta, \sigma_{\epsilon} \mid d_{i}, Z_{i}, \alpha_{i}, \epsilon_{i t}\right) & =f_{i t} \ln \operatorname{Pr}\left(f_{i t}=1 \mid d_{i}, Z_{i}, \alpha_{i}, \epsilon_{i t}\right) \\
& +\left(1-f_{i t}\right) \ln \operatorname{Pr}\left(f_{i t}=0 \mid d_{i}, Z_{i}, \alpha_{i}, \epsilon_{i t}\right) .
\end{aligned}
$$

The parameters, $\varphi, \varphi_{d}, \lambda, \rho_{\zeta \epsilon}$ in (A-2), could have been identified if we knew $\alpha_{i}, \delta, \sigma_{\epsilon}$ and $\sigma_{\alpha}$, where $\sigma_{\alpha}$ the standard deviation of the marginal distribution of $\alpha_{i}$. Such a two step procedure is quite standard in models for cross sectional data, where estimates of the first stage errors are employed to control for the endogeneity of the endogenous regressors. The problem, however, with models for panel data is that the estimates of $\mathrm{E}\left(\epsilon_{i t} \mid d_{i}, Z_{i}, \alpha_{i}\right)=d_{i t}-\mathbf{z}_{i t}^{\prime} \delta-\alpha_{i}$ remain unidentified since we do not observe $\alpha_{i}$, even though $\delta, \sigma_{\epsilon}$ and $\sigma_{\alpha}$ can be consistently estimated from the first stage reduced form estimation of equation (5). Here we show that using a two step procedure, where $\delta, \sigma_{\epsilon}$ and $\sigma_{\alpha}$ are estimated in the first stage, $\mathrm{E}\left(\epsilon_{i t} \mid d_{i}, Z_{i}\right)$ can still be identified, which can then be used for the identification of the structural parameters.

Before we discuss identification for our non-linear model, we first consider identification for a linear model. Let $f\left(\alpha_{i} \mid d_{i}, Z_{i}\right)$ be the conditional distribution of time invariant individual effect $\alpha_{i}$ conditional on $d_{i}$ and $Z_{i}$. Assume for the moment that $f_{i t}^{*}$ is some observed continuous variable. Now, since $d_{i}, Z_{i}$, and $\alpha_{i}$ are in the conditioning set, of which $\epsilon_{i t}$ is a function of, we can suppress $\epsilon_{i t}$, while writing the conditional expectation of $f_{i t}^{*}$. Thus we have $E\left(f_{i t}^{*} \mid d_{i}, Z_{i}, \epsilon_{i t}, \alpha_{i}\right)=E\left(f_{i t}^{*} \mid d_{i}, Z_{i}, \alpha_{i}\right)$, which is given by

$$
\begin{aligned}
E\left(f_{i t}^{*} \mid d_{i}, Z_{i}, \alpha_{i}\right) & = & \mathbf{z}_{i t}^{f \prime} \varphi+d_{i t} \varphi_{d}+\lambda \alpha_{i}+\rho_{\zeta \epsilon} \frac{\epsilon_{i t}}{\sigma_{\epsilon}}+E\left(\bar{\zeta}_{i t} \mid d_{i}, Z_{i}, \alpha_{i}\right) \\
& = & \mathbf{z}_{i t}^{\prime \prime} \varphi+d_{i t} \varphi_{d}+\lambda \alpha_{i}+\rho_{\zeta \epsilon} \frac{\left(d_{i t}-\mathbf{z}_{i t}^{\prime} \delta-\alpha_{i}\right)}{\sigma_{\epsilon}} \\
& = & \mathbf{z}_{i t}^{f \prime} \varphi+d_{i t} \varphi_{d}+\rho_{\zeta \epsilon} \frac{\left(d_{i t}-\mathbf{z}_{i t}^{\prime} \delta\right)}{\sigma_{\epsilon}}+\left(\lambda-\frac{\rho_{\zeta \epsilon}}{\sigma_{\epsilon}}\right) \alpha_{i}
\end{aligned}
$$


For any individual, $i$, taking expectation of the above with respect to the conditional distribution of $\alpha, f(\alpha \mid d, Z)$ we obtain

$$
\begin{aligned}
E\left(f_{t}^{*} \mid d, Z\right)=\int E\left(f_{t}^{*} \mid d, Z, \alpha\right) f(\alpha \mid d, Z) d(\alpha) & = & & \mathbf{z}_{t}^{f \prime} \varphi+d_{t} \varphi_{d}+\rho_{\zeta \epsilon} \frac{\left(d_{t}-\mathbf{z}_{t}^{\prime} \delta\right)}{\sigma_{\epsilon}} \\
& + & & \left(\lambda-\frac{\rho_{\zeta \epsilon}}{\sigma_{\epsilon}}\right) \int \alpha f(\alpha \mid d, Z) d(\alpha) .
\end{aligned}
$$

Using Bayes rule we can write $f(\alpha \mid d, Z)$ as

$$
f(\alpha \mid d, Z)=\frac{f(d, Z \mid \alpha) g(\alpha)}{h(d, Z)}
$$

where $g$ and $h$ are density functions. The above can be written as

$$
f(\alpha \mid d, Z)=\frac{f(d \mid Z, \alpha) p(Z \mid \alpha) g(\alpha)}{h(d \mid Z) p(Z)}
$$

Since by our assumption the time invariant individual effects, $\alpha_{i}$, are independent of the exogenous variables $Z_{i}$, hence $p(Z \mid \alpha)=p(Z)$, that is,

$$
f(\alpha \mid d, Z)=\frac{f(d \mid Z \alpha) g(\alpha)}{h(d \mid Z)}=\frac{f(d \mid Z, \alpha) g(\alpha)}{\int f(d \mid Z, \alpha) g(\alpha) d \alpha}
$$

Hence,

$$
\begin{aligned}
\int \alpha f(\alpha \mid d, Z) d(\alpha) & =\int \frac{\alpha f(d \mid Z, \alpha) g(\alpha) d \alpha}{\int f(d \mid Z, \alpha) g(\alpha) d \alpha} \\
& =\frac{\int \alpha \prod_{t=1}^{T} f\left(d_{t} \mid Z, \alpha\right) g(\alpha) d \alpha}{\int \prod_{t=1}^{T} f\left(d_{t} \mid Z, \alpha\right) g(\alpha) d \alpha} \\
& =\frac{\int \alpha \prod_{t=1}^{T} \frac{1}{\sigma_{\epsilon}} \phi\left(\frac{d_{t}-\mathbf{z}_{t}^{\prime} \delta-\alpha}{\sigma_{\epsilon}}\right) g(\alpha) d \alpha}{\int \prod_{t=1}^{T} \frac{1}{\sigma_{\epsilon}} \phi\left(\frac{d_{t}-\mathbf{z}_{t}^{\prime} \delta-\alpha}{\sigma_{\epsilon}}\right) g(\alpha) d \alpha} \\
& =\frac{\int \sigma_{\alpha} \tilde{\alpha} \prod_{t=1}^{T} \frac{1}{\sigma_{\epsilon}} \phi\left(\frac{d_{t}-\mathbf{z}_{t}^{\prime} \delta-\sigma_{\alpha} \tilde{\alpha}}{\sigma_{\epsilon}}\right) \phi(\tilde{\alpha}) d \tilde{\alpha}}{\int \prod_{t=1}^{T} \frac{1}{\sigma_{\epsilon}} \phi\left(\frac{d_{t}-\mathbf{z}_{t}^{\prime} \delta-\sigma_{\alpha} \tilde{\alpha}}{\sigma_{\epsilon}}\right) \phi(\tilde{\alpha}) d \tilde{\alpha}}
\end{aligned}
$$

where the second and the third equality follow from the fact that conditional on $Z$ and $\alpha$, each of the $d_{t}, d_{t} \in\left\{d_{1}, \ldots, d_{T}\right\}$ are independently normally distributed with mean $\mathbf{z}_{t}^{\prime} \delta+\alpha$ and standard deviation $\sigma_{\epsilon} . g(\alpha)$ by our assumption is normally distributed with mean zero and variance $\sigma_{\alpha}^{2}$ and $\tilde{\alpha}=\frac{\alpha}{\sigma_{\alpha}}$ follows a standard normal distribution. Given that $\phi$ is a smooth exponential function of its argument and denominator of the right hand side of equation (A-8) is the estimated marginal 
maximum likelihood, which converges to its true value on the LHS, it can be shown that

$$
\frac{\int \sigma_{\alpha} \tilde{\alpha} \prod_{t=1}^{T} \frac{1}{\sigma_{\epsilon}} \phi\left(\frac{d_{t}-\mathbf{z}_{t}^{\prime} \delta-\sigma_{\alpha} \tilde{\alpha}}{\sigma_{\epsilon}}\right) \phi(\tilde{\alpha}) d \tilde{\alpha}}{\int \prod_{t=1}^{T} \frac{1}{\sigma_{\epsilon}} \phi\left(\frac{d_{t}-\mathbf{z}_{t}^{\prime} \delta-\sigma_{\alpha} \tilde{\alpha}}{\sigma_{\epsilon}}\right) \phi(\tilde{\alpha}) d \tilde{\alpha}} \stackrel{\int \frac{\hat{\sigma}_{\alpha}}{\equiv} \tilde{\alpha} \prod_{t=1}^{T} \frac{1}{\hat{\sigma}_{\epsilon}} \phi\left(\frac{d_{t}-\mathbf{z}_{t}^{\prime} \hat{\delta}-\hat{\sigma}_{\alpha} \tilde{\alpha}}{\hat{\sigma}_{\epsilon}}\right) \phi(\tilde{\alpha}) d \tilde{\alpha}}{\int \prod_{t=1}^{T} \frac{1}{\hat{\sigma}_{\epsilon}} \phi\left(\frac{d_{t}-\mathbf{z}_{t}^{\prime} \hat{\delta}-\hat{\sigma}_{\alpha} \tilde{\alpha}}{\hat{\sigma}_{\epsilon}}\right) \phi(\tilde{\alpha}) d \tilde{\alpha}} .
$$

The right hand side of (A-8) is the estimated expected a posteriori value of $\alpha, \hat{\alpha}\left(d, Z, \hat{\delta}, \hat{\sigma}_{\epsilon}, \hat{\sigma}_{\alpha}\right)$. To estimate the RHS of equation (A-8), numerical integration with respect to $\tilde{\alpha}_{i}$ can be carried out using Gauss-Hermite quadratures. Therefore under asymptotic equivalence we can write (A-4) as

$$
\int E\left(f_{t}^{*} \mid d, Z, \alpha\right) f(\alpha \mid d, Z) d(\alpha) \stackrel{a s y}{=} \mathbf{z}_{t}^{f \prime} \varphi+d_{t} \varphi_{d}+\rho_{\zeta \epsilon} \frac{\left(d_{t}-\mathbf{z}_{t}^{\prime} \delta\right)}{\sigma_{\epsilon}}+\left(\lambda-\frac{\rho_{\zeta \epsilon}}{\sigma_{\epsilon}}\right) \hat{\alpha}\left(d, Z, \hat{\delta}, \hat{\sigma}_{\epsilon}, \hat{\sigma}_{\alpha}\right)
$$

and since

$$
\frac{d_{t}-\mathbf{z}_{t}^{\prime} \delta-\hat{\alpha}_{i}}{\sigma_{\epsilon}} \stackrel{\text { asy }}{=} \frac{d_{t}-\mathbf{z}_{t}^{\prime} \hat{\delta}-\hat{\alpha}_{i}}{\hat{\sigma}_{\epsilon}}
$$

hence

$$
\int E\left(f_{t}^{*} \mid d, Z, \alpha\right) f(\alpha \mid d, Z) d(\alpha) \stackrel{a s y}{\equiv} \mathbf{z}_{t}^{f \prime} \varphi+d_{t} \varphi_{d}+\lambda \hat{\alpha}+\rho_{\zeta \epsilon}\left(\frac{d_{t}-\mathbf{z}_{t}^{\prime} \hat{\delta}-\hat{\alpha}}{\hat{\sigma}_{\epsilon}}\right)
$$

Therefore, if population parameters, $\delta, \sigma_{\epsilon}$ and $\sigma_{\alpha}$ were known, the above implies that we could write the linear predictor of $f_{t}^{*}$, given $d$ and $Z$ in error form as

$$
\begin{aligned}
f_{t}^{*} & =\mathbf{z}_{t}^{f \prime} \varphi+d_{t} \varphi_{d}+\rho_{\zeta \epsilon} \frac{\left(d_{t}-\mathbf{z}_{t}^{\prime} \delta-\hat{\alpha}\right)}{\sigma_{\epsilon}}+\lambda \hat{\alpha}+\tilde{\zeta}_{t} \\
& =\mathbf{z}_{t}^{f \prime} \varphi+d_{t} \varphi_{d}+\rho_{\zeta \epsilon} \frac{\hat{\epsilon}_{t}}{\sigma_{\epsilon}}+\lambda \hat{\alpha}+\tilde{\zeta}_{t}
\end{aligned}
$$

where $\hat{\epsilon}_{t}=d_{t}-\mathbf{z}_{t}^{\prime} \delta-\hat{\alpha}=\mathrm{E}\left(\epsilon_{t} \mid d, Z\right)$, which is identified, as claimed earlier. Conditional of $d$ and $Z, \tilde{\zeta}_{t}$ is i.i.d. and normally distributed with mean 0 and variance $\sigma_{\tilde{\zeta}}^{2}$ and $\hat{\alpha}$ in the above equation is defined at population parameters. For liner models, say if $f_{t}^{*}$ was observed and continuous, the parameters of interest, $\varphi, \varphi_{d}$ and $\rho_{\zeta \epsilon}$, can be consistently estimated by running a pooled OLS regression, with estimated a posteriori values, $\hat{\alpha}$ substituted for $\alpha$ and consistent first step estimates $\hat{\sigma}_{\epsilon}$ and $\hat{\delta}$ for $\sigma_{\epsilon}$ and $\delta$ respectively. The test of exogeneity of $d_{t}$ can be carried out by testing the significance of the estimates of $\rho_{\zeta \epsilon}$ and $\lambda$. The average partial effect of any exogenous variable $z_{k t}$ and endogenous $d_{t}$ 
are respectively given by

$$
\frac{\partial E\left(f_{t}^{*} \mid d, Z\right)}{\partial z_{k t}}=\varphi_{k} \quad \text { and } \quad \frac{\partial E\left(f_{t}^{*} \mid d, Z\right)}{\partial d_{t}}=\varphi_{d}
$$

Now let us consider our non-linear model, where $f_{t}^{*}$, is a latent variable underlying $f_{t}$ which takes value 0 or 1 . It follows from (A-11) and the fact that in probit models the parameters are identified only up to a scale, that the probability of being financially constrained, given $d_{i}$ and $Z_{i}$, is given by

$$
\begin{aligned}
\operatorname{Pr}\left(f_{t}=1 \mid d, Z, \hat{\epsilon}_{t}, \hat{\alpha}\right) & =\operatorname{Pr}\left(f_{t}^{*}>0 \mid d, Z, \hat{\epsilon}_{t}, \hat{\alpha}\right) \\
& =\Phi\left(\mathbf{z}_{t}^{f \prime} \varphi \frac{1}{\sigma_{\tilde{\zeta}}}+d_{t} \frac{\varphi_{d}}{\sigma_{\tilde{\zeta}}}+\frac{\lambda}{\sigma_{\tilde{\zeta}}} \hat{\alpha}+\frac{\rho_{\zeta \epsilon}}{\sigma_{\tilde{\zeta}}} \frac{\hat{\epsilon}_{t}}{\sigma_{\epsilon}}\right) .
\end{aligned}
$$

However, $\operatorname{Pr}\left(f_{t}=1 \mid d, Z, \hat{\epsilon}_{t}, \hat{\alpha}\right) \neq \operatorname{Pr}\left(f_{t}=1 \mid d, Z, \epsilon_{t}, \alpha\right)$, and for any individual $i$, the mean effect or the average partial effect (APE) of changing a variable say $z_{k}$ in time period $t$ from $z_{k t}$ to $z_{k t}+\kappa$ is given by

$$
\begin{aligned}
\frac{\Delta \operatorname{Pr}\left(f_{t}=1\right)}{\Delta z_{k t}} & =\left[\int \operatorname{Pr}\left(f_{t}=1 \mid d, Z_{-k}, z_{k_{-t}},\left(z_{k t}+\kappa\right), \alpha, \epsilon_{t}\right) d g\left(\alpha, \epsilon_{t}\right)\right. \\
& \left.-\int \operatorname{Pr}\left(f_{t}=1 \mid d, Z_{-k}, z_{k_{-t}}, z_{k t}, \alpha, \epsilon_{t}\right) d g\left(\alpha, \epsilon_{t}\right)\right] / \kappa
\end{aligned}
$$

where $g\left(\alpha, \epsilon_{t}\right)$ is the distribution function of $\alpha$ and $\epsilon_{t}$. Hence, to recover the above measure in (A-14), like Chamberlain (1984), we assume a distribution for $\alpha_{i}$ conditional on $d_{i}$ and $Z_{i}$ :

$$
\alpha_{i}=\Psi\left(d_{i}, Z_{i}\right)+\bar{\alpha}_{i}
$$

where $\bar{\alpha}_{i}$ is normally distributed with mean 0 , variance $\sigma_{\bar{\alpha}}^{2}$ and is independent of everything else. However, for any individual $i$, we have shown above that,

$$
\mathrm{E}(\alpha \mid d, Z)=\int \alpha f(\alpha \mid d, Z) d(\alpha)=\Psi(d, Z)=\hat{\alpha}\left(d, Z, \delta, \sigma_{\epsilon}, \sigma_{\alpha}\right)
$$

The above implies that conditionally on $d$ and $Z, \epsilon_{t}$ is distributed as

$$
\epsilon_{t}=d_{t}-\mathbf{z}_{t}^{\prime} \delta-\hat{\alpha}-\bar{\alpha}=\hat{\epsilon}_{t}-\bar{\alpha}
$$

Hence, under the assumption about the conditional distribution of $\alpha_{i}$, we can write the linear pro- 
jection of $f_{t}^{*}$ as

$$
f_{t}^{*}=\mathbf{z}_{t}^{f \prime} \varphi+d_{t} \varphi_{d}+\lambda \hat{\alpha}+\rho_{\zeta \epsilon} \frac{\hat{\epsilon}_{t}}{\sigma_{\epsilon}}+\left(\lambda-\frac{\rho_{\zeta \epsilon}}{\sigma_{\epsilon}}\right) \bar{\alpha}+\bar{\zeta}_{t},
$$

with the composite error term $\left(\lambda-\frac{\rho_{\zeta \epsilon}}{\sigma_{\epsilon}}\right) \bar{\alpha}_{i}+\bar{\zeta}_{i t}=\underline{\zeta}_{i t}$, which is uncorrelated with any of the covariates and is normally distributed with mean zero and variance $\left(\lambda-\frac{\rho_{\zeta \epsilon}}{\sigma_{\epsilon}}\right)^{2} \sigma_{\bar{\alpha}}^{2}+\sigma_{\bar{\zeta}}^{2}=\sigma_{\underline{\zeta}}^{2}$. Therefore, the above assumption about the conditional distribution of $\alpha_{i}$ implies that,

$$
\operatorname{Pr}\left(f_{i t}=1 \mid d_{i}, Z_{i}\right)=\Phi\left(\mathbf{z}_{i t}^{f \prime} \varphi \frac{1}{\sigma_{\underline{\zeta}}}+d_{i t} \frac{\varphi_{d}}{\sigma_{\underline{\zeta}}}+\frac{\lambda}{\sigma_{\underline{\zeta}}} \hat{\alpha}_{i}+\frac{\rho_{\zeta \epsilon}}{\sigma_{\underline{\zeta}}} \frac{\hat{\epsilon}_{i t}}{\sigma_{\epsilon}}\right)
$$

Since $\sigma_{\underline{\zeta}}$ in (A-16) remain unidentified, the parameters of interest can only be identified up to a scale.

Now, having assumed the conditional distribution of $\alpha_{i}$, for any individual $i$, we now have

$$
\operatorname{Pr}\left(f_{t}=1 \mid d, Z, \alpha, \epsilon_{t}\right)=\operatorname{Pr}\left(f_{t}=1 \mid d, Z, \hat{\alpha}(.), \hat{\epsilon}_{t}, \bar{\alpha}\right)
$$

and

$$
\int \operatorname{Pr}\left(f_{t}=1 \mid d, Z, \hat{\alpha}(.), \hat{\epsilon}_{t}, \bar{\alpha}\right) d F\left(\hat{\alpha}(.), \hat{\epsilon}_{t}, \bar{\alpha}\right)=\iint \operatorname{Pr}\left(f_{t}=1 \mid d, Z, \hat{\alpha}(.), \hat{\epsilon}_{t}, \bar{\alpha}\right) d G\left(\hat{\alpha}(.), \hat{\epsilon}_{t}\right) h(\bar{\alpha}) d \bar{\alpha}
$$

where $F\left(\hat{\alpha}(),. \hat{\epsilon}_{t}, \bar{\alpha}\right)$ is the joint distribution function of the arguments and $G\left(\hat{\alpha}(),. \hat{\epsilon}_{t}\right)$ is the joint distribution of $\hat{\alpha}($.$) and \hat{\epsilon}_{t}$. The equality above follows, since $\hat{\alpha}($.$) and \hat{\epsilon}_{t}$ by our assumption are independent of $\bar{\alpha}$. Also, since $\bar{\alpha}$ is independent of $d$ and $Z$, we can write the above as

$$
\begin{array}{r}
\int \operatorname{Pr}\left(f_{t}=1 \mid d, Z, \hat{\alpha}(.), \hat{\epsilon}_{t}, \bar{\alpha}\right) d F\left(\hat{\alpha}(.), \hat{\epsilon}_{t}, \bar{\alpha}\right) \\
=\iint \operatorname{Pr}\left(f_{t}=1 \mid d, Z, \hat{\alpha}(.), \hat{\epsilon}_{t}, \bar{\alpha}\right) h\left(\bar{\alpha} \mid d, Z, \hat{\alpha}(.), \hat{\epsilon}_{t}\right) d \bar{\alpha} d G\left(\hat{\alpha}(.), \hat{\epsilon}_{t}\right) \\
=\int \operatorname{Pr}\left(f_{t}=1 \mid d, Z, \hat{\alpha}(.), \hat{\epsilon}_{t}\right) d G\left(\hat{\alpha}(.), \hat{\epsilon}_{t}\right) .
\end{array}
$$

Thus we have shown that

$$
\int \operatorname{Pr}\left(f_{t}=1 \mid d, Z, \alpha, \epsilon_{t}\right) d g\left(\alpha, \epsilon_{t}\right)=\int \operatorname{Pr}\left(f_{t}=1 \mid d, Z, \hat{\alpha}(.), \hat{\epsilon}_{t}\right) d G\left(\hat{\alpha}(.), \hat{\epsilon}_{t}\right)
$$


To obtain the sample analog of RHS of (A-19), for fixed $d=\bar{d}$ and $Z=\bar{Z}$, we can compute

$$
\frac{1}{\sum_{i=1}^{N} T_{i}} \sum_{i=1}^{N} \sum_{t=1}^{T_{i}} \operatorname{Pr}\left(f_{i t}=1 \mid \bar{d}, \bar{Z}, \hat{\alpha}_{i}(.), \hat{\epsilon}_{i t}\right) .
$$

With (A-19) we can now compute (A-14), the mean effect of changing a variable say $z_{k}$ from $\bar{z}_{k}$ to $\bar{z}_{k}+\kappa$ given $d=\bar{d}$ and $Z_{-k}=\bar{Z}_{-k}$.

Now consider the selection equation. The projection of $s_{t}^{*}$, the latent variable underlying selection, in error form conditional on $\epsilon_{t}$ is given by

$$
s_{t}^{*}=\mathbf{z}_{t}^{s \prime} \gamma+d_{t} \gamma_{d}+\theta \alpha+\rho_{v \epsilon} \frac{\epsilon_{t}}{\sigma_{\epsilon}}+\bar{v}_{t} .
$$

By the same logic that we used to arrive at equation (A-16) for the financial constraint equation, we can write the selection equation as

$$
s_{t}^{*}=\mathbf{z}_{t}^{s \prime} \gamma+d_{t} \gamma_{d}+\theta \hat{\alpha}+\rho_{v \epsilon} \frac{\hat{\epsilon}_{t}}{\sigma_{\epsilon}}+\underline{v}_{t}
$$

where $\underline{v}_{t}=\left(\theta-\frac{\rho_{v \epsilon}}{\sigma_{\epsilon}}\right) \bar{\alpha}_{i}+\bar{v}_{t}$ which is uncorrelated with any of the covariates and is normally distributed with mean zero and variance $\left(\theta-\frac{\rho_{v \epsilon}}{\sigma_{\epsilon}}\right)^{2} \sigma_{\bar{\alpha}}^{2}+\sigma_{\bar{v}}^{2}=\sigma_{\underline{v}}^{2}$. However, $\underline{\zeta}_{t}$ and $\underline{v}_{t}$ are correlated, with the correlation coefficient being

$$
\rho_{\underline{\zeta} \underline{v}}=\frac{\left(\lambda-\frac{\rho_{\zeta \epsilon}}{\sigma_{\epsilon}}\right)\left(\theta-\frac{\rho_{v \epsilon}}{\sigma_{\epsilon}}\right) \sigma_{\bar{\alpha}}^{2}+\rho_{\bar{\zeta} \bar{v}}}{\sigma_{\underline{\zeta}} \sigma_{\underline{v}}} .
$$

Having assumed a conditional distribution for $\alpha_{i}$, the $\mathrm{R} \& \mathrm{D}$ equations for the $\mathrm{R} \& \mathrm{D}$ switching regression model can now be written as

$$
r_{1 t}=\mathbf{z}_{t}^{r \prime} \beta+\beta_{f}+\beta_{1}(.)+\mu \hat{\alpha}+\rho_{\eta_{1} \epsilon} \frac{\sigma_{\eta_{1}}}{\sigma_{\epsilon}} \hat{\epsilon}_{t}+\underline{\eta}_{1 t},
$$

if $f_{i t}^{*}>0$,

$$
r_{0 t}=\mathbf{z}_{t}^{r \prime} \beta+\beta_{0}(.)+\mu \hat{\alpha}+\rho_{\eta_{0} \epsilon} \frac{\sigma_{\eta_{0}}}{\sigma_{\epsilon}} \hat{\epsilon}_{t}+\underline{\eta}_{0 t},
$$

if $f_{t}^{*} \leq 0$. The error terms $\underline{\eta}_{1 i t}$ and $\underline{\eta}_{0 i t}$ are respectively given by $\underline{\eta}_{1 i t}=\left(\mu-\frac{\rho_{\eta_{1} \epsilon}}{\sigma_{\epsilon}}\right) \bar{\alpha}_{i}+\bar{\eta}_{1 i t}$ and $\underline{\eta}_{0 i t}=\left(\mu-\frac{\rho_{\eta_{0} \epsilon}}{\sigma_{\epsilon}}\right) \bar{\alpha}_{i}+\bar{\eta}_{0 i t}$, which by assumption, are normally distributed with mean zero and variances $\sigma_{\underline{\eta}_{1}}^{2}=\left(\mu-\frac{\rho_{\eta_{1} \epsilon}}{\sigma_{\epsilon}}\right)^{2} \sigma_{\bar{\alpha}}^{2}+\sigma_{\bar{\eta}_{1}}^{2}$ and $\sigma_{\underline{\eta}_{0}}^{2}=\left(\mu-\frac{\rho_{\eta_{0} \epsilon}}{\sigma_{\epsilon}}\right)^{2} \sigma_{\bar{\alpha}}^{2}+\sigma_{\bar{\eta}_{0}}^{2}$ respectively. We finally note that $\underline{\eta}_{1 i t}$ and 
$\underline{\eta}_{0 i t}$ are correlated with $\underline{\zeta}_{i t}$ and $\underline{v}_{i t}$. The correlation between $\underline{\eta}_{1 i t}$ and $\underline{\zeta}_{i t}$ and between $\underline{\eta}_{1 i t}$ and $\underline{v}_{i t}$ are respectively given by

$$
\rho_{\underline{\eta}_{1} \underline{\zeta}}=\frac{\left(\mu-\frac{\rho_{\eta_{1} \epsilon}}{\sigma_{\epsilon}}\right)\left(\lambda-\frac{\rho_{\zeta \epsilon}}{\sigma_{\epsilon}}\right) \sigma_{\bar{\alpha}}^{2}+\rho_{\bar{\eta}_{1} \bar{\zeta}}}{\sigma_{\underline{\eta}_{1}} \sigma_{\underline{\zeta}}} \quad \text { and } \quad \rho_{\underline{\eta}_{1} \underline{v}}=\frac{\left(\mu-\frac{\rho_{\eta_{1} \epsilon}}{\sigma_{\epsilon}}\right)\left(\theta-\frac{\rho_{v \epsilon}}{\sigma_{\epsilon}}\right) \sigma_{\bar{\alpha}}^{2}+\rho_{\bar{\eta}_{1} \bar{v}}}{\sigma_{\underline{\eta}_{1}} \sigma_{\underline{v}}} \text {. }
$$

Replacing the 1's above with 0 's we get the correlation between $\underline{\eta}_{0 i t}$ and $\underline{\zeta}_{i t}$ and between $\underline{\eta}_{0 i t}$ and $\underline{v}_{i t}$ respectively.

\section{B Derivation of the Correction Terms}

To avoid complicating the notations, we denote the error components, $\underline{\eta}_{1}, \underline{\eta}_{0}, \underline{\zeta}$ and $\underline{v}$ of equations (12a), (12b), (13) and (14) respectively as $\eta_{1}, \eta_{0}, \zeta$ and $v$. We know that the conditional expectation of $\eta$, where $\eta$ is either $\eta_{1}$ or $\eta_{0}$, given $\zeta$ and $v, \mathrm{E}[\eta \mid \zeta, v]$, is given by

$$
\mathrm{E}[\eta \mid \zeta, v]=\mu_{\eta}+\frac{\sigma_{\eta}\left(\rho_{\eta \zeta}-\rho_{\eta v} \rho_{\zeta v}\right)\left(\zeta-\mu_{\zeta}\right)}{\sigma_{\zeta}\left(1-\rho_{\zeta v}^{2}\right)}+\frac{\sigma_{\eta}\left(\rho_{\eta v}-\rho_{\eta \zeta} \rho_{\zeta v}\right)\left(v-\mu_{v}\right)}{\sigma_{v}\left(1-\rho_{\zeta v}^{2}\right)}
$$

Since, $\mu_{\eta}=\mu_{\zeta}=\mu_{v}=0$ we have,

$$
\mathrm{E}[\eta \mid \zeta, v]=\frac{\sigma_{\eta}\left(\rho_{\eta \zeta}-\rho_{\eta v} \rho_{\zeta v}\right)(\zeta)}{\sigma_{\zeta}\left(1-\rho_{\zeta v}^{2}\right)}+\frac{\sigma_{\eta}\left(\rho_{\eta v}-\rho_{\eta \zeta} \rho_{\zeta v}\right)(v)}{\sigma_{v}\left(1-\rho_{\zeta v}^{2}\right)}
$$

Define, $\bar{\zeta}=\frac{\zeta}{\sigma_{\zeta}}$ and $\bar{v}=\frac{v}{\sigma_{v}}$, then

$$
\mathrm{E}[\eta \mid \zeta, v]=\frac{\sigma_{\eta}\left(\rho_{\eta \zeta}-\rho_{\eta v} \rho_{\zeta v}\right) \bar{\zeta}}{\left(1-\rho_{\zeta v}^{2}\right)}+\frac{\sigma_{\eta}\left(\rho_{\eta v}-\rho_{\eta \zeta} \rho_{\zeta v}\right) \bar{v}}{\left(1-\rho_{\zeta v}^{2}\right)}
$$

which can be written as

$$
\mathrm{E}[\eta \mid \zeta, v]=\frac{\sigma_{\eta} \rho_{\eta \zeta}}{\left(1-\rho_{\zeta v}^{2}\right)}\left(\bar{\zeta}-\rho_{\zeta v} \bar{v}\right)+\frac{\sigma_{\eta} \rho_{\eta v}}{\left(1-\rho_{\zeta v}^{2}\right)}\left(\bar{v}-\rho_{\zeta v} \bar{\zeta}\right)
$$

Hence,

$$
\begin{aligned}
& \mathrm{E}[\eta \mid \zeta>-a, v>-b]=\mathrm{E}\left[\eta \mid \bar{\zeta}>\frac{-a}{\sigma_{\zeta}}, \bar{v}>\frac{-b}{\sigma_{v}}\right]=\frac{\int_{\frac{-b}{\sigma_{v}}}^{\infty} \int_{\frac{-a}{\sigma_{\zeta}}}^{\infty} \mathrm{E}[\eta \mid \bar{\zeta}, \bar{v}] \phi_{2}\left(\bar{\zeta}, \bar{v}, \rho_{\zeta v}\right) d \bar{\zeta} d \bar{v}}{\Phi_{2}\left(\frac{a}{\sigma_{\zeta}}, \frac{b}{\sigma_{v}}, \rho_{\zeta v}\right)} \\
& =\frac{1}{\Phi_{2}\left(\frac{a}{\sigma_{\zeta}}, \frac{b}{\sigma_{v}}, \rho_{\zeta v}\right)} \frac{\sigma_{\eta} \rho_{\eta \zeta}}{\left(1-\rho_{\zeta v}^{2}\right)} \int_{\frac{-b}{\sigma_{v}}}^{\infty} \int_{\frac{-a}{\sigma_{\zeta}}}^{\infty}\left(\bar{\zeta}-\rho_{\zeta v} \bar{v}\right) \phi_{2}\left(\bar{\zeta}, \bar{v}, \rho_{\zeta v}\right) d \bar{\zeta} d \bar{v} \\
& +\frac{1}{\Phi_{2}\left(\frac{a}{\sigma_{\zeta}}, \frac{b}{\sigma_{v}}, \rho_{\zeta v}\right)} \frac{\sigma_{\eta} \rho_{\eta v}}{\left(1-\rho_{\zeta v}^{2}\right)} \int_{\frac{-b}{\sigma_{v}}}^{\infty} \int_{\frac{-a}{\sigma_{\zeta}}}^{\infty}\left(\bar{v}-\rho_{\zeta v} \bar{\zeta}\right) \phi_{2}\left(\bar{\zeta}, \bar{v}, \rho_{\zeta v}\right) d \bar{\zeta} d \bar{v},
\end{aligned}
$$


where, $\phi_{2}$ and $\Phi_{2}$ denote respectively the density and cumulative density function function of a standard bivariate normal. Now, consider the expression $\int_{\frac{-b}{\sigma_{v}}}^{\infty} \int_{\frac{-a}{\sigma_{\zeta}}}^{\infty}\left(\bar{\zeta}-\rho_{\zeta v} \bar{v}\right) \phi_{2}\left(\bar{\zeta}, \bar{v}, \rho_{\zeta v}\right) d \bar{\zeta} d \bar{v}$, of the RHS in (B-2). Given that $\phi_{2}\left(\bar{\zeta}, \bar{v}, \rho_{\zeta v}\right)=\phi(\bar{\zeta}) \frac{1}{\sqrt{\left(1-\rho_{\zeta v}^{2}\right)}} \phi\left(\frac{\bar{v}-\rho_{\zeta v} \bar{\zeta}}{\sqrt{\left(1-\rho_{\zeta v}^{2}\right)}}\right)$, the concerned expression can be written as

$$
\begin{array}{r}
\int_{\frac{-b}{\sigma_{v}}}^{\infty} \int_{\frac{-a}{\sigma_{\zeta}}}^{\infty}\left(\bar{\zeta}-\rho_{\zeta v} \bar{v}\right) \phi(\bar{\zeta}) \frac{1}{\sqrt{\left(1-\rho_{\zeta v}^{2}\right)}} \phi\left(\frac{\bar{v}-\rho_{\zeta v} \bar{\zeta}}{\sqrt{\left(1-\rho_{\zeta v}^{2}\right)}}\right) d \bar{\zeta} d \bar{v}= \\
\int_{\frac{-a}{\sigma_{\zeta}}}^{\infty} \bar{\zeta} \phi(\bar{\zeta})\left(1-\Phi\left(\frac{\frac{-b}{\sigma_{v}}-\rho_{\zeta v} \bar{\zeta}}{\sqrt{\left(1-\rho_{\zeta v}^{2}\right)}}\right)\right) d \bar{\zeta}-\rho_{\zeta v} \int_{\frac{-b}{\sigma_{v}}}^{\infty} \int_{\frac{-a}{\sigma_{\zeta}}}^{\infty} \bar{v} \phi(\bar{\zeta}) \frac{1}{\sqrt{\left(1-\rho_{\zeta v}^{2}\right)}} \phi\left(\frac{\bar{v}-\rho_{\zeta v} \bar{\zeta}}{\sqrt{\left(1-\rho_{\zeta v}^{2}\right)}}\right) d \bar{\zeta} d \bar{v}
\end{array}
$$

Now, let $y=\frac{\bar{v}-\rho_{\zeta v} \bar{\zeta}}{\sqrt{\left(1-\rho_{\zeta v}^{2}\right)}}$, then $d y=\frac{d \bar{v}}{\sqrt{\left(1-\rho_{\zeta v)}^{2}\right)}}$. Having defined $y$, the right hand side of (B-3) can now be written as

$$
\begin{aligned}
& \left.\int_{\frac{-a}{\sigma_{\zeta}}}^{\infty} \bar{\zeta} \phi(\bar{\zeta})\left(1-\Phi\left(\frac{\frac{-b}{\sigma_{v}}-\rho_{\zeta v} \bar{\zeta}}{\sqrt{\left(1-\rho_{\zeta v}^{2}\right)}}\right)\right) d \bar{\zeta}-\rho_{\zeta v} \int_{\frac{-b}{\bar{\sigma} v}-\rho_{\zeta v \bar{\zeta}}}^{\infty} \int_{\frac{-a}{\sigma_{\zeta}}}^{\infty}\left(y \sqrt{\left(1-\rho_{\zeta v}^{2}\right.} \rho_{\zeta v}^{2}\right)+\rho_{\zeta v} \bar{\zeta}\right) \phi(\bar{\zeta}) \phi(y) d \bar{\zeta} d y \\
& =\int_{\frac{-a}{\sigma_{\zeta}}}^{\infty} \bar{\zeta} \phi(\bar{\zeta})\left(1-\Phi\left(\frac{\frac{-b}{\sigma_{v}}-\rho_{\zeta v} \bar{\zeta}}{\sqrt{\left(1-\rho_{\zeta v}^{2}\right)}}\right)\right) d \bar{\zeta}
\end{aligned}
$$

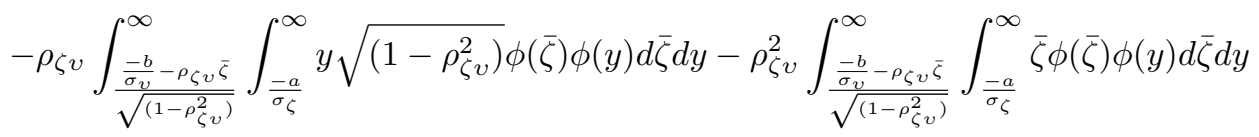

$$
\begin{aligned}
& =\left(1-\rho_{\zeta v}^{2}\right) \int_{\frac{-a}{\sigma_{\zeta}}}^{\infty} \bar{\zeta} \phi(\bar{\zeta})\left(1-\Phi\left(\frac{\frac{-b}{\sigma_{v}}-\rho_{\zeta v} \bar{\zeta}}{\sqrt{\left(1-\rho_{\zeta v}^{2}\right)}}\right)\right) d \bar{\zeta}-\rho_{\zeta v} \sqrt{\left(1-\rho_{\zeta v}^{2}\right)} \int_{\frac{\frac{-b}{\sigma v}-\rho_{\zeta v \bar{\zeta}}}{\sqrt{\left(1-\rho_{\zeta v}^{2}\right)}}}^{\infty} \int_{\frac{-a}{\sigma_{\zeta}}}^{\infty} y \phi(\bar{\zeta}) \phi(y) d \bar{\zeta} d y \\
& =\left(1-\rho_{\zeta v}^{2}\right) \int_{\frac{-a}{\sigma_{\zeta}}}^{\infty} \bar{\zeta} \phi(\bar{\zeta}) \Phi\left(\frac{\frac{b}{\sigma_{v}}+\rho_{\zeta v} \bar{\zeta}}{\sqrt{\left(1-\rho_{\zeta v}^{2}\right)}}\right) d \bar{\zeta}-\rho_{\zeta v} \sqrt{\left(1-\rho_{\zeta v}^{2}\right)} \int_{\frac{\frac{-b}{\sigma v}-\rho_{\zeta v} \bar{\zeta}}{\sqrt{\left(1-\rho_{\zeta v}^{2}\right)}}}^{\infty} \int_{\frac{-a}{\sigma_{\zeta}}}^{\infty} y \phi(\bar{\zeta}) \phi(y) d \bar{\zeta} d y .
\end{aligned}
$$


Now, note that $\bar{\zeta} \phi(\bar{\zeta}) d \bar{\zeta}=-d \phi(\bar{\zeta})$ and $\phi(\bar{\zeta})=\phi(-\bar{\zeta})$, hence using integration by parts, the first part of the last equation of (B-5) can now be written as

$$
\begin{aligned}
& \left(1-\rho_{\zeta v}^{2}\right) \int_{\frac{-a}{\sigma_{\zeta}}}^{\infty} \bar{\zeta} \phi(\bar{\zeta}) \Phi\left(\frac{\frac{b}{\sigma_{v}}+\rho_{\zeta v} \bar{\zeta}}{\sqrt{\left(1-\rho_{\zeta v}^{2}\right)}}\right) d \bar{\zeta}=\left(1-\rho_{\zeta v}^{2}\right) \int_{\frac{-a}{\sigma_{\zeta}}}^{\infty}-d \phi(\bar{\zeta}) \Phi\left(\frac{\frac{b}{\sigma_{v}}+\rho_{\zeta v} \bar{\zeta}}{\sqrt{\left(1-\rho_{\zeta v}^{2}\right)}}\right) \\
= & -\left.\left(1-\rho_{\zeta v}^{2}\right) \phi(\bar{\zeta}) \Phi\left(\frac{\frac{b}{\sigma_{v}}+\rho_{\zeta v} \bar{\zeta}}{\sqrt{\left(1-\rho_{\zeta v}^{2}\right)}}\right)\right|_{\frac{-a}{\sigma_{\zeta}}} ^{\infty}+\rho_{\zeta v} \sqrt{\left(1-\rho_{\zeta v}^{2}\right)} \int_{\frac{-a}{\sigma_{\zeta}}}^{\infty} \phi(\bar{\zeta}) \phi\left(\frac{\frac{b}{\sigma_{v}}+\rho_{\zeta v} \bar{\zeta}}{\sqrt{\left(1-\rho_{\zeta v}^{2}\right)}}\right) d \bar{\zeta} \\
= & \left(1-\rho_{\zeta v}^{2}\right) \phi\left(\frac{a}{\sigma_{\zeta}}\right) \Phi\left(\frac{\frac{b}{\sigma_{v}}-\rho_{\zeta v} \frac{a}{\sigma_{\zeta}}}{\sqrt{\left(1-\rho_{\zeta v}^{2}\right)}}\right)+\rho_{\zeta v} \sqrt{\left(1-\rho_{\zeta v}^{2}\right)} \int_{\frac{-a}{\sigma_{\zeta}}}^{\infty} \phi(\bar{\zeta}) \phi\left(\frac{\frac{b}{\sigma_{v}}+\rho_{\zeta v} \bar{\zeta}}{\sqrt{\left(1-\rho_{\zeta v}^{2}\right)}}\right) d \bar{\zeta} .
\end{aligned}
$$

The second expression of the last line in equation (B-5) can be written as

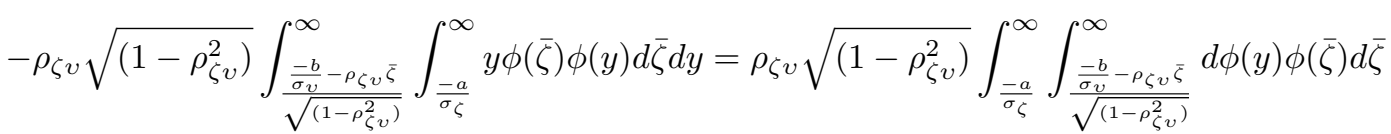

$$
\begin{aligned}
& =\left.\rho_{\zeta v} \sqrt{\left(1-\rho_{\zeta v}^{2}\right)} \int_{\frac{-a}{\sigma_{\zeta}}}^{\infty} \phi(y)\right|_{\frac{\frac{-b}{\sigma_{v}}-\rho_{\zeta v \bar{\zeta}}}{\sqrt{\left(1-\rho_{\zeta v}^{2}\right)}}} ^{\infty} \phi(\bar{\zeta}) d \bar{\zeta}=-\rho_{\zeta v} \sqrt{\left(1-\rho_{\zeta v}^{2}\right)} \int_{\frac{-a}{\sigma_{\zeta}}}^{\infty} \phi\left(\frac{\frac{b}{\sigma_{v}}+\rho_{\zeta v} \bar{\zeta}}{\sqrt{\left(1-\rho_{\zeta v}^{2}\right)}}\right) \phi(\bar{\zeta}) d \bar{\zeta} .
\end{aligned}
$$

Plugging the results obtained in (B-6) and (B-7) into (B-4), we obtain

$$
\int_{\frac{-b}{\sigma_{v}}}^{\infty} \int_{\frac{-a}{\sigma_{\zeta}}}^{\infty}\left(\bar{\zeta}-\rho_{\zeta v} \bar{v}\right) \phi_{2}\left(\bar{\zeta}, \bar{v}, \rho_{\zeta v}\right) d \bar{\zeta} d \bar{v}=\left(1-\rho_{\zeta v}^{2}\right) \phi\left(\frac{a}{\sigma_{\zeta}}\right) \Phi\left(\frac{\frac{b}{\sigma_{v}}-\rho_{\zeta v} \frac{a}{\sigma_{\zeta}}}{\sqrt{\left(1-\rho_{\zeta v}^{2}\right)}}\right)
$$

Similarly, it can be shown that

$$
\int_{\frac{-b}{\sigma_{v}}}^{\infty} \int_{\frac{-a}{\sigma_{\zeta}}}^{\infty}\left(\bar{v}-\rho_{\zeta v} \bar{\zeta}\right) \phi_{2}\left(\bar{\zeta}, \bar{v}, \rho_{\zeta v}\right) d \bar{\zeta} d \bar{v}=\left(1-\rho_{\zeta v}^{2}\right) \phi\left(\frac{b}{\sigma_{v}}\right) \Phi\left(\frac{\frac{a}{\sigma_{\zeta}}-\rho_{\zeta v} \frac{b}{\sigma_{v}}}{\sqrt{\left(1-\rho_{\zeta v}^{2}\right)}}\right)
$$

Hence,

$$
\mathrm{E}\left[\eta \mid \bar{\zeta}>\frac{-a}{\sigma_{\zeta}}, \bar{v}>\frac{-b}{\sigma_{v}}\right]=\frac{\sigma_{\eta} \rho_{\eta \zeta} \phi\left(\frac{a}{\sigma_{\zeta}}\right)}{\Phi_{2}\left(\frac{a}{\sigma_{\zeta}}, \frac{b}{\sigma_{v}}, \rho_{\zeta v}\right)} \Phi\left(\frac{\frac{b}{\sigma_{v}}-\rho_{\zeta v} \frac{a}{\sigma_{\zeta}}}{\sqrt{\left(1-\rho_{\zeta v}^{2}\right)}}\right)+\frac{\sigma_{\eta} \rho_{\eta v} \phi\left(\frac{b}{\sigma_{v}}\right)}{\Phi_{2}\left(\frac{a}{\sigma_{\zeta}}, \frac{b}{\sigma_{v}}, \rho_{\zeta v}\right)} \Phi\left(\frac{\frac{a}{\sigma_{\zeta}}-\rho_{\zeta v} \frac{b}{\sigma_{v}}}{\sqrt{\left(1-\rho_{\zeta v}^{2}\right)}}\right)
$$


Now, consider

$$
\begin{aligned}
& \mathrm{E}[\eta \mid \zeta \leq-a, v>-b]=\mathrm{E}\left[\eta \mid \bar{\zeta} \leq \frac{-a}{\sigma_{\zeta}}, \bar{v}>\frac{-b}{\sigma_{v}}\right]=\frac{\int_{\frac{-b}{\sigma_{v}}}^{\infty} \int_{-\infty}^{\frac{-a}{\sigma_{\zeta}}} \mathrm{E}[\eta \mid \bar{\zeta}, \bar{v}] \phi_{2}\left(\bar{\zeta}, \bar{v}, \rho_{\zeta v}\right) d \bar{\zeta} d \bar{v}}{\Phi_{2}\left(\frac{-a}{\sigma_{\zeta}}, \frac{b}{\sigma_{v}},-\rho_{\zeta v}\right)} \\
& =\frac{1}{\Phi_{2}\left(\frac{-a}{\sigma_{\zeta}}, \frac{b}{\sigma_{v}},-\rho_{\zeta v}\right)} \frac{\sigma_{\eta} \rho_{\eta \zeta}}{\left(1-\rho_{\zeta v}^{2}\right)} \int_{\frac{-b}{\sigma_{v}}}^{\infty} \int_{-\infty}^{\frac{-a}{\sigma_{\zeta}}}\left(\bar{\zeta}-\rho_{\zeta v} \bar{v}\right) \phi_{2}\left(\bar{\zeta}, \bar{v}, \rho_{\zeta v}\right) d \bar{\zeta} d \bar{v} \\
& +\frac{1}{\Phi_{2}\left(\frac{-a}{\sigma_{\zeta}}, \frac{b}{\sigma_{v}},-\rho_{\zeta v}\right)} \frac{\sigma_{\eta} \rho_{\eta v}}{\left(1-\rho_{\zeta v}^{2}\right)} \int_{\frac{-b}{\sigma_{v}}}^{\infty} \int_{-\infty}^{\frac{-a}{\sigma_{\zeta}}}\left(\bar{v}-\rho_{\zeta v} \bar{\zeta}\right) \phi_{2}\left(\bar{\zeta}, \bar{v}, \rho_{\zeta v}\right) d \bar{\zeta} d \bar{v} .
\end{aligned}
$$

By a method analogous to that used in deriving (B-8), it can be shown that

$$
\mathrm{E}\left[\eta \mid \bar{\zeta} \leq \frac{-a}{\sigma_{\zeta}}, \bar{v}>\frac{-b}{\sigma_{v}}\right]=\frac{-\sigma_{\eta} \rho_{\eta \zeta} \phi\left(\frac{a}{\sigma_{\zeta}}\right)}{\Phi_{2}\left(\frac{-a}{\sigma_{\zeta}}, \frac{b}{\sigma_{v}},-\rho_{\zeta v}\right)} \Phi\left(\frac{\frac{b}{\sigma_{v}}-\rho_{\zeta v} \frac{a}{\sigma_{\zeta}}}{\sqrt{\left(1-\rho_{\zeta v}^{2}\right)}}\right)+\frac{\sigma_{\eta} \rho_{\eta v} \phi\left(\frac{b}{\sigma_{v}}\right)}{\Phi_{2}\left(\frac{-a}{\sigma_{\zeta}}, \frac{b}{\sigma_{v}},-\rho_{\zeta v}\right)} \Phi\left(\frac{\frac{-a}{\sigma_{\zeta}}+\rho_{\zeta v} \frac{b}{\sigma_{v}}}{\sqrt{\left(1-\rho_{\zeta v}^{2}\right)}}\right) .
$$

\section{C Asymptotic Covariance Matrix of the Second and Third Stage Estimates}

In this section we give the asymptotic covariance matrix of the coefficients of the second stage and third stage R\&D switching regression model. Newey (1984) has shown that sequential estimators can be interpreted as members of a class of Method of Moments (MM) estimators and that this interpretation facilitates derivation of asymptotic covariance matrices for multi-step estimators. Let $\Theta=\left\{\Theta_{1}, \Theta_{2}, \Theta_{3}\right\}$, where $\Theta_{1}, \Theta_{2}$, and $\Theta_{3}$ are respectively the parameters to be estimated in the first, second and third step estimation of the sequential estimator. Following Newey (1984) we write the first, second, and third step estimation as an MM estimation based on the following population moment conditions:

$$
\begin{gathered}
E\left(L_{i 1 \Theta_{1}}\right)=E \frac{\partial \ln L_{i 1}\left(\Theta_{1}\right)}{\partial \Theta_{1}}=0 \\
E\left(L_{i 2 \Theta_{2}}\right)=E \frac{\partial \ln L_{i 2}\left(\Theta_{1}, \Theta_{2}, \hat{\alpha}_{i}\left(., \Theta_{1}\right), \hat{\epsilon}_{i t}\left(., \Theta_{1}\right)\right)}{\partial \Theta_{2}}=0
\end{gathered}
$$

and

$$
E\left[F_{i t}\left(X_{i t}, \Theta_{1}, \Theta_{2}, \Theta_{3}\right)\right]=E\left[s_{i t} X_{i t}\left(r_{i t}-X_{i t}^{\prime} \Theta_{3}\right)\right]=0
$$


where $L_{i 1}\left(\Theta_{1}\right)$ is the likelihood function for individual $i$, for the first step reduced form long-term debt equation. $L_{i 2}\left(\Theta_{1}, \Theta_{2}, \hat{\alpha}_{i}\left(., \Theta_{1}\right)\right)$ is the likelihood function for the second step estimation in which the joint probability of a firm being an innovator and the firm being financially constrained is estimated. Equation (C-3) is the first order condition for minimizing the sum of squared error for the pooled OLS regression of $X_{i t}$ on $r_{i t}$ for those firms, that have been selected, $s_{i t}=1 . X_{i t}=\left\{f_{i t}, \mathbf{z}_{i t}^{r \prime}\right.$, $C F_{i t}, L Q_{i t}, S I N S_{i t-1, t}, D I V_{i t}, \hat{\alpha}_{i}\left(., \Theta_{1}\right), C_{11}\left(., \Theta_{1}\right)_{i t}, C_{12}\left(., \Theta_{1}, \Theta_{2}\right)_{i t}, C_{13}\left(., \Theta_{1}, \Theta_{2}\right)_{i t}, C_{01}\left(., \Theta_{1}\right)_{i t}$, $C_{02}\left(., \Theta_{1}, \Theta_{2}\right)_{i t}, C_{03}\left(., \Theta_{1}, \Theta_{2}\right)_{i t}$, Industry Dummies, Time Dummies $\}$ and $\hat{\alpha}_{i}\left(., \Theta_{1}\right) \equiv \hat{\alpha}_{i}\left(d_{i}, Z_{i}, \Theta_{1}\right)$ is the expected a posteriori (EAP) values, based on the first stage reduced form estimates.

The estimates for $\Theta_{1}, \Theta_{2}$, and $\Theta_{3}$ are obtained by solving the sample analog of the above population moment conditions. The sample analog of moment conditions for the first step estimation is given by

$$
\frac{1}{N} L_{1 \hat{\Theta}_{1}}=\frac{1}{N} \sum_{i=1}^{N} L_{i 1 \hat{\Theta}_{1}}=\frac{1}{N} \sum_{i=1}^{N} \frac{\partial \ln L_{i 1}\left(\hat{\Theta}_{1}\right)}{\partial \Theta_{1}}
$$

where $L_{i 1}\left(\Theta_{1}\right)$ is given by equation $(25), \Theta_{1}=\left\{\delta, \sigma_{\epsilon}, \sigma_{\alpha}\right\}$ and $N$ is the total number of individuals/firms. Under standard regularity conditions, the first step, reduced form ML estimate, $\hat{\Theta}_{1}$, is consistent and the asymptotic covariance matrix of $\hat{\Theta}_{1}$ coincides with asymptotic covariance matrix obtained in the ML estimation.

The sample analog of population moment condition for the second step estimation is given by

$$
\frac{1}{N} L_{2 \hat{\Theta}_{2}}=\frac{1}{N} \sum_{i=1}^{N} L_{i 2 \hat{\Theta}_{2}}=\frac{1}{N} \sum_{i=1}^{N} \sum_{t=1}^{T_{i}} \frac{\partial \ln L_{i t 2}\left(\hat{\Theta}_{1}, \hat{\Theta}_{2}, \hat{\alpha}_{i}\left(., \hat{\Theta}_{1}\right), \hat{\epsilon}_{i t}\left(., \hat{\Theta}_{1}\right)\right)}{\partial \Theta_{2}}
$$

where $L_{i t 2}\left(\Theta_{1}, \Theta_{2}, \hat{\alpha}_{i}\left(., \Theta_{1}\right), \hat{\epsilon}_{i t}\left(., \Theta_{1}\right)\right)$ is given by equation (31) and $\Theta_{2}=\left\{\varphi \frac{1}{\sigma_{\underline{\zeta}}}, \frac{\varphi_{d}}{\sigma_{\underline{\zeta}}}, \frac{\lambda}{\sigma_{\underline{\zeta}}}, \frac{\rho_{\zeta \epsilon}}{\sigma_{\underline{\zeta}}} ; \gamma \frac{1}{\sigma_{\underline{v}}}\right.$, $\left.\frac{\gamma_{d}}{\sigma_{\underline{v}}}, \frac{\theta}{\sigma_{\underline{v}}}, \frac{\rho_{v \epsilon}}{\sigma_{\underline{v}}} ; \rho_{\underline{\underline{\underline{v}}}}\right\}$. In Appendix A, we have shown, that with $\alpha_{i}$ substitute by their EAP values $\hat{\alpha}_{i}\left(d_{i}, z_{i}, \Theta_{1}\right)$ still leads to the identification of $\Theta_{2}$. Let $\Theta_{1}^{*}$ and $\Theta_{2}^{*}$, respectively be the true values of $\Theta_{1}, \Theta_{2}$. Under the assumptions we make, maximizing $L_{i 2}\left(\hat{\Theta}_{1}, \Theta_{2},.\right)$ is asymptotically equivalent to maximizing $L_{i 2}\left(\Theta_{1}^{*}, \Theta_{2},.\right)$, where $\hat{\Theta}_{1}$ is a consistent first step estimate of $\Theta_{1}$. Murphy and Topel (1985) and Newey (1984), have derived the asymptotic distribution of the second step estimates of a two step sequential estimator.

Murphy and Topel have shown that the second step ML estimate of $\Theta_{2}$ is consistent and asymp- 
totically normally distributed with asymptotic covariance matrix given by

$$
V_{2}^{*}=\frac{1}{N}\left[V_{2}+V_{2}\left[R_{2} V_{1} R_{2}^{\prime}-R_{1} V_{1} R_{2}^{\prime}-R_{2} V_{1} R_{1}^{\prime}\right] V_{2}\right]
$$

where $V_{1}$ is the asymptotic covariance matrix of $\sqrt{N}\left(\hat{\Theta}_{1}-\Theta_{1}^{*}\right)$ based on maximization of $L_{1}\left(\Theta_{1}\right)$, $V_{2}$ is the asymptotic covariance matrix of $\sqrt{N}\left(\hat{\Theta}_{2}-\Theta_{2}^{*}\right)$ based on maximization of $L_{2}\left(\Theta_{1}, \Theta_{2}, \alpha_{i}\right)$ conditional on $\Theta_{1}$ and $\alpha_{i}$,

$$
R_{1}=E\left[\frac{1}{N}\left(\frac{\partial \ln L_{2}}{\partial \Theta_{2}}\right)\left(\frac{\partial \ln L_{1}}{\partial \Theta_{1}^{\prime}}\right)\right]
$$

and

$$
R_{2}=E\left[\frac{1}{N}\left(\frac{\partial \ln L_{2}}{\partial \Theta_{2}}\right)\left(\frac{\partial \ln L_{2}}{\partial \Theta_{1}^{\prime}}\right)\right]
$$

The sample analog of $R_{1}$ and $R_{2}$ are given by

$$
\hat{R}_{1}=\frac{1}{N} \sum_{i=1}^{N}\left(\frac{\partial \sum_{t=1}^{T_{i}} \ln L_{i t 2}}{\partial \Theta_{2}}\right)\left(\frac{\partial \ln L_{i 1}}{\partial \Theta_{1}^{\prime}}\right)
$$

and

$$
\hat{R}_{2}=\frac{1}{N} \sum_{i=1}^{N}\left(\frac{\partial \sum_{t=1}^{T_{i}} \ln L_{i t 2}}{\partial \Theta_{2}}\right)\left(\frac{\partial \sum_{t=1}^{T_{i}} \ln L_{i t 2}}{\partial \Theta_{1}^{\prime}}\right)
$$

where the derivatives are evaluated at $\hat{\Theta}_{1}$ and $\hat{\Theta}_{2}$. Let $\Theta_{2 f}$ and $\Theta_{2 s}$ respectively denote the parameters of the financial constraint and the selection equation of the second step. Since the second step is essentially a combination of Heckman and bivariate probit, $\frac{\partial \ln L_{2}}{\partial \Theta_{2}}$ and $\frac{\partial \ln L_{2}}{\partial \Theta_{1}}$ both involve taking the derivative of cumulative density function of a standard bivariate normal with respect to $\Theta_{2 f}, \Theta_{2 s}, \rho_{\underline{\zeta} \underline{v}}$ and $\Theta_{1}$, and evaluated at $\hat{\Theta}_{2 f}, \hat{\Theta}_{2 s}, \hat{\rho}_{\underline{\underline{v}}}$, and $\hat{\Theta}_{1}$. The score functions of a bivariate probit are stated in Greene (2002). Murphy and Topel (1985) and Newey (1984), derive the asymptotic distribution of the second step estimates of a two step sequential estimator only for a single cross section of the data. However, since we are dealing with panel data, the derivative of EAPs, $\hat{\alpha}_{i}\left(d_{i}, z_{i}, \delta, \sigma_{\epsilon}, \sigma_{\alpha}\right)$ with respect to $\Theta_{1}=\left\{\delta, \sigma_{\epsilon}, \sigma_{\alpha}\right\}$, that appear in the likelihood $L_{i t 2}\left(\Theta_{1}, \Theta_{2},.\right)$ is also evaluated. That is, 
the derivative of $\hat{\alpha}_{i}\left(d_{i}, z_{i}, \delta, \sigma_{\epsilon}, \sigma_{\alpha}\right)$,

$$
\frac{\partial \hat{\alpha}_{i}\left(d_{i}, z_{i}, \delta, \sigma_{\epsilon}, \sigma_{\alpha}\right)}{\partial \Theta_{1}}=\frac{\partial}{\partial \Theta_{1}}\left(\frac{\int \sigma_{\alpha} \tilde{\alpha}_{i} \prod_{t=1}^{T_{i}} \frac{1}{\sigma_{\epsilon}} \phi\left(\frac{d_{i t}-z_{i t} \delta-\sigma_{\alpha} \tilde{\alpha}_{i}}{\sigma_{\epsilon}}\right) \phi\left(\tilde{\alpha}_{i}\right) d \tilde{\alpha}_{i}}{\boldsymbol{L}_{i 1}\left(\delta, \sigma_{\epsilon}, \sigma_{\alpha}\right)}\right)
$$

as an argument of $L_{i 2}\left(\Theta_{1}, \Theta_{2}, \alpha_{i}\right)$ is evaluated at $\hat{\Theta}_{1}=\left\{\hat{\delta}, \hat{\sigma}_{\epsilon}, \hat{\sigma}_{\alpha}\right\}$ for each individual.

To derive, the asymptotic distribution of the third step estimates $\Theta_{3}$ consider the Taylor's expansion of stacked up moment conditions

$$
\left[\begin{array}{c}
L_{1 \Theta_{1}}\left(\Theta_{1}\right) \\
L_{2 \Theta_{2}}\left(\Theta_{1}, \Theta_{2}\right) \\
F\left(\Theta_{1}, \Theta_{2}, \Theta_{3}\right)
\end{array}\right]
$$

where

$$
\frac{1}{N} F\left(\hat{\Theta}_{1}, \hat{\Theta}_{2}, \hat{\Theta}_{3}\right)=\frac{1}{N} \sum_{i=1}^{N} \sum_{t=1}^{T_{i}} F_{i t}\left(X_{i t}, \hat{\Theta}_{1}, \hat{\Theta}_{2}, \hat{\Theta}_{3}\right)=\frac{1}{N} \sum_{i=1}^{N} \sum_{t=1}^{T_{i}} s_{i t} X_{i t}(\hat{\Xi})\left(r_{i t}-X_{i t}(\hat{\Xi})^{\prime} \hat{\Theta}_{3}\right)
$$

is the sample analog of the population moment condition given in (C-3). A series of Taylor's expansion of $L_{1 \Theta_{1}}\left(\Theta_{1}\right), L_{2 \Theta_{2}}\left(\Theta_{1}, \Theta_{2}\right)$ and $F\left(\Theta_{1}, \Theta_{2}, \Theta_{3}\right)$ gives

$$
\frac{1}{N}\left[\begin{array}{ccc}
L_{1 \Theta_{1} \Theta_{1}} & 0 & 0 \\
L_{2 \Theta_{1} \Theta_{2}} & L_{2 \Theta_{2} \Theta_{2}} & 0 \\
F_{\Theta_{1}} & F_{\Theta_{2}} & F_{\Theta_{3}}
\end{array}\right]\left[\begin{array}{c}
\sqrt{N}\left(\Theta_{1}-\Theta_{1}^{*}\right) \\
\sqrt{N}\left(\Theta_{2}-\Theta_{2}^{*}\right) \\
\sqrt{N}\left(\Theta_{3}-\Theta_{3}^{*}\right)
\end{array}\right]=-\frac{1}{\sqrt{N}}\left[\begin{array}{c}
L_{1 \Theta_{1}} \\
L_{2 \Theta_{2}} \\
F
\end{array}\right]
$$

In matrix notation the above can be written as

$$
B_{N} \sqrt{N}\left(\Theta-\Theta^{*}\right)=-\frac{1}{\sqrt{N}} \Lambda_{N}
$$

Under the standard regularity conditions for Generalized Method of Moments (GMM), see Hansen (1982) and Newey (1984), $B_{N}$ converges in probability to the lower block triangular matrix $B_{*}=$ $\lim E B_{N}$ and $\frac{1}{\sqrt{N}} \Lambda_{N}$ converges in distribution to an asymptotically normal random variable with mean zero and a covariance matrix $A_{*}=\lim E \frac{1}{N} \Lambda_{N} \Lambda_{N}^{\prime}$, where $A_{*}$ is given by

$$
A_{*}=\left[\begin{array}{ccc}
V_{L_{1} L_{1}} & V_{L_{1} L_{2}} & V_{L_{1} F} \\
V_{L_{2} L_{1}} & V_{L_{2} L_{2}} & V_{L_{2} F} \\
V_{F L_{1}} & V_{F L_{2}} & V_{F F}
\end{array}\right]
$$


where a typical element of $A_{*}$, say $V_{L_{1} L_{2}}$ is given by $V_{L_{1} L_{2}}=\frac{1}{N} E\left[L_{1 \Theta_{1}}\left(\Theta_{1}\right) L_{2 \Theta_{2}}\left(\Theta_{1}, \Theta_{2}\right)^{\prime}\right]$. Under the regularity conditions $\sqrt{N}\left(\Theta-\Theta^{*}\right)$ is asymptotically normal with zero mean and covariance matrix given by $B_{*}^{-1} A_{*} B_{*}^{-1 \prime}$. To derive the asymptotic distribution of $\sqrt{N}\left(\Theta_{3}-\Theta_{3}^{*}\right)$ consider the partitioned matrix of $B_{*}$

$$
B_{*}=\frac{1}{N}\left[\begin{array}{cc}
{\left[\begin{array}{cc}
L_{1 \Theta_{1} \Theta_{1}} & 0 \\
L_{2 \Theta_{1} \Theta_{2}} & L_{2 \Theta_{2} \Theta_{2}}
\end{array}\right]} & {\left[\begin{array}{l}
0 \\
0
\end{array}\right]} \\
{\left[\begin{array}{ll}
F_{\Theta_{1}} & F_{\Theta_{2}}
\end{array}\right]} & {\left[\begin{array}{c}
F_{\Theta_{3}}
\end{array}\right]}
\end{array}\right],
$$

where with a slight abuse of notation we denote by $L_{1 \Theta_{1} \Theta_{1}}$ the expectation of $L_{1 \Theta_{1} \Theta_{1}}$. Then by an application of the partitioned inverse formula and by using the facts that $\left(\frac{1}{N} L_{1 \Theta_{1} \Theta_{1}}\right)^{-1} V_{L_{1} L_{1}}$ $\left(\frac{1}{N} L_{1 \Theta_{1} \Theta_{1}}\right)^{-1}=V_{1}$ and $\left(\frac{1}{N} L_{2 \Theta_{2} \Theta_{2}}\right)^{-1} V_{L_{2} L_{2}}\left(\frac{1}{N} L_{2 \Theta_{2} \Theta_{2}}\right)^{-1}=V_{2}$, where $V_{1}$ is the asymptotic covariance matrix of $\sqrt{N}\left(\hat{\Theta}_{1}-\Theta_{1}^{*}\right)$ based on maximization of $L_{1}\left(\Theta_{1}\right), V_{2}$ is the asymptotic covariance matrix of $\sqrt{N}\left(\hat{\Theta}_{2}-\Theta_{2}^{*}\right)$ based on maximization of $L_{2}\left(\Theta_{1}, \Theta_{2}, \alpha_{i}\right)$ conditional on $\Theta_{1}$ and $\alpha_{i}$, we arrive at the asymptotic distribution of $\sqrt{N}\left(\Theta_{3}-\Theta_{3}^{*}\right), V_{3}^{*}$, given by

$$
\begin{array}{r}
V_{3}^{*}=F_{\Theta_{3}}^{-1}\left\{\left[F_{\Theta_{1}}-\left[F_{\Theta_{2}} V_{2} L_{\Theta_{2} \Theta_{1}}\right] V_{1}\left(\left[F_{\Theta_{1}}-\left[F_{\Theta_{2}}^{\prime} V_{2} L_{\Theta_{2} \Theta_{1}}^{\prime}\right]\right]+V_{L_{1} L_{2}} V_{2} L_{\Theta_{2} \Theta_{2}}^{\prime}-V_{L_{1} F}\right)\right.\right. \\
\left.+F_{\Theta_{2}} V_{2}\left[V_{L_{2} L_{1}} V_{1}\left[F_{\Theta_{2}}^{\prime} V_{2} L_{\Theta_{2} \Theta_{1}}^{\prime}\right]+F_{\Theta_{2}}^{\prime}-V_{L_{2} F}\right]-V_{F L_{1}} V_{1}\left[F_{\Theta_{2}}^{\prime} V_{2} L_{\Theta_{2} \Theta_{1}}^{\prime}\right]-V_{F L_{2}} V_{2} F_{\Theta_{2}}^{\prime}\right\} F_{\Theta_{3}}^{-1 \prime}+F_{\Theta_{3}}^{-1}\left\{V_{F F}\right\} F_{\Theta_{3}}^{-1 \prime}
\end{array}
$$




\section{D Second and Third Stage Estimation Results}

\section{List of Variables}

$f$ : Dummy for financial constraints; SINS: Share of Innovative sales in the total sales of the firm; $D E B T$ : Long term debt to capital asset ratio; $C F$ : Ratio of cash flows to capital asset; $L Q$ : Ratio of cash reserves to capital asset; DIV: Dummy for positive dividends; MKSH: (Market Share) Ratio of total sales of the firm to the industry total sales; SIZE: Logarithm of the number of people employed; $A G E$ : Age of the firm in years ; RAINT: Ratio of intangible assets to total capital asset ratio; DNCF: Dummy for negative cash flows; DMULTI: Dummy that takes value 1 if the number of enterprises consolidated within a firm is more than one.

Table 6.3: Second Stage Estimates

\begin{tabular}{|c|c|c|c|c|c|c|}
\hline & $\begin{array}{r}\text { Financial } \\
\text { Constraints }\end{array}$ & Innovation & $\begin{array}{r}\text { Financial } \\
\text { Constraints } \\
\end{array}$ & Innovation & $\begin{array}{r}\text { Financial } \\
\text { Constraints } \\
\end{array}$ & Innovation \\
\hline & (A0) & (A1) & (B0) & (B1) & (C0) & (C1) \\
\hline$S I N S_{t}$ & $\begin{array}{l}0.010^{* * *} \\
(0.002)\end{array}$ & & $\begin{array}{c}0.010^{* * *} \\
(0.002)\end{array}$ & & $\begin{array}{l}0.009^{* * *} \\
(0.002)\end{array}$ & \\
\hline$D E B T_{t}$ & $\begin{array}{l}0.471^{* * *} \\
(0.149)\end{array}$ & $\begin{array}{l}-0.250^{* * *} \\
(0.061)\end{array}$ & $\begin{array}{l}0.468^{* * *} \\
(0.148)\end{array}$ & $\begin{array}{l}-0.250^{* * *} \\
(0.061)\end{array}$ & $\begin{array}{c}0.123^{* *} \\
(0.052)\end{array}$ & $\begin{array}{l}-0.248^{* * *} \\
(0.061)\end{array}$ \\
\hline$C F_{t}$ & $\begin{array}{l}0.009^{* *} \\
(0.004)\end{array}$ & & $\begin{array}{l}0.009^{* *} \\
(0.004)\end{array}$ & & & \\
\hline$L Q_{t}$ & $\begin{array}{l}-0.102^{* * *} \\
(0.031)\end{array}$ & $\begin{array}{l}0.048^{* * *} \\
(0.013)\end{array}$ & $\begin{array}{l}-0.102^{* * *} \\
(0.031)\end{array}$ & $\begin{array}{l}0.048^{* * *} \\
(0.012)\end{array}$ & $\begin{array}{l}-0.030^{* * *} \\
(0.012)\end{array}$ & $\begin{array}{l}0.048^{* * *} \\
(0.012)\end{array}$ \\
\hline$D I V_{t}$ & $\begin{array}{r}-0.031 \\
(0.081)\end{array}$ & $\begin{array}{l}-0.109^{* *} \\
(0.042)\end{array}$ & $\begin{array}{r}-0.031 \\
(0.081)\end{array}$ & $\begin{array}{l}-0.109^{* *} \\
(0.043)\end{array}$ & $\begin{array}{l}-0.178^{* * *} \\
(0.055)\end{array}$ & $\begin{array}{l}-0.110^{* * *} \\
(0.043)\end{array}$ \\
\hline$M K S H_{t}$ & $\begin{array}{l}-0.015^{* *} \\
(0.006)\end{array}$ & $\begin{array}{l}0.212^{\text {*** }} \\
(0.012)\end{array}$ & $\begin{array}{l}-0.015^{* *} \\
(0.006)\end{array}$ & $\begin{array}{l}0.212^{* * *} \\
(0.019)\end{array}$ & $\begin{array}{r}-0.002 \\
(0.004)\end{array}$ & $\begin{array}{l}0.215^{* * *} \\
(0.012)\end{array}$ \\
\hline$S I Z E_{t}$ & $\begin{array}{l}0.180^{* * *} \\
(0.012)\end{array}$ & $\begin{array}{l}0.101^{* * *} \\
(0.022)\end{array}$ & $\begin{array}{l}0.179^{* * *} \\
(0.012)\end{array}$ & $\begin{array}{l}0.101^{* * *} \\
(0.022)\end{array}$ & $\begin{array}{l}0.189^{* * *} \\
(0.012)\end{array}$ & $\begin{array}{l}0.101^{* * *} \\
(0.021)\end{array}$ \\
\hline$A G E_{t}$ & $\begin{array}{l}-0.001 \\
(0.002)\end{array}$ & $\begin{array}{l}-0.007^{* * *} \\
(0.001)\end{array}$ & $\begin{array}{r}-0.001 \\
(0.002)\end{array}$ & $\begin{array}{l}-0.007^{* * *} \\
(0.001)\end{array}$ & $\begin{array}{l}-0.003^{*} \\
(0.002)\end{array}$ & $\begin{array}{l}-0.007^{* * *} \\
(0.001)\end{array}$ \\
\hline$R A I N T_{t}$ & $\begin{array}{r}-0.042 \\
(0.112)\end{array}$ & $\begin{array}{l}0.441^{* * *} \\
(0.104)\end{array}$ & & $\begin{array}{l}0.447^{* * *} \\
(0.103\end{array}$ & & $\begin{array}{l}0.447^{* * *} \\
(0.103)\end{array}$ \\
\hline$D N C F_{t}$ & $\begin{array}{r}0.104 \\
(0.075)\end{array}$ & & $\begin{array}{r}0.104 \\
(0.075)\end{array}$ & & $\begin{array}{l}0.227^{* * *} \\
(0.056)\end{array}$ & \\
\hline$D M U L T I_{t}$ & & $\begin{array}{l}2.071^{* * *} \\
(0.055)\end{array}$ & & $\begin{array}{l}2.071^{* * *} \\
(0.055)\end{array}$ & & $\begin{array}{l}2.060^{* * *} \\
(0.055)\end{array}$ \\
\hline$\frac{\lambda}{\sigma_{\underline{\zeta}}}$ & $\begin{array}{l}-0.447^{* * *} \\
(0.1486)\end{array}$ & & $\begin{array}{l}-0.444^{* * *} \\
(0.148)\end{array}$ & & $\begin{array}{l}-0.099^{* *} \\
(0.051)\end{array}$ & \\
\hline$\frac{\theta}{\sigma_{\underline{v}}}$ & & $\begin{array}{l}0.270^{* * *} \\
(0.062)\end{array}$ & & $\begin{array}{l}0.270^{* * *} \\
(0.062)\end{array}$ & & $\begin{array}{c}0.269^{* * *} \\
(0.062)\end{array}$ \\
\hline$\frac{\rho_{\zeta \epsilon}}{\sigma_{\underline{\zeta}}}$ & $\begin{array}{l}-1.363^{* * *} \\
(0.432)\end{array}$ & & $\begin{array}{l}-1.355^{* * *} \\
(0.432)\end{array}$ & & $\begin{array}{l}-0.354^{* *} \\
(0.153)\end{array}$ & \\
\hline$\frac{\rho_{v \epsilon}}{\sigma_{\underline{v}}}$ & & $\begin{array}{c}0.612^{* * *} \\
(0.173)\end{array}$ & & $\begin{array}{c}0.612^{* * *} \\
(0.173)\end{array}$ & & $\begin{array}{l}0.607^{* * *} \\
(0.173) \\
\end{array}$ \\
\hline $\begin{array}{l}\rho_{\underline{\zeta v}} \\
\text { Likelihood-Ratio test: } \chi_{1}^{2}\end{array}$ & \multicolumn{2}{|c|}{$\begin{array}{l}0.528^{* * *} \\
(412.049)\end{array}$} & \multicolumn{2}{|c|}{$\begin{array}{l}0.528^{* * *} \\
(412.094)\end{array}$} & \multicolumn{2}{|c|}{$\begin{array}{l}0.530^{* * *} \\
(411.582)\end{array}$} \\
\hline
\end{tabular}


Table 6.4: Average Partial Effects for Second Stage

The APE's in this table are for the specification in column (C0) and (C1) of Table 3.

\begin{tabular}{|c|c|c|c|c|}
\hline & \multicolumn{2}{|c|}{ Finance } & \multicolumn{2}{|c|}{ Innovation } \\
\hline & Coefficient & APE & Coefficient & APE \\
\hline$\overline{\overline{S I N S_{t}}}$ & $\begin{array}{c}0.009^{* * *} \\
(0.002)\end{array}$ & 0.001 & & \\
\hline$D E B T_{t}$ & $\begin{array}{c}0.123^{* *} \\
(0.052)\end{array}$ & 0.016 & $\begin{array}{l}-0.248^{\text {*** }} \\
(0.061)\end{array}$ & -0.091 \\
\hline$L Q_{t}$ & $\begin{array}{l}-0.030^{* * *} \\
(0.012)\end{array}$ & -0.004 & $\begin{array}{c}0.048^{\text {*** }} \\
(0.012)\end{array}$ & 0.017 \\
\hline$D I V_{t}$ & $\begin{array}{l}-0.178^{* * *} \\
(0.055)\end{array}$ & -0.022 & $\begin{array}{l}-0.110^{\text {*** }} \\
(0.043)\end{array}$ & -0.013 \\
\hline$M K S H_{t}$ & $\begin{array}{l}-0.002 \\
(0.004)\end{array}$ & -0.0003 & $\begin{array}{c}0.215^{\text {*** }} \\
(0.012)\end{array}$ & 0.037 \\
\hline$S I Z E_{t}$ & $\begin{array}{c}0.189^{* * *} \\
(0.012)\end{array}$ & 0.025 & $\begin{array}{c}0.101^{\text {*** }} \\
(0.021)\end{array}$ & 0.079 \\
\hline$A G E_{t}$ & $\begin{array}{c}-0.003^{*} \\
(0.002)\end{array}$ & -0.0005 & $\begin{array}{l}-0.007^{* * *} \\
(0.001)\end{array}$ & -0.003 \\
\hline$R A I N T_{t}$ & & & $\begin{array}{c}0.447^{\text {*** }} \\
(0.103)\end{array}$ & 0.163 \\
\hline$D N C F_{t}$ & $\begin{array}{c}0.227^{\text {*** }} \\
(0.056)\end{array}$ & 0.034 & & \\
\hline$D M U L T I_{t}$ & & & $\begin{array}{l}2.060^{\text {**** }} \\
(0.055)\end{array}$ & 0.545 \\
\hline
\end{tabular}

Significance levels : $\quad *: 10 \% \quad * *: 5 \% \quad * * *: 1 \%$ 
Table 6.5: Third Stage: R\&D Switching Equation

\begin{tabular}{lc}
\hline \hline$f_{t}$ & $-0.3077^{* *}$ \\
$S I N S_{t}$ & $(0.1539)$ \\
$f_{t} * C F_{t}$ & $0.0122^{* * *}$ \\
& $(0.0012)$ \\
$\left(1-f_{t}\right) * C F_{t}$ & $0.0993^{* * *}$ \\
$f_{t} * D I V_{t}$ & $(0.0162)$ \\
& 0.0001 \\
$\left(1-f_{t}\right) * D I V_{t}$ & $(0.001)$ \\
$M K S H_{t}$ & $-0.2101^{* * *}$ \\
& $(0.0728)$ \\
$S I Z E_{t}$ & -0.0396 \\
& $(0.0245)$ \\
$A G E_{t}$ & $0.0074^{* * *}$ \\
& $(0.0017)$ \\
$D M U L T I_{t}$ & $-0.0429^{* * *}$ \\
$\mu$ & $(0.0109)$ \\
& $-0.0095^{* * *}$ \\
$C_{11}(.)_{t}$ & $(0.0009)$ \\
$C_{12}(.)_{t}$ & $0.2297^{* * *}$ \\
$C_{13}(.)_{t}$ & $(0.4413)$ \\
& $0.0155^{* * *}$ \\
$C_{01}(.)_{t}$ & $(0.0053)$ \\
$C_{02}(.)_{t}$ & $0.3278^{* * *}$ \\
$C_{03}(.)_{t}$ & $(0.0803)$ \\
& $0.2245^{* *}$ \\
$T 0 t a$ & $(0.0895)$ \\
& $1.1382^{* * *}$ \\
& $(0.1613)$ \\
& $-0.0687^{* * *}$ \\
& $(0.0176)$ \\
& $-0.2492^{* *}$ \\
& $(0.1161)$ \\
& $0.2943^{* * *}$ \\
& $(0.0519)$ \\
\hline
\end{tabular}

Total Number of Observations: 13034

Number of Censored Observations: 6767 
Table 6.6: APE's for the Third Stage

The table reports the Average Partial Effects of some of the variables on R\&D intensity. While the APE of $f_{t}$, the reported financial constraint faced by the firms is unconditional, the APE's of the rest of the variables in column (a) is conditional on being selected. The APE's of the variables reported in column (b) are conditional on being selected and conditional on being financially constrained. The APE's of the variables reported in column (c) are conditional on being selected and conditional on being not financially constrained.

\begin{tabular}{lccc}
\hline \hline$f_{t}$ & & -0.2635 & \\
\hline \hline & $\mathbf{a}$ & $\mathbf{b}$ & $\mathbf{c}$ \\
\hline$S I Z E_{t}$ & -0.0482 & -0.0632 & -0.0456 \\
$M K S H_{t}$ & 0.7013 & -0.0137 & 0.7026 \\
$A G E_{t}$ & -0.0076 & -0.0036 & -0.0077 \\
$D I V_{t}$ & -0.0305 & -0.0866 & -0.0205 \\
$D M U L T I_{t}$ & 0.0881 & -0.0945 & 0.1192 \\
\hline \hline
\end{tabular}

\section{E Descriptive Statistics}

Table 6.7: Descriptive Statistics of Variables for Censored and Non-Censored Variables

\begin{tabular}{|l|c|c|c|}
\hline & CIS2.5 & CSI3 & CIS3.5 \\
\hline$r$ & 0.5061 & 0.3377 & 0.1914 \\
SINS & 8.5349 & 8.8979 & 5.668 \\
\hline No. of Censored obs. & $(2946)$ & $(1844)$ & $(1981)$ \\
\hline$D E B T$ & 0.7359 & 0.712 & 0.9155 \\
$C F$ & 0.8601 & 0.9671 & 0.3978 \\
$D M U L T I$ & 0.2107 & 0.261 & 0.2607 \\
LQ & 0.9644 & 0.9407 & 0.9420 \\
$D I V$ & 0.1825 & 0.1832 & 0.1772 \\
$M K S H$ & 0.5396 & 0.7318 & 0.6443 \\
LOG $($ SIZE $)$ & 4.5745 & 4.1161 & 4.328 \\
$A G E$ & 20.71 & 23.51 & 22.99 \\
$R A I N T$ & 0.036 & 0.0386 & 0.0506 \\
$D N C F$ & 0.0873 & 0.0929 & 0.127 \\
\hline Total no. of obs. & $(5362)$ & $(3424)$ & $(4248)$ \\
\hline \hline
\end{tabular}

The figures reported are the means of the respective variables 
Table 6.8: Total number of enterprise, $N_{f}$, and number of enterprise within a firm surveyed, $n_{f}$

The table illustrates the number of firms, in each of the three CIS waves, for which the number of number of enterprise surveyed is equal to the number of enterprise present in the firm, $N_{f}=n_{f}$, and the number of firms, for which the number of enterprises present in the firm exceeds the number of enterprises surveyed. These figures pertain to the CIS data set prior to merging with the SFGO and the SFKO data set. Since not all the CIS firms are in the SFGO and the SFKO data set, the data used for estimation after cleaning, is a bit less than half the size of the original data set.

\begin{tabular}{|c|c|c|c|c|c|c|c|c|}
\hline \multicolumn{3}{|c|}{ CIS2.5 } & \multicolumn{3}{|c|}{ CSI3 } & \multicolumn{3}{|c|}{ CIS3.5 } \\
\hline & No. of firms & No. of firms & & No. of firms & No. of firms & & No. of firms & No. of firms \\
\hline$N_{f}$ & $N_{f}=n_{f}$ & $N_{f}>n_{f}$ & $N_{f}$ & $N_{f}=n_{f}$ & $N_{f}>n_{f}$ & $N_{f}$ & $N_{f}=n_{f}$ & $N_{f}>n_{f}$ \\
\hline 1 & 9400 & 0 & 1 & 6155 & 0 & 1 & 7096 & 0 \\
\hline 2 & 151 & 1255 & 2 & 67 & 823 & 2 & 137 & 978 \\
\hline 3 & 20 & 608 & 3 & 4 & 424 & 3 & 24 & 553 \\
\hline 4 & 3 & 316 & 4 & 3 & 237 & 4 & 2 & 290 \\
\hline 5 & 3 & 247 & 5 & 2 & 108 & 5 & & 222 \\
\hline 6 & & 149 & 6 & & 115 & 6 & & 122 \\
\hline 7 & & 107 & 7 & & 48 & 7 & & 105 \\
\hline 8 & & 60 & 8 & & 77 & 8 & & 50 \\
\hline 9 & 2 & 93 & 9 & & 58 & 9 & & 77 \\
\hline 10 & & 83 & 10 & & 39 & 10 & & 82 \\
\hline 11 & & 106 & 11 & & 63 & 11 & & 50 \\
\hline 12 & & 49 & 12 & & 39 & 12 & & 58 \\
\hline 13 & & 43 & 13 & & 15 & 13 & & 49 \\
\hline 14 & & 59 & 14 & & 50 & 14 & & 46 \\
\hline 15 & & 46 & 15 & & 17 & 15 & & 25 \\
\hline 16 & & 31 & 16 & & 28 & 16 & & 51 \\
\hline 17 & & 62 & 17 & & 15 & 17 & & 15 \\
\hline 18 & & 36 & 18 & & 26 & 18 & & 55 \\
\hline 19 & & 37 & 19 & & 13 & 19 & & 8 \\
\hline 20 & & 29 & 20 & & 21 & 20 & & 28 \\
\hline 21 & & 13 & 21 & & 2 & 21 & & 43 \\
\hline 22 & & 23 & 22 & & 27 & 22 & & 36 \\
\hline 23 & & 15 & 24 & & 5 & 23 & & 18 \\
\hline 25 & & 34 & 25 & & 9 & 24 & & 25 \\
\hline 26 & & 46 & 26 & & 8 & 25 & & 11 \\
\hline 27 & & 4 & 27 & & 21 & 27 & & 17 \\
\hline 29 & & 14 & 28 & & 13 & 28 & & 19 \\
\hline 30 & & 14 & 29 & & 8 & 29 & & 11 \\
\hline 31 & & 18 & 30 & & 8 & 30 & & 15 \\
\hline 32 & & 15 & 31 & & 3 & 31 & & 7 \\
\hline 33 & & 11 & 32 & & 16 & 32 & & 16 \\
\hline 34 & & 18 & 34 & & 22 & 33 & & 25 \\
\hline 37 & & 15 & 40 & & 10 & 37 & & 21 \\
\hline 38 & & 15 & 45 & & 14 & 38 & & 13 \\
\hline 43 & & 15 & 48 & & 18 & 39 & & 20 \\
\hline 44 & & 17 & 50 & & 19 & 40 & & 9 \\
\hline 45 & & 14 & 57 & & 16 & 41 & & 10 \\
\hline 48 & & 20 & 60 & & 16 & 46 & & 15 \\
\hline 49 & & 22 & & & & 50 & & 16 \\
\hline 51 & & 28 & & & & 53 & & 47 \\
\hline 56 & & 19 & & & & 55 & & 16 \\
\hline 66 & & 33 & & & & & & \\
\hline 85 & & 41 & & & & & & \\
\hline
\end{tabular}


Figure 6.1: APE of long-term Debt to Asset Ratio on Unconditional Probability of Innovation.

(a)

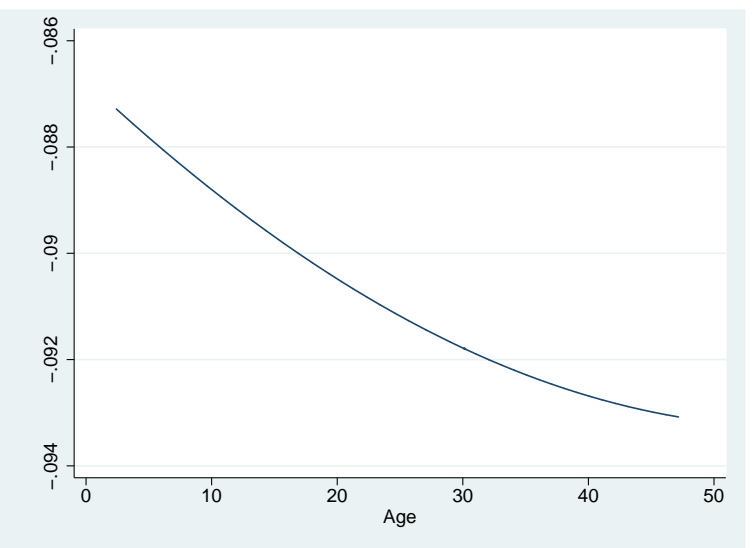

(c)

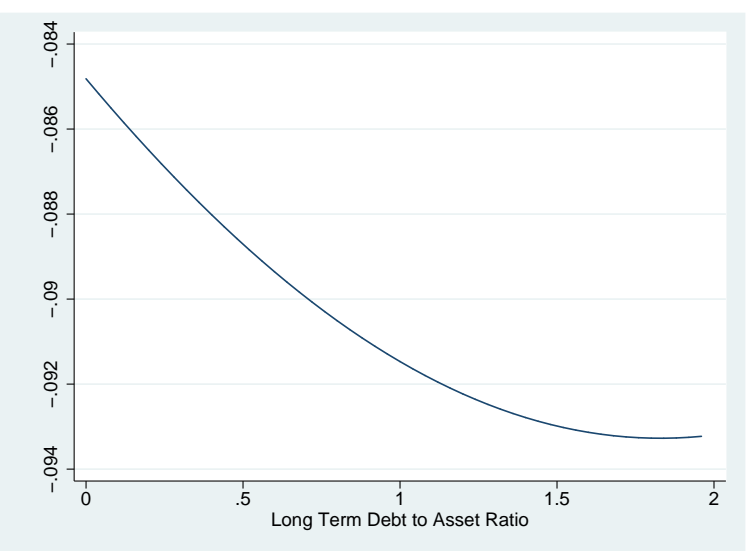

(b)

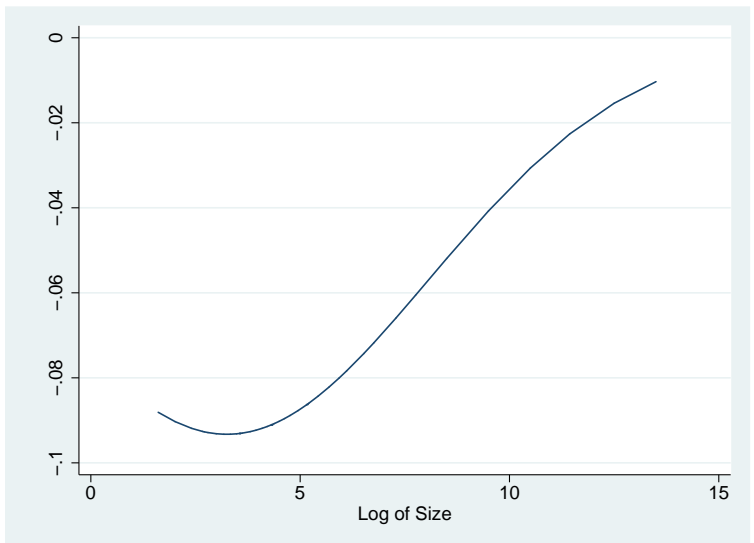


Figure 6.2: APE of long-term Debt to Asset Ratio on Probability of Innovation conditional on being Financially Constrained, $\frac{\partial \operatorname{Pr}\left(s_{i t}=1 \mid f_{i t}=1\right)}{\partial d_{i t}}$, and APE of long-term Debt to Asset Ratio on Probability of Innovation conditional on not being Financially Constrained, $\frac{\partial \operatorname{Pr}\left(s_{i t}=1 \mid f_{i t}=0\right)}{\partial d_{i t}}$.

(a)



(c)

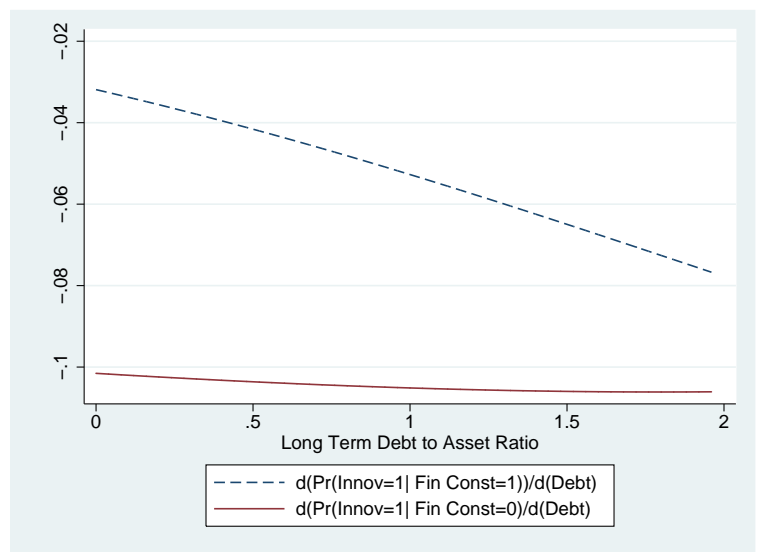

(b)

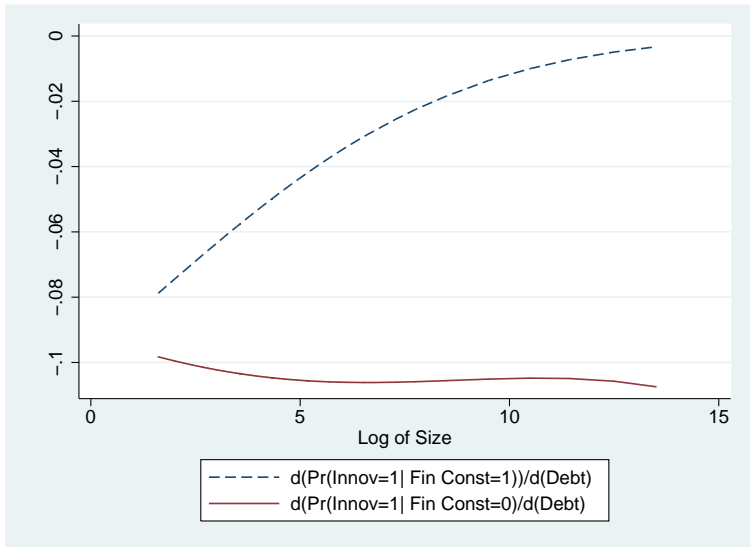





\section{Conclusions}

\subsection{Summary, limitations and further research}

The central message that comes out of the study is that market failure for $R \& D$ investment can be very acute. The three empirical chapters on $R \& D$ and innovation activity confirm this. In order to arrive at this result, in all the three chapters, we have used information on financial constraints as reported by the enterprises. This alternative procedure to test the implication of financing frictions on R\&D investment, bypasses some the criticism levelled against the more traditional approach of using reduced form accelerator type model or the Euler equation approach. Besides presenting evidence of market failure due to financing friction for $R \& D$ related activity, another major contribution of the thesis has been to show how incentives, that vary with firm distribution, to innovate interact with financing decision, or in other words, we show how financing and innovation decision vary with the distribution of firm characteristic such as size, age, leverage, and financing constraints. The study also shows how among the set of innovating firms, R\&D intensity vary with firm characteristics, and how $R \& D$ intensity for each given firm characteristic changes under financial constraints. Another important contribution of the thesis has been to show how agency problem between bond holders and stock holders can arise over $R \& D$ investment which is risky because of the technical uncertainty and because of the intangibility of the assets involved. In the rest of this chapter we summarize our finding, point out the limitations, and discuss some directions for future research.

In Chapter 2 we estimated both linearized as well as non-linear form of Euler equation, augmented with financial variables, for investment derived from the optimization problem of the firm. The study shows that, ceteris paribus, firms that are highly leveraged are more likely to face binding financing constraints and that financing constraints affect firm level investment. However, we were also able to point out the misspecification in estimation due ignoring the fixed component of adjustment cost. For future research, it would be interesting to analyze the interaction of financing frictions and non-convex adjustment costs. Non-convexity of adjustment costs imply that firm-level investment is lumpy, and 
hence, firms invest infrequently but each investment is large. The presence of financing frictions could affect the frequency, as well as the amount, at which investment projects are undertaken.

In Chapter 3 as stated earlier, we use direct information on financial constraints as reported by the firms, to assess its effect on $R \& D$ investment. For estimation we uses a semiparametric sample selection estimator. Here we show that financial constraints adversely affect R\&D activity, however the effect of financial constraint is reduced when other constraints to innovation bind. The empirical specification was derived from an optimal lending contract studied by Gale and Hellwig (1985). One of the limitations of this study is that, since balance sheet information of the firms were not available, we could not include financial state variables in the model, which otherwise could have given us a richer specification for estimation. We overcome this limitation in Chapter 5, where we study financing and innovation policy in greater detail using panel data instead of a single cross section as in this chapter.

In Chapter 4 we have analyzed the nature and the degree of obstacles, in particular financial constraints, to innovative activity using statistical information from CIS 3.5 for the Netherlands. In this chapter we took a different approach to assess the impact of financial constraints on innovation activity. Rather than looking at the impact of financial constraints on R\&D investment, we studied the impact on firm decisions to abandon, prematurely stop, seriously slow down or desist from starting an innovative project as a result of financial and other hampering factors. Our analysis leads us to conclude that the constraints faced by innovative firms are important and have had a major negative impact on innovative activity. The chapter ends with a discussion of policy measures that have been taken to overcome, or at least attenuate these obstacles, such as R\&D tax incentives, venture capital financing and policy mix packages.

In Chapter 5 we use the framework of real options to study the interaction of financing and $R \& D$ investment decision. We show how agency problem between bond holders and stock holders can arise over $\mathrm{R} \& \mathrm{D}$ investment, which is risky in our model not due to high variance of cash flows, but due to asset intangibility and presence of technical uncertainty in successful completion of the R\&D project. We find that, under certain situations, higher intangibility of assets and lower intensity of completion can both lead stock holders to overinvest, thereby shift the risk of undertaking the R\&D on to the bond holders. The chapter also compares R\&D investment to that of scale expansion. We find that under certain, reasonable circumstance R\&D investment is more desirable than scale expansion and yet it might be difficult to finance with debt. However, in this study we only indicate the existence of the potential agency problem that can arise between the bond holders and the owners of the firm. 
To compute the value of loan commitment it is important that agency cost due to the risk involved in $\mathrm{R} \& \mathrm{D}$ project be computed. We also recognize that a richer model for $\mathrm{R} \& \mathrm{D}$, incorporating learning, an option to abandon the R\&D project prior to liquidation, and accumulation of intellectual capital stock over time could have some bearing on the results we report. For our future work we intend to incorporate such features into our model.

The sixth and the final chapter of the thesis again analyzes the effect of financial constraints on $\mathrm{R} \& \mathrm{D}$ investment. One contribution of this chapter has been to show how to aggregate enterprise level data up to the company/firm level, when not all enterprises belonging to the firm had been surveyed. We performed this exercise since financial variables, which are the regressors in the model, were only available at the company level. This exercise was performed for about 20 to 25 percent of the firms, the others being single enterprise firms. We believe that better aggregation procedure, for example Bayesian techniques, are available when there are missing data. For our future work we intend to use such methods for aggregation.

In Chapter 6, we not only assess the impact of financing frictions on $R \& D$ intensity, but also study how financing decision and decision to innovate are interlinked. We find that financing and innovation decision vary over the distribution of firm characteristics such as age, size, leverage, and being financially constrained. The study in this chapter shows that firms that are more leveraged are likely to be financially constrained and that highly leveraged firms are less likely to be innovators. Besides, we also find that financing decision, the decision to innovate, the financial constraint faced, and the amount of $\mathrm{R} \& \mathrm{D}$ investment are all endogenously determined.

In this chapter we also introduced a new estimator for panel data with endogenous regressor that helps us to identify parameters of interest for a system of equations. Though in the literature there are many estimators for panel data with endogenous regressors, given the nature of our data where the panel was short and unbalanced, and our problem where we had to estimate a system of four equations, the existing estimators did not prove helpful. However, for the study in chapter 6 , we had only one endogenous regressor. The procedure can easily be generalized to include additional endogenous regressors. Introducing dynamics, more than one time invariant individual effect and possible semiparametric extensions will also be considered.

Though, Chapter 6 is an extensive study of financing and innovation activity of a firm, one particular limitation of the study has been the lack of dynamics in the model that was explored. Economic considerations such as adjustment cost would would raise the issue of introducing dynamics in the model. One reason for not including dynamics in the model was because information on 
R\&D expenditure was available only for alternative time periods, while any specification for convex adjustment cost requires having lagged dependent variable. It is not that we do not recognize a possible misspecification for not letting R\&D investment respond such costs, but in a static framework, as we have shown in chapter $3, \mathrm{R} \& \mathrm{D}$ investment is only a function of future expected profitability and the the degree of financing friction faced. Besides, there is a question of arriving at an empirical specification derived from a dynamic contractual model of financing and investment. In general, we recognize that it is difficult to have an empirical model that adheres closely to theoretical models in finance and economics, some of which do not even deliver closed form solutions. In such a situation, the method of indirect inference may be one possible route, which many researchers are taking to study the complicated interaction between financing and investment decisions.

As stated in the introductory chapter, innovative activity is important for economic growth and welfare. But due to the nature of $R \& D$ activity that gives rise to worst kind of information asymmetric problem, market failure for $R \& D$ investment can be very acute. Considering this fact, it is important that further research be carried out on the topic of financing of innovations. Though the literature in finance and economics recognizes that market failure for $R \& D$ can be severe, we do not know of any paper that has estimated the price differential on external finance for $R \& D$ investment and physical investment. This is not only an interesting research question but also important from the point of view of policy making. 


\section{Bibliography}

Aboody, D., And B. Lev (2000): "Information Asymmetry, R\&D, and Insider Gains," Journal of Finance, 55, $2747-2766$.

Aghion, P. (2006): "A Primer on Innovation and Growth," Bruegel Policy Brief, 06, 1-8.

Aghion, P., N. Bloom, R. Blundell, R. Griffith, and P. Howitt (2005): "Competition and Innovation: An Inverted-U Relationship," Quarterly Journal of Economics, 120, 701-728.

Aghion, P., R. Blundell, R. Griffith, P. Howitt, and S. Pranti (2006): "The Effects of Entry on Incumbent Innovation and Productivity," NBER Working Paper 1202\%.

Aghion, P., T. Fally, and S. Scarpetta (2006): "Credit Constraints as a Barrier to the Entry and Post-entry Growth of Firms: Lessons From Firm-level Cross County Panel Data," Working Paper.

Akerlof, G. (1970): "The Market for "Lemons": Quality, Uncertainty, and the Market Mechanism," The Quarterly Journal of Economics, 84, 488-500.

Albuquerque, R., and H. A. Hopenhayn (2004): "Optimal Lending Contracts and Firm Dynamics," Review of Economic Studies, 71, 285-315.

Alderson, M., And B. L. Betker (1996): "Liquidation Costs and Accounting Data," Financial Management, 25, 25-36.

Allen, F., And D. Gale (2000): Comparing Financial Systems. MIT Press.

Almeida, H., and M. Campello (2002): "Financial Constraints and Investment-Cash Flow Sensitivities: New Research Directions," Working Paper, New York University, Stern Business School. 
Alti, A. (2003): "How Sensitive is Investment to Cash Flow when Financing is Frictionless?," Journal of Finance, 58, 707-722.

Anton, J., And D. Yao (1998): "The Sale of Intellectual Property: Strategic Disclosure, Property Rights, and Incomplete Contracts," Working paper, The Wharton School, University of Pennsylvania.

Arellano, M., and S. R. Bond (1991): "Some tests of specification for panel data: Monte Carlo evidence and an application to employment equations," Review of Economic Studies, 58, 277-297.

Arellano, M., And O. Bover (1995): "Another Look at the Instrumental-Variable Estimation of Error-Components Models," Journal of Econometrics, 68, 29-51.

Audretsch, D. (1995): Innovation and Industry Evolution. MIT Press.

Berger, A., And G. Udell (1998): "The Economics of Small Business Finance: The Roles of Private Equity and Debt Markets in the Financial Growth Cycle," Journal of Banking and Finance, $22,613-673$.

Berk, J. B., R. C. Green, And V. NAik (2004): "Valuation and Return Dynamics of New Ventures," Review of Financial Studies, 17, 1-35.

Bhattacharya, S., and J. R. Ritter (1983): "Innovation and Communication: Signaling with Partial Disclosure," Review of Economic Studies, 50, 331-346.

Black, B., and R. Gilson (1998): "Venture Capital and the Structure of Capital Markets: Banks Versus Stock Markets," Journal of Financial Economics, 47, 243-277.

Blass, A., and O. Yosha (2001): "Financing R\&D in Mature Companies: An Empirical Analysis," Working Paper, Bank of Israel, Tel Aviv University, and CEPR.

Blundell, R., And J. Powell (2003): "Endogeneity in Nonparametric and Semiparametric Regression Models," in Advances in Economics and Econonometrics: Theory and Applications, Eighth World Congress, Vol. II, ed. by L. H. M. Dewatripont, and S. Turnovsky. Cambridge University Press, Cambridge.

Bond, S., And J. G. Cummins (2001): "Noisy share prices and the q model of investment," Institute for Fiscal Studies, Working Papers, 01/22. 
Bond, S., J. Elston, J. Mairesse, and B. Mulkay (1997): "Financial factors and investment in Belgium, France, German and the UK: A comparison using company panel data," Institute for Fiscal Studies, Working Papers, W97/08.

Bond, S., D. HARHoff, And J. van REenen (2003): "Investment, R\&D and Financial Constraints in Britain and Germany," Annales d'Econométrie et de Statistique, forthcomming.

Bond, S., And C. Meghir (1994): "Dynamic Investment Models and the Firms Financial Policy," Review of Economic Studies, 61, 197-222.

Brouwer, E. (2007): "Innovatie en Mededinging: Op Zoek naar de Bron van Welvaart en Vooruitgang," TILEC Discussion Paper 021.

Brown, J. R., S. M. Fazzari, and B. C. Petersen (2009): "Financing Innovation and Growth: Cash Flow, External Equity, and the 1990's R\&D Boom," Journal of Finance, 64, 151-185.

Canepa, A., and P. Stoneman (2002): "Financial Constraints on Innovations: A European Cross Country Study," Kiel Institute of World Economics, Working Paper.

Childs, P. D., D. C. Mauer, and S. H. Ott (2005): "Interactions of Corporate Financing and Investment Decisions: The Effects of Agency Conflicts," Journal of Financial Economics, 76, 667-690.

Childs, P. D., and A. J. Triantis (1999): "Dynamic R\&D Investment Policies," Management Science, 45, 1359-1377.

Cleary, S. (1999): "The Relationship between Firm Investment and Financial Status," Journal of Finance, 54, 673-692.

Cochrane, J. (2005): "The Risk and Return of Venture Capital," Journal of Financial Economics, $75,3-52$.

Cohen, W., R. Levin, and D. Mowery (1987): "Firm Size and R \&D Intensity: A ReExamination," Journal of Industrial Economics, 4, 543-565.

Cohen, W., and D. Levinthal (1989): "Innovation and Learning: the two faces of R\&D," Economic Journal, 99, 569-596.

Cohen, W. M., And S. Klepper (1996): "A Reprise of Size and R\&D," The Economic Journal, 106, 925-951. 
Cooley, T. F., And V. Quadrini (2001): "Financial Markets and Firm Dynamics," American Economic Review, 91, 1286-1310.

CoOper, R., And J. EJARque (2001): "Exhuming Q: market power vs. capital market imperfections," N.B.E.R., Working Papers, 8182.

Cooper, R. W., and J. C. Haltiwanger (2006): "On the Nature of Capital Adjustment Costs," Review of Economic Studies, 73, 611-633.

De Bondt, R., P. Slaets, and B. Cassiman (1992): "Innovation and Learning: the two faces of R\&D," International Journal of Industrial Organization, 10, 3554.

Dixit, A. K., AND R. S. PINDYCK (1994): Investment under Uncertainty. Princeton University Press.

Doms, M., And T. Dunne (1998): "Capital Adjustment Patterns in Manufacturing Plants," Review of Economic Dynamics, 1, 409-429.

Dow, J., G. Gorton, and A. Krishnamurthy (2005): "Equilibrium Asset Prices with Imperfect Corporate Control," American Economic Review, 95, 659-681.

EGAmi, M. (2009): "A framework for the study of expansion options, loan commitments and agency costs," Journal of Corporate Finance, 15, 345-357.

Engel, D., and M. Keilbach (2007): "Firm-level Implications of Early Stage Venture Capital Investment - An Empirical Investigation," Journal of Empirical Finance, 14, 150-167.

Erickson, T., And T. M. Whited (2000): "Measurement error and the relationship between investment and q," Journal of Political Economy, 108, 1027-57.

FAma, E. F., AND K. R. FRench (1995): "Size and book-to-market factors in earnings and returns," Journal of Finance, 50, 131-155.

- (2000): "Forecasting Profitability and Earnings," Journal of Business, 73, 161-175.

- (2002): "Testing Trade-off and Pecking Order Predictions about Dividends and Debt," Review of Financial Studies, 15, 1-37.

Fazzari, S. M., R. G. Hubbard, and B. Petersen (1988): "Financing Constraints and Corporate Investment," Brookings Papers on Economic Activity, 1, 144-195. 
Gale, D., And M. Hellwig (1985): "Incentive Compatible Debt Contracts: The One Period Problem," Review of Economic Studies, 52, 647-663.

Gale, D., And M. Hellwig (1986): "The Optimal Debt Contract: A Comparative Static Analysis," CARESS Working Paper, 86-06.

Galia, F., and D. Legros (2004): "Complementarities Between Obstacles to Innovation: Evidence from France," Research Policy, 33, 1185-1199.

Geroski, P. A. (1990): "Innovation, Technological Opportunity and Market Share," Oxford Economic Papers, 42, 586-602.

Gibbons, R. D., D. Hedeker, S. C. Charles, and P. Frisch (1994): "A Random-Effects Probit Model for Predicting Medical Malpractice Claims," Journal of the American Statistical Association, 89, 760-767.

Gomes, J., A. Yaron, and L. Zhang (2006): “Asset Pricing Implications of Firms' Financing Constraints," Review of Financial Studies, 19, 1321-1356.

Gomes, J. F. (2001): "Financing Investment," American Economic Review, 91, 1263-1285.

Gompers, P. (1995): "Optimal Investment, Monitoring, and the Staging of Venture Capital," Journal of Finance, 50, 1461-1489.

Gompers, P., A. Kovner, J. Lerner, and D. Scharfstein (2007): "Venture Capital Investment Cycles: The Impact of Public Markets," Journal of Financial Economics, 87, 1-23.

Greene, W. H. (2002): Econometric Analysis. Prentice Hall, $4^{\text {th }}$ edn.

Greenwald, B., J. Stiglitz, and A. Weiss (1984): "Informational Imperfections in the Capital Market and Macroeconomic Fluctuation," American Economic Review, 74, 194-199.

Hall, B. (1993): "R\&D Tax Policy During the Eighties: Success or Failure?," Tax Policy and the Economy, 7, 1-36.

(1994): "Corporate Capital Structure and Investment Horizons in the United States,19761987," Business History Review, 68, 110-143.

Hall, B. (2002): "The Financing of Research and Development," Oxford Review of Economic Policy, $18,35-51$. 
Hall, B., And J. Lerner (2010): "The Financing of R\&D and Innovation," in Handbook of the Economics of Innovation, ed. by B. H. Hall, and N. Rosenberg. Cambridge University Press, Cambridge, forthcoming.

Hansen, L. P. (1982): "Large Sample Properties of Generalized Method of Moments Estimators," Econometrica, 50, 1029-1054.

Hansen, L. P., and K. J. Singleton (1982): "Genralized Instrumental Variables Estimation of Nonlinear Expectation Model," Econometrica, 50, 1269-1286.

Harhoff, D. (1998): "Are there Financing Constraints for R\&D and Investment in German Manufacturing Firms," Annales d'Economie et de Statistique, 49/50, 421-456.

Hart, O., And J. Moore (1994): “A theory of Debt based on the Inalienability of Human Capital," Quarterly Journal of Economics, 109, 841-879.

Heckman, J. (1979): "Sample selection bias as a specification error," Econometrica, 47, 153-161.

Hellmann, T., and M. Puri (2002): "Venture Capital and the Professionalization of Start-up Firms: Empirical Evidence," Journal of Finance, 57, 169-197.

Hennessy, C., And T. M. Whited (2007): "How Costly is External Financing? Evidence from a Structural Estimation," Journal of Finance, 62, 1705-1745.

Himmelberg, C., and B. Petersen (1994): "R\&D and Internal Finance: A Panel Study of Small Firms in High-Tech Industries," Review of Economics and Statistics, 76, 38-51.

Holmstrom, B. (1989): "Agency Costs and Innovation," Journal of Economic Behavior and Organization, 12, 305-327.

Hubbard, R. G. (1998): "Capital Market Imperfections and Investment," Journal of Economic Literature, 36, 193-225.

Hubbard, R. G., and A. Kashyap (1992): "Internal Net Worth and the Investment Process: An Application to US Agriculture," Journal of Political Economy, 100, 506-34.

Hubbard, R. G., A. K. Kashyap, and T. M. Whited (1995): "Internal Finance and Firm Investment," Journal of Money, Credit, and Banking, 7, 683-701. 
Huergo, E., and J. Jaumandreu (2004): "How does Probability of Innovation change with Firm Age?," Small Business Economics, 22, 193-207.

Jaramillo, F., F. Schianterelli, and A. Weiss (1996): "Before and After Financial Liberalization: An Euler Equation Approach to Panel Data for Ecuadorian Firms," Journal of Development Economics, 51, 367-386.

Jensen, M., And W. Meckling (1976): "Theory of the Firm: Managerial Behavior, Agency Costs and Ownership Structure," Journal of Financial Economics, 3, 305-360.

Kaplan, S., And A. Schoar (2005): "Private Equity Performance: Returns, Persistence and Capital," Journal of Finance, 60, 1791-1823.

Kaplan, S., and P. Stromberg (2000): "Financial Contracting Theory Meets the Real World: An Empirical Analysis of Venture Capital Contracts," NBER Working Paper no. 7600.

Kaplan, S. N., And L. Zingales (1997): "Do Investment-Cash Flow Sensitivities provide Useful Measures of Financing Constraints?," Quarterly Journal of Economics, 112, 169-215.

— (2000): "Investment-Cash Flow Sensitivity are not Valid Measures of Financing Constraints," Quarterly Journal of Economics, 115, 707-712.

Kortum, S., And J. Lerner (2000): "Assessing the Contribution of Venture Capital to Innovation," RAND Journal of Economics, 31, 674-692.

Lambrecht, B., and S. C. Myers (2008): "Debt and Managerial Rents in a Real-Options Model of the Firm," Journal of Financial Economics, 89, 209-231.

Leland, H. E. (1994): "Corporate Debt Value, Bond Covenants, and Optimal Capital Structure," Journal of Finance, 49, 1213-1252.

(1998): "Agency Costs, Risk Management, and Capital Structure," Journal of Finance, 53, $1213-1243$.

Leland, H. E., And D. H. Pyle (1977): "Informational Asymmetries, Financial Structure, and Financial Intermediation," Journal of Finance, 32, 371-387.

Lewbel, A. (2000): "Semiparametric Qualitative Response Model Estimation with Unknown Heteroscedasticity and Instrumental Variables," Journal of Econometrics, 97, 145-177. 
(2004): "Simple Estimators for Hard Problems: Endogeneity in Discrete Choice Related Models," Unpublished Manuscript.

(2007): "Endogenous Selection or Treatment Model Estimation," Journal of Econometrics, $141,777-806$.

Lewbel, A., and S. Schennach (2007): "A Simple Ordered Data Estimator for Inverse Density Weighted Functions," Journal of Econometrics, 136, 189-211.

Ljungqvist, A., and M. Richardson (2003): "The Cash Flow, Return and Risk Characteristics of Private Equity," New York University, Working Paper.

Lokshin, B., And P. Mohnen (2007): "Measuring the Effectiveness of R\&D Tax Credits in the Netherlands," UNU-MERIT Working Paper 2007-025.

Love, I. (2003): "Financial development and financing constraints: international evidence from the structural investment model," Review of Financial Studies, 16, 765-791.

Mairesse, J., B. Hall, and B. Mulkay (1999): "Firm-Level Investment in France And The United States: An Exploration of What We Have Learned in Twenty Years," Annales dEconomie et de Statistique, 55-56, 27-63.

Mauer, D. C., and S. Sarkar (2004): "Real Options, Agency Conflicts, and Optimal Capital Structure," Journal of Banking and Finance, 29, 1405-1428.

Mella-Barral, P. (1999): "The Dynamics of Default and Debt Reorganization," Review of Financial Studies, 12, 535-578.

Mella-Barral, P., and W. R. Perraudin (1997): "Strategic Debt Service," Journal of Finance, $52,531-556$.

Mello, A., And J. Parsons (1992): "Measuring the Agency Cost of Debt," Journal of Finance, 47, 1887-1904.

Miltersen, K. R., And E. S. Schwartz (2004): "R\&D Investments with Competitive Interactions," Review of Finance, 8, 355401.

Modigliani, F., And M. H. Miller (1958): "The Cost of Capital, Corporation Finance, and the Theory of Investment," American Economic Review, 48, 261-297. 
Mohnen, P., F. Palm, S. S. van der Loeff, and A.K.Tiwari (2008): "Financial Constraints and Other Obstacles: are they a Threat to Innovation Activity?," De Economist, 156, 201-214.

Mohnen, P., And L. H. Röller (2005): "Complementarities in Innovation Policy," European Economic Review, 49, 1431-1450.

Mohnen, P., And J. Rosa (2002): "Barriers to Innovation in Service Industries in Canada," in Institutions and Systems in the Geography of Innovation, ed. by M. Feldman, and N. Massard, pp. 231-250. Kluwer Academic Publishers, Boston.

Moyen, N. (2004): "Investment-Cash Flow Sensitivities: Constrained versus Unconstrained Firms," Journal of Finance, 69, 2061-2092.

Mulkay, B., B. Hall, and J. Mairesse (2001): "Firm Level Investment and R\&D in France and the United States," in Investing Today for the World of Tomorrow, ed. by D. Bundesbank. Springer Verlag, Berlin.

Murphy, K. M., And R. H. Topel (1985): "Estimation and Inference in Two-Step Econometric Models," Journal of Business 8 Economic Statistics, 3, 370-379.

Myers, S. (1977): "Determinants of corporate borrowing," Journal of Financial Economics, 5, $147-175$.

_ (1984): “The Capital Structure Puzzle," Journal of Finance, 39, 575-592.

Myers, S., ANd N. S. Majluf (1984): "Corporate Financing and Investment Decisions when Firms have Information that Investors Do Not Have," Journal of Financial Economics, 13, 187-221.

NeWEy, W., AND K. WeSt (1987): "Hypothesis testing with efficient method of moments estimation," International Economic Review, 28, 777-787.

Newey, W. K. (1984): "A Method of Moment Interpretation of Sequential Estimators," Economics Letters, 14, 201-206.

Newey, W. K., and D. McFadden (1986): "Large Sample Estimation and Hypothesis Testing," in Handbook of Econometrics, ed. by R. F. Engle, and D. McFadden, pp. 2111-2245. Elsevier.

Nilsen, O. A., And F. Schiantarelli (2003): "Zeros And Lumps In Investment: Empirical Evidence On Irreversibilities and Nonconvexities," American Economic Review, The Review of Economics and Statistics(85), 1021-1037. 
Niosi, J., M. Cloutier, And A. Lejeune (2002): Biotechnologie et Industrie au Québec. Les Editions Transcontinental, Montréal.

Opler, T., And S. Titman (1993): "The Determinants of Leveraged Buyout Activity: Free Cash Flow vs. Financial Distress Costs," Journal of Finance, 48, 1985-1999.

_ (1994): "Financial Distress and Corporate Performance," Journal of Finance, 49, 10151040.

PindyCK, R. S. (1993): "Investments of Uncertain Cost," Journal of Financial Economics, 34, 53 $-76$.

Poterba, J. (1988): "Comment on 'Financing Constraints and Corporate Investment'," Brookings Papers on Economic Activity, 1, 200-204.

Rajan, R. G., And L. Zingales (2001): "Financial Systems, Industry Structure, and Growth," Oxford Review of Economic Policy, 17, 467-482.

Raymond, W., P. Mohnen, F. Palm, and S. S. van der Loeff (2007): "Persistence of innovation in Dutch manufacturing: Is it spurious?," Review of Economics and Statistics, forthcoming.

Röller, L., M. Tombak, and R. Siebert (1997): "Why Firms form Research Joint Ventures: Theory and Evidence," CEPR Discussion Paper Series, 1654, 1021-1037.

Ross, S. A., R. W. Westerfield, and B. D. Jordan (2006): Fundamentals of Corporate Finance. McGraw-Hill, sixth edn.

SAvignac, F. (2006): "The Impact of Financial Constraints on Innovation: Evidence from French Manufacturing Firms," Cahiers de la Maison des Sciences Economiques v06042, Université Panthéon-Sorbonne (Paris I).

Schumpeter, J. A. (1942): Capitalism, Socialism, and Democracy. Harper Colophon, New York.

Schwartz, E. S., And M. Moon (2000): "Evaluating Research and Development Investments," in Project Flexibility, Agency and Competition, ed. by M. J. Brennan, and L. Trigeorgis, pp. 85-106. Oxford University Press.

SHI, C. (2003): "On the Trade-off between the Future Benefits and Riskiness of R\&D: A Bondholders' Perspective," Journal of Accounting and Economics, 35, 227-254. 
Stein, J. C. (2003): "Agency, Information and Corporate Investment," in Handbook of the Economics of Finance, ed. by M. H. George Constantinides, and R. Stulz, pp. 111-165. Elsevier.

Stiglitz, J., And A. Weiss (1981): "Credit Rationing and Markets with Imperfect Information," American Economic Review, 71, 393-411.

(1983): "Incentive Effects of Terminations: Applications to the Credit and Labor Markets," American Economic Review, 73, 912-927.

Stockdale, B. (2002): "UK Innovation Survey 2001," Economic Trends, 580, 36-42.

Svensson, R. (2007): "Commercialization of Patents and External Financing During the R\&D Phase," Research Policy, 36, 1052-1069.

Titman, S., And R. Wessels (1988): “The Determinants of Capital Structure Choice,” Journal of Finance, 43, 1-19.

Tiwari, A., P. Mohnen, F. Palm, and S. S. van Der Loeff (2008): "Financial Constraints and R\&D Investment; Evidence from CIS," in Determinants of Innovative Behaviour: A Firm's Internal Practices and its External Environments, ed. by A. Kleinknecht, R. Ott, C. van Beers, and R. Verburg. Palgrave, London.

Townsend, R. (1979): "Optimal Contracts and Competitive Markets with Costly State Verification," Journal of Economic Theory, 21, 265-293.

Whited, T. M. (1988): "Why do investment Euler equations fail?," Journal of Business and Economic Statistics, 16, 469-478.

(1992): "Debt, Liquidity Constraints, and Corporate Investment: Evidence from Panel Data," Journal of Finance, 47, 1425-1460.

(2008): "What Can Cash Shortfalls and Windfalls Tell Us About Finance Constraints?," in The Economics of Imperfect Markets, ed. by G. Calcagnini, and E. Saltari. Springer, New York, forthcoming.

Whited, T. M., And G. Wu (2005): "Financial Constraints Risk," Review of Financial Studies, $19,531-559$.

Williamson, O. E. (1988): "Corporate Finance and Corporate Governance," Journal of Finance, $43,567-591$. 
Wooldridge, J. M. (2004): "Estimating Average Partial Effects Under Conditional Moment Independence Assumptions," Working Paper, Michigan State University, Department of Economics. (2005): "Unobserved Heterogeneity and Estimation of Average Partial Effects," in Inference for Econometric Models: Essays in Honor of Thomas Rothenberg, ed. by D. Andrews, and J. Stock, pp. 27-55. Cambridge University Press, Cambridge. 


\section{Nederlandse samenvatting}

Het belang van innovatieve activiteiten van bedrijven voor het verzorgen van economische groei en welvaart wordt tegenwoordig algemeen erkend en is uitvoerig gedocumenteerd in de wetenschappelijke literatuur. Hoe belangrijk dit ook moge zijn, we weten eveneens dat het marktfalen voor R\&D investeringen vrij ernstig kan zijn. Bedrijven zonder interne financieringsmiddelen, boren externe bronnen aan om hun innovatieve activiteiten te bekostigen. Kapitaalmarktfricties, gegenereerd door informatieasymmetrie, leiden evenwel vaak tot een grote kloof tussen de kost van externe en interne financiering. Dit idee van dure externe financiering staat in schril contrast met de completemarkt aanpak die ten grondslag ligt aan de conventionele investeringsmodellen die verwachte toekomstige winstgevendheid en gebruikerskosten van kapitaal als de bepalende factoren voor investeringen beschouwen.

Informatietheoretische modellen in de financiering en de economie tonen aan hoe informatieasymmetrie kan leiden tot het heffen van een grote opslag op externe middelen, en in extreme gevallen, zelfs tot het rantsoeneren ervan. Gezien de aard van R\&D is het zo dat de risico's die bij investeringen in R\&D activiteiten komen kijken groter zijn dan bij fysieke investeringen. Bijgevolg zouden investeringen in $\mathrm{R} \& \mathrm{D}$ activiteiten aan nog groter marktfalen onderhevig kunnen zijn dan fysieke investeringen.

Deze informatietheoretische modellen geven echter slechts een kwalitatieve richting aan voor empirisch werk, in de eerste plaats omdat weinige zowel endogene investeringen als financieringsbeslissingen modelleren, en in de tweede plaats omdat slechts enkele van deze modellen op observeerbare variabelen gestoeld zijn. Bijgevolg heeft de empirische literatuur zich, met uitzondering van een paar studies, verlaten op twee losse argumenten om testen van het verband tussen financiering en investering te motiveren. En stroming in de literatuur, die bedrijven ad hoc als constrained en unconstrained classificeert en gebruik maakt van reduced-form accelerator type modellen, veronderstelt 
dat de investeringen van 'geconstrainde' bedrijven gevoeliger zijn voor interne middelen dan het geval is voor de 'niet-geconstrainde' bedrijven. Een tweede stroming in de literatuur die gebruik maakt van structurele Eulervergelijkingen, veronderstelt dat de incrementele intertemporele substitutie van investeringen vandaag voor investeringen morgen wordt benvloed door de schaduwwaarde van schaarse externe middelen. Hoewel deze modellen oorspronkelijk ontwikkeld werden voor de studie van investeringen op het niveau van het bedrijf, zijn ze eveneens gebruikt voor de studie van patronen in R\&D investeringen van hele sectoren.

Beide methodologien zijn echter al in vraag gesteld aangezien zij mogelijk niet in staat zijn de effecten van financieringsfricties op R\&D investering op bedrijfsniveau adequaat te identificeren. Voor de modellen van het reduced-form accelerator type volgt de kritiek uit het feit dat de proxies die de onderliggende investeermogelijkheden controleren niet perfect meetbaar zijn, en dat de kasstromen die als maatstaf dienen voor interne rijkdom gecorreleerd zouden kunnen zijn met vraagsignalen. Tevens, om het effect van financieringsfricties op investeringen op bedrijfsniveau vast te stellen, zijn de bedrijven, zoals eerder vermeld, geclassificeerd als geconstraind of niet-geconstraind. Bijgevolg wordt de endogeneteit van de financieringsconstraints niet in acht genomen, wat impliceert dat de conclusies die we trekken over de gevoeligheid van de investeringen voor gerealiseerde kasstromen als proxy voor verschuivingen in interne rijkdom wel eens niet geheel correct zouden kunnen zijn. Wat de schatting van Eulervergelijkingen betreft, daar de vergelijkingen afgeleid zijn onder de aanname van geleidelijke aanpassingskost en dus de vaste component genegeerd wordt, lijdt het model aan misspecificatie. In Hoofdstuk 2, dat over investeringen op bedrijfsniveau gaat, beschrijven we deze bron van misspecificatie.

Gegeven de bovenstaande argumenten is het objectief van deze thesis deels alternatieve strategien te gebruiken om de effecten van financieringsfricties op $R \& D$ investment te bestuderen. Om precies te zijn, in drie van de hoofdstukken gebruiken we de rapportage van bedrijven over hun financile constraints, om de mate van $R \& D$-investeringsgerelateerd marktfalen te bepalen. Om het gebruik van gerapporteerde financile constraints te motiveren leiden we een empirische specificatie af van een theoretisch model in een contractueel kader. Het gebruik van de gerapporteerde financile constraint als regressor laat ons tevens toe het probleem aan te pakken van gelijktijdigheid van investeringsbeslissing en observatie van de constraint.

Naast de kwestie welke weerslag financieringsfrictie heeft op investeringen en innovatie, gaat de thesis ook dieper in op hoe andere factoren de investeringen van het bedrijf en de innovatiebeslissing benvloeden. In Hoofdstuk 6 bestuderen we hoe financierings- en innovatiebeslissingen gerelateerd zijn 
over de verdeling van bedrijfseigenschappen zoals grootte, leeftijd, leverage, en de financile constraints waaraan zij onderhevig zijn.

De verzameling van studies is weergegeven in vijf hoofdstukken die onafhankelijk van mekaar gelezen kunnen worden. Dientengevolge is enige herhaling, met name in de bespreking van de bestaande literatuur, onvermijdelijk gebleken. De thesis draagt in verschillende opzichten bij aan de literatuur over financieringsfricties en investeringen. In hoofdstuk 2 bestuderen we het effect van financieringsfricties op investering in fysiek kapitaal dat op bedrijfsniveau plaats heeft. De studie levert bewijs dat het probleem van asymmetrische informatie de allocatie van investeeruitgaven van een bedrijf benvloedt. Het blijkt dat het opnemen van het schaduwprijseffect van externe financiering de prestaties van de Eulervergelijkingen sterk verbetert ten opzichte van de standaard neoklassieke specificatie. We construeren tevens een index van financile constraints gebaseerd op de schattingen van het structurele model. Dan blijkt dat de investering van het bedrijf vermindert naarmate de financile constraints strakker worden. Een laatste bevinding van dit hoofdstuk is dat voor een groep van bedrijven die om de beurt investeren en desinvesteren, de Eulervergelijking gebaseerd op geleidelijke aanpassingskost ongepast lijkt, wat de misspecificatie ten gevolge van het negeren van de vaste of niet-convexe component van de aanpassingskost weergeeft.

In Hoofdstuk 3 doen we een empirisch onderzoek naar de effecten van financieringsconstraints op de investering in R\&D. Deze analyse wordt uitgevoerd op de CIS Nederland data. Gebruik makend van directe informatie over financile constraints, verkregen door bij bedrijven uitgevoerde enqutes, in plaats van de gangbare handelsbalansinformatie, presenteert deze studie bewijs dat financile constraints de beslissing van een bedrijf benvloedt hoeveel te investeren in R\&D activiteiten. Door het bestuderen van de effecten van financile constraints op $R \& D$ investeringen, onderzoeken we tevens welke eigenschappen van een bedrijf dit bedrijf financieel geconstrained maken. Het blijkt dat oude bedrijven of bedrijven die bij een groep behoren minder onderhevig zijn aan financile constraints wanneer het op R\&D investeringen aankomt. Wij zijn ons niet bewust van andere artikelen die het negatieve effect van financieringsconstraints, door ondernemingen gerapporteerd, op R\&D investeringen empirisch aantonen.

In hoofdstuk 4 onderzoeken we het belang van financile en andere obstakels voor innovatie in Nederland middels de statistische informatie van de CIS 3.5 innovatie-enqute. We rapporteren resultaten aangaande het effect van deze obstakels voor de beslissing van een bedrijf om een innovatief project te laten schieten, voortijdig stop te zetten, te vertragen, of helemaal niet te starten. Uit deze studie blijkt dat financieringsconstraints een zeer belangrijke remmende factor betekenen voor 
het nastreven van innovatie. We vinden tevens dat bepaalde marktfundamentals, zoals marktonzekerheid en economische onzekerheid, waarvan bedrijven hun investeringsbeslissingen laten afhangen relevanter worden als de financile constraints niet langer bindend zijn. Dit hoofdstuk besluit met een bespreking van enkele beleidsmaatregelen die getroffen zijn om deze obstakels te overwinnen, of op zijn minst hun effect te verzachten.

In hoofdstuk 5 bestuderen we financierings- en $R \& D$ investeringsbeslissingen in een real-options kader. Hoewel er in de corporate finance literatuur een veelvoud van studies bestaat die agency problemen bestudeert tussen de verschillende groepen van belanghebbenden bij investeringen van het bedrijf, hebben wij geen studies gevonden die specifiek op de agency issues tussen aandeelhouders en obligatiehouders voor R\&D investeringen ingaat. Hier bestuderen wij de gevolgen van risico's geassocieerd met $\mathrm{R} \& \mathrm{D}$ investeringen voor agencyconflicten tussen obligatiehouders en aandeelhouders van het bedrijf. Het risico geassocieerd met $R \& D$ investeringen komt voornamelijk voort uit de immaterile aard van de activa die gebruikt worden in het $R \& D$ proces, en verder uit de technische onzekerheid die gepaard gaat met het succesvol afronden van het project. Onze bevinding is dat wanneer de immaterialiteit van de activa hoog is en de intensiteit waarmee men het R\&D proces uitvoert laag, dan resulteert een overinvestering van de kant van de aandeelhouders, wat impliceert dat ze risico's afwentelen op de obligatiehouders. Los van de studie van het agencyprobleem, maakt dit hoofdstuk tevens de vergelijking tussen $R \& D$ investering en algemene schaalvergroting van het bedrijf. Middels deze vergelijking scheppen we klaarheid in de overvloed aan empirische studies die vaststellen dat $R \& D$ intensieve bedrijven minder leveraged zijn dan bedrijven die geen $R \& D$ uitvoeren.

In Hoofdstuk 6 gebruiken we panel data van drie golven om enerzijds het effect van van financile constraints op $R \& D$ investment en anderzijds de determinanten van financile constraints te bestuderen. We onderzoeken tevens de factoren die bedrijven aansporen om in R\&D activiteiten te investeren. De bevindingen van Hoofdstuk 6 kunnen als volgt worden samengevat. Ten eerste, financile constraints hebben een negatief effect op de R\&D intensiteit gemeten als de ratio tussen R\&D uitgaven en vaste activa. Ten tweede, bedrijven met veel leverage zijn zwaarder financieel geconstraind, en zijn bijgevolg minder geneigd te investeren in R\&D activiteiten. Ten derde, in geval leverage stijgt is het waarschijnlijker dat een bedrijf niet innoveert als het geen financile constraints heeft tegen als het ze wel heeft. Ten vierde, de verandering in de kans dat een bedrijf innoveert, geassocieerd met een verandering van $\mathrm{n}$ eenheid in leverage, gegeven dat dit bedrijf geen financile constraints heeft, is nagenoeg constant. Dezelfde verandering, gegeven dat het bedrijf wl finan- 
cile constraints heeft, varieert over de verdeling van bedrijfseigenschappen zoals leeftijd, grootte, en leverage. Ten vijfde, de beslissing om te innoveren, de financile constraints die men heeft, en de kapitaalstructuur die men hanteert zijn endogeen. Ten zesde, de R\&D intensiteit van bedrijven met verschillende eigenschappen, onder de conditie van financile constraints en de conditie van geen financile constraints, verschillen van mekaar. Ten laatste, de gevoeligheid van $R \& D$ investeringen voor kasstromen is hoger voor financieel geconstrainde bedrijven. De gebruikte econometrische exercitie is een drie-stapsprocedure, waarbij de verwachte a posteriori waardes van tijdsinvariante individuele effecten, verkregen uit de reduced form van het eerste stadium, als substituut gebruikt worden voor de tijdsinvariante individuele effecten in het tweede en derde stadium. Het hoofdstuk biedt een theoretische onderbouwing van een dergelijke procedure. De schatter voorgesteld om een systeem van vergelijkingen met endogene regressors te schatten in een panel data setup is, voor zover ons bekend, nieuw in de literatuur.

Hoofdstuk 7 ten slotte, vat de belangrijkste bevindingen van de thesis samen, bespreekt de grenzen van het huidige werk, en presenteert mogelijke richtingen voor verder onderzoek. 
